\title{
Improved Cookstoves and Better Health in Bangladesh
}

Lessons from Household Energy and Sanitation Programs

Final Report June 2010

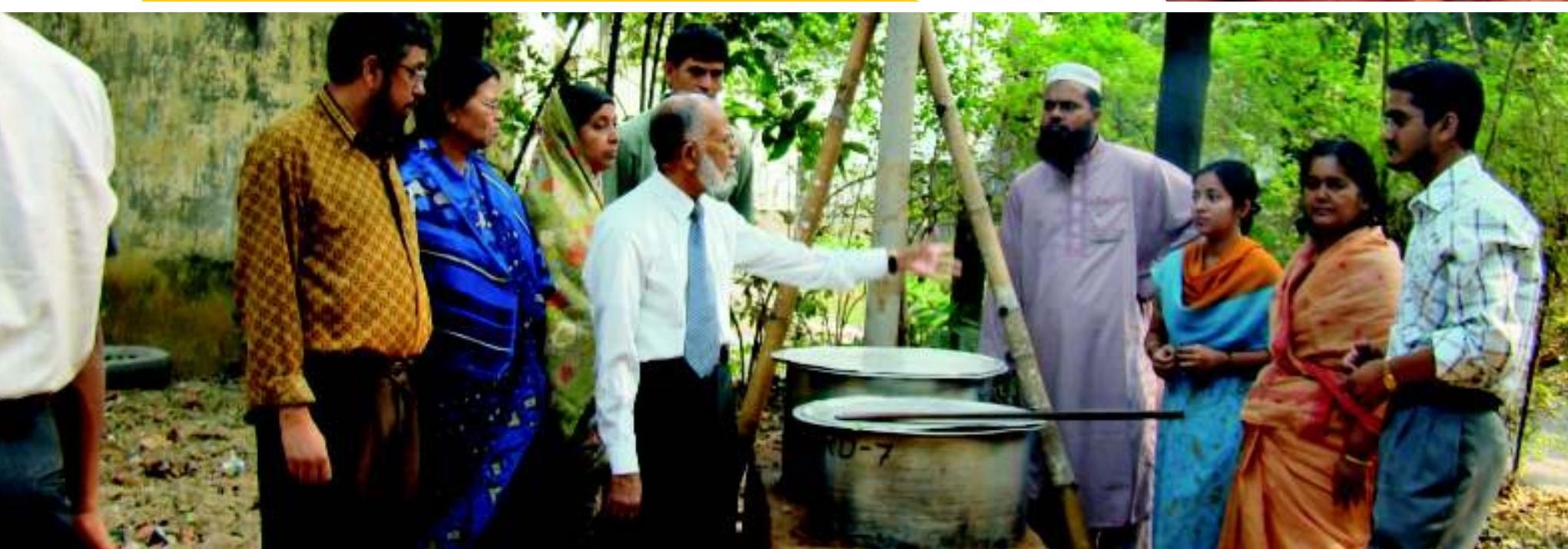





\section{Improved Cookstoves and Better Health in Bangladesh \\ Lessons from Household Energy and Sanitation Programs}

Final Report June 2010 
@2010 The International Bank for Reconstruction and Development/The World Bank

1818 H Street, NW,

Washington, D.C. 20433

USA

\section{Disclaimer}

This volume is a product of the staff of the International Bank for Reconstruction and Development/ The World Bank. The findings, interpretations, and conclusions expressed in this paper do not necessarily reflect the views of the Executive Directors of The World Bank or the governments they represent. The World Bank does not guarantee the accuracy of the data included in this work. The boundaries, colors, denominations, and other information shown on any map in this work do not imply any judgment on the part of The World Bank concerning the legal status of any territory or the endorsement or acceptance of such boundaries.

\section{Rights and Permissions}

The material in this work is copyrighted. Copying and/or transmitting portions or all of this work without permission may be a violation of applicable law. The International Bank for Reconstruction and Development/The World Bank encourages dissemination of its work and will normally grant permission promptly.

All queries on rights and licenses, including subsidiary rights, should be addressed to the Office of the Publisher, The World Bank, 1818 H Street, NW, Washington, DC20433, USA, fax: 202-522-2422, email: pubrights@worldbank.org.

\section{Photo Credits}

German Technical Cooperation, Village Education Resource Centre, Bangladesh Council of Scientific and Industrial Resarch and Prabir Mallik.

Designed and Printed by Macro Graphics Pvt. Ltd. www.macrographics.com 


\section{Contents}

Acknowledgments

Abbreviations and Acronyms

Executive Summary

Study Objectives and Approach

Health Impacts of Indoor Air Pollution

Experiences from the Household Energy Sector in Bangladesh

Experiences from International Improved Cookstove Programs

Experiences from the National Sanitation Program

Way Forward

xiii

Conclusions

xiv

$\mathrm{XV}$

\section{Indoor Air Pollution in Bangladesh}

Health Impacts of Indoor Air Pollution

Health Impacts for Bangladesh

Health and Indoor Air Pollution: Unanswered Questions

Bangladesh Scenario

Clean Energy Initiatives in Bangladesh

Objectives of this Review

Structure of the Report

Review Methodology

Detailed Review

Conclusions

Household Energy Initiatives in Bangladesh

BCSIR: Improved Cookstove Program, Phase II

GTZ: Sustainable Energy for Development Program: Improved Cookstoves Component 
USAID: Reduction of Exposure to Indoor Air Pollution through Household Energy and

Behavioral Improvements

BCSIR/LGED: Biogas Program

27

IDCOL/SNV: National Domestic Biogas and Manure Program

IDCOL: Rural Electrification and Renewable Energy Development Program 32

$\begin{array}{ll}\text { Conclusions } & 37\end{array}$

Lessons from Household Energy Initiatives in Bangladesh 39

Institutional Arrangements $\quad 39$

Awareness and Motivation $\quad 42$

Development and Promotion of Technologies 44

Financial Aspects $\quad 47$

$\begin{array}{ll}\text { Conclusions } & 50\end{array}$

Review of International Cookstove Programs 51

Brief Overview of International Improved Cookstove Programs

Lessons Learnt from International Improved Cookstove Programs 57

Conclusions $\quad 62$

Lessons from Sanitation Initiatives in Bangladesh 63

Bangladesh's Total Sanitation Campaign $\quad 63$

Comparison of Sanitation Programs in Bangladesh $\quad 66$

$\begin{array}{ll}\text { Institutional Arrangements } & 67\end{array}$

$\begin{array}{ll}\text { Awareness and Motivation } & 71\end{array}$

Development and Promotion of Technologies $\quad 73$

$\begin{array}{ll}\text { Financial Aspects } & 74\end{array}$

$\begin{array}{ll}\text { Conclusions } & 77\end{array}$

Summary and Recommendations $\quad 79$

Status of Improved Stoves in Bangladesh $\quad 80$

Lessons from Successful Programs $\quad 81$

Way Forward $\quad 88$

$\begin{array}{ll}\text { Conclusions } & 91\end{array}$

Appendix 1: Summary of Literature Reviewed on the Health Impacts of Indoor Air Pollution 93

Appendix 2: Rapid Review Programs 106

Bibliography 109

References 109

Other Relevant Source Items $\quad 112$

$\begin{array}{ll}\text { Personal Communications } & 115\end{array}$ 
Boxes

Box $1.1 \quad$ Bangladesh's Renewable Energy Policy Objectives 8

Box 4.1 Evaluating Household Energy and Health Interventions: Catalogue of Methods 41

Box 4.2 Awareness of Health Impacts 43

Box 4.3 Carbon Finance: An Emerging Opportunity for Household Energy 49

Box 6.1 Community Engagement Process $\quad 72$

$\begin{array}{lll}\text { Box } 6.2 & \text { Moving Up the Sanitation Ladder } & 73\end{array}$

Box 6.3 Financial Mechanism in the National Sanitation Program $\quad 74$

Box 7.1 Conclusions of the WHO Cost-Benefit Evaluation for Household Energy and 85 Health Interventions

\section{Figures}

Figure 1.1 Energy Use and Expenditures in Rural Bangladesh, 2004

Figure 1.2 Factors Contributing to Environmental Health Risks 5

$\begin{array}{ll}\text { Figure } 2.1 \text { Review Process } & 10\end{array}$

Figure 3.1 Institutional Diagram: BCSIR Improved Cookstove Program 20

Figure 3.2 Institutional Diagram: GTZ Sustainable Energy for Development Program 23

Figure 3.3 Institutional Diagram: USAID Reduction in Indoor Air Pollution Program 25

Figure 3.4 Institutional Diagram: BCSIR/LGED Biogas Program 28

Figure 3.5 Institutional Diagram: National Domestic Biogas and Manure Program 31

Figure 3.6 Institutional Diagram: Rural Electrification and Renewable Energy 33 Development Program

Figure 6.1 Reasons for Not Installing a Latrine: Results by Division, Bangladesh 64

Figure 6.2 Progress in Sanitation Coverage (October 2003 to June 2008) 66

Figure 6.3 Integrated Institutional Setup: Bangladesh Total Sanitation Campaign 70

\section{Tables}

Table 1.1 Bangladesh: Share of DALYs Lost by Cause and Environmental Factor 6

Table 1.2 Synergies between Energy and Sanitation Sectors $\quad 8$

Table 2.1 Key Issues and Questions 11

Table 2.2 Programs Selected for Detailed Review 13

Table 3.1 Overview of Selected Household Energy Programs in Bangladesh 16

Table 3.2 BCSIR Stove Performance Data $\quad 21$

Table 3.3 Price of Improved Cookstoves under USAID/Winrock Indoor Air Pollution 27 Reduction Program

Table 3.4 Grants for Solar Home Systems

Table 3.5 Cost of Solar Home Systems

Table 3.6 Credit Facilities Available to Users for Solar Home Systems 36

Table 4.1 Use and Maintenance Issues for Household Energy Programs 46

Table 4.2 Cost of Technologies 47 
Table 5.1 Findings of International Improved Cookstove Program Reviews

Table 6.1 Change in Approach for the Total Sanitation Campaign in Bangladesh

Table 6.2 Comparison of Sanitation Programs in Bangladesh

Table 6.3 Sources of Funds in Union Parishads for Achieving Total Sanitation

Table 6.4 Types of Sanitary Latrines Developed by DISHARI, VERC, SEDA/NGO Forum

Table 6.5 Source of Funds for Entrepreneurs in the Study Area 


\section{Acknowledgments}

- his study is a collaborative effort between the World Bank and the government of Bangladesh under the overall leadership of the Local Government Engineering Department, Ministry of Local Government, Rural Development and Cooperatives of Bangladesh. The report has also received significant support from several agencies of the government of Bangladesh, including the Infrastructure Development Company Limited, the Department of Environment, and the Bangladesh Council of Scientific and Industrial Research.

Significant contributions from representatives of nongovernmental organizations, donor agencies, and local government agencies during the meetings and workshops held at various stages of the study and their technical support to the study through data and information are gratefully acknowledged.

The World Bank team was led by Priti Kumar and included M. Khaliquzzaman, Jonathan Rouse, and Vani Kurup. Special gratitude is extended to Douglas Barnes, who made substantial contributions to this report and guided the team during the final stages of report writing. Thanks are due to John Dawson for his meticulous contributions in editing the report.

Technical background reports produced by three organizations underpin this document. The Village Education Resource Center focused on sanitation programs in Bangladesh, led by Md. Yakub Hossain with support from Anowar Hossain Mollah, A. M. Hasan Rashid Khan, Md. Quamrul Islam, Subash Chandra Saha, and Samar Prasad Das. Winrock International reviewed the national and international household energy programs, led by Lutfiyah Ahmed with Suman Basnet and Wendy R. Aulakh. The team from the International Centre for Diarrhoeal Disease Research, Bangladesh was led by Steven Luby and Abdullah Brooks with support from Emily Gurley and Md. Shohel Shomik. The Center undertook a review of the health impacts of indoor air pollution and designed a health-based protocol for improved stove projects.

We are indebted to internal and external peer reviewers, namely Sudeshna Ghosh Banerjee, Jeremy Levin, Yewande Awe, Mark Ellery, Rokeya Ahmed, Luis Alberto Andres, and Celine Ferre from the World Bank, and Priyadarshini Karve from the Appropriate Rural Technology Institute, India. The guidance of Kseniya Lvovsky in scoping out the study is acknowledged.

We would like to express our sincere appreciation to Xian Zhu, former Country Director for Bangladesh, Robert Floyd, former Country Program Coordinator for Bangladesh, and Karin Kemper, former Sector 
Manager, South Asia Social, Environment and Water Resources Management Unit, for their overall guidance and support to this activity.

Finally, the contributions of the Energy Sector Management Assistance Program, the BankNetherlands Partnership Program, and the Trust
Fund for Environment and Social Sustainable Development are gratefully acknowledged.

The opinions presented here and any errors are the sole responsibility of the authors and should not be attributed to the individuals or institutions acknowledged in this report. 


\title{
Abbreviations and Acronyms
}

\author{
BCSIR Bangladesh Council of Scientific and Industrial Research \\ BRAC Bangladesh Rural Advancement Committee \\ DALY disability-adjusted life year \\ DANIDA Danish International Development Agency \\ DISHARI Decentralized Integrated Sanitation, Hygiene and Reform Initiative \\ ESMAP Energy Sector Management Assistance Program \\ GTZ German Technical Cooperation \\ IDCOL Infrastructure Development Company Limited \\ KfW Kreditanstalt für Wiederaufbau \\ LGED Local Government Engineering Department \\ NGO nongovernmental organization \\ PM particulate matter \\ SEDA Sustainable Energy Development Agency \\ SNV Netherlands Development Organization \\ SOUL Save Our Urban Life \\ USAID United States Agency for International Development \\ VERC Village Education Resource Center \\ WASH Water, Sanitation, and Hygiene (Program) \\ WHO World Health Organization

\section{Currency Equivalents (2009)} \\ US\$ 1 (U.S. dollar) = Tk 68.5 (Bangladesh takas)
}





\section{Executive Summary}

T wo billion people in the developing world still depend on wood, animal dung, and crop residues for fuel for cooking and heating. Although biomass fuels can be a low-cost and reasonably clean fuel when burnt in efficient stoves, traditional cookstoves are often inefficient and highly polluting. This can lead to high levels of pollution in homes. Mitigating such indoor air pollution can translate not only into improved health and positive economic outcomes, but can also have significant environmental and human welfare benefits.

Bangladesh has made notable advances towards attaining its Millennium Development Goals, which include a two-thirds reduction in infant and child mortality by 2015 . However, indoor air pollution still remains a major concern for 25 million households, despite a number of initiatives aimed at addressing it.

In Bangladesh, as in other developing countries, most households are not expected to be able to move up the energy ladder from using traditional cookstoves to cleaner fuels, such as liquefied petroleum or natural gas, solar energy, or electricity, for some years. Even well-off households continue to use a mix of modern and traditional energy sources. Thus there is an immediate need to address indoor air pollution from traditional, biomass fuels, at both policy and grassroots levels. With forests depleting and the need to provide energy to the ever-growing energy-starved population, strategies are urgently required for the delivery of clean energy services at the household level.

\section{Study Objectives and Approach}

Mitigating indoor air pollution through improved cookstoves offers great advantages in terms of reductions in mortality and morbidity, as well as savings in either money spent on buying fuels or in the time required to collect them. The overall benefits can lead to greater rural productivity and a better quality of life for many of the rural poor.

Despite widespread promotional efforts and several large and small-scale initiatives, improved cookstoves have not been widely adopted in Bangladesh. Reasons include the relatively high capital and maintenance cost of stoves, perceived or actual inconvenience of using improved stoves, and incompatibility with traditional food preparation. Further, the design of cost-effective indoor air pollution reduction strategies has been hindered 
by technology-focused design processes, and a lack of information about impact on particulate concentrations in poor households. Data have been scarce because monitoring in village environments is difficult and costly.

On the other hand, Bangladesh has achieved tremendous success with its sanitation initiative the Total Sanitation Campaign. The premise for this study is that given the similarities between the sanitation and household energy sectors it should be possible to follow the lead of the Total Sanitation Campaign and develop successful demand-based approaches for an improved cookstove program.

The objective of this study is to identify lessons for improving cookstoves in Bangladesh through an evaluation of existing programs, the international experience on improved stoves, and the lessons from successes in the sanitation sector.

Bangladesh's new Renewable Energy Policy endorses creating a better environment for renewable energy technologies and promoting market development for improved cookstoves (Government of Bangladesh 2009). This study supports this policy direction by examining possible strategies to move forward the development of markets for improved stoves in Bangladesh.

The study consists of several components: a national review of household energy programs; an evaluation of national sanitation programs; and an examination of improved cookstove programs from around the world, including China, Guatemala, Haiti, Mongolia, Nepal, and Uganda. The study is based on published literature, consultations with organizations throughout Bangladesh, site visits, and structured discussions with beneficiaries and other stakeholders. In addition, key informants, such as entrepreneurs, community mobilizers, field-level staff, and local government representatives, were consulted through semistructured interviews.

\section{Health Impacts of Indoor Air Pollution}

Extensive scientific research has consistently documented the ill-health effects of breathing smoke from biomass fuels commonly burned in the developing world for cooking and heating (Bruce, Perez-Padilla, and Albalak 2000). The World Health Organization (WHO 2007) estimates that as much as 3.6 percent of the total burden of disease in Bangladesh is attributable to exposure to indoor air pollution; 32,000 children below 5 years of age die annually due to acute lower respiratory infections, and 14,000 adults die due to chronic obstructive pulmonary disease. Women and children in the developing world are disproportionately exposed to polluted air due to use of biomass fuels for cooking and heating.

Smoke from biomass fuels contains a large number of pollutants, such as small particulates, which can compromise the respiratory tract, making people vulnerable to viral and bacterial infections (Gurley et al. 2008). It also contains toxic pollutants, including aromatic hydrocarbons and carbon monoxide. Children exposed to indoor air pollution have two to three times greater likelihood of experiencing a serious episode of acute lower respiratory infection, and adults are much more likely to suffer from chronic respiratory disease. There are also documented links between exposure to indoor air pollution and tuberculosis, preterm birth, low birthweight, and asthma.

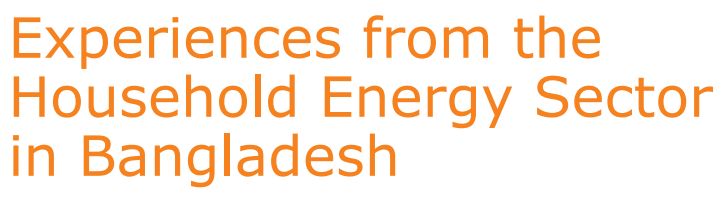

Six household energy programs in Bangladesh were selected for this review, including three improved cookstove programs, two biogas programs, and one solar home system program. Findings revealed that improved cookstoves have the potential to alleviate many household energy problems in Bangladesh. 
However, there is a significant lack of awareness concerning indoor air pollution in Bangladesh, despite many years of study on the issue. There are examples of effectively involving communities and leveraging microcredit in some programs, and these provide opportunities for learning and duplication.

In Bangladesh, household decisions to adopt - or reject - new technologies are based on a complex set of factors, including cultural and financial. Investing in cookstoves is often not viewed as a high priority. Household energy issues are significantly impacted by gender roles: women generally use stoves, while men often control family finances and make household decisions. There is a need to better understand, and respond to, these issues.

\section{Experiences from International Improved Cookstove Programs}

The review of international cookstove programs provided many useful lessons for improved cookstove programs in Bangladesh.

Lessons from the international programs emphasize the need for a wide range of efficient stove designs tailored to user requirements as a prerequisite for program success. They should have proven efficiency, the ability to reduce indoor air pollution, and good durability and safety. Further, the viability of the program in the long term often depends on strong commercial approaches to promoting stoves. Targeted marketing has also been seen to be an effective strategy; stoves should be marketed to households facing fuelwood scarcity or high costs of purchasing wood, as they would be the most likely group to benefit from improved stoves, at least in the initial stages of a program.

International experiences also provided various examples of innovative financing techniques, including the use of subsidies. In some countries, such as Nepal and Uganda, users were able to meet the full cost of stoves. Elsewhere, such as in China and Guatemala, subsidies were used to stimulate initial demand (in China) or to enable the poor to access relatively expensive stoves (in Guatemala). In Mongolia, credit was extended to users, while efforts in Haiti focused on reducing the cost of stoves through mass production.

Carbon-financed stove programs also presented some interesting and useful lessons. In these cases there was implicit focus on sustainability, and therefore, in addition to rigorous monitoring, most projects made provision for maintenance of stoves. Initiatives led by both government and by nongovernmental organizations (NGOs) have much to learn from this approach, while at the same time being highly strategic in resource allocation to monitoring and evaluation.

\section{Experiences from the National Sanitation Program}

The detailed review of sanitation programs in Bangladesh focused on four organizations known to have an excellent record of accomplishment in program implementation. Programs selected for evaluation represented a range of approaches, institutional arrangements, and actors, including government, donors, and NGOs. The common theme was that they all were adhering to the basic characteristics of the Total Sanitation Campaign of the government, which aimed to achieve 100 percent sanitation coverage by 2010 . The achievements of the Total Sanitation Campaign in Bangladesh illustrate that considerable development advances can take place at the village level with support for technical assistance and information dissemination without substantial direct subsidies for the improved sanitation devices.

Several key lessons may be drawn from the success of the Total Sanitation Campaign. One is that strong national policy support for innovative action can dramatically transform government, partner, and community actions into a participatory social movement, which in this case led to more than 90 
million people in Bangladesh gaining access to, and using, latrines in a five-year period. In this context, an important aspect of policy was a consensus among local and national governments to switch from the previous rather unsuccessful attempts to promote subsidized toilets (which are rival and excludable) to the promotion of an open defecation-free environment (which is nonrival and nonexcludable). Other important features included the availability of a wide range of low-cost and affordable sanitation hardware with the target of reaching the very poor with targeted subsidies, and the presence of a strong entrepreneur force for wider outreach, which strengthened the commercial approach and made products readily available locally.

\section{Way Forward}

The review of the status of improved stove programs in Bangladesh, along with the best practices from around the world, leads to several recommendations for consideration. One clear message is the need for a more unified program without diminishing the creativity of the various groups advocating improved stoves in Bangladesh. In fact, creativity and a wide variety of approaches should be encouraged. The government's role is not necessarily to be the main actor, but rather to facilitate a process that promotes variety, improved durability, better safety, and greater efficiency of improved stoves. Just as government ownership drove success in total sanitation, so leveraging government support will also be a vital part of tackling indoor air pollution. In addition, combining efforts to improve indoor air quality with sanitation and hygiene promotion may result in greater benefits than the sum of the parts, due to the complementary nature of the interventions.

The ultimate goal is to have a variety of improved stoves for sale in retail markets all over Bangladesh. One role for the government to play in supporting this is the testing and certification of stoves. A technical group needs to be given the responsibility for testing stoves both in the laboratory and in the field, which both play a part in the development of effective, usable technologies. The international literature on improved stoves mostly agrees that laboratory tests are appropriate for assessing the technical performance of stoves and whether they meet certain standards, but that the real test of performance takes place in actual homes. Many methods exist to assist in this development process. The role of a technical group would be to certify that a stove being promoted in the marketplace actually meets certain standards in terms of efficiency, pollution, durability, and safety. This should be done in a way that does not stifle creativity, but ensures that the public receives an acceptable product. Once certified, the stove could qualify for government assistance through loans, marketing, and dissemination, or even some form of subsidy. There also needs to be more of a focus on understanding and addressing the significant barriers to adoption that exist within the homes of the poor.

To administer a stove program at government level, an institution with a commercial approach and good field-level experience in quality-assured technology promotion and dissemination may be well suited. One model that may be applicable to the promotion of improved stoves is the program of the Infrastructure Development Company Limited (IDCOL) for household photovoltaic systems. Here, an organization would provide loans and partial grants to NGOs, private companies, or microfinance organizations to promote stoves. This is not a simple process, and involves several different types of activities, including:

*ualifying and certifying stoves through independent technical groups that qualify for the program;

* Qualifying firms or NGOs for the program on the basis of selected institutional characteristics and qualified staff to carry out projects; 
* Evaluating the financial plan of the proposal to make sure it is economically justified and financially viable after all program incentives or subsidies are accounted for;

* Encouraging development of greater diversity of products, perhaps through technical assistance grants or through some kind of grant competition;

- Keeping abreast of new stoves being promoted worldwide, including manufactured stoves, and, if attractive, encouraging them to enter the market through local partners;

* Monitoring the results once the programs are in the field by keeping track not only of the number of stoves but also of their effectiveness and the satisfaction of consumers;

* Establishing a proper balance between loans and grants in the program to ensure that the program is based on market incentives rather than subsidies.

The possible program described above should not involve any type of prohibition on the private sector or NGOs developing their own programs with their own financing. In fact, the grants and loans should be available to all who qualify, and the technical agency could verify the effectiveness of the stoves of any agency on an as-needed basis. Such groups certainly will have their own technical staff to qualify their own products. The idea is to develop a level playing field for those involved in the promotion of improved stoves in Bangladesh and to create a conducive atmosphere that encourages different organizations to develop and retail a wider range of improved stoves in the country. Thus, the overall goal of government activities should be to promote the development of improved stoves in Bangladesh to alleviate the problems caused by both indoor air pollution and shortage of biomass fuels. The future cookstove program should follow the same path, with the government's role being primarily to ensure that no one is exposed to unsafe and inefficient fuel use while cooking, and secondarily to promote, regulate, and perhaps certify the marketing of fuelefficient stoves to enable households to choose options that suit their means.

\section{Conclusions}

The future of an indoor air pollution reduction program for mitigating the ill-effects of biomass burning requires the dedication of government institutions, civil society, and the private sector. Entrepreneurs in particular need to be encouraged and supported to develop better stoves and promote them in a conducive marketplace. Although this will not be easy, the benefits of improved stoves could be quite high for the poorest populations in Bangladesh, including the reduction in the labor required to collect fuelwood for daily cooking tasks and the improved health resulting from cleaner indoor environments.

The key lessons for promoting improved stoves in Bangladesh do involve significant changes in the handling of household biomass energy problems. This obviously means that the government will have to establish an agency that will be responsible for administering a program to promote improved stoves. The responsibility of the agency would be to work with qualified private firms, NGOs, and other organizations to develop and implement the program in partnership with local governments. In addition, there will be issues concerning the quality of the stoves, the financial and economic incentives to develop new models, and the loans, grants, or community funds to support the promotion of stoves. Finally, once there are a wide variety of stoves available to the public that are safe, efficient, and reliable, a national publicity campaign can be initiated to promote the health and efficiency aspects of the stoves.

There is no reason why developing countries, including Bangladesh, should have populations dependent on stoves that have not changed in design for hundreds or even thousands of years. 
Daily advances in other types of appliances around the world have not reached the world's poorest populations, who still depend on open fires for cooking. In fact, Bangladesh has among the developing world's best programs in sanitation and household renewable energy. The ideas from these and other programs can be employed to change the polluting and inefficient centuries-old ways of cooking for people who still prepare meals with biomass energy. 


\section{Indoor Air Pollution in Bangladesh}

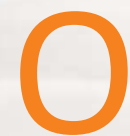

ver 2 billion people living in rural and peri-urban areas in developing countries still depend on energy from biomass (for example fuelwood, animal dung, crop residues, and other biomass fuels in open fires or using poorly functioning stoves) for their daily needs, such as cooking and heating. Biomass can be a low-cost and reasonably clean fuel when burned well; however, the continued use of traditional cooking practices and inefficient stoves in closed environments leads to high exposure to indoor air pollution.

A large section of the households in developing countries are not expected to move up the energy ladder to cleaner options, such as liquefied petroleum or natural gas, solar energy, or electricity, for a long time. Even the well-off households are expected to continue to use a mix of modern and traditional energy sources. Thus, the need to mitigate indoor air pollution will remain an important issue in the foreseeable future.

\section{Health Impacts of Indoor Air Pollution}

Extensive scientific research has consistently documented the ill-health effects of breathing smoke from biomass fuels commonly burned in the developing world for cooking and heating
(Bruce, Perez-Padilla, and Albalak 2000). The illeffects of polluted air are a major concern because so many people are exposed daily to high levels of pollution in their homes. The World Health Organization (WHO) estimates that 2.4 billion people worldwide (approximately 30 percent of all people) rely on burning biomass fuels for cooking and heating their homes (Rehfuess, Mehta, and Prüss-Üstün 2006). People in the developing world are disproportionately exposed to polluted air due to use of biomass fuels for cooking and heating.

WHO reports that indoor air pollution is responsible for an estimated 2.7 percent of the global burden of disease and 1.6 million deaths, concluding that the ill-effects of indoor air pollution are more than five times those resulting from outdoor air pollution (WHO 2005; Gurley et al. 2008). In developing countries, indoor air pollution accounts for 3.7 percent of the total burden of disease, making it the fourth most serious health risk factor after malnutrition, unsafe sex, and lack of safe water and effective sanitation (WHO 2007). Exposure to polluted indoor air is typically greater among women (and children), who due to their gender roles and household responsibilities are most exposed to smoke. Acute respiratory infections from indoor air pollution kill an estimated 900,000 children under 5 annually in developing countries (WHO 2005). 
Smoke from biomass fuels contains a large number of pollutants, such as small particulates, which can compromise the respiratory tract, making people vulnerable to viral and bacterial infections (Gurley et al. 2008). It also contains toxic pollutants, including aromatic hydrocarbons and carbon monoxide. Children exposed to indoor air pollution have two to three times greater likelihood of experiencing a serious episode of acute lower respiratory infection compared to those not exposed, even after controlling for socioeconomic conditions (Smith 2000). Adults exposed to indoor air pollution from biomass burning are also much more likely to suffer from chronic obstructive pulmonary disorder (Bruce, Perez-Padilla, and Albalak 2000; Ezzati and Kammen 2001; Smith et al. 2000).

Indoor air pollution is also reported to cause tuberculosis (a leading cause of death in the developing world) and is associated with low birthweight and poor pregnancy outcomes (Boy, Bruce, and Delgado 2002; Siddiqui et al. 2005). Exposure to carbon monoxide has been linked with preterm birth (Ritz et al. 2000). Asthma (Azizi, Zulkifli, and Kasim 1995; Mohamed et al. 1995), stunting, and anemia (Mishra and Retherford 2007) may also be associated with exposure to polluted indoor air. However, additional studies are recommended to better understand the relationship between indoor air pollution and these health outcomes. Burns and scalds from burning biomass in open fires in homes receive less attention but are additional adverse health outcomes associated with burning biomass (Johnson and Bryden 2006). In addition to episodes of acute respiratory illness, respiratory symptoms such as cough and burning throat have been significantly associated with exposure to indoor air pollution, including in a small study in Bangladesh (Khaliquzzaman et al. 2007).

\section{Health Impacts for Bangladesh}

Not only are poor populations in the developing world exposed to indoor air pollution more frequently, the levels of biomass smoke they are exposed to are many times higher than acceptable standards for indoor air quality. Standards for air quality published by the United States Environmental Protection Agency (EPA 2006) state that 24-hour average levels of $\mathrm{PM}_{10}{ }^{1}$ of 150 micrograms per cubic meter $\left(\mu \mathrm{g} / \mathrm{m}^{3}\right)$ are acceptable. One study in Bangladesh found that household levels frequently reached $300 \mu \mathrm{g} / \mathrm{m}^{3}$, although spikes of up to $4,864 \mathrm{\mu g} / \mathrm{m}^{3}$ were observed, and that regional levels varied (Dasgupta et al. 2006a).

Globally and in Bangladesh, acute respiratory infections are the leading cause of death among all age groups combined, and among children below 5 years of age (Bruce, Perez-Padilla, and Albalak 2000; Baqui et al. 2001). Bangladesh has the highest rate of tuberculosis in the world (Zaman et al. 2006; Begum et al. 2007). As Bangladesh struggles to meet the Millennium Development Goals, reducing exposure to indoor air pollution could increase the chances of attaining Millennium Development Goals 4 and 5 , which call for a reduction in maternal and child mortality (Rehfuess, Mehta, and PrüssÜstün 2006). By reducing the amount of biomass used for cooking and heating in Bangladeshi homes, contributions could also be made to attaining Millennium Development Goal 7, ensuring environmental sustainability (Rehfuess, Mehta, and Prüss-Üstün 2006). WHO (2007) estimates that in Bangladesh alone there were an estimated 32,330 deaths from acute lower respiratory infections among children below 5 years and 13,620 deaths among adults from chronic obstructive pulmonary disease attributable to solid fuel burning in homes. This equates to 3.6 percent of the total national burden of disease in Bangladesh (WHO 2007).

According to Demographic Health Survey data, 74 percent of people in South Asia, including 88 percent of people in Bangladesh, are exposed to the effects of burning biomass in their homes (Rehfuess,

$1 \mathrm{PM}_{10}=$ particulate matter comprising particles with a diameter of 10 micrometers or less. 
Mehta, and Prüss-Üstün 2006). Women and children are thought to be the most affected because of their domestic role in meal preparation. Studies from South Asia showed that women and children (below 5 years of age) spent more time in the proximity to fires in the home and hypothesized that this increased proximity to fires was related to higher levels of indoor air pollution exposure (Balakrishnan et al. 2004; Dasgupta et al. 2006b). However, another study from Bangladesh suggests that pollution from fires rapidly spreads throughout all rooms of a house, exposing all individuals in the house to high levels of indoor air pollution, and not just the person who is cooking (Dasgupta et al. 2006a).

\section{Health and Indoor Air Pollution: Unanswered Questions}

Certain critical questions about the relationship between indoor air pollution and health remain unanswered (Smith 2000). First, despite decades of intervention attempts, very little is known about the improvements in air quality that indoor air pollution interventions produce in the real world (Ezzati and Kammen 2002; Smith et al. 2007). Evidence of improved air quality is essential for any indoor air pollution intervention. The few studies that actually examined the use of improved cookstoves have shown mixed results. In some cases, levels of indoor air pollution were reduced (Albalak et al. 2001), while in other studies, interventions actually increased the levels of indoor air pollution (Smith 2002). In one study from Guatemala, improved cookstoves did reduce levels of $\mathrm{PM}_{2.5}{ }^{2}$ and carbon monoxide but the improvements over open fires were not dramatic and tended to fade over time (Naeher, Smith, and Leaderer 2000). For any indoor air pollution intervention in Bangladesh to be successful, it is necessary that the intervention is effective in reducing indoor air pollution levels

$2 \mathrm{PM}_{2.5}=$ particulate matter comprising particles with a diameter of 2.5 micrometers or less. in the household, and thereby reduces exposures. In laboratory tests and observational studies, increased ventilation has shown promising results in dramatically reducing indoor air pollution levels (Dasgupta et al. 2006a; Still and MacCarty 2006). However, there have been no evaluations of improved ventilation interventions to date.

Second, despite the vast knowledge about poor health outcomes associated with breathing biomass smoke in the home, very little is known about the best way to prevent these outcomes (Ezzati and Kammen 2002). Even if interventions reduce the amount of indoor air pollution, the level of reduction required to show health benefits is not known. In addition, the intervention that is most effective at reducing indoor air pollution is also not known. Only a few studies have examined the relationship between indoor air pollution interventions and health outcomes. Preliminary data from an evaluation of improved cookstoves in Guatemala, which used a randomized control trial study design, showed that children living in households using improved cookstoves were significantly less likely to suffer from pneumonia not caused by respiratory syncytial virus than those in households using traditional stoves (Smith et al., unpublished data). Additionally, women using the improved cookstoves experienced reduced blood pressure and were less likely to report eye soreness and headache (Diaz et al. 2007; McCracken et al. 2007). For the first time, an experimental study design that was used to evaluate an indoor air pollution intervention showed improved health outcomes in intervention households. Evidence must show that indoor air pollution interventions are able to reduce indoor air pollution levels, as well as improve the health of their users.

Third, currently there are few data available on the seasonality of indoor air pollution. Common sense would suggest that increased heating needs during colder months might increase the amount of biomass burned in households or that during the monsoon people might be less likely to cook 
outside in Bangladesh. Households with substantial ventilation during the summer might, by design, have very little ventilation in the winter. One study has examined indoor air pollution levels during the winter in Bangladesh, but measurements from other seasons would be useful in determining the seasonality of indoor air pollution (Dasgupta et al. 2006a). Future studies should also attempt to document the variation in indoor air pollution throughout the year, highlighting any potential seasonal opportunities or challenges to behavior change interventions.

\section{Bangladesh Scenario}

The World Bank's Bangladesh Country Environment Analysis (World Bank 2006) reports that the majority of people in Bangladesh are poor, live in rural areas, and rely on solid biomass fuels. They are consistently exposed to polluted indoor air due to traditional cooking practices. Fuelwood accounts for 44 percent of total household energy use and 38 percent of expenditure in rural Bangladesh (Figure 1.1) (Asaduzzaman, Barnes, and Khandakar 2007). Poor households spend less than wealthier households on energy, but the amount represents a greater percentage of their income. The lowestincome households spend slightly more than Tk 3,000 , or 15 percent of their annual income, on energy. High-income households spend twice as much, but their income is more than four times higher, so it is a much smaller percentage of their overall income. This pattern is common in other developing countries.

With less than 7 percent forest cover and a growing population, it is becoming increasingly difficult for rural households to obtain biomass fuels to meet their cooking needs. Liquid petroleum gas has not penetrated the rural market at any scale, and remains unaffordable to many even in urban areas. Only 0.3 percent of rural households nationally use it (included under "Others" in Figure 1.1).

Figure 1.1 Energy Use and Expenditures in Rural Bangladesh, 2004

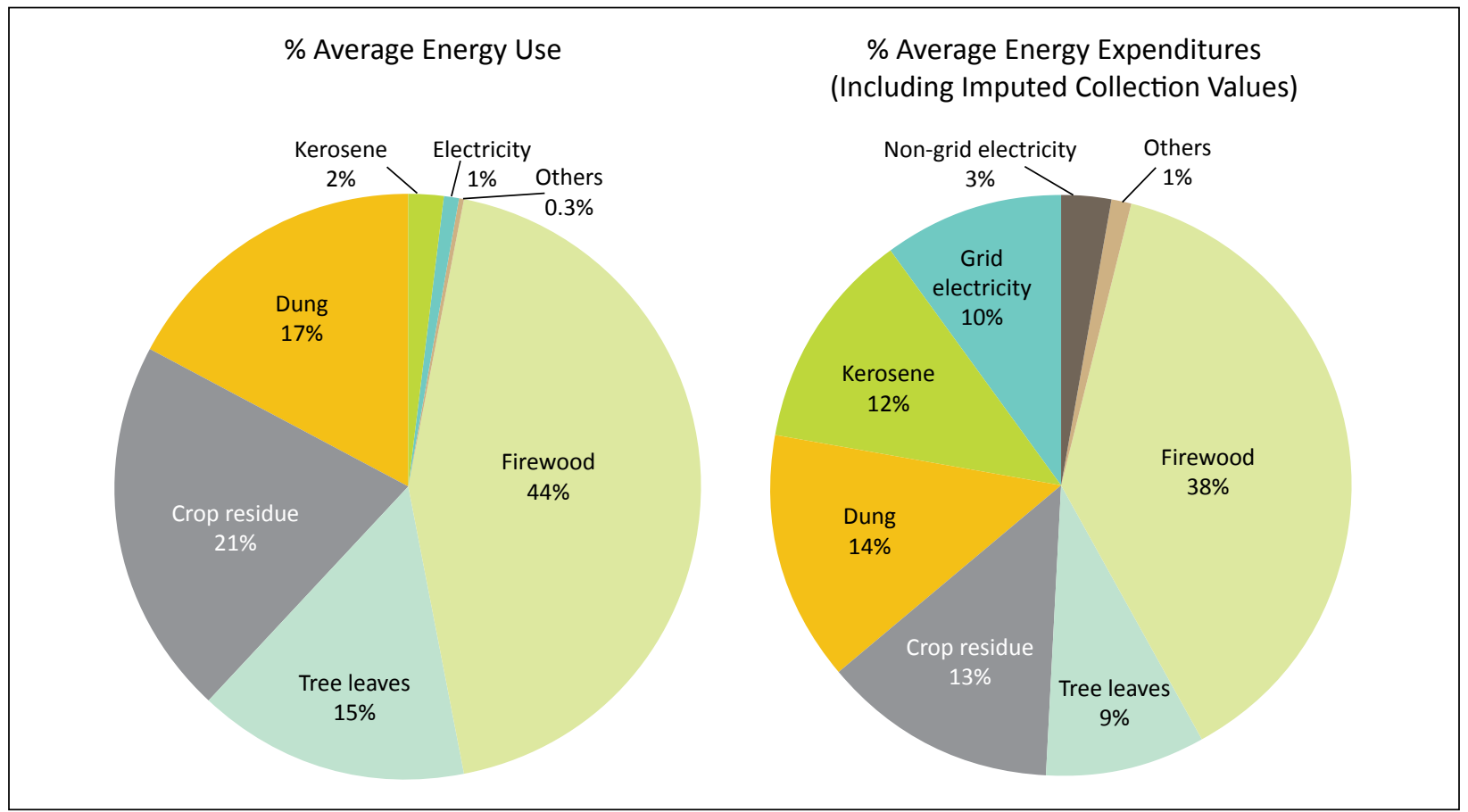

Source: Asaduzzaman, Barnes, and Khandakar 2007. 


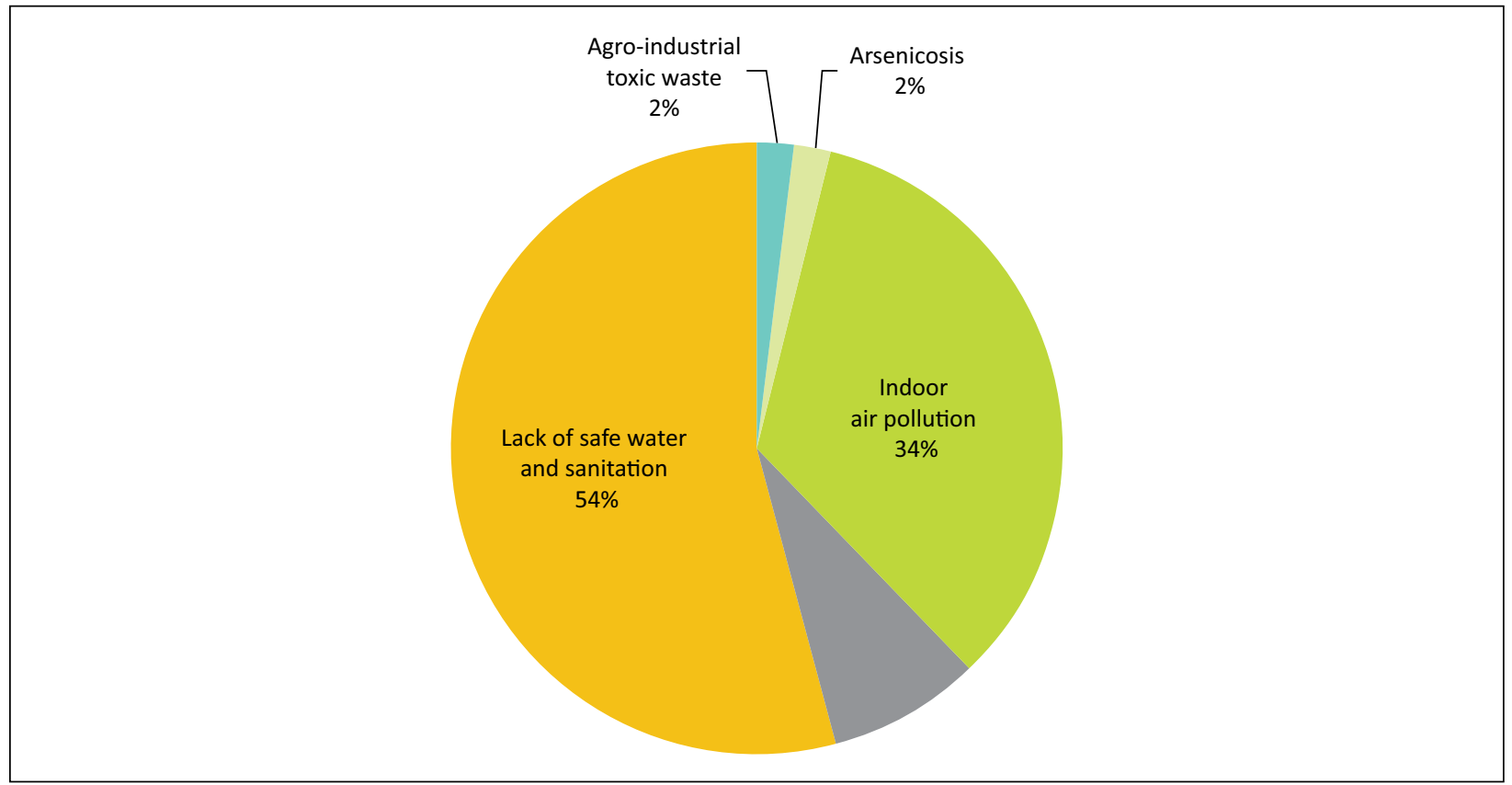

Source: World Bank 2006.

Kerosene, however, is available even in rural areas, and is used by 97 percent of the rural population, but only accounts for about 2 percent of the energy consumed. Prices are regulated, but the continued widespread reliance on biomass indicates that affordability remains an issue. Figure 1.1 again illustrates this; although liquid petroleum gas and kerosene are used by so few households, they account for 13 percent of the energy expenditure.

As a result of international oil price increases, households are becoming increasingly reliant on lower-grade biomass fuels, including unprocessed agricultural residue and cow dung. Rises in international commodity prices (including food and fuel) can have a disproportionately adverse impact on the poverty of the population (World Bank 2008). Moves such as this down the energy ladder tend to result in exposure to even higher levels of indoor air pollution. In Bangladesh, the estimated top five causes of disease burden due to environmental factors (Figure 1.2) include indoor air pollution.
Economic losses associated with environmental risk factors, such as polluted indoor air and poor water and sanitation, are estimated to be more than 4 percent of gross domestic product (GDP), and reduced exposure to environmental health risks could result in savings equivalent to 3.5 percent of GDP (World Bank 2006). These factors combine to underline the importance and urgency of investing in cleaner, more efficient cooking technologies.

Over the past decade, Bangladesh has achieved annual economic growth rates of 4-5 percent and reduction in population growth rate from 2.5 percent in the 1980 s to 1.7 percent since 1990. The per capita GDP growth rate increased to 3.7 percent in 2004, from a rate of 2.5 percent in the 1980s. The country is on target to meet many of the Millennium Development Goals, notably for infant and child mortality rates. However, despite these achievements, recent studies have found that environmental health risks contribute significantly to the national burden of disease, with respiratory 
Table 1.1 Bangladesh: Share of DALYs Lost by Cause and Environmental Factor

\begin{tabular}{|c|c|c|c|c|}
\hline Cause & $\%$ & Environmental factor & Share of cause (\%) & Share of total (\%) \\
\hline \multirow{2}{*}{$\begin{array}{l}\text { Respiratory infections } \\
\text { and diseases }\end{array}$} & \multirow[t]{2}{*}{17} & Indoor air pollution & \multirow[t]{2}{*}{$30-50$} & \multirow[t]{2}{*}{$5-8$} \\
\hline & & Urban air pollution & & \\
\hline Perinatal causes & 14 & Not applicable & - & - \\
\hline Diarrheal disease & 12 & $\begin{array}{l}\text { Low access to safe water, poor } \\
\text { sanitation and hygiene }\end{array}$ & $80-90$ & $10-11$ \\
\hline Injuries & 11.5 & Not applicable & - & - \\
\hline Nutrition/endocrine & 10 & Not applicable & - & - \\
\hline Malignant neoplasms & 2 & Agro-industrial toxics & $5-25$ & $0.1-0.5$ \\
\hline Other & 33.5 & Arsenicosis & - & $0.3-0.4$ \\
\hline Total & 100 & & - & $16.4-21.9$ \\
\hline
\end{tabular}

Source: World Bank 2006.

Note: Disability-adjusted life years (DALYs) reflect a combination of the number of years lost from early deaths and fractional years lost when a person is disabled by illness or injury.

infections and diseases from indoor air pollution contributing to as high as 8 percent of disabilityadjusted life years (DALYS) (Table 1.1).

With Bangladesh's largely rural population ( 85 percent of the total 140 million) and high poverty levels ( 36 percent of the people live on less than US\$ 1 per day), the challenge of addressing indoor air pollution exposure is a daunting but important task. Current epidemiological understanding suggests that Bangladesh's efforts to attain the health-related Millennium Development Goals will significantly strengthen if indoor air pollution is addressed.

Mitigating indoor air pollution through improved cookstoves offers great advantages in terms of reductions in mortality and morbidity, as well as increased economic savings. In addition to the direct health consequences of indoor air pollution, other benefits include reduced environmental impacts due to lower fuel consumption, reduced time and financial burden of wood collection and purchase, reduced time savings from cooking, and reduced injuries arising from carrying heavy loads. The overall benefits can lead to greater rural productivity and a better quality of life for many of the rural poor. This is in line with the recent national Renewable Energy Policy introduced by the government of Bangladesh. The new policy endorses creating an enabling environment for renewable energy technologies (Government of Bangladesh 2009).

\section{Clean Energy Initiatives in Bangladesh}

In Bangladesh, programs to address household energy and indoor air pollution have been implemented by various government, nongovernmental, and international organizations since the 1970s. The development and promotion of improved cookstoves and biogas in Bangladesh can be divided into three stages.

During the 1970s and early 1980s research and development for efficient energy usage was started to save trees and the environment. The Bangladesh Council of Scientific and Industrial Research (BCSIR) mainly led this work. It developed and piloted different models of improved cookstoves and biodigesters. In 1972 the first demonstration biogas plant was established at the Bangladesh Agricultural University, Mymensingh campus, and 
1976 saw the establishment of the first biogas plant at BCSIR.

The late 1980 s and 1990 s saw a marked shift away from saving trees to saving people's lives and improving health and welfare through programs led by BCSIR and the Local Government Engineering Department (LGED) that disseminated improved cookstoves and biodigesters to thousands of households throughout the country. These programs were supported by local governments and to some extent by NGOs and community groups and focused on gender issues related to cooking and fuel collection.

In the past few years the focus of household energy programs has progressively shifted away from grant assistance to commercial approaches. This has led to increased marketing and promotion of improved cookstoves and biogas by NGOs, private entrepreneurs, and microfinance providers. Agencies such as the Infrastructure Development Company Limited (IDCOL) and German Technical Cooperation (GTZ), and NGOs such as the Village Education Resource Center (VERC), are now the main organizations promoting improved cookstoves, biogas, and solar home systems in Bangladesh. The recently introduced Renewable Energy Policy will further fuel attempts to stimulate market development for improved cookstoves (Government of Bangladesh 2009).

Despite an increased interest in promoting the use of clean household energy options to decrease indoor air pollution, progress to date is far from meeting the needs of the people. Although about 130 million people in Bangladesh are exposed to high levels of smoke from the burning of biomass, only about 300,000 improved cookstoves and slightly over 26,000 biogas plants have been installed. Furthermore, in the absence of a proper system for long-term monitoring of the many improved cookstove units that have been produced it is unclear how many of these are still operational, much less having an impact on reducing indoor air pollution. Some experts in Bangladesh suggest that just a few percent of these stoves installed under the government program are still in use, though no one is sure. Even if the number in use was known, because limited testing of the stoves was undertaken particularly with respect to indoor air pollution - the impact of the stoves could still remain unknown.

The Ministry of Power, Energy and Mineral Resources of the government of Bangladesh recently introduced its first Renewable Energy Policy (Government of Bangladesh 2009). The policy endorses creating an enabling environment for renewable energy technologies and supports attempts to stimulate market development for improved cookstoves. The objectives of the policy are summarized in Box 1.1.

\section{Objectives of this Review}

The goal of this study is to explore options for improving cookstoves in Bangladesh through an evaluation of existing programs, the international experience on improved stoves, and the lessons from successful interventions of the sanitation sector. After all, one of Bangladesh's greatest development successes has been to achieve near total sanitation, which has promising synergies with the household energy sector (Table 1.2). The lessons from the Total Sanitation Campaign and other successful improved cookstove approaches employed around the world provide insights for making recommendations for an improved stove program in Bangladesh.

More specifically, the purpose of this review is to identify service delivery methods, technologies, and financing approaches that may be suitable for large-scale improved cookstove programs for sustainable indoor air pollution mitigation. This report documents the approaches taken and presents the key findings on emerging lessons. It concludes with a series of recommendations.

This report is intended for household energy researchers and development professionals involved in project development and policy formulation. 


\section{Box 1.1 Bangladesh's Renewable Energy Policy Objectives}

The objectives of the Renewable Energy Policy in the context of cookstoves are to:

$\checkmark$ Harness the potential of renewable energy resources and dissemination of renewable energy technologies in rural, peri-urban, and urban areas;

- Enable, encourage, and facilitate both public and private sector investment in renewable energy projects;

- Develop sustainable energy supplies to substitute indigenous nonrenewable energy supplies;

- Promote appropriate, efficient, and environment-friendly use of renewable energy;

- Carry out training and facilitate the use of renewable energy at every level of energy usage;

- Create an enabling environment and legal support to encourage the use of renewable energy;

- Promote development of local technology in the field of renewable energy;

- Promote clean energy in the context of the Clean Development Mechanism;

$\checkmark$ Set policy targets for developing renewable energy resources.

\section{Table 1.2 Synergies between Energy and Sanitation Sectors}

\begin{tabular}{|l|l|}
\hline \multicolumn{2}{|c|}{ Energy } \\
\begin{tabular}{|l|l|} 
Women and children are responsible for fuel \\
collection and are most exposed to polluted \\
indoor air.
\end{tabular} & $\begin{array}{l}\text { Women and children lack privacy and safety with regard } \\
\text { to sanitation practices if they defecate in the open. }\end{array}$ \\
\hline $\begin{array}{l}\text { Lack of awareness of health risks due to exposure to } \\
\text { polluted indoor air. }\end{array}$ & Lack of awareness of health risks due to poor sanitation. \\
\hline $\begin{array}{l}\text { Most households use low-grade biomass fuel and } \\
\text { are most in need of cleaner fuels and efficient } \\
\text { cookstoves. }\end{array}$ & $\begin{array}{l}\text { The poor lack access to and information on good } \\
\text { sanitation approaches and suffer from diarrheal diseases. }\end{array}$ \\
\hline $\begin{array}{l}\text { Energy technologies should be appropriately priced, } \\
\text { effective and sustainable to be acceptable to even } \\
\text { the poorest households. }\end{array}$ & $\begin{array}{l}\text { Sanitation facilities should be appropriately priced, } \\
\text { effective and sustainable to be acceptable to the poorest } \\
\text { households. }\end{array}$ \\
\hline
\end{tabular}

\section{Structure of the Report}

This report begins by describing, in this chapter, the background to indoor air pollution in Bangladesh, and the rationale for the review that led to this report. The next chapter outlines the methodology used for the review work, and the breadth of projects considered. A description of six household energy programs in Bangladesh, including improved cookstove, biogas, and solar energy initiatives, is the subject of chapter 3 .
The lessons from various programs are at the center of this report and its recommendations. Thus, the subsequent three chapters present lessons from similar programs both in Bangladesh and around the world. They include biomass or household energy programs in Bangladesh, cookstove programs implemented in Asia, East Africa, and Central America, and the sanitation program in Bangladesh. The report concludes with a summary of household energy and improved stove recommendations for Bangladesh. 


\section{Review Methodology}

S trategies for addressing indoor air pollution and adaptation of cleaner technologies to reduce the health toll in Bangladesh must draw on lessons from best practices in the field. To this effect a range of renewable household energy and sanitation programs in Bangladesh, and international improved cookstove programs, were reviewed to identify their key features or innovative approaches that could be used to inform a future improved cookstove program.

The study consisted of two components: reviews of household energy and sanitation programs in Bangladesh, and reviews of international improved cookstove programs. Winrock International and VERC undertook the reviews, with Winrock focusing on renewable household energy programs in Bangladesh and international improved cookstove programs, and VERC focusing on sanitation programs in Bangladesh.

The review was undertaken in two phases: (a) rapid review of household energy and sanitation programs; and (b) detailed review of key programs identified during the rapid review, culminating in the consolidation of the findings presented in this report (Figure 2.1).

A rapid review of major initiatives in the household energy and sanitation sectors was undertaken in late
2007 to select programs for more detailed review. The rapid review process included consultations with Dhaka-based program offices and a literature review where possible. The programs selected in the sanitation sector are listed in Appendix 2. The programs had a special emphasis on a participatory approach and used methodologies such as community-managed and demand-driven initiatives.

\section{Detailed Review}

The detailed review involved focus group discussions; key informant interviews with stakeholders, including entrepreneurs, local government officials, LGED engineers, and local leaders; case studies of user and nonuser households; semistructured interviews; household-level surveys; and thematic round tables based on key aspects. Desk studies and literature reviews were also carried out. Appendix 1 presents a summary of literature reviewed for health-related information on indoor air pollution.

Information was collected on the following key aspects:

- Institutional arrangements: exploring the service delivery mechanism to identify key constraints and incentives, role of stakeholders, and inclusiveness with regard to very poor households; 
Figure 2.1 Review Process

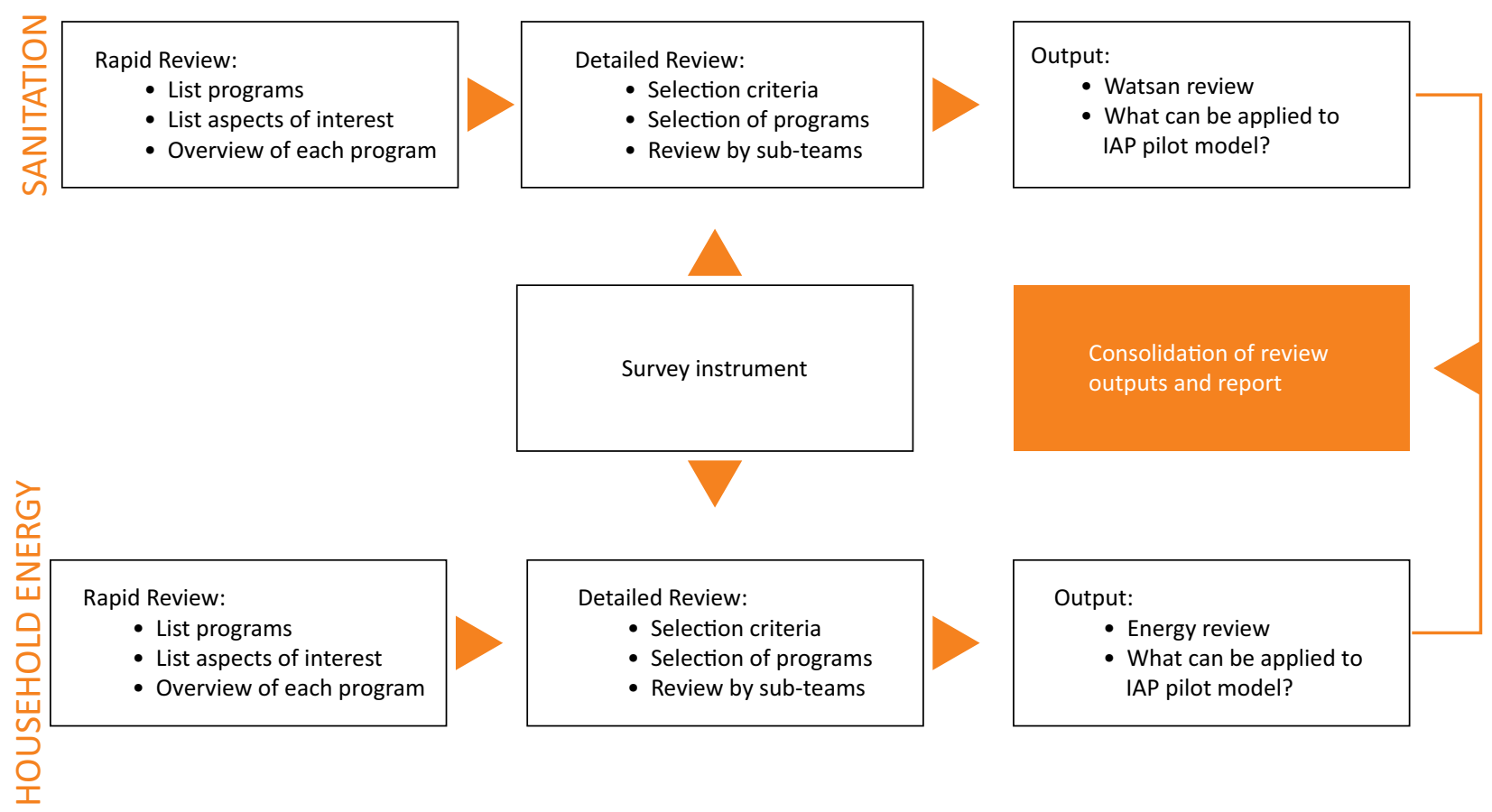

- Awareness and motivation: exploring effective, innovative, and participatory approaches to community mobilization;

- Development and promotion of technologies: identifying successful approaches to introducing improved cooking or sanitation technologies, operation and maintenance issues, and a monitoring system for user feedback and quality control;

- Financial aspects: identifying successful approaches to financing and enterprise development, including monitoring mechanisms.

The information collected and detailed questions concerning these issues are set forth in Table 2.1. This method was employed consistently across programs so that comparisons could be made between them, highlighting their similarities and differences.

\section{Household Energy Programs}

Six programs selected for the detailed review included three improved cookstove promotion programs, three biogas promotion programs, and one solar home system program. Two of the programs were implemented mainly by government agencies, namely BCSIR and LGED; two by IDCOL, a government-owned company; and two by national and international NGOs. Some of the programs were initiated two decades ago, while others were initiated only two to three years ago.

The study team selected eight sites for fieldwork, based on consultation with implementing organizations, availability of implementation staff, and access to program areas. For large programs with multiple implementing partners, such as the National Domestic Biogas and Manure Program and the Sustainable Energy for Development Program, the team visited the sites of comparatively large and small partner organizations to detect any differences in approaches and implementation issues. Information collected during the rapid review was verified during these discussions, and key issues identified during the focus group discussions were raised and explored further. In all 142 users were 


\section{Table 2.1 Key Issues and Questions}

Key issues

Institutional arrangements

Institutional setup for

implementation

Building capacity and

commitment of local

policy makers and program

implementers to promote

intervention

Monitoring mechanisms
What are the key organizations and partners

involved in this program?

What is the management structure?

What is the role of the local government agencies

in promoting the use of improved technologies

and practices?

How is monitoring and evaluation undertaken

during and after the program?
Information collection tools

Interview with program implementers and local government agencies

\section{Awareness and motivation}

Awareness of benefits of household energy technologies

Social marketing or promotion of improved technologies
What awareness-raising activities are undertaken to promote improved technologies and practices?

How effective are these activities in promoting the use of improved technologies and practices?

Do these activities engage a wide range of stakeholders?

Did the program have a specific social marketing or promotional component?

What messages and materials were developed?

How were the messages disseminated?

Were there synergies with other awarenessraising activities in the area?
Interview with program implementers
Interview with program implementers

Focus group discussions
Interview with program implementers, technical staff, entrepreneurs, beneficiaries

\section{Development and promotion of technologies}

\begin{tabular}{|c|c|c|}
\hline $\begin{array}{l}\text { Adoption of improved } \\
\text { technologies and practices }\end{array}$ & $\begin{array}{l}\text { What percentage of households is using the } \\
\text { improved technologies and practices promoted? } \\
\text { Are these households simultaneously using } \\
\text { traditional technologies, such as stoves? }\end{array}$ & $\begin{array}{l}\text { Interview with program } \\
\text { implementers } \\
\text { Literature review }\end{array}$ \\
\hline $\begin{array}{l}\text { Identification and } \\
\text { validation of suitable } \\
\text { technology }\end{array}$ & $\begin{array}{l}\text { How was the technology identified? } \\
\text { Was the technology tested in a controlled } \\
\text { laboratory environment and under real } \\
\text { conditions, with internationally accepted } \\
\text { methodology? } \\
\text { Did households test the technology and provide } \\
\text { feedback? } \\
\text { Was the technology adapted to meet local needs? }\end{array}$ & $\begin{array}{l}\text { Interview with program } \\
\text { implementers, technical staff, } \\
\text { field staff } \\
\text { Literature review }\end{array}$ \\
\hline $\begin{array}{l}\text { Impact on indoor air } \\
\text { pollution }\end{array}$ & $\begin{array}{l}\text { What is the measured reduction in } \mathrm{PM}_{2.5} \text { and } \\
\text { carbon monoxide levels due to the use of } \\
\text { improved technologies and improved practices? } \\
\text { What are some of the user-reported benefits of } \\
\text { improved indoor air quality? }\end{array}$ & $\begin{array}{l}\text { Interview with program } \\
\text { implementers } \\
\text { Literature review } \\
\text { Focus group discussions }\end{array}$ \\
\hline
\end{tabular}




\begin{tabular}{|c|c|c|}
\hline Key issues & Key questions & Information collection tools \\
\hline $\begin{array}{l}\text { Access to improved } \\
\text { household renewable } \\
\text { energy technologies }\end{array}$ & $\begin{array}{l}\text { What is the mechanism for getting access to } \\
\text { improved technologies? } \\
\text { Is information on improved technologies and } \\
\text { practices easily available? }\end{array}$ & $\begin{array}{l}\text { Interview with program } \\
\text { implementers }\end{array}$ \\
\hline \multicolumn{3}{|l|}{ Financial aspects } \\
\hline $\begin{array}{l}\text { Financial and market } \\
\text { systems for improved } \\
\text { energy technologies }\end{array}$ & $\begin{array}{l}\text { Does the program include a market development } \\
\text { component for improved technologies? } \\
\text { What are the training needs for developing } \\
\text { enterprise development skills? } \\
\text { What are the criteria for selection of } \\
\text { entrepreneurs? } \\
\text { Is there special emphasis on engaging women } \\
\text { entrepreneurs? } \\
\text { How do entrepreneurs get access to finances for } \\
\text { their businesses? } \\
\text { What are the terms and conditions for loans? Do } \\
\text { entrepreneurs have access to microcredit? }\end{array}$ & $\begin{array}{l}\text { Interview with program } \\
\text { implementers, microcredit staff, } \\
\text { entrepreneurs } \\
\text { Focus group discussions }\end{array}$ \\
\hline $\begin{array}{l}\text { Product quality control } \\
\text { mechanism }\end{array}$ & $\begin{array}{l}\text { How is product quality maintained? } \\
\text { Is product quality tied to loans? } \\
\text { What is the mechanism for providing technical } \\
\text { assistance to maintain product quality? } \\
\text { Is there any provision for refresher trainings? } \\
\text { What is the plan for quality control beyond the } \\
\text { program period? }\end{array}$ & $\begin{array}{l}\text { Interview with program } \\
\text { implementers, technical staff, } \\
\text { entrepreneurs } \\
\text { User surveys }\end{array}$ \\
\hline $\begin{array}{l}\text { Access to improved } \\
\text { household renewable } \\
\text { energy technologies }\end{array}$ & $\begin{array}{l}\text { What is the mechanism for getting access to } \\
\text { improved technologies? } \\
\text { Is information on improved technologies and } \\
\text { practices easily available? }\end{array}$ & $\begin{array}{l}\text { Interview with program } \\
\text { implementers }\end{array}$ \\
\hline
\end{tabular}

consulted during fieldwork, along with 41 other technicians and representatives from organizations.

\section{International Programs}

The international improved cookstove programs for review were selected based on the availability of information. A detailed review of international indoor air pollution programs was based on secondary information obtained through various program publications, independent evaluations, information available on websites, and articles. For some programs, communications with program staff were carried on through e-mails for additional information. The review of country-specific programs focused on the institutional, financial, technological, and community engagement aspects. Some multicountry indoor air pollution programs, such as GTZ-HERA (Household Energy for Sustainable Development), were also analyzed.

\section{Sanitation Programs}

Four organizations finally selected for the detailed review were known to have very good expertise in implementing sanitation programs by ensuring successful community mobilization towards a desired change. During the fieldwork, 45 users of latrines 
(both male and female) were consulted, in addition to 56 entrepreneurs and local representatives. Two focus group discussions were also held with entrepreneurs and users. The organizations have been quite successful in promoting latrines and behavior change by engaging the community using unorthodox techniques, including engendering a sense of embarrassment about prevailing sanitation practices. These are at the heart of the success and sustainability of total sanitation.

\section{Assessment}

The effectiveness of the approaches and scaling-up processes were assessed based on the following framework indicators:

* Ultimate beneficiary, involvement of different stakeholders, aspect of governance and equity, self-financing, and how the interventions address the very poor;
- Access of the people in the community to basic technology options and skills, and availability of materials at the doorstep;

Level of success.

The programs selected for detailed review are listed in Table 2.2.

\section{Conclusions}

The methodology of this review covers many aspects of the programs and is fairly comprehensive. The advantage of collecting information on similar aspects of programs is that it permits comparisons of institutions, how the programs were financed, how technologies were developed and disseminated, and the response of customers to technologies and their motivation to adopt them. The next chapter considers the most important household energy programs in Bangladesh.

\section{Table 2.2 Programs Selected for Detailed Review}

\begin{tabular}{|c|c|}
\hline \multicolumn{2}{|r|}{ enting agency } \\
\hline \multicolumn{2}{|l|}{ Household energy } \\
\hline Dissemination of improved cookstoves & BCSIR \\
\hline $\begin{array}{l}\text { Sustainable Energy for Development Program: } \\
\text { improved cookstoves component }\end{array}$ & GTZ \\
\hline $\begin{array}{l}\text { Reduction of exposure to indoor air pollution through } \\
\text { household energy and behavioral improvements } \\
\text { (indoor air pollution program) }\end{array}$ & Winrock, VERC, and Concern Worldwide Bangladesh \\
\hline Biogas Program & BCSIR/LGED \\
\hline National Domestic Biogas and Manure Program & IDCOL/Netherlands Development Organization (SNV) \\
\hline $\begin{array}{l}\text { Rural Electrification and Renewable Energy Development } \\
\text { Program }\end{array}$ & IDCOL \\
\hline \multicolumn{2}{|l|}{ Sanitation } \\
\hline Water, Sanitation and Hygiene (WASH) Program & Bangladesh Rural Advancement Committee (BRAC) \\
\hline $\begin{array}{l}\text { Decentralized Integrated Sanitation, Hygiene and } \\
\text { Reform Initiative (DISHARI) Program }\end{array}$ & World Bank \\
\hline Community-Led Total Sanitation Program & VERC \\
\hline Community WatSan Program supported by NGO Forum & Sustainable Energy Development Agency (SEDA) \\
\hline
\end{tabular}





\section{Household Energy Initiatives in Bangladesh}

angladesh is a country in which there have been many important household energy initiatives. They have ranged in scale from small to quite large, but they all contain lessons for the development of improved cookstove programs for the country. The programs are reviewed and compared based mostly on their institutional form, their cost structure, the technology promoted, and the acceptance of those technologies by consumers.

Six household energy programs are reviewed using a standard methodology described in the previous chapter. The programs include the BCSIR dissemination of improved cookstoves, the GTZ Sustainable Energy for Development Program (improved cookstoves component), the United States Agency for International Development (USAID)/ Winrock program on reduction of exposure to indoor air pollution through household energy and behavioral improvements, the BCSIR/LGED Biogas Program, the IDCOL National Domestic Biogas and Manure Program, and the IDCOL Rural Electrification and Renewable Energy Development Program.

These programs include a range of household energy projects, including cookstove initiatives, a biogas program, and a solar household photovoltaic program. The technologies are different, but they all have to deal with issues such as technology innovation, marketing, and consumer acceptance. The overview of the projects indicates that some of them have resulted in hundreds of thousands of adopted products, while others have resulted in as few as hundreds of adoptions. Table 3.1 provides a synopsis of the programs that are detailed in the following sections.

\section{BCSIR: Improved Cookstove Program, Phase II}

Implemented from 1988 to 2001, this governmentled program had the primary objective of development and dissemination of improved cookstove models suitable for Bangladesh.

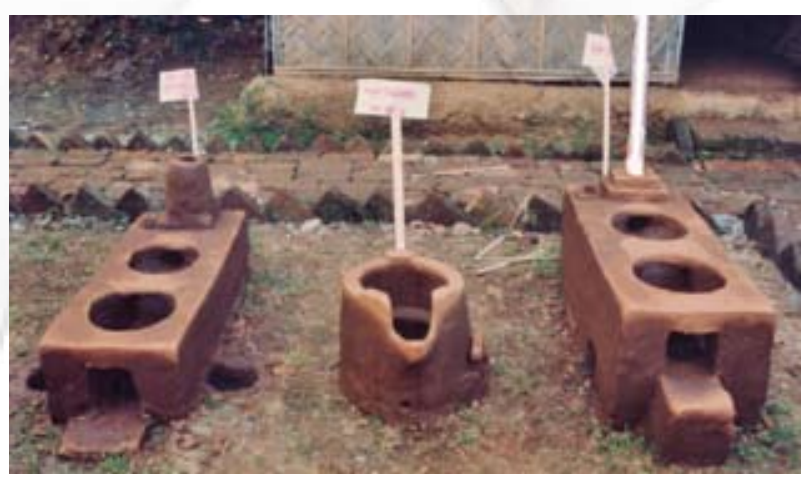

Cookstove models developed by BCSIR. 


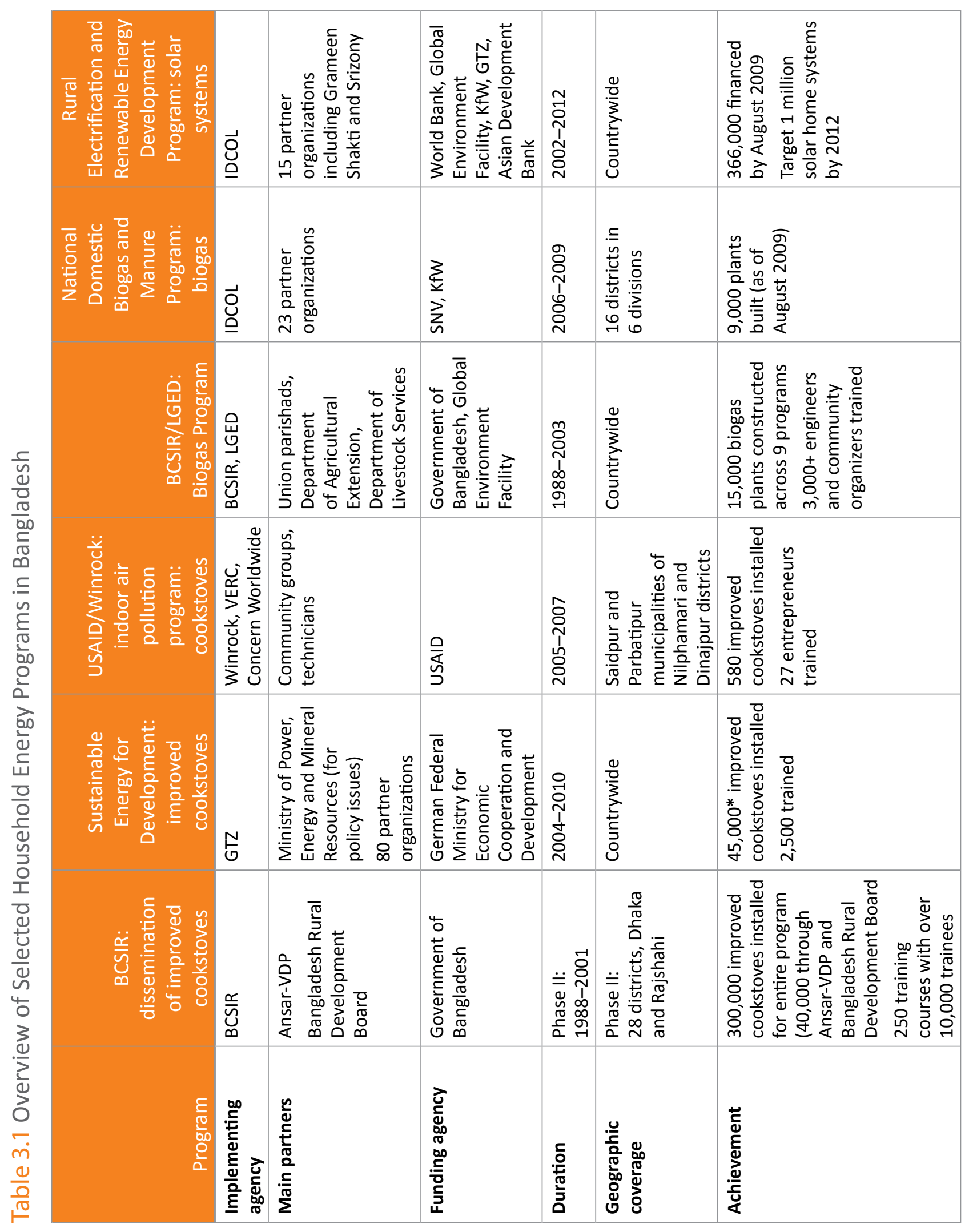




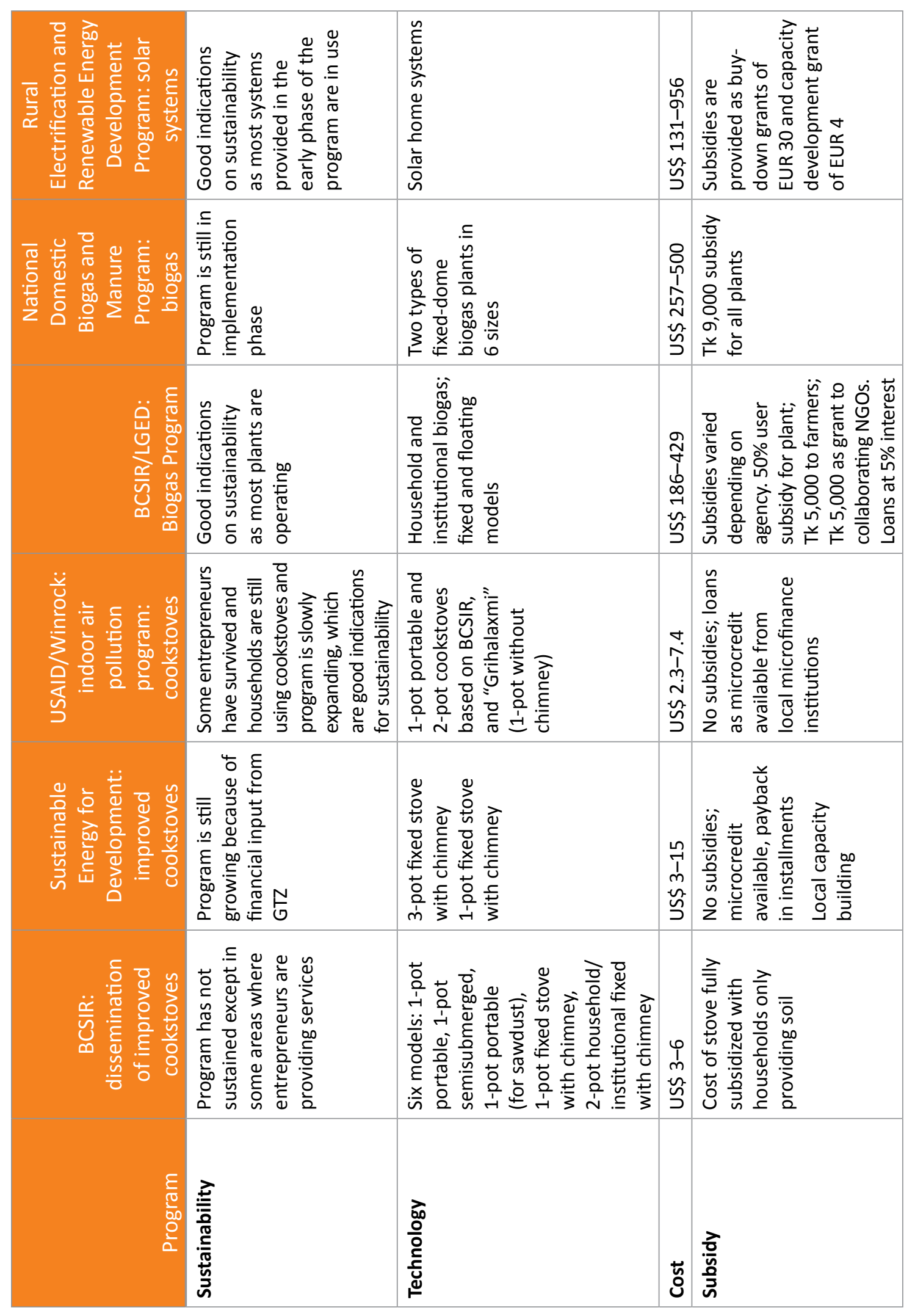




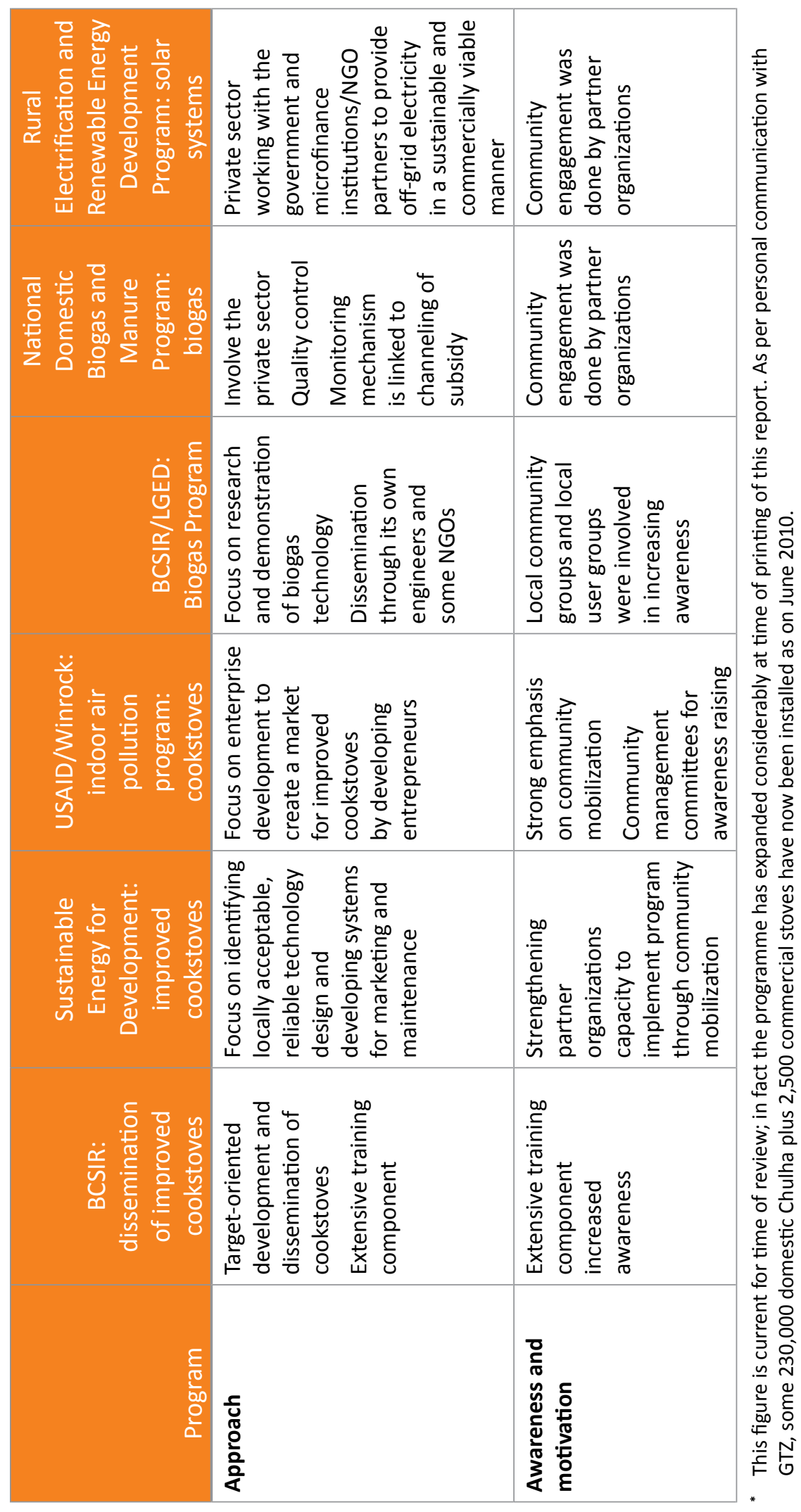




\section{Institutional Arrangements}

The leading organization, BCSIR, received government funds and worked in extensive coordination with local government institutions and through several government partners. In total about 300,000 improved cookstoves were disseminated through the BCSIR-led program. For the purposes of this report, BCSIR's collaboration with two government partners - Bangladesh Ansar and Village Defense Party (Ansar-VDP), and the Bangladesh Rural Development Board - is described. Ansar-VDP is a part-time volunteer law enforcement force working at the union and village level with direct linkages with the villagers. The Bangladesh Rural Development Board is under the Ministry of Local Government, Rural Development and Cooperatives and is the largest service-oriented institutional setup of the government of Bangladesh. It is directly engaged in rural development and poverty alleviation and works with farmer cooperatives. Ansar-VDP and the Bangladesh Rural Development Board provided field-level supervisors and trained fieldworkers for motivating households and providing training to adopt improved cookstoves. The supervisors and fieldworkers were on BCSIR's payroll and received a minimal remuneration of Tk 10-20 per stove from the households. Most of the fieldworkers were women, as it is easier for women to gain access to households. Ansar-VDP disseminated approximately 25,000 improved cookstoves ${ }^{3}$ and the Bangladesh Rural Development Board disseminated approximately 15,000-16,000 improved cookstoves ${ }^{4}$ through its extension program. Figure 3.1 shows the institutional arrangements for this program.

At the upazila or subdistrict level, the team coordinated with district-level Ansar-VDP and BCSIR staff for monitoring program activities. At the upazila level, the supervisors of the Bangladesh Rural Development Board credit program were

3 Discussion with Mr. Shah Alam, Deputy Director, Ansar-VDP, Dhaka, September 2007.

4 Discussion with Mr. Rafiqul Islam, Deputy Director, Bangladesh Rural Development Board, Dhaka, September 2007. responsible for the stove program and provided all necessary support to the program. At subupazila levels inspectors, technicians, and women fieldworkers were in direct contact with the users.

Local capacity building was enhanced by an extensive training component that included training of women fieldworkers. BCSIR trained more than 10,000 people (including a number of NGOs, local clubs, unemployed youths, and staff of Ansar-VDP, the Bangladesh Rural Development Board, and the Department of Public Health Engineering) in 250 training courses. The program did not have any provision for user training, but users were instructed on stove use and maintenance at the time of installation, and given the opportunity to discuss performance and usage issues during follow-up visits.

While there was no support for entrepreneurship development, several trainees, such as the supervisors, started their own stove-making businesses after the program ended in 2001. Program monitoring was program-led through staff and partner organizations. Monitoring was carried out with the help of the upazila rural development officers.

\section{Awareness and Motivation}

The extensive training provided through the program aided awareness raising. Other

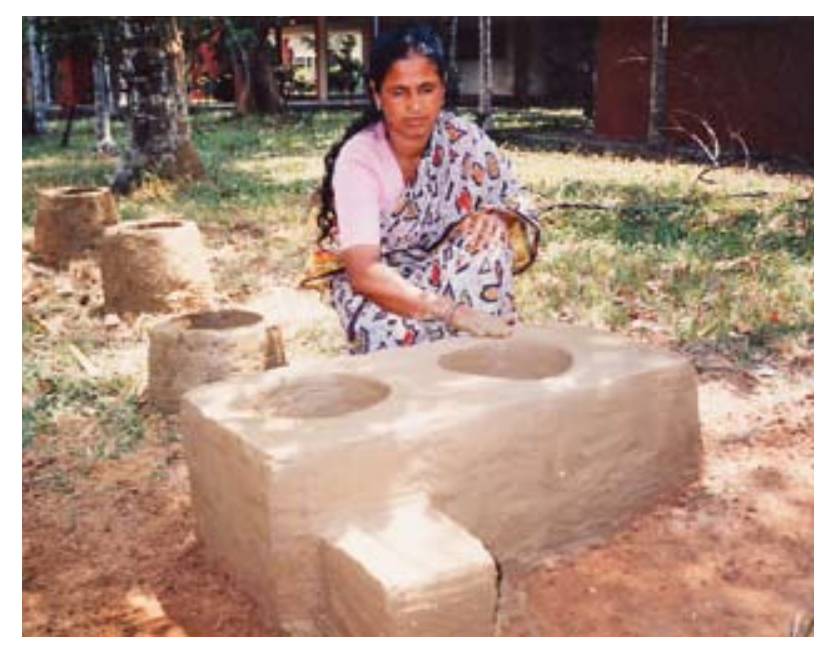




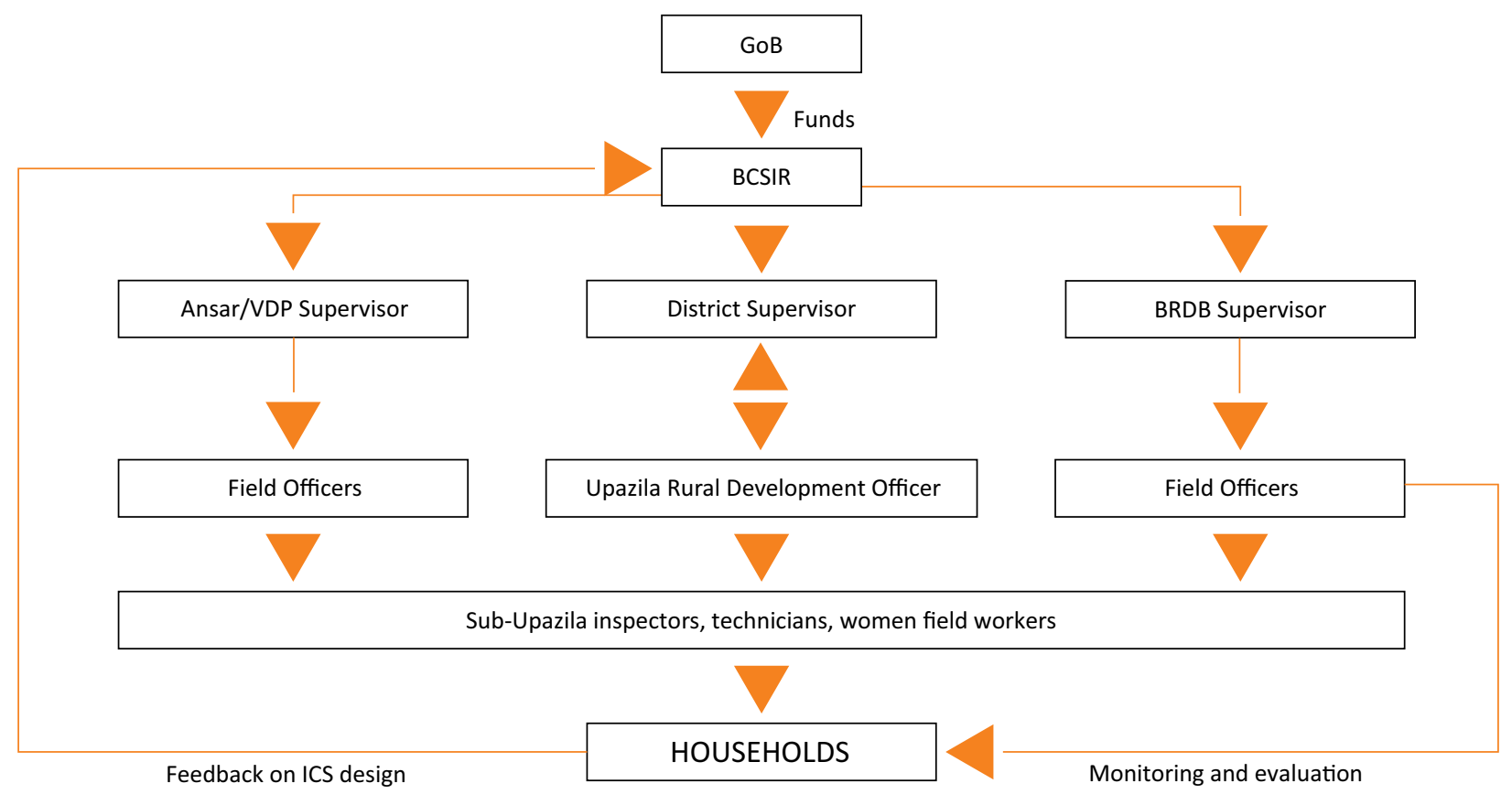

awareness-raising activities included local demonstrations, display centers, seminars, and radio and television spots. Local government institution representatives were encouraged to attend local demonstrations and upazila-level seminars. Being a government program, it received special rates from the government's media outlets (Bangladesh Television and Bangladesh Betar Radio), through which a number of advertisements and short films on improved cookstoves were disseminated. These advertisements created such a high level of awareness that the program teams were inundated with requests for cookstoves.

The survey team found while visiting one of the thana supervisors under the project in Natore district that a number of former program employees had launched their own improved cookstove businesses and developed their own strategies (including posters, demonstrations, liaising with sanitation workers) to raise awareness and to continue to utilize the networks established by the BCSIR program to market their products.

\section{Development and Promotion of Technologies}

BCSIR developed and promoted (a) one-pot portable cookstoves; (b) one-pot semisubmerged stoves; (c) one-pot portable stoves for use with sawdust or rice husk; (d) one-pot fixed stove with chimney; (e) twopot fixed household-sized stoves with chimney; and (f) two-pot fixed institutional stoves with chimney. Entrepreneurs, users, and other programs later modified these designs to suit local conditions.

Ten in-house scientists of BCSIR carried out random sampling of improved stoves to test for performance. In addition, the improved cookstoves installed were listed and monitored on a monthly basis. The performance efficiency for BCSIR stoves was reported to be 25-28 percent (Khan 2000), which reduced fuel consumption by over 50 percent (Table 3.2 ).

User surveys revealed that key usability issues were uncertainty about post-warranty service, lack of raw materials such as fuelwood, and technical 
Table 3.2 BCSIR Stove Performance Data

\begin{tabular}{|l|c|c|c|c|c|}
\multicolumn{2}{r}{} & \multicolumn{2}{c}{ Fuel } & Carbon & Carbon \\
\multicolumn{1}{c}{ Stove type } & Efficiency $^{\mathrm{a}}$ & consumption & monoxide ${ }^{\mathrm{b}}$ & dioxide \% & Saving \% \\
\hline Improved one-pot stove & $25 \%$ & $1.35 \mathrm{~kg}(85 \mathrm{~min})$ & $\leq 1.0$ & - & 55 \\
\hline Improved two-pot stove & $28 \%$ & $1.2 \mathrm{~kg}(75 \mathrm{~min})$ & $\leq 1.0$ & - & 58.3 \\
\hline Traditional stove & $13 \%$ & $3.0 \mathrm{~kg}(90 \mathrm{~min})$ & 0.24 & 2.95 & Baseline \\
\hline
\end{tabular}

a. Efficiency values (rounded off) are based on the numbers reported in Khan 2000.

b. The concentration of carbon monoxide emission in traditional stove, improved one-pot, and improved two-pot stove with chimney could not be measured as values were less than 1 percent and below the measuring range of the equipment used.

difficulties such as blocked chimneys and air inlets. According to the user surveys, households changed stove dimensions during maintenance and, in some cases, made significant changes to stove dimensions, such as attaching an additional pot hole to a two-pot stove to convert it into a threepot stove. This is actually quite a common feature of low-cost stoves in other programs around the world. Custom-made stoves are made from local materials, and women are used to making their own stoves, so they have no problem altering these stoves to make them more convenient for their cooking needs. This unfortunately leads to lower performance in efficiency and smoke removal.

\section{Financial Aspects}

The program was government funded and lacked a commercial approach. It offered direct subsidies, with a focus on reaching a predetermined number of households. The program provided direct subsidy to households in the form of an installation fee. Indirect subsidy was in the form of program overhead costs (for example staff cost and training). No subsidies were provided for any stoves constructed after the program period.

The program-appointed supervisor at upazila level managed a number of trained technicians who installed improved cookstoves in households for a fee. The program provided free molds, accessories, and technicians' fees for the first 200 households, who only had to supply mud for construction. For the rest of the stoves, the households provided mud and materials, but the technicians' fees were provided from the program. Fieldworkers received the following fees for stoves constructed:

* One-pot portable improved stove: Tk 50 (US\$ 0.74);

* Two-pot fixed improved stove with chimney: Tk 100 (US\$ 1.50);

* Two-pot fixed institutional improved stove with chimney: Tk 500 (US\$ 7.35).

The cookstove program was not channeled through the credit program of the Bangladesh Rural Development Board because the cost of the stoves was too low at Tk 200 (US\$3) to Tk 400 (US\$ 6).

\section{GTZ: Sustainable Energy for Development Program: Improved Cookstoves Component}

The Sustainable Energy for Development Program has been implemented by GTZ (2004-2010) with the objective to promote improved cookstoves through a commercial, sustainable approach. The program has focused efforts on identifying locally acceptable and reliable technology and design, and developing systems for marketing and maintenance.

\section{Institutional Arrangements}

The GTZ Sustainable Energy for Development Program supports 80 partner organizations, mainly 
NGOs, as primary players in promoting three models of improved stoves throughout Bangladesh. Partner organizations are in direct contact with the consumers and have a strong community presence or microcredit operations through which the improved stoves can be channeled to the households. Figure 3.2 shows the institutional arrangements for this program.

GTZ receives financial and policy support from the German Federal Ministry for Economic Cooperation and Development and the government of Bangladesh (Ministry of Power, Energy and Mineral Resources), respectively. It supports its partner organizations and manufacturers in finance, training, and business development areas. These in turn provide finance, training, installation, and after-sales support to the end user.

Training is a key component of the GTZ program. It is needs based and provided through the partner organizations. GTZ has trained about 2,500 people, including stove technicians, NGO workers and private entrepreneurs, ${ }^{5}$ who have constructed more than 45,000 improved cookstoves to date. ${ }^{6}$ Partner organizations also engage local masons and other interested persons to impart training on cookstove construction, business development, and marketing techniques. These people receive financial support from GTZ, via the partner organizations, to set up cookstove construction or accessory businesses. The training is followed by local exhibitions at which local stakeholders, including local government representatives such as union chairpersons and members, participate.

Training of users is the responsibility of the partner organizations concerned and is usually imparted after stove construction. It was observed that most

5 Potential entrepreneurs are required to have an education of at least grade 3-4 and potential trainers are required to have an education of at least grade 10-12 (discussion with Dr. Khaliquzzaman and Mr. Otto Gomm, German Technical Cooperation (GTZ), Dhaka, September 2007 and January 2008).

6 German Technical Cooperation (GTZ) Sustainable Energy for Development Program: The Killer in the Kitchen (http://www.lgedrein.org/archive_file/killerinthekitchen.pdf). cookstove users did not receive training for using the technology; instead they learnt by observing their neighbors use improved cookstoves. GTZ has trained both men and women, but has found that the men tend to go on to build more stoves, while women tend to stop after constructing one in their home, because it is more difficult for women to travel long distances and offer technical assistance in a timely fashion. This is likely to be due to pervading cultural norms in Bangladesh. The partner organizations now specifically select only male technicians and entrepreneurs.

Program monitoring is led by partner organizations and coordinated by GTZ. Currently partner organizations, such as Palli Shakti and Grameen Shakti, use staff for program monitoring during loan collection visits (see below). Monitoring is sometimes tied in with payment collection visits to those households that took loans to pay for the stoves. This has been found to be a successful way to build accountability into a cookstove program.

\section{Awareness and Motivation}

The program does not promote any specific community engagement strategy, though it has produced posters and leaflets that it distributes to its partner organizations. For example, site visits

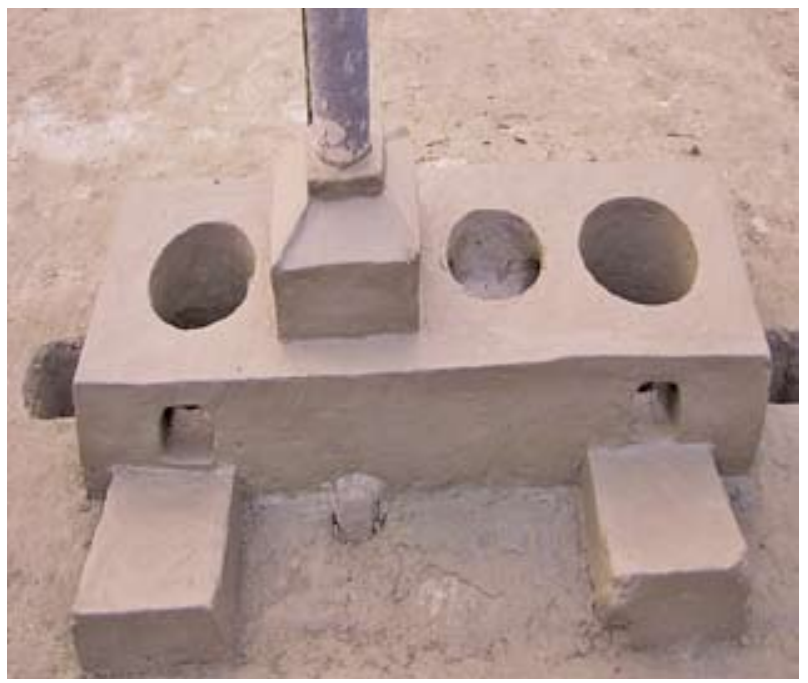

Three pot improved cookstove promoted by GTZ. 


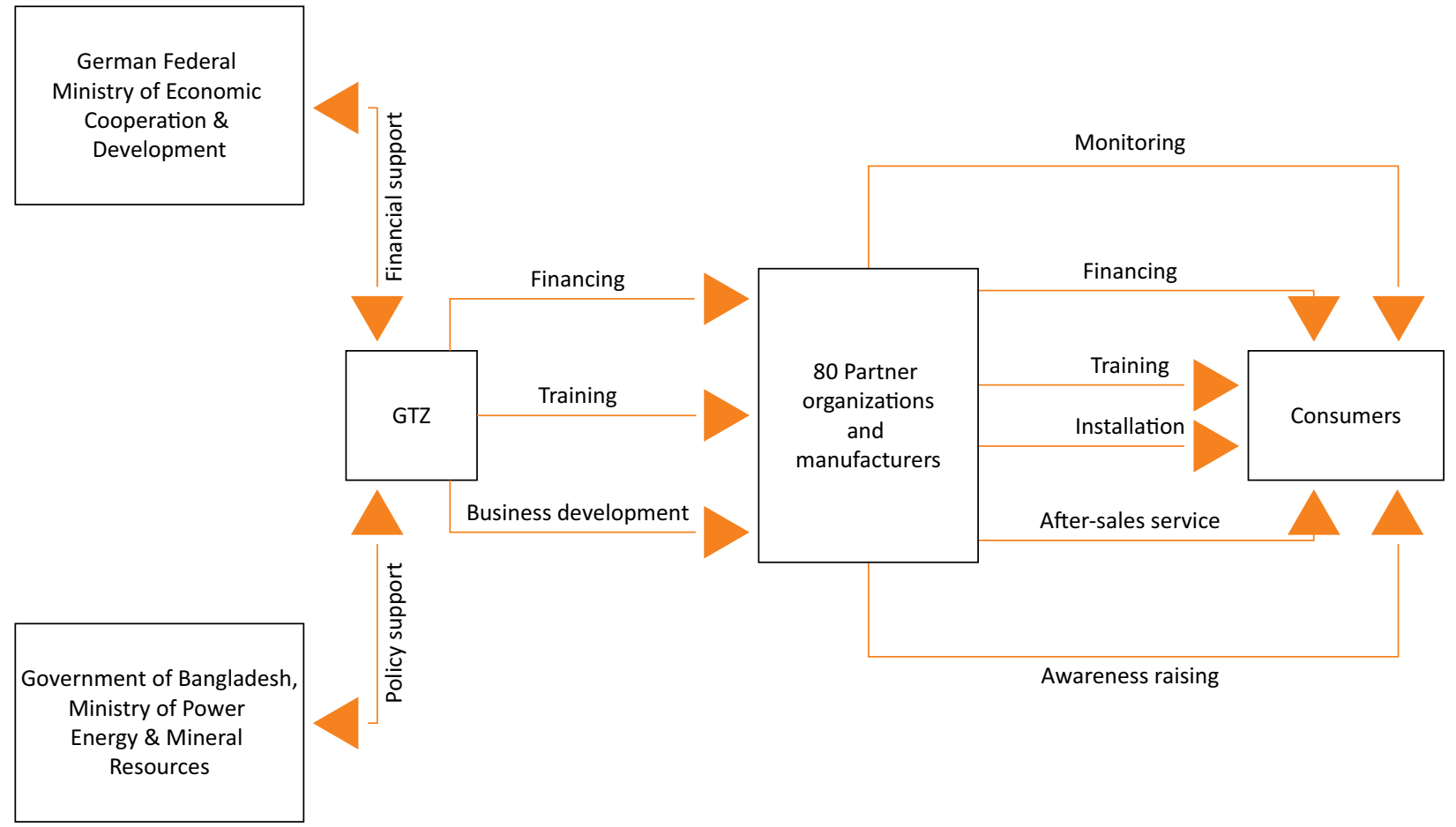

showed that one partner organization, Palli Shakti, does not employ a specific community engagement approach. Instead it undertakes awareness activities that include door-to-door marketing, distribution of leaflets and posters, and discussions with local leaders, such as union parishad members and local entrepreneurs. Grameen Shakti, another partner organization, relies on its local staff to identify households that are willing to purchase a cookstove. Staff receive monthly targets for sales and disseminate information about cookstoves, primarily through door-to-door marketing and distribution of leaflets and posters developed by GTZ and Grameen Shakti.

Local government institutions participate in the training aspects of the community and preside over the training certificate ceremony. Partner organizations are encouraged to undertake community mobilization activities that are most appropriate for local conditions to ensure that target communities accept messages and that dissemination is cost-effective. Currently, GTZ is supporting promotional activities by organizing local exhibitions and fairs for renewable energy technologies, including improved cookstoves.

\section{Development and Promotion of Technologies}

GTZ is promoting a three-pot fixed stove with chimney, based on an earlier design from BCSIR. It is also promoting a one-pot fixed stove with a chimney. Testing for efficiency and carbon monoxide emissions by GTZ has been limited. Of the 10,000 stoves that GTZ has disseminated, preliminary assessment of only one three-pot stove with chimney has been conducted. This model was found to be 26-27 percent efficient (compared to 5-15 percent for traditional stoves) and saved 50-60 percent fuel.

User surveys revealed usability issues such as lack of raw materials, technical problems (blocked chimneys and air inlets, as with the BCSIR program), and uncertainty about post-warranty service. Users 
reported that chimneys were difficult to install in a traditional kitchen and if they were of poor quality they accumulated more dust and soot, resulting in frequent clogging.

\section{Financial Aspects}

The stoves promoted by this program ranged from Tk 200 to 1,000 (US\$ 3 to 15). Palli Shakti is selling two varieties of the three-pot type - mud only for Tk 700 and a mud-brick for Tk 1,000 (US\$ 15). No direct subsidies are provided to users. GTZ allows its partner organizations to formulate financing mechanisms for selling the improved cookstoves.

The partner organizations use existing microcredit mechanisms to channel funds. However, because the cost of the stove is low compared to the amount of credit that is normally given for other programs, the payback period is very short, usually six months. Most partner organizations also allow payment in installments. Palli Shakti charges 10 percent interest and allows payments in three installments. Due to the small amount of credit required for improved cookstoves, Grameen Shakti offers the loans in two installments. Fieldworkers have indicated that most households can afford to pay for the improved cookstoves without taking credit. The one-pot cookstove that GTZ has started disseminating may not require any financing mechanism as, at Tk 200 (US\$ 3), it should be within the purchasing ability of poor rural households. However, for very poor families, the cost can be too high to pay at once.

As an example, the total financial support provided by GTZ to Palli Shakti is Tk 700,700 (US\$10,304), primarily for the following activities:

- Support for a chimney and grate manufacturing facility: Tk 95,000 (US\$ 1,397);

* Working (seed) capital for installation of commercial improved cookstoves: Tk 50,000 (US\$ 735);

Working capital for installation of domestic improved cookstoves: Tk 150,000 (US\$ 2,206);
* Support for training and promotion: Tk 405,700 (US\$ 5,966).

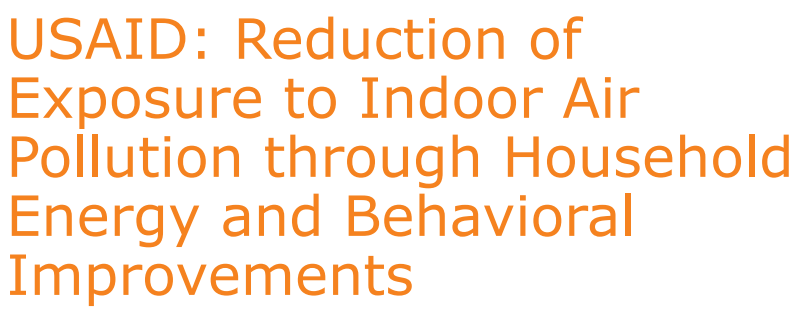

This program was implemented in the northwest of Bangladesh from 2005 to 2007 with the main objectives of increasing awareness of indoor air pollution; changing household energy behavior; and promoting and developing a commercial market for improved cookstoves and entrepreneurs. The program disseminated 580 improved cookstoves. A number of studies were also completed alongside the program.

\section{Institutional Arrangements}

Winrock International, VERC, and Concern Worldwide Bangladesh jointly implemented this USAID-funded project. VERC led the technology component of the program. Concern Worldwide developed behavior change messages and disseminated these messages through health volunteers, ward health committees, and municipal governments. The Appropriate Rural Technology Institute (India) collaborated with Winrock and VERC and undertook improved cookstove testing. Local municipal authorities were engaged for awareness raising, and members of the government's network of health volunteers were trained to promote behavior change messages for indoor air pollution reduction and use of improved cookstoves. Figure 3.3 shows the institutional arrangements for this program.

Several types of training were offered, such as cookstove construction, enterprise development, leadership and management, and kitchen improvement. Thirty health volunteers were also trained in behavior change communication and awareness-raising techniques. The users did not 


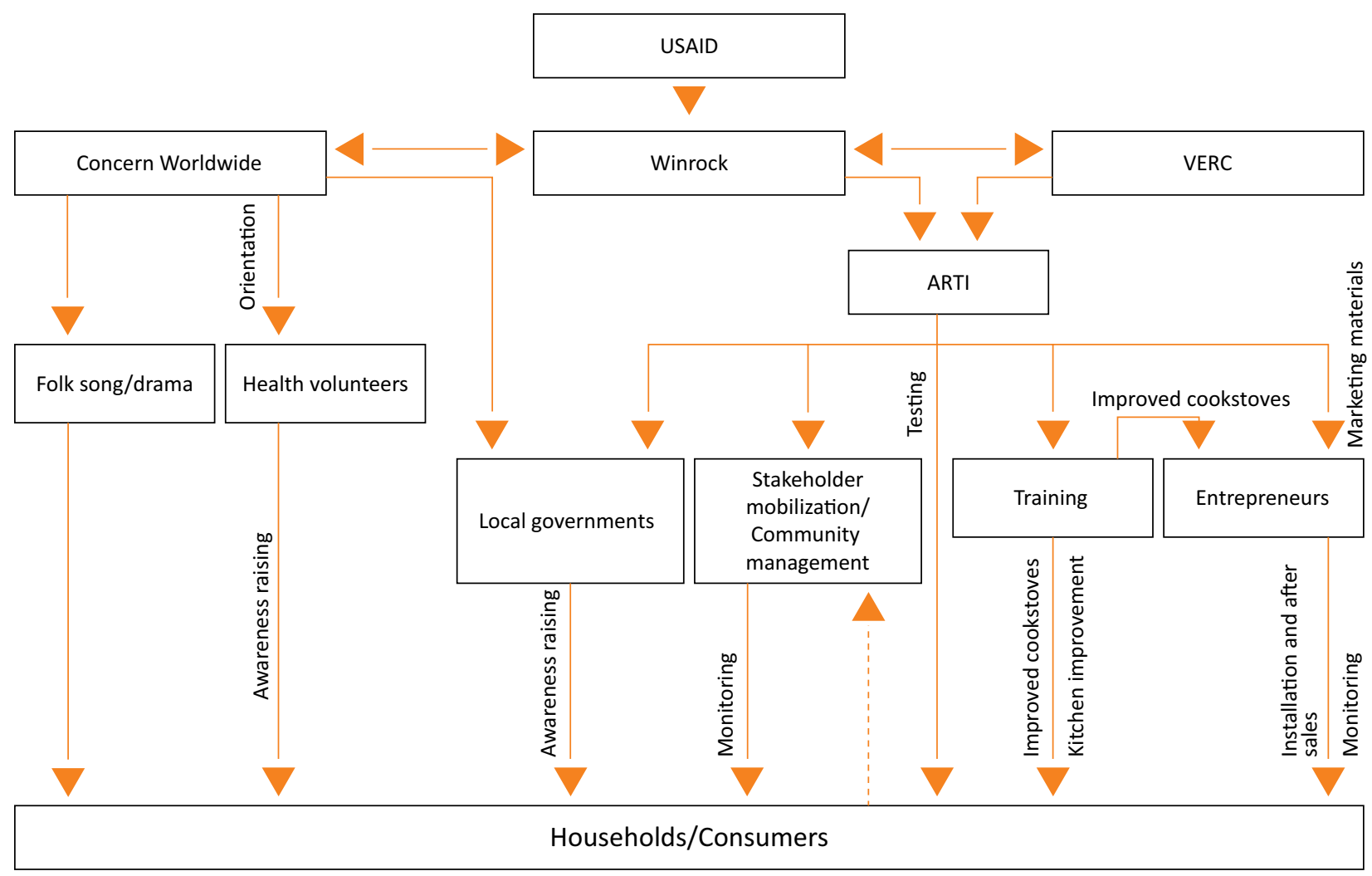

receive any training on stove construction and maintenance, although catalysts, entrepreneurs, and program staff shared this information during awareness-raising activities. Stakeholders and entrepreneurs were involved in the monitoring process.

Enterprise development was a key component of the program and helped improve stove construction. Trainings were geared towards potential entrepreneurs and "catalysts" - local women who were interested in raising indoor air pollution-related awareness in the initial stages of the program. The program's approach promoted private sector engagement in the manufacture, supply, and installation of improved cookstoves. Three types of entrepreneurs were supported: (a) manufacturing entrepreneurs, who made improved cookstove components, such as chimneys and grates; (b) installation entrepreneurs, who installed improved cookstoves on a turnkey basis; and (c) retail entrepreneurs, who sold improved cookstove components. The program also established a seed fund to provide initial capital to improved cookstove entrepreneurs. Toward the end of the program, refresher trainings in enterprise development were provided to 20 entrepreneurs and seven new entrepreneurs.

\section{Awareness and Motivation}

Concern Worldwide and VERC organized orientation sessions for local government representatives, including ward health committee members, to disseminate information about indoor air pollution, the benefits of improved cookstoves, and the objectives of the program.

The program had a strong emphasis on community mobilization. Community-based groups were created and linked with local ward health committees to monitor activities. Local-level health volunteers 


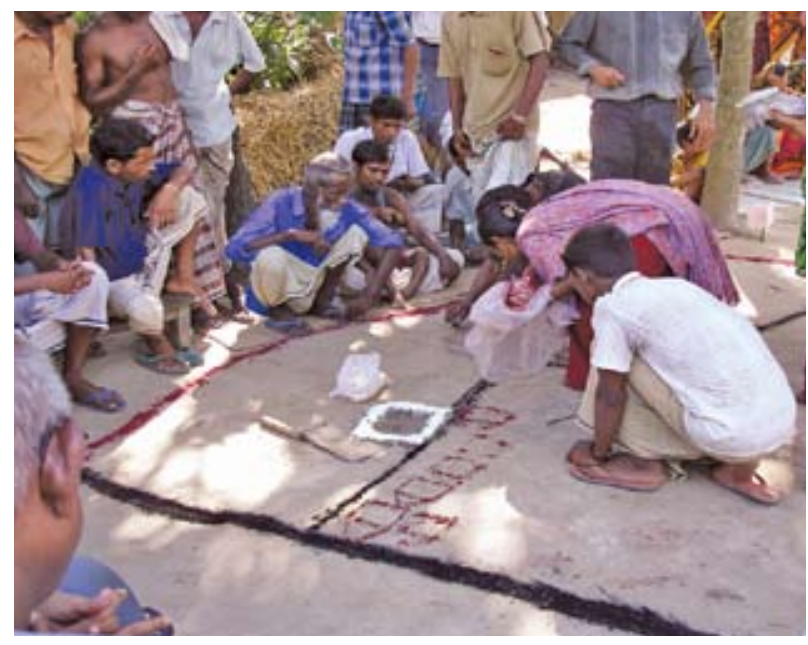

Community mobilization in an indoor air pollution programme.

disseminated behavior change information. Thirteen community management committees formed through a participatory process were responsible for awareness raising and monitoring improved cookstove construction activities in their respective areas. These committees held weekly meetings where program staff, interested households, and local leaders gathered to discuss program progress and address any issues.

From the outset, VERC employed the methodology for participatory assessment ${ }^{7}$ to achieve community buy-in and raise awareness. Other types of awareness-raising activities included courtyard meetings for households; working with a network of health volunteers and members of the community management committees; school sessions for students and teachers of local schools and colleges; and film showings for the community, including local government representatives (such as ward commissioners), health workers, health volunteers, and entrepreneurs. The program focused on using locally appropriate media, such as folk songs and drama. Users, in general, did not make reference to posters and leaflets during the field study.

7 The methodology for participatory assessment (MPA) is a collection of successful participatory tools developed for the World Bank's water supply and sanitation programs. This MPA has been adapted by the Asia Regional Cookstove Program for the household energy sector.

\section{Development and Promotion of Technologies}

This program promoted three types of improved cookstoves: one-pot portable and two-pot cookstoves (based on BCSIR models), and the Grihalaxmi, a one-pot stove without a chimney developed from a model from the Appropriate Rural Technology Institute, with a top grate that acts as a flame concentrator and a cast-iron bottom grate.

There was a strong focus on identifying stoves that were suitable for the cooking practices of the target community. With technical assistance from the Appropriate Rural Technology Institute, the stoves were tested using controlled cooking tests, 48-hour monitoring of particulate matter $\left(\mathrm{PM}_{2.5}\right)$ and carbon monoxide, water boiling tests, and kitchen performance tests, which measured fuel use in real households over several days. The 48-hour monitoring was conducted for improved cookstoves that had been in use for at least one month. The BCSIR stoves decreased $\mathrm{PM}_{2.5}$ in the indoor air by $71-85$ percent and carbon monoxide by $98-99$ percent. However, these results are based on tests conducted on only eight stoves, including two traditional stoves.

Usage issues reported included increased fuelwood consumption, lower than required positioning of the grate, and degeneration of the grate causing fuel to fall to the bottom of the stove. Issues of stove maintenance included ash accumulation in the void beneath the chimney, decrease in chimney diameter due to soot accumulation, and decrease in the diameter of the air passage from the first to the second pot.

\section{Financial Aspects}

The program promoted three types of improved cookstoves at project-fixed prices - BCSIR one-pot portable at Tk 155 (US\$ 2.3), BCSIR two-pot at Tk 365-505 (US\$ 5.4-7.4), and the Grihalaxmi at Tk 230 (US\$ 3.4) (Table 3.3). The actual price of the stoves with installation, particularly the two-pot model with 


\section{Table 3.3 Price of Improved Cookstoves under USAID/Winrock Indoor Air Pollution Reduction Program}

\begin{tabular}{|c|c|c|c|}
\hline Type of cookstove & Total cost (Tk) & $\begin{array}{l}\text { Project contribution to } \\
\text { technician fee (Tk) }\end{array}$ & Cost to households (Tk) \\
\hline \multicolumn{4}{|l|}{ BCSIR two-pot: } \\
\hline Bamboo/thatched roof & 485 (US\$ 7.1) & 120 (US\$ 1.8) & 365 (US\$ 5.4) \\
\hline Metal roof & 565 (US\$ 8.3) & 120 (US\$1.8) & 445 (US\$ 6.5) \\
\hline Cement roof & 625 (US\$ 9.2) & 120 (US\$ 1.8) & 505 (US\$ 7.4) \\
\hline BCSIR one-pot portable & 245 (US\$ 3.6) & 90 (US\$ 1.3) & 155 (US\$ 2.3) \\
\hline Grihalaxmi & 290 (US\$ 4.3) & 60 (US\$ 0.9) & 230 (US\$ 3.4) \\
\hline
\end{tabular}

chimney, varied according to the construction material of the roof of the house, as a hole had to be made for the chimney. This led to the price of each stove being based on estimates of local costs and negotiations between the households and the technician.

Some technicians-turned-entrepreneurs sold the stoves at a price of Tk 230 (US\$ 3.4) in their locality and at higher rates (up to Tk 500 to 600 , US\$ 7 to 9 ) in outside areas. The study team discovered that many households viewed improved cookstoves as something distributed free of cost by NGOs, but people were willing to pay very low prices for improved cookstoves if they had to.

The majority of program households were already taking loans as microcredit from local microfinance institutions for various uses. Therefore, the program partnered with some of these NGOs and institutions involved in lending to provide orientation on indoor air pollution and improved cookstoves to loan officers from the NGOs and encourage them to provide an additional loan of a maximum Tk 1,000 (US\$ 15) for the purchase of improved cookstoves along with some kitchen improvements, where needed.

\section{BCSIR/LGED: Biogas Program}

BCSIR initiated its biogas research and development activities in the mid 1970s and implemented a three-phase Biogas Pilot Plant Program to promote biogas dissemination from 1982 to 2004 , resulting in more than 21,000 plants installed throughout Bangladesh. In its Biogas Program, BCSIR established memoranda of understanding with a number of organizations, including NGOs, such as BRAC for monitoring support, and government departments, including the Department of Agricultural Extension, the Department of Livestock Services, and LGED for implementing the Biogas Program. For the purpose of this report the focus of the review is on LGED's dissemination program. The program, implemented from 1988 to 2003 with the main objective of research and demonstration of biogas technology, constructed 22,100 biogas plants.

\section{Institutional Arrangements}

The union parishads, the Department of Public Health Engineering, the Department of Agricultural Extension, and LGED were involved in program implementation. Through memoranda of understanding, BCSIR trained a large number of people in biogas plant construction, which helped raise awareness about the project. Figure 3.4 shows the institutional arrangements for this program.

The Department of Agricultural Extension supported the program by advising households on animal husbandry (the manure from which would provide feedstock for the biogas plants); funding motivational activities and awareness raising targeted at farmers; assisting in identifying potential 


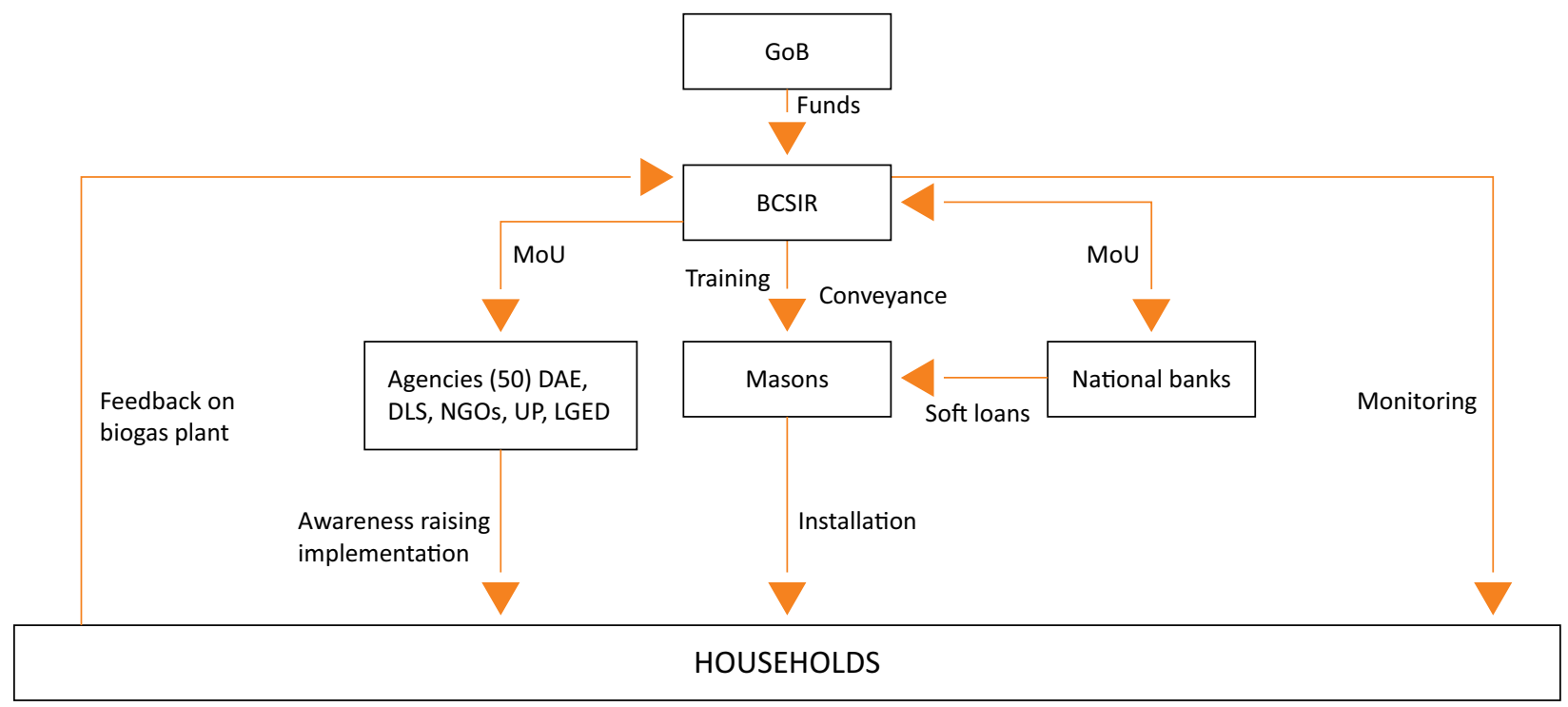

biogas households and following up on the biogas activities of upazila agriculture officers and block supervisors; participating in the monthly meetings of the biogas project; and conveying decisions to the upazila agriculture officers. The Department of Livestock Services was responsible for attending biogas coordination committee meetings and circulating the biogas project decisions to the district livestock officer and upazila livestock officer to assist with biogas project implementation. The program agencies coordinated extensively with the local government, which assisted with the program through the Upazila Development Coordination Committee. The Committee disseminated information and expertise on biogas, helped identify potential biogas customers (primarily farmers), provided administrative support for proper program implementation, and monitored the activities of gas stove manufacturers.

The program did not have an entrepreneurship development focus; however, there was an important training component on biogas plant construction, use, and maintenance. Through a memorandum of understanding between LGED and BCSIR, BCSIR assisted with capacity building of LGED staff and masons. Over 12,000 local-level engineers, community organizers, and masons were trained in biogas construction, use, and maintenance from 1996 to 2003. More than 3,000 users were also trained, but not in biogas plant maintenance.

Following a program-led monitoring scheme, BCSIR/LGED employed engineers in every district for monitoring plants and providing troubleshooting services. Microfinance agencies, which linked financing services to the households (see below), helped improve the monitoring mechanism, as households paid the installments only if the plant was operating properly, necessitating service providers to provide continuous follow-up.

\section{Awareness and Motivation}

The program engaged local community groups, in particular a community-based poultry association, to create demand for biogas among poultry farm owners. The focus on poultry was based on a supply chain assessment that revealed that poultry droppings were an important raw material for biogas plants. Local leaders, particularly high school principals, also advocated biogas in their communities and disseminated information on the 
benefits of biogas. The program also involved local user groups, specifically LGED water management groups at the union level, to reach households. This approach was less costly and more locally appropriate to reaching households and is an example of using existing structures for little additional cost.

As a government program, it received special rates from the government's media outlets (Bangladesh Television and Bangladesh Betar Radio) for advertisements and short films on improved cookstove and biogas technologies. The strong training component of the program also led to local awareness-raising and capacity-building activities.

\section{Development and Promotion of Technologies}

Fixed-dome biogas plants were typically used ${ }^{8}$ in the program (Ghimire 2005), though the floating model was also promoted. Locally manufactured metal-framed gas stoves and lamps, popularly known as "hajak", were used for cooking and lighting, respectively, using biogas. These appliances were supplied by BCSIR.

Stakeholders interviewed during this study reported that the BCSIR/LGED models were not as efficient as the IDCOL/SNV models. Key drawbacks of biogas technology included uncertainties about post-warranty services; high initial costs; technical difficulties; and lack of feedstock given the general reduction in the number of domestic animals, particularly cows. Inadequate gas production was one of the most common problems facing biogas users. As a result of inadequate gas supply, households often resorted to using traditional cookstoves to meet their cooking needs.

8 Several different designs for biogas systems have been developed and promoted in Bangladesh. The BCSIR biogas plant design was initially based on the Indian floating dome model. However, this model developed problems and, over time, BCSIR/LGED made some changes to its biogas plant design to suit the Bangladesh environment, for example having flexibility in the type of inlet and outlet pipes.

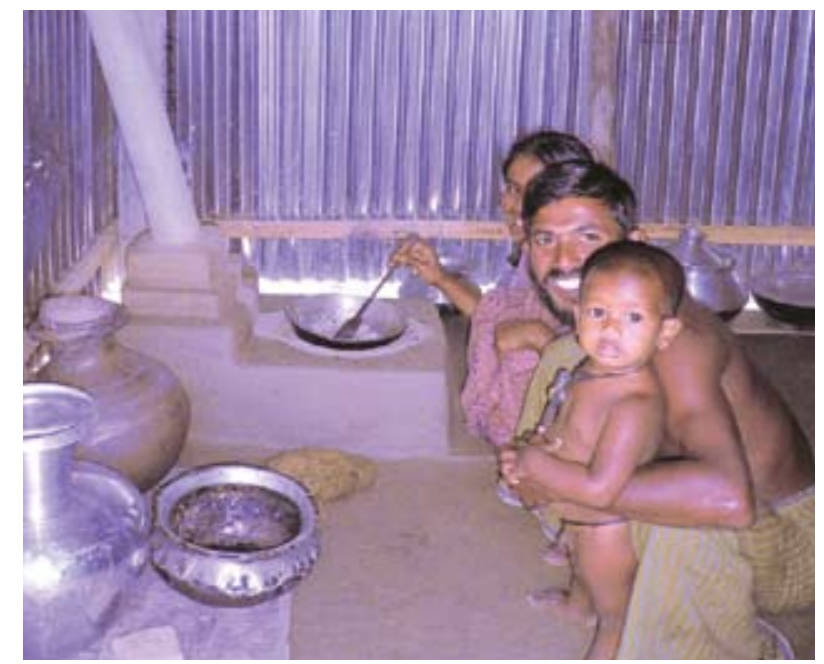

The review team heard frequent complaints about masons not using good-quality raw materials during plant construction, issues with plant dimensions, and technical problems, such as the cow dung not passing into the digester and frequent breakdown of the mixing device. After-sales support was not adequate in these instances, and households stopped paying their monthly installments. Some also sold off their cows due to financial problems (for example, parts of Cholna village in Narsingdi district were affected by floods that left many households short of cash).

Trained local masons continue to provide aftersales service to households, although they are no longer associated with the program. Plant owners also contacted masons from other districts for troubleshooting purposes. Although some poultry farms have closed, the local poultry association has continued to help households identify other sources of feedstock (cow dung and poultry waste from neighboring households).

\section{Financial Aspects}

The LGED program was government funded, with strong support from the Ministry of Science and Technology and the Ministry of Local Government. The plant cost was Tk 13,000-30,000 (US\$ 186429) depending on the size. Biogas plants were 
promoted under a number of different programs, including the Sustainable Rural Energy Program. Biogas plants require a much higher investment from the user and thus most programs provided some subsidy as well as linkages to financing. Subsidies provided varied widely from a 50 percent user subsidy, to Tk 5,000 per plant for farmers to motivate them. An additional Tk 5,000 was given to collaborating NGOs as a grant.

The plants constructed under the Sustainable Rural Energy Program were partially subsidized by LGED, which engaged seven NGOs in the program's later stages. Organizations such as Grameen Shakti and Save Our Urban Life (SOUL) installed plants and also linked financing services to the households. This not only made it easier for users to install the biogas plants, but also improved the monitoring mechanism (see above). Focus group discussions among users revealed that providing loans for purchase of cattle to increase biogas production would have been appreciated.

The LGED biogas activities had a small bio slurry development component and farmers could obtain loans from the local national bank, Sonali Bank, at 5 percent interest (flat rate) repaid in monthly installments over seven years. The loan size ranged from Tk 15,000-20,000 (US\$ 220-294) per plant. Bio slurry was promoted as organic fertilizer with the support of the local government and had considerable demand from tobacco growers. The dried slurry sold for Tk 300 (US\$ 4.4) per $50 \mathrm{~kg}$ bag.

\section{IDCOL/SNV: National Domestic Biogas and Manure Program}

The National Domestic Biogas and Manure Program, the largest biogas promotion program in Bangladesh, was implemented from 2006 to 2009 by IDCOL with financial and technical support from the Netherlands Development Organization (SNV) and Kreditanstalt für Wiederaufbau (KfW). Its objective was to develop and disseminate domestic biogas in rural areas and establish a sustainable and commercial biogas sector in Bangladesh. The program had built 9,000 plants as of August 2009.

\section{Institutional Arrangements}

The National Domestic Biogas and Manure Program had a semigovernmental structure that took advantage of government, NGO, and private sector leverages. IDCOL worked with 23 partner organizations, which included construction partners, lending partners, and manufacturing partners. The Biogas Steering Committee, comprising stove scientists and representatives from several relevant ministries, played an important role by approving partner organizations and annual plans and establishing standards for biogas plants and their components. Figure 3.5 shows the institutional arrangements for this program.

SNV provided technical assistance for establishing quality control procedures; developing standards for biogas plants, training curricula, and materials; and providing assistance to slurry extension activities. IDCOL/SNV ensured that the construction partners (the main point of contact for customers) were constructing the plants as per specification, and verified the plant on site if necessary.

The lending partners provided microfinance to households, channeled grants from IDCOL, and were responsible for identifying participating households, approving the required amount of credit, verifying plant construction against the established standards, providing recommendations for construction, and regularly reporting to IDCOL on loan disbursement. Manufacturing partners produced gas stoves and other accessories.

Union parishads were primarily engaged in awareness raising, and local government representatives attended local demonstrations and workshops. More than 2,000 people were trained, including masons, supervisors, managers of the partner organization field offices, and users. Approximately 50 percent of the trainees were users. Refresher 
Figure 3.5 Institutional Diagram: National Domestic Biogas and Manure Program

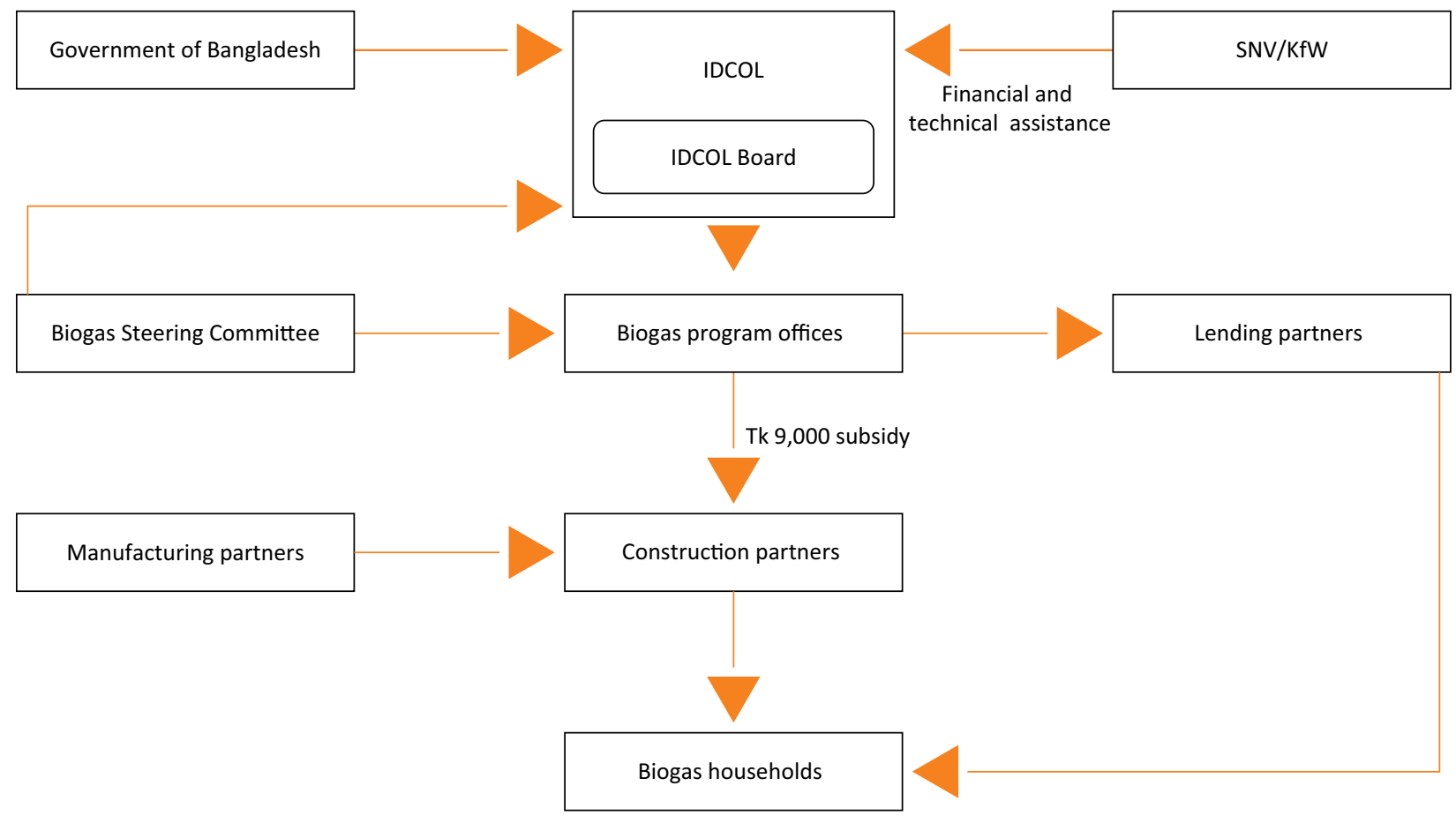

trainings and training of trainers were unique to the program and were highly valued.

The program had a multilevel monitoring system whereby the Biogas Steering Committee and partner organizations monitored progress. Partner organizations only received a grant when a household signed off on proper construction and installation of the technologies and IDCOL staff and the biogas program office had verified the installation. The program's Biogas Steering Committee was responsible for monitoring overall program progress and reports to the IDCOL Board. Day-to-day monitoring was done by the partner organizations that sold and installed the biogas systems. They ensured that plants were of high quality as per the program's plan and that all stakeholders were performing their roles as per the agreement.

\section{Awareness and Motivation}

Community engagement was the responsibility of individual partner organizations, with the program supplying posters and leaflets, and advertising through the media. The study team visited selected field sites of partner organizations SOUL, based in Narsingdi district, and Grameen Shakti, in Natore district. The team found that local SOUL staff persons were directly promoting biogas technology. For awareness raising, Grameen staff made house-to-house visits and advertised in local newspapers. Trained engineers advised households on what type of biogas plants to acquire based on the cooking needs of the households and the number of domestic animals (cows) available.

User surveys indicated that over 46 percent of users learnt about biogas plants through word of mouth from their relatives and neighbors, 18 percent got information from the media (radio and television), and 12 percent from print material such as leaflets and booklets. User training had a focus on women (of the 900 users trained, a third were women). There was an opportunity for those women to be employed by partner organizations, as the National 
Domestic Biogas and Manure Program was planning to incorporate user training with an emphasis on training local women who could play the role of motivators and also be engaged as biogas masons.

\section{Development and Promotion of Technologies}

IDCOL was promoting, at the time of this survey, fixeddome biogas plants. The program had standardized its biodigester designs and established a system for entrepreneur development and design and installation quality control. Stakeholders reported that the IDCOL/SNV models were more efficient than the BCSIR models. However, lack of flexibility in design (for example the requirement that the inlet, digester, and outlet were all placed in one straight line, which was difficult for people who did not have enough land; and underground placement of pipes, making monitoring and leak detection very difficult) and implementation procedures presented problems for some households and entrepreneurs. Despite these concerns, the standardization of design and implementation mechanisms and strict quality control measures helped in scaling up biogas systems and developing a biogas market. Local masons lacked adequate training, which resulted in poor-quality biogas digesters in some areas, causing

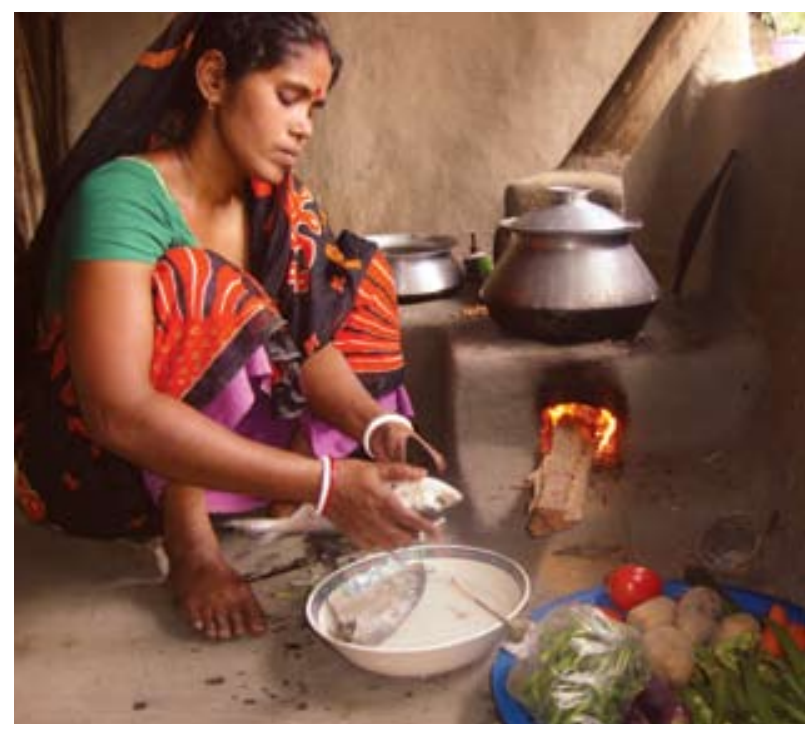

5 percent of biogas plants constructed under the National Domestic Biogas and Manure Program to break down, according to a 2008 user survey.

\section{Financial Aspects}

The cost of a biogas plant was Tk 18,000-35,000 (US\$ 257-500). IDCOL provided Tk 9,000 (US\$ 130) as a one-time plant investment subsidy to households. Households could pay the remaining amount in cash. Alternatively, households could also take a microcredit loan from the lending and construction partner organizations at 10-12 percent interest rate and for a maximum period of two years by paying a minimum 15 percent of plant cost (after subsidy) as down payment. About 65 percent of the households constructing biogas plants required that credit support. Analysis showed the financial internal rate of return (break-even interest rate) was 17 percent for a typical biogas plant with the investment subsidy.

The program established a biogas credit refinancing facility (seven-year credit with a one-year grace period and at an interest rate of 6 percent) for the lending and construction partner organizations to lend to the households. Maximum refinancing that could be availed per plant was 147 euros. The program assumed that total investment on a biogas plant, including interest on loan, could be recovered within four to five years.

\section{IDCOL: Rural Electrification and Renewable Energy Development Program}

The Rural Electrification and Renewable Energy Development Program was designed to support the Bangladesh government's objectives to provide electricity to the rural population. The program is still ongoing and is unique in the developing world as an example of the private sector working with the government and microfinance institutions and NGO partners to provide off-grid electricity in a sustainable and commercially viable manner. The study team 
Figure 3.6 Institutional Diagram: Rural Electrification and Renewable Energy Development Program

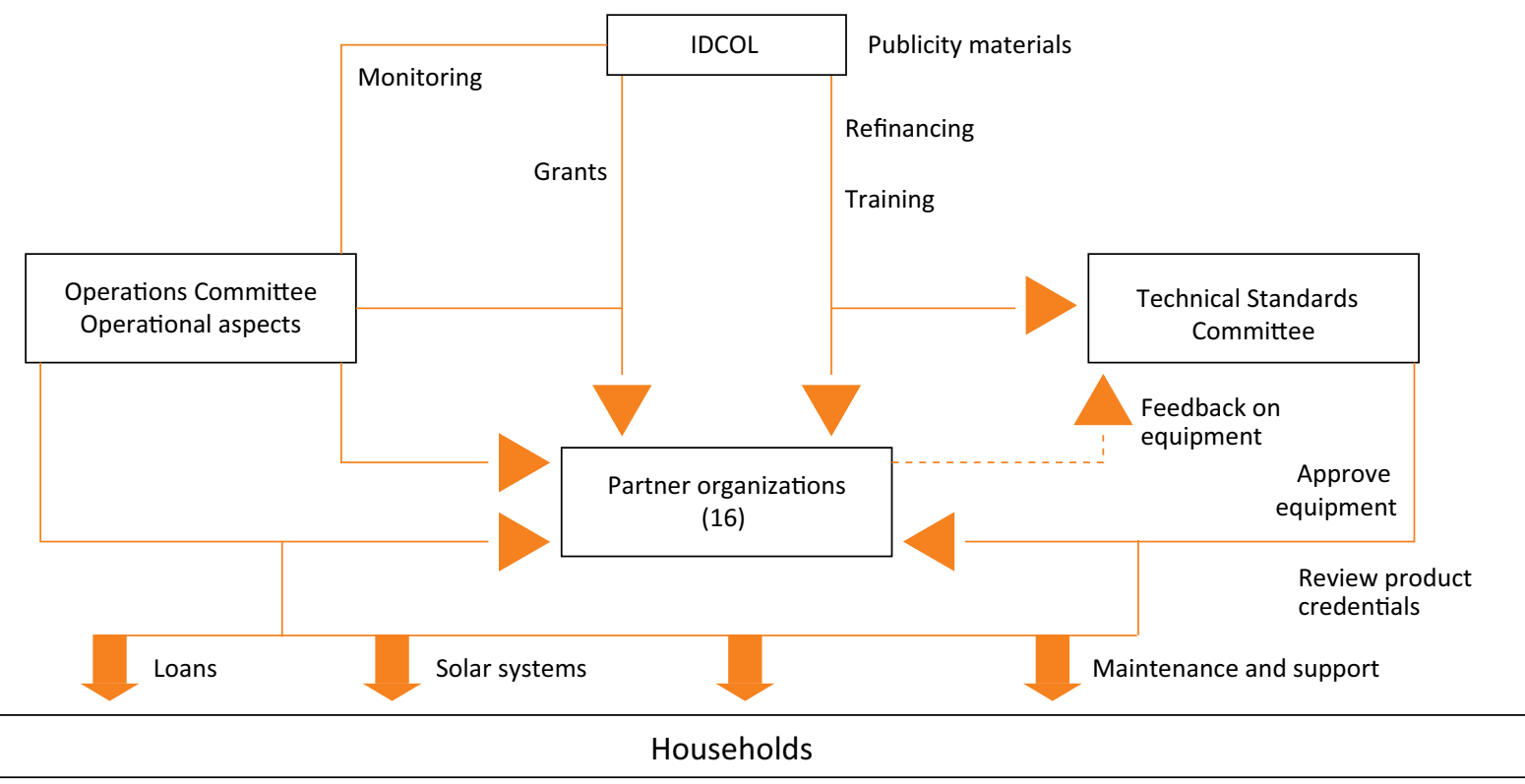

examined the work of two partner organizations in this program - Grameen Shakti and Srizony.

\section{Institutional Arrangements}

The program has a semigovernmental structure and thus takes advantage of government, NGO, and private sector coordination. The program is funded by the World Bank, the Global Environment Facility, GTZ, $\mathrm{KfW}$, and more recently by the Asian Development Bank, and works with 15 local NGOs and private organizations, known as partner organizations of IDCOL. The role of the partner organizations is to identify project areas, select potential customers, install systems, provide maintenance support, and extend loans to the households. IDCOL provides grants and refinance, sets technical specifications for solar equipments eligible for receiving grants and refinance, develops publicity materials, provides training, and monitors partner organizations' performance. Figure 3.6 shows the institutional arrangements for this program.

The program does not have direct linkages with the local government for implementation. However, partner organizations engage the union parishad chairpersons and members during awareness-raising activities. IDCOL supports institutional development of partner organizations by providing technical, logistical, and promotional training assistance to its partners through the Technical Standards Committee $^{9}$ and the Operations Committee, ${ }^{10}$ which are responsible for technical and operational aspects, respectively.

IDCOL supports its partners for software, covering 80 percent of the training costs, and conducting training programs to build awareness among partner organization staff and the users. User training is also conducted regularly to educate the beneficiary households on how to use solar home systems and fix simple problems without having to wait for technicians. However, during visits to Srizony and Fulpur upazila, Mymensingh, it was

9 The Technical Standards Committee comprises members from Bangladesh University of Engineering and Technology, Rural Electrification Board, LGED, and IDCOL.

10 The Operations Committee is chaired by the Chief Executive Officer of IDCOL, and comprises members of all partner organizations and representatives from IDCOL. 
found that user training on use and maintenance of solar home systems was limited. Usually technicians from local electrical shops provide repair and maintenance services against payment.

The thrust of this program is on the development of partner organizations (usually private sector companies or NGOs), which may be considered to be solar entrepreneurs, who select program areas and potential customers, extend loans, install solar home systems, and provide maintenance support either directly through their program staff or, as with Grameen Shakti, by training local technicians in installation and providing after-sales service.

The program has a multilevel monitoring mechanism whereby the partner organizations only receive a grant when a household signs off on proper installation of the technologies and after verification by IDCOL staff. For Srizony, monitoring of awareness-raising activities is through regular staff meetings, which include discussions on feedback from users. For Grameen's solar program in Fulpur, monitoring typically takes place when Grameen staff visit households to collect loans. Households also get an opportunity to discuss operation and maintenance issues during these visits. The contract between IDCOL and its partner organizations has a provision for annual monitoring of the partner organization's work. This is a crucial component of a partner organization's evaluation to maintain its partner status.

\section{Awareness and Motivation}

Community engagement is the responsibility of individual partner organizations. IDCOL provides promotional support, such as distributing publicity materials and developing television and radio spots. Word of mouth and publicity are effective in attracting new customers. The study team observed on a visit to Paikgacha upazila of Khulna district that Srizony holds local demonstrations at community gathering places, including markets and educational institutions.

\section{Development and Promotion of Technologies}

A range of solar home systems between 10 and 130 watt-peak $(\mathrm{Wp})^{11}$ are available. Initially, the program promoted systems of $30 \mathrm{Wp}$ and above. Affordable $10 \mathrm{Wp}$ systems, powerful enough to light one 5-watt compact fluorescent lamp and two light-emitting diode lamps, have recently been introduced.

The products and components to be used in the solar home systems receive a certificate from accredited testing and certification organizations. The Technical Standards Committee has also developed guidelines and a standard list of specifications for solar home system components.

According to IDCOL, 5-10 percent of the households using solar home systems face problems with their systems. Some users tamper with the accessories and connections, causing various inefficiencies and poor performance. The most widely reported drawbacks of solar home systems included uncertainty about after-sales services once loans are fully repaid. However, some of the partner organizations have introduced a yearly maintenance contract option with the households at marginal cost after the free service period. Although the IDCOL program includes a thorough training component and every system is physically verified, many households tend to overuse the batteries for entertainment purposes (for example television). There are also reports of linking direct lines from the battery, which can lead to a quick discharge, and use of nonapproved batteries for charging with the solar panel.

\section{Financial Aspects}

IDCOL provides two types of grants: a buy-down grant (to the households to lower costs of solar

11 Watt-peak (Wp) is a measure of power output, most often used in relation to photovoltaic solar energy devices. Related units such as kilowatt-peak ( $\mathrm{kWp}$ ) and megawatt-peak are also used, and in the context of domestic installations $\mathrm{kWp}$ is the most common unit encountered. 


\section{Table 3.4 Grants for Solar Home Systems}

\begin{tabular}{|c|c|c|c|}
\hline \multicolumn{4}{|c|}{ Amount of grant available per solar home system per household } \\
\hline Item & Total & Buy-down grant & $\begin{array}{c}\text { Institutional development } \\
\text { grant }\end{array}$ \\
\hline \multicolumn{4}{|l|}{ World Bank funds } \\
\hline First 20,000 systems & US\$ 90 & US\$ 70 & US\$ 20 \\
\hline Next 20,000 systems & US\$ 70 & US\$ 55 & US\$ 15 \\
\hline Next 30,000 systems & US\$ 50 & US\$ 40 & US\$ 10 \\
\hline \multicolumn{4}{|l|}{ GTZ funds } \\
\hline 58,160 systems & $€ 38$ (US\$ 58) & $€ 30$ (US\$ 46) & $€ 8$ (US\$ 12) \\
\hline 100,000 systems & $€ 34$ (US\$ 52) & $€ 30$ (US\$ 46) & $€ 4$ (US\$ 6) \\
\hline \multicolumn{4}{|l|}{ KfW funds } \\
\hline First 30,000 systems & $€ 38$ (US\$ 58) & $€ 30$ (US\$ 46) & $€ 8$ (US\$ 12) \\
\hline Next 35,000 systems & $€ 36$ (US\$ 55) & $€ 30$ (US\$ 46) & $€ 6$ (US\$ 9) \\
\hline Next 135,000 systems & $€ 34$ (US\$ 52) & $€ 30$ (US\$ 46) & $€ 4$ (US\$ 6) \\
\hline Next 100,000 systems & $€ 28$ (US\$ 43) & $€ 25$ (US\$ 38) & $€ 3$ (US\$ 5) \\
\hline Next 71,000 systems & $€ 22$ (US\$ 34) & $€ 20$ (US\$ 31) & $€ 2$ (US\$ 3) \\
\hline
\end{tabular}

Source: IDCOL website http://www.idcol.org.

home systems) and an institutional development grant (to the partner organizations to build their institutional capacity) (Table 3.4). The same amount of subsidy is provided for all solar home system sizes, allowing poor households that prefer smaller sizes to pay less and still own a system. The subsidy amount decreases as more solar home systems get sold, to allow the commercial sector to transition in as demand grows. According to Grameen Shakti, which has sold over 150,000 solar home systems, the decline in subsidy has not affected the demand for the systems as word of mouth and microcredit schemes continue to spur demand.

Under this program, a rural household can buy a solar home system either through direct payment or through credit from the partner organizations. The success of this approach is evident because about 84 percent of the solar home systems are sold through a credit mechanism, according to IDCOL estimates. Different partner organizations extend credit on different terms and conditions. The loan tenor varies from one to five years, and the interest rate varies from 8 percent to 15 percent per annum on declining balance method and 1015 percent per annum on equal principal payment method. But in all instances, the repayment frequency is monthly.

Households are required to pay a minimum 10 percent of the system cost as down payment. On receipt of the down payment, the partner organizations enter into a sale or lease agreement (provisions of which are approved by IDCOL), install the system (mostly on credit), and make electronic disbursement requests to IDCOL for refinance and grants, as applicable. After in-house checking IDCOL conducts physical verification of the solar home systems installed. IDCOL releases the grants and refinance amount only if the inspection result is satisfactory. The refinance amount does not exceed US\$ 285 (equivalent in taka) per system. 
Table 3.5 Cost of Solar Home Systems

\begin{tabular}{|r|r|r|r|r|}
\hline & \multicolumn{2}{|c|}{ Grameen Shakti } & \multicolumn{2}{c|}{ Srizony, Bangladesh } \\
\hline & Taka & US\$ & Taka & US\$ \\
\hline 10 & 8,900 & 131 & n.a. & n.a. \\
\hline 20 & 14,900 & 219 & n.a. & n.a. \\
\hline 40 & 22,500 & 331 & 22,000 & 324 \\
\hline 50 & 27,900 & 410 & 27,000 & 397 \\
\hline 65 & 33,500 & 493 & n.a. & n.a. \\
\hline 75 & n.a. & n.a. & 34,500 & 507 \\
\hline 85 & 42,500 & 625 & n.a. & n.a. \\
\hline 130 & 65,000 & 956 & n.a. & n.a. \\
\hline
\end{tabular}

n.a. not applicable.

Table 3.6 Credit Facilities Available to Users for Solar Home Systems

\begin{tabular}{|c|c|c|c|c|c|c|}
\hline Organization & Options & $\begin{array}{l}\text { Down } \\
\text { payment }\end{array}$ & $\begin{array}{c}\text { Loan } \\
\text { period } \\
\text { (months) }\end{array}$ & $\begin{array}{l}\text { Interest } \\
\text { rate }\end{array}$ & $\begin{array}{l}\text { Interest } \\
\text { type }\end{array}$ & Remarks \\
\hline Grameen Shakti & 1 & $25 \%$ & 24 & $4 \%$ & Flat & \\
\hline Grameen Shakti & 2 & $15 \%$ & 36 & $6 \%$ & Flat & \\
\hline Grameen Shakti & 3 & $15 \%$ & 36 & $5 \%$ & Flat & With postdated checks \\
\hline Grameen Shakti & 4 & $100 \%$ & & & & $4 \%$ discount \\
\hline Grameen Shakti & 5 & $25 \%$ & 12 & $0 \%$ & & $\begin{array}{l}\text { Mosque, madrasa, temple, } \\
\text { church, orphanage, etc. }\end{array}$ \\
\hline Grameen Shakti & $\begin{array}{l}\text { Micro } \\
\text { utility }\end{array}$ & $10 \%$ & 42 & \multicolumn{2}{|c|}{$\begin{array}{l}\text { No additional interest } \\
\text { rate }\end{array}$} & $\begin{array}{l}\text { Can share system with } \\
\text { others for a fee }\end{array}$ \\
\hline Srizony & & $15 \%$ & 48 & $8.50 \%$ & & \\
\hline
\end{tabular}

IDCOL offers soft loans of 10-year maturity with a two-year grace period at 6 percent interest per annum to its partner organizations. Usually, IDCOL does not require any collateral or security for the loan, except for a lien created on the project accounts. Unless there is an event of default, partner organizations are authorized to operate the project accounts on their own. IDCOL also provides partner organizations with infrastructure support (computers, motorcycles, demonstration kits, and battery chargers) and promotional support (distributing publicity materials and developing television and radio spots).
Prices of solar home systems are market driven. Table 3.5 shows selling prices of solar home systems from two partner organizations of IDCOL.

Srizony Bangladesh and Grameen Shakti extend loans to the households for purchase and installation of solar home systems and after-sales service (Table 3.5). Grameen Shakti, one of IDCOL's largest partners, offers five payment options, with the initial down payment of 15-25 percent, and an interest rate of 4-6 percent (Table 3.6). Srizony, a smaller partner, offers 15 percent initial down 
payment and a loan period of 48 months or five years. Compared to Grameen Shakti, Srizony has a higher interest rate (5 percent vs. 8.5 percent).

\section{Conclusions}

The various programs present an interesting challenge for understanding the way forward for improved stoves in Bangladesh. The diversity of the programs actually enhances the ability to draw lessons from them. Some have extensive market development components, while others have none. Some stress entrepreneur training while others pay no attention to it. Thus, both the common features and the differences permit this study to examine some of the lessons from these programs, and this is the topic of the next chapter. 



\section{Lessons from Household Energy Initiatives in Bangladesh}

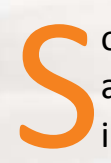
o far, this report has examined the nature and functioning of individual programs. The insights gained from the case studies are interesting. Technologies need to be well developed and accepted by consumers, and there is a need for testing, ideally by an outside, independent agency, or at least by those implementing the program. In addition, there are many different institutions involved in household energy and there is a need for coordination among them. Many of the programs do not even address the issue of commercialization of their household energy appliances. These and other issues are examined in this chapter, which draws general lessons from the household energy initiatives in Bangladesh. This will be done by examining the four thematic features of each program: institutional arrangements, awareness and motivation, development and promotion of technologies, and financial aspects.

\section{Institutional Arrangements}

\section{Summary of Findings}

Three types of institutional structures were found to exist among the six programs studied:

* Led by government agency: BCSIR improved cookstoves and BCSIR/LGED Biogas Program;
- NGO/private partnership structure: GTZ Sustainable Energy for Development Program and USAID/Winrock indoor air pollution program;

* Led by board or semigovernmental structure: National Domestic Biogas and Manure Program and Rural Electrification and Renewable Energy Development Program.

With regard to the institutional structures, the now defunct government-led programs of BCSIR (both improved cookstoves and biogas), with their very good linkages with the local government and community organizers, were able to establish a network for cookstove dissemination, which continues to be used by entrepreneurs and other programs. However, they did not promote a commercial approach and had poor management practices. On the other end of the spectrum, the private programs (GTZ Sustainable Energy for Development and USAID/Winrock), while on a much smaller scale than the IDCOL programs, did not have completely streamlined management structures. Their flexible structures, however, supported commercialization of household energy systems by providing technology and financing services under the same roof through partner organizations. Innovation and efficiency were 
maximized as partner organizations competed with each other to provide the most attractive services to users. The semiprivate programs (the IDCOL-led National Domestic Biogas and Manure Program and the solar Rural Electrification and Renewable Energy Development Program), with the dual advantage of government and NGO or private sector leverages, had the potential for creating a long-lasting commercial approach. Both these programs had the best management structures, with dedicated program offices and clear-cut roles and responsibilities. They also had rules for assignment of promoters for biogas and solar devices. These IDCOL programs could serve as best examples of institutional management approaches for largescale programs that use partner organizations and create true entrepreneurs, thus creating a marketdriven situation based on demand and supply.

From an institutional standpoint, it was found that the NGO and private programs reviewed did not require extensive coordination with the government. However, local government coordination needs to be part of the project plan and should be linked to the program objectives. Thus, programs with strong involvement of the local government, such as those of GTZ and USAID/Winrock, fared better in awareness raising, as people were more likely to take the information and messages seriously from

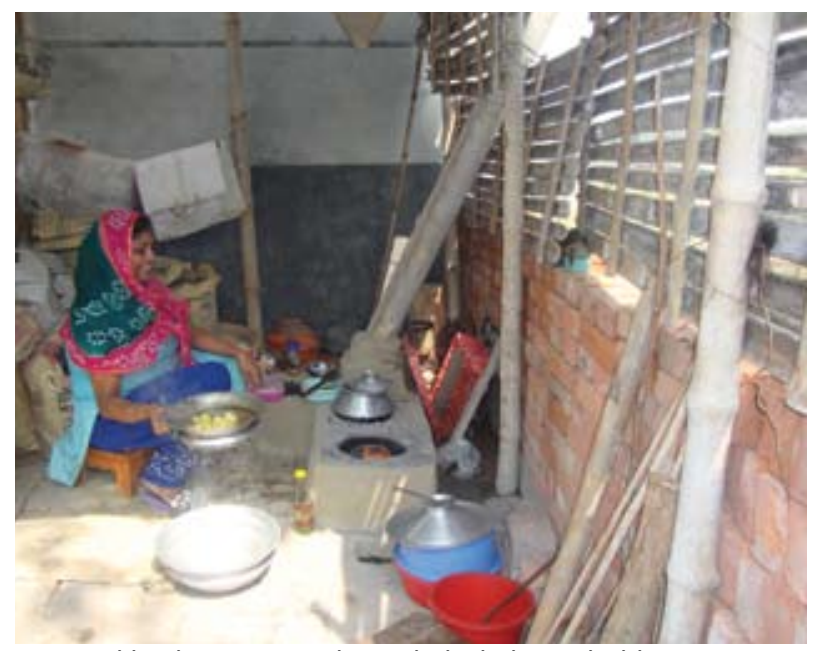

A typical kitchen in a rural Bangladeshi household. a government body. Other advantages were easier multiagency coordination, enhancing local efforts to promote program objectives across a range of local government, nongovernmental, private, and civil parties; and improved program implementation as staff of local government agencies were trained and program activities were implemented using the existing institutional structures of those agencies.

All six household energy programs reviewed focused on training and capacity building for entrepreneurs or for partner organizations and staff (supply-side training); user trainings (demand-side) were not a strong point in most. Suitable user training means that users do not need to depend on technicians for small repair and maintenance works. Lack of user training, especially for improved cookstove users, has led to discontinuation of use after the programs ended, as many trainees did not continue with technology installation and there was a lack of trained people for repair and maintenance at the user level. Government-led programs trained only government staff or those of its partnering institutions, and dedicated user trainings were not carried out. Users were instructed on cookstove use and maintenance only during installation. The GTZ program is the only one that provides training of trainers as well as hands-on training for constructing the improved cookstoves and courses on entrepreneur development and marketing. It has even developed detailed training manuals for training of stove manufacturers and training of trainers. Among the semigovernmental programs, the National Domestic Biogas and Manure Program is the only program providing refresher training, which is highly valued among the community.

Unlike the government programs, private programs (GTZ Sustainable Energy for Development and USAID/Winrock programs) laid great emphasis on entrepreneurship development, including selection of potential entrepreneurs. GTZ is providing financial support to entrepreneurs through partner organizations to set up improved cookstove or improved cookstove accessory businesses. The 
USAID/Winrock approach was to train local women to raise awareness and thus create private sector entrepreneurs. The National Domestic Biogas and Manure Program's approach of promoting different partners for different components of biogas, such as financing, manufacturing, and construction, is a valuable model for entrepreneurship development.

While all programs have or had some level of program monitoring and evaluation mechanism for quality assurance, in the majority the program monitoring process was not of the required standard. Government programs fared the worst. Programs used their partner organizations (for example GTZ) or stakeholders and entrepreneurs (USAID) for monitoring, despite their vested interests in outcomes. The strongest monitoring in Bangladesh occurred in the IDCOL programs, which have a multilevel monitoring mechanism that requires partner organizations to monitor the technology over the financing period in order to receive full payment. An evaluation system is in place where staff or other partners visit users to verify the effectiveness of services provided by the partner organizations.

Monitoring is an important part of the project cycle, enabling feedback into project design and approach during implementation. For example, basic laboratory stove testing should be undertaken before technologies are disseminated to ensure safety and understand performance. Further monitoring should be undertaken in the field to gauge effectiveness in real-life conditions. Evaluation is usually more of a retrospective tool. These techniques need to be carefully planned and geared towards the type of intervention, the audience for findings, and the resources and capacity of the implementer. It is important to consider sampling methods to ensure representative findings and to avoid gathering unnecessary data, thus wasting time and money. A wide range of questionnaire surveys, monitoring protocols and datasheets already exist, and many are freely available (Box 4.1). Making use of these is strongly advised, but it is vital that they be carefully adapted to local conditions, including careful translation and piloting. While some aspects of monitoring (for example basic stove testing and adoption monitoring) are feasible for most organizations, others require significant skills and funding (for example indoor air pollution monitoring), and yet others, such as health impact monitoring, require substantial skills, and time frames ideally measured in years rather than

\section{Box 4.1 Evaluating Household Energy and Health Interventions: Catalogue of Methods}

This review has identified improved monitoring and evaluation of household energy programs as a key need. Many aspects of programs can be monitored, including rates of adoption, extent of market development, performance of technologies, and impacts on indoor air pollution and exposure, health, socioeconomic indicators, and the environment. This subject has been thoroughly treated in a recent report by WHO cataloguing methods of evaluating household energy and health interventions (WHO 2008).

This catalogue of methods is intended to help governments, NGOs, and universities involved with household energy interventions to develop monitoring and evaluation strategies appropriate to their needs and resources. It describes a diverse range of evaluation options ranging from simple questionnaires to complex monitoring techniques, such as measurement of indoor air pollution levels through physical monitoring instruments place in the household. It also provides guidance on identifying which areas to focus on, and choosing between methods according to feasibility, objectives, and type of intervention. These techniques are fairly well established as they have been applied in a wide variety of countries. However, many programs still have minimal monitoring and evaluation systems in place, and there is a need to ensure that they are part of project and program design. 
weeks. This type of technique is more appropriate for project impact evaluation.

In addition to assessing overall program performance and the impacts of interventions on users' health, welfare, wealth, and empowerment, it can also be useful to undertake a cost-benefit analysis. WHO has published guidelines for conducting a costbenefit analysis of household energy and health interventions (WHO 2006), as well as documents presenting an evaluation of the costs and benefits of such interventions globally and regionally. Together, these different aspects of monitoring and evaluation can enable policy makers to make decisions on how to address household energy issues, including technology choice, delivery method, effectiveness, and cost-benefit ratio.

The review of institutional mechanisms showed that the lack of a national household energy policy or strategy results in disorganized and uncoordinated dissemination of household energy technologies by different programs, leading to variations in technology standards and monitoring mechanisms and duplication of capacity-building efforts. Some implementing organizations also emphasized the importance of working with partners that share similar approaches to development, and the importance of keeping institutional arrangements as straightforward as possible. The GTZ program has in excess of 150 partner organizations. They find it challenging to administer this number of separate and small contracts. Some programs with many partner organizations use an intermediary body solely to administer contracts and reduce this burden.

\section{Lessons Learnt: Institutional Arrangements}

On the institutional arrangements, the main lessons learnt were as follows:

* While varied institutional arrangements can help achieve numerical program targets, an integrated institutional mechanism for monitoring and assurance of quality after-sales services to the technology users is required for a successful program.

* Engaging the local government is beneficial for effective awareness raising, increased coordination at the local level, and improved program implementation.

* Decentralization of activities can be successful as it contracts work to a large number of partner organizations, thus generating capacity, expanding coverage, and ensuring sustainability. However, institutional strengthening of these partner organizations (for manufacturing, construction, and financing) is often necessary.

* Highly motivated entrepreneurs can help pursue program objectives beyond the program period.

* Training and capacity building of all stakeholders, staff, and consumers (including use and maintenance training for women) is an important component of any program to ensure effective use of technology.

* A multilevel monitoring mechanism that requires partner organizations to monitor the technology over the financing period to receive full payment can be a good model for a successful cookstove program.

\section{Awareness and Motivation}

\section{Summary of Findings}

The programs reviewed engaged with local communities and networks to varying degrees. While there are clear benefits to working with the local community, this activity should be linked with all other key activities of the program. For example, the government programs had extensive community outreach, but due to lack of financial and monitoring support, local communities did not support key activities beyond the program. 
Community-based organizations can play an important role in supporting programs and entrepreneurs by raising awareness about the benefits of the technologies promoted, and by creating stronger linkages between beneficiary households, implementing organizations and entrepreneurs, and local government institutions. Existing community-based organizations can help in cost sharing to cover initial installation costs for poorer households and to help identify households that would qualify for subsidies or financial assistance, where appropriate. Community-based organizations with support from NGOs and local government institutions can also play an important role in monitoring and quality control activities. While the BCSIR/LGED Biogas Program did not have a specific focus on community engagement, it did include a very strong training component that helped to raise awareness. While BCSIR's improved cookstove program encouraged district supervisors to set up demonstration centers in their homes, IDCOL's Biogas Program utilized local LGED water user group meetings. The USAID/Winrock program used existing networks of community health workers to share indoor air pollution information as a community health issue and to tap their already established outreach and awarenessraising activities and mechanisms. The potential to link to these existing health networks is seriously underutilized by household energy programs. The
USAID/Winrock and IDCOL approaches are examples of use of existing setups at incremental cost.

The household energy programs reviewed utilized a range of awareness-raising approaches. The USAID/Winrock program and GTZ's Sustainable Energy for Development Program focused more on using locally appropriate media, such as folk songs and drama. These methods are not only more accessible for the local audience but are also very cost-effective. Almost all programs developed conventional materials, such as posters and leaflets. It was difficult to find information on the effectiveness of these materials. Many users still did not fully understand the key messages regarding proper use of their technologies improved cookstove users were often not aware of the health impacts of exposure to indoor air pollution, which is particularly important if they are to be motivated to use the improved stoves exclusively in order to reduce exposure to indoor air pollution (Box 4.2).

Although the GTZ program has user-training components, it does not focus on women. The National Domestic Biogas and Manure Program, however, has trained over 900 users, of which about a third are women. There are some challenges in organizing women's training. Due to their household responsibilities, women are generally not available for day-long or week-long training sessions. Women's

\section{Box 4.2 Awareness of Health Impacts}

All 70 women users of improved cookstoves, biogas plants, and solar home systems consulted were asked about the various benefits of these household energy technologies. Benefits reported by 26 percent of the improved cookstoves users, the largest number of respondents, included health benefits, particularly benefits for the eyes. However, the users did not appear to be aware of other benefits, such as reduced risk of pneumonia (for children), chronic obstructive pulmonary disease, and tuberculosis. About 22 percent of the users also reported environmental benefits in terms of reduced fuel consumption. For biogas, the health benefits were significant and the users noted that cooking with biogas did not produce any smoke. Correspondingly, 35 percent of the users reported that cooking with biogas was cleaner as there was no soot production. About 16 percent of the users of solar home systems mentioned health benefits due to reduced indoor air pollution from kerosene lamps and increased cleanliness due to less smoke and soot production from kerosene lamps, and 17 percent reported environmental benefits due to reduced indoor pollution. 


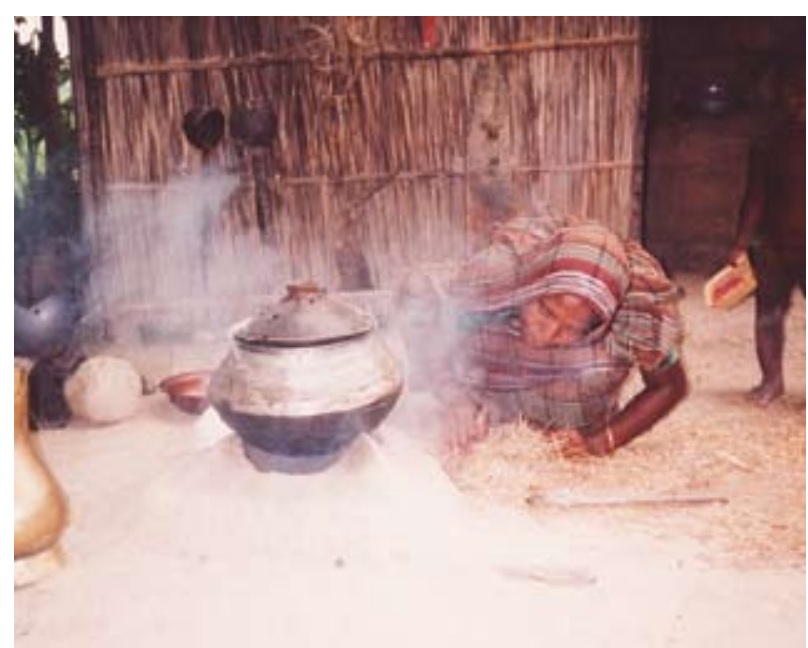

Smoke from traditional stoves cause eye and lung problems in rural women.

presence is even scarcer when developing women technicians or entrepreneurs, as societal influences in Bangladesh do not allow women to travel too far from home for such purposes. Many organizations are also not keen to take on the responsibility for the safety of these women while they are on the job. To address this issue, Grameen Shakti has established a number of technology centers that also include hostels so that women can receive training while living in the vicinity of the training area.

The potential role of women as entrepreneurs and promoters of cookstoves and other household energy programs has not been tapped by the programs. Supply-side training of the end users, typically women, would help promote the cookstoves, as it would help the users to maintain and use the cookstove effectively.

\section{Lessons Learnt: Awareness and Motivation}

On awareness and motivation, the main lessons learnt were as follows:

* Community-based organizations can play an important role at incremental cost in supporting entrepreneurs by raising awareness about the benefits of the technologies promoted, and by creating stronger linkages between entrepreneurs, beneficiary households, implementing organizations, and local government institutions.

* Locally appropriate awareness-raising approaches for programs are crucial for uptake of technologies. Involving community leaders and health volunteers in awarenessraising activities can increase acceptance of the technology.

- Awareness of the benefits (improved health and quality of life) of technology helps create demand, though dissemination should not be constrained by availability and affordability of technologies by the households.

* User training on maintenance and use should be extended to women, who are the main users of the technology.

\section{Development and Promotion of Technologies}

\section{Summary of Findings}

For cookstove technology to penetrate households across all economic strata, there is a need to have a wide range of cookstove technologies to cater to different user requirements. This is why solar home systems gained acceptance, as the technology is available and affordable even to the very poor households.

Several models of improved cookstoves have been designed and promoted in Bangladesh. However, most models are some variation of a model designed by BCSIR in 1978 with the addition of a simple grate in the combustion chamber to increase combustion efficiency. The design was not the result of extensive user consultation; stoves were designed in laboratories to technical rather than sociocultural and real-life specifications. Consequently, the designs have not really met the needs of all households, which has discouraged 
use of and investment in improved cookstoves. Moreover, there is a wide range of cookstoves with minor variations in circulation, due to the lack of a standard design. Entrepreneurs and other programs have modified the design depending on the local conditions and availability of materials, which could impact its efficiency, ease of use, and maintenance.

While a standard design for cookstoves, as with biogas plants, would help in monitoring quality, such standardization would be difficult to achieve, as Bangladeshi rural homes do not use standardized pots for cooking (different sizes of pots are used depending on the quantity of food cooked and whether food is being cooked or reheated). Household-level research is necessary to come up with designs that can accommodate different-sized pots while maintaining efficiency. On the other hand, standardization could lead to lack of flexibility in design, which may constrain the size or efficiency of cookstoves, as reported for plants under the National Domestic Biogas and Manure Program.

Moreover, validating stoves for indoor air pollution reduction is difficult due to lack of standard stovetesting facilities. BCSIR and Bangladesh University of Engineering and Technology could collectively be the institutions responsible for standardizing and validating technologies fit for indoor air pollution reduction.

There is limited information available on emissions and efficiency testing for improved cookstoves. Much of the testing was done in laboratories, and observations in the field do not always mirror laboratory test results. Also, except for USAID/ Winrock, there was no monitoring done on the health impacts of the improved cookstoves. This is an important factor if Bangladesh is to attain the health and development-related Millennium Development Goals.

Poor construction, operation, and maintenance, and unapproved alterations, can result in decreased performance and efficiency of stoves over time, resulting in an increase in indoor air pollution. Thus, performance monitoring of technologies is a very important aspect for cookstove programs. Overall, while limited, the various studies conducted on the performance of the stoves in terms of efficiency and pollution reduction potential indicate that the stoves developed in Bangladesh were technically sound. Khan (2000) reported 25-28 percent efficiency for the BCSIR stoves, which reduced fuel consumption by over 50 percent. These figures are comparable to most improved cookstoves developed in other countries. The GTZ three-pot stove with chimney was found to be 26-27 percent efficient (compared to 5-15 percent for traditional stoves) and saved 50-60 percent fuel. Similarly, the USAID/Winrock program study also found that the BCSIR stoves decreased $\mathrm{PM}_{2.5}$ in the indoor air by 71 to 84 percent and carbon monoxide by 98 to 99 percent, which is much better than the improvements in air quality reported by other studies done in the region. However, it should be noted that these tests were conducted for a total of eight stoves, including two traditional stoves. Therefore, further testing is required to establish statistically significant results. As different tests have revealed varying results in $\mathrm{PM}_{2.5}$ and carbon monoxide reduction potential of stoves, there is a need for standardization of such tests so that the effectiveness of different stoves can be compared and evaluated.

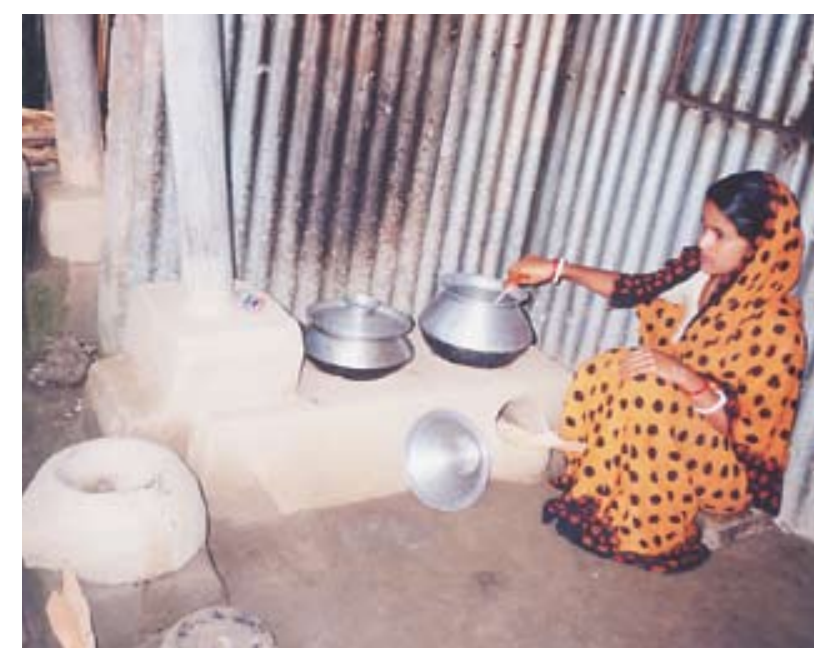


Frequent or even day-to-day monitoring (as done for IDCOL's National Domestic Biogas and Manure Program) is important, as households usually modify stove designs during maintenance, leading to reduction in efficiency and indoor air pollution reduction potential (Table 4.1). A key service issue for improved cookstoves is that current designs of chimneys are difficult to maintain and fit in all types of houses. Chimneys with rough inner surfaces have resulted in accumulation of soot and clogging, requiring more maintenance. Without adequate training and follow-up, households do not know how to clean chimneys, and there have been reports of smoke backing up into the room and smoke exiting through the pot holes. One of the project organizations also underlined the importance of returning to homes some months after initial installation of stoves to establish the longer-term performance.

Post-warranty service, especially after-sales support, is key to the acceptance of cookstoves. Regular technical audits through independent organizations to monitor performance would help ensure quality products and components with warranties are used in building stoves. This would help build user confidence in the product. In addition, ensuring manufacturing facilities and outlets are in place in line with demand creation is also an important aspect of technology development and planning.

\section{Lessons Learnt: Development and Promotion of Technologies}

On development and promotion of technologies, the main lessons learnt were as follows:

* The key issues critical to technology performance are good design and quality components and basic consumer awareness of use and maintenance.

* The stove design should be needs based and suited to the local environment, cooking methods, and socioeconomics of the community. Standardization of design and implementation mechanism would help improve monitoring of quality and thus customer satisfaction.

* Performance monitoring for stoves should be an important component of any improved cookstove promotion program, as information on emissions and efficiency testing are important for designing effective cookstoves. Although testing may start in the laboratory, initial and follow-up testing in the field is vital.

- Reliable after-sales support and services produce great confidence among consumers, leading to acceptance of technology.

\section{Table 4.1 Use and Maintenance Issues for Household Energy Programs}

\begin{tabular}{|l|l|l|}
\hline \multicolumn{1}{|c|}{ Technology } & \multicolumn{2}{|c|}{ Use issues } \\
Improved & $\begin{array}{l}\text { Does not accommodate small pots (two-pot stove) } \\
\text { Difficult to clean chimneys } \\
\text { Smoke production } \\
\text { Chimney cap gets corroded over time } \\
\text { Grate becomes fragile over time }\end{array}$ & $\begin{array}{l}\text { Chimney clogs up } \\
\text { Air inlets get blocked while cleaning } \\
\text { stove }\end{array}$ \\
\hline Biogas plant & $\begin{array}{l}\text { Mixer handle breaks down } \\
\text { Inadequate gas production }\end{array}$ & $\begin{array}{l}\text { Cleaning gas pipe to remove water } \\
\text { Cleaning slurry tank }\end{array}$ \\
\hline Solar home system & $\begin{array}{l}\text { Battery discharges quickly } \\
\text { Low voltage }\end{array}$ & $\begin{array}{l}\text { Tampering with wiring and improper } \\
\text { battery use }\end{array}$ \\
\hline
\end{tabular}




\section{Financial Aspects}

\section{Summary of Findings}

A commercial approach to the promotion of improved household energy technologies was lacking in the now-defunct government BCSIR programs in Bangladesh. However, commercial viability has gained ground and efforts in this direction can be seen with private programs, such as those of GTZ and USAID/Winrock, that focus on developing improved cookstove entrepreneurs. The semigovernmental IDCOL solar home systems program promotes innovative financing by involving microcredit organizations and quality control measures to increase commercial viability. An analysis of the correlation between wealth ranking and the technologies adopted by each of the economic groups in the field visit sites showed that solar home systems and biogas were usually only owned by rich households. Medium-income households may own a solar home system or an improved cookstove. The poor and very poor households could not afford even the improved cookstoves. Making cookstove technologies commercially viable and affordable to the poor is a major challenge. Most prices were set according to cost, rather than affordability or market research. The USAID/Winrock program initially suggested prices to entrepreneurs based on cost, though later found them selling stoves for much more, suggesting they had themselves responded to the market. The GTZ program set prices based on manufacturing costs, transport, installation cost, and a small margin for the implementing organization.

Given this scenario, the cost of the stove would be a key factor in achieving complete coverage of cookstoves (Table 4.2). The programs reviewed promoted a wide price range (US\$ 3 to 870 ) for household energy technologies, which was beneficial in stimulating a market by providing a range of options. For biogas and solar home systems, the price range was thousands of takas. For improved cookstoves, the GTZ program initially offered a three-pot stove option costing Tk 700 (US\$ 10) and has recently introduced cheaper one-pot and two-pot models costing about Tk 200-600 (US\$ 3-9).

The now defunct government-funded programs with a greater emphasis on reaching a large number of households had offered direct subsidies, while IDCOL's biogas and solar home systems programs provide short-term and small indirect

\section{Table 4.2 Cost of Technologies}

\begin{tabular}{|c|c|c|c|}
\hline Program & Technology & Cost in Tk (US\$) & Subsidy offered \\
\hline $\begin{array}{l}\text { Dissemination of improved } \\
\text { cookstoves (BCSIR) }\end{array}$ & $\begin{array}{l}\text { Improved } \\
\text { cookstoves }\end{array}$ & $\begin{array}{r}\text { Tk 200-400 } \\
\text { (US\$3-6) }\end{array}$ & $\begin{array}{l}\text { Cost of the stove fully subsidized with } \\
\text { households providing only soil }\end{array}$ \\
\hline $\begin{array}{l}\text { Sustainable Energy for } \\
\text { Development (GTZ) }\end{array}$ & $\begin{array}{l}\text { Improved } \\
\text { cookstoves }\end{array}$ & $\begin{array}{r}\text { Tk 200-700 } \\
\text { (US\$ 3-10) }\end{array}$ & No subsidies \\
\hline $\begin{array}{l}\text { indoor air pollution program } \\
\text { (USAID/Winrock/VERC) }\end{array}$ & $\begin{array}{l}\text { Improved } \\
\text { cookstoves }\end{array}$ & $\begin{array}{r}\text { Tk } 150-500 \\
\text { (US\$2-7) }\end{array}$ & No subsidies \\
\hline Biogas Program (BCSIR/LGED) & Biogas plants & $\begin{array}{r}\text { Tk } 10,000-30,000 \\
\text { (US\$ 143-429) }\end{array}$ & $\begin{array}{l}\text { Subsidies varied depending on agency. } 50 \% \\
\text { user subsidy for plant; Tk 5,000 to farmers; Tk } \\
5,000 \text { as grant to collaborating NGOs }\end{array}$ \\
\hline $\begin{array}{l}\text { National Domestic Biogas and } \\
\text { Manure Program (IDCOL/SNV) }\end{array}$ & Biogas plants & $\begin{array}{r}\text { Tk } 18,000-33,000 \\
\text { (US\$257-472) }\end{array}$ & Tk 7,000 subsidy for all plants \\
\hline $\begin{array}{l}\text { Rural Electrification and } \\
\text { Renewable Energy Development } \\
\text { Program (IDCOL) }\end{array}$ & $\begin{array}{l}\text { Solar home } \\
\text { systems }\end{array}$ & $\begin{array}{r}\text { Tk 8,000-61,000 } \\
\text { (US\$ 114-872) }\end{array}$ & $\begin{array}{l}\text { Subsidies are provided as buy-down grants of } \\
\text { Tk } 1,250 \text { and capacity development grant of } \\
\text { Tk } 400\end{array}$ \\
\hline
\end{tabular}


subsidies. However, IDCOL programs focus on commercialization and incorporate microcredit grants or seed funds for entrepreneurs, as did the USAID/Winrock improved cookstove program.

A number of approaches were used to finance the technologies and make them more affordable to rural households. GTZ provides financial incentives to partner organizations for each stove built. While this is not a true commercial approach, it demonstrates how important profit is as a motivating factor and was also found to improve accountability of technicians. Providing financing options to households to operate their technologies would be helpful in increasing cookstove acceptability. The review found that loan repayment was generally good for all the organizations providing loans. Partner organizations for larger household energy programs, such as the Rural Electrification and Renewable Energy Development Program and the National Domestic Biogas and Manure Program, reported high recovery rates, while GTZ has reported some difficulties. GTZ also reduced the number of repayments as much as possible within the capabilities of borrowers to minimize transaction costs.

Customer satisfaction was an important criterion for proper loan recovery, and users satisfied

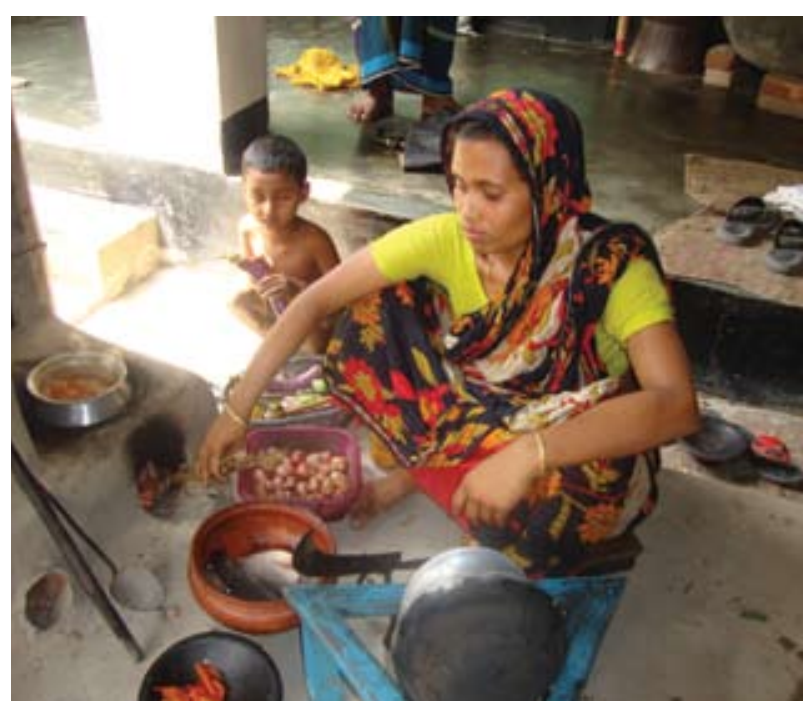

with the technology and after-sales service were more willing to make their payments. Indeed, if a fault develops with a stove, some users withheld installments until it was fixed. This is another benefit of having installers collect loan payments, as it further increases accountability. The USAID/ Winrock and GTZ programs motivated local, existing microfinance institutions to provide loans to their members for improved cookstoves; new bespoke facilities were not required. Most poor families tend to have more than one loan and therefore have repayment problems, which needs to be kept in mind while promoting loan financing for poorer households.

Carbon financing can make additional funds available to support dissemination of more household energy systems and establish a robust monitoring and evaluation process and ensure after-sales services to the users, as long as the carbon revenue continues to flow in (Box 4.3). A number of carbon stove programs are being developed at present in Bangladesh, mainly building on programs formerly run by NGOs and donors, including the GTZ Sustainable Energy for Development Program.

A number of solar home system projects are presently attracting carbon finance through the Clean Development Mechanism in Bangladesh. These are implemented by IDCOL through a network of partner organizations, and by Grameen Shakti through its own network of local offices. The World Bank has signed emission reduction purchase agreements for these projects. The projects give an indication of the scale required to make carbon finance viable: the Grameen Shakti project aims to disseminate just under 1 million solar home systems between 2007 and 2015, resulting in emission reductions equivalent to around 50,000 tonnes of carbon dioxide per annum. This scale is achieved by bundling the activities of numerous organizations or offices, enabling the projects to benefit from economies of scale. 


\section{Box 4.3 Carbon Finance: An Emerging Opportunity for Household Energy}

Bangladesh is set to become one of the pioneers in securing carbon finance for a large-scale improved stove program. An international carbon finance organization has been working with partners in Bangladesh to develop a project that is now awaiting validation. It is intended to be registered as a Clean Development Mechanism project.

There are examples of carbon-financed improved stove programs registered both with the voluntary and compliance (i.e. Clean Development Mechanism) markets, including in Uganda and Ghana. Other projects are under development in India.

The development of a new methodology by the Gold Standard (http://www.cdmgoldstandard.org) offers a bespoke framework and methodology for developing carbon finance projects. However, the up-front investment required to develop a viable carbon finance project can be considerable (often in excess of US\$100,000); projects usually need to be substantial to justify this, and very rigorous monitoring and evaluation is required.

One of the main challenges in determining carbon savings from stoves is not only quantifying fuel savings, but understanding the extent to which fuel saved is from nonrenewable sources. Determining this alone can be a complex and expensive process. Reduction in wood derived from renewable sources is not considered to count towards carbon savings.

Accurate and detailed monitoring is essential for any carbon project: in these projects the elaborate monitoring systems include reporting on usage based on surveys of all recipients of the solar home system. The carbon finance is being used to speed the expansion of these programs, which were established before this stream of funding became available. Finance is used to cover overheads, and loans are also offered to consumers to widen access. These, too, require detailed monitoring and reporting to satisfy the independent assessors.

\section{Lessons Learnt: Financial Aspects}

On financial aspects, the main lessons learnt were as follows:

* Subsidy-driven household energy programs cannot be sustained beyond the program period because as subsidy ends, prices of technologies increase, thus reducing demand, viability, and after-sales service as a cascade effect.

* A diverse variety of stoves and plants with a wide price range can be essential for the acceptability of a program. Very low cost options can help promote these technologies even to the very poor, sometimes without the need for loans. This can be achieved by constructing technically efficient, locally designed, improved cookstoves built from locally available materials, which can be reasonably priced to be affordable to the very poor.

- A variety of approaches, such as microfinance services, loans, and financial incentives, can be used to finance household energy technologies to make them more affordable for rural households.

* Profit (such as financial incentives to partner organizations for each stove built and seed funds for entrepreneurs) can be a motivating factor in adoption of technologies.

* Pricing needs to be considered in light of costs as well as the market environment.

- Innovative financing, which combines microcredit organizations and quality control measures, can help increase the commercial viability of a program. 
* Customer satisfaction is essential for loan repayments. Thus, when program monitoring is tied in with payment collection visits to those households that took loans to pay for the stoves, it can ensure accountability in a stoves program.

* Carbon finance may provide a way of funding further large-scale household energy programs in the future.

\section{Conclusions}

The challenge of addressing indoor air pollution exposure in 30 million rural Bangladeshi homes may seem daunting but it is an important task to significantlystrengthen Bangladesh's efforts to attain the health-related Millennium Development Goals. Of all the household energy technologies reviewed, improved cookstoves has the potential to be the cheapest and easiest to implement. The ideal future improved cookstove program for Bangladesh needs to strengthen itself in institutional and technological aspects. It would need to have a level of technology appropriate to the task, with a standard and efficient design, standardized emissions and indoor air pollution testing, efficient performance, and compatibility with user requirements. Importantly, future improved cookstove programs in Bangladesh need to focus on, and address, the significant barriers to adoption that exist within the homes of the poor. Household decisions to adopt - or reject new technologies may be based on a complex set of factors, including cultural and financial. Investing in cookstoves is generally not viewed as a high priority, both because smoke is not perceived as a major health issue and because biomass energy is often collected from the local environment, so there are no cash outlays to be saved from stove adoption. In addition, household energy issues are significantly impacted by gender roles: women generally use stoves, while men control family finances and make household decisions.

Large-scale certification of cookstoves and cookstove manufacturers would add to consumer confidence in the product. The implementation should follow an integrated approach by gathering all household energy programs together under one platform. There should be an exit strategy in place for the program implementers, who would generate commercial and demand-driven approaches to sustain the viability of the program in the long term. Bangladesh should continue to tap its existing potential as a frontrunner in microcredit and community engagement approaches. 


\section{Review of International Cookstove Programs}

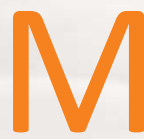

illions of improved cookstoves have been successfully and sustainably disseminated in Asia, Latin America and the Caribbean, and Africa. Unfortunately, successes in the South Asia region, including Bangladesh, have been limited and sporadic. This chapter presents the results from a review of international improved cookstove programs of selected countries (China, Guatemala, Haiti, Mongolia, Nepal, and Uganda) from different regions of the world, based on their potential relevance for an improved cookstove program in Bangladesh. Both published papers and informal reports available on the Web were used as information sources. The findings of the review of programs per country are presented in Table 5.1. Following this is a comparative discussion of the programs under four thematic heads (institutional arrangements, awareness and motivation, development and promotion of technologies, and financial aspects), along with lessons learnt that could be applied to a future improved cookstove program in Bangladesh.

\section{Brief Overview of International Improved Cookstove Programs}

Most of the international programs were launched to conserve fuelwood or reduce the financial burden of households from fuel purchase for cooking and heating. Some programs also had the specific objective to reduce indoor air pollution.

The first phase of the National Improved Stove Program in China started with the objective of rapid dissemination of stoves in 860 counties through subsidies to households, counties, and technical institutions to meet energy shortages in rural areas by doubling stove efficiency. In the second phase, the program focused on commercialization of stoves by reducing subsidies, giving tax and loan benefits to rural energy companies, undertaking training, and offering administrative support. The third phase centered on quality control by certification and standardization.

In Mongolia, the project of the Energy Sector Management Assistance Program (ESMAP), which was launched at the request of the Mongolian government, aimed to introduce improved $\mathrm{G} 2$ stoves to the ger population ${ }^{12}$ of Ulaanbaatar, which would reduce indoor air pollution and the amount of coal consumed by households for heating and cooking purposes. The objectives of the project included improving the stoves and developing retrofit kits,

12 The "ger" is the traditional tented accommodation of Mongolia. The ger districts of Ulaanbaatar are the poor peri-urban settlements that have sprung up on the edge of the city. 


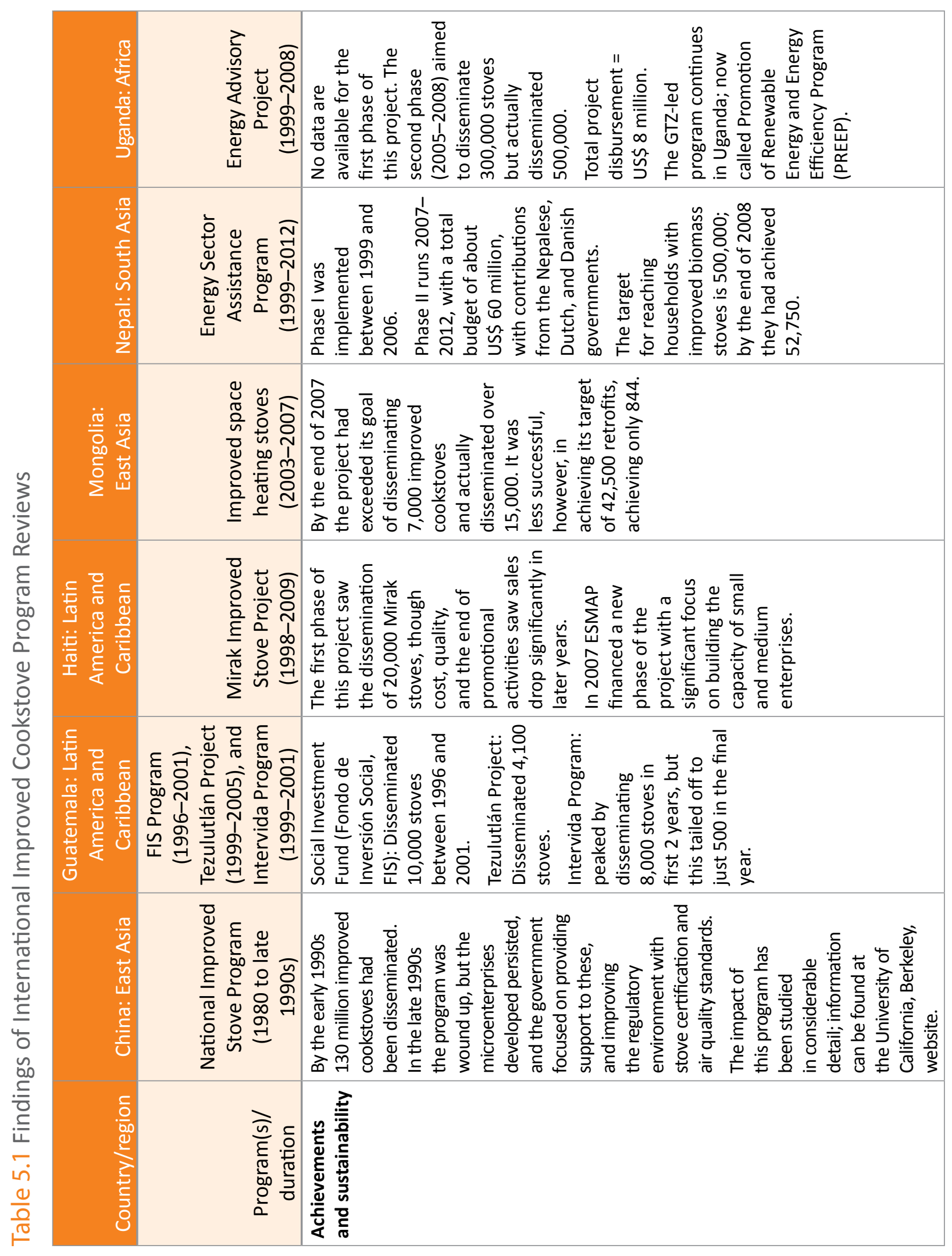




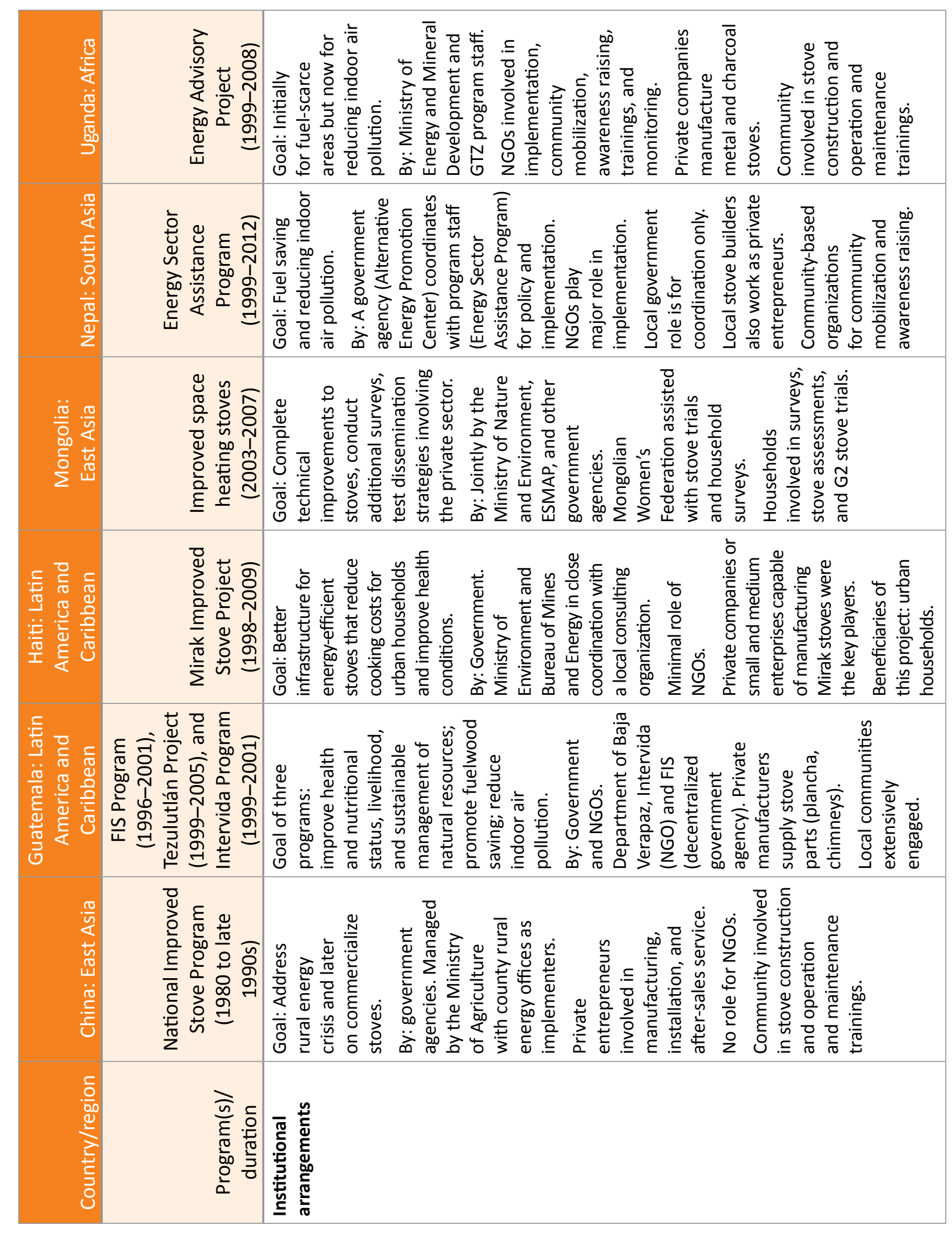




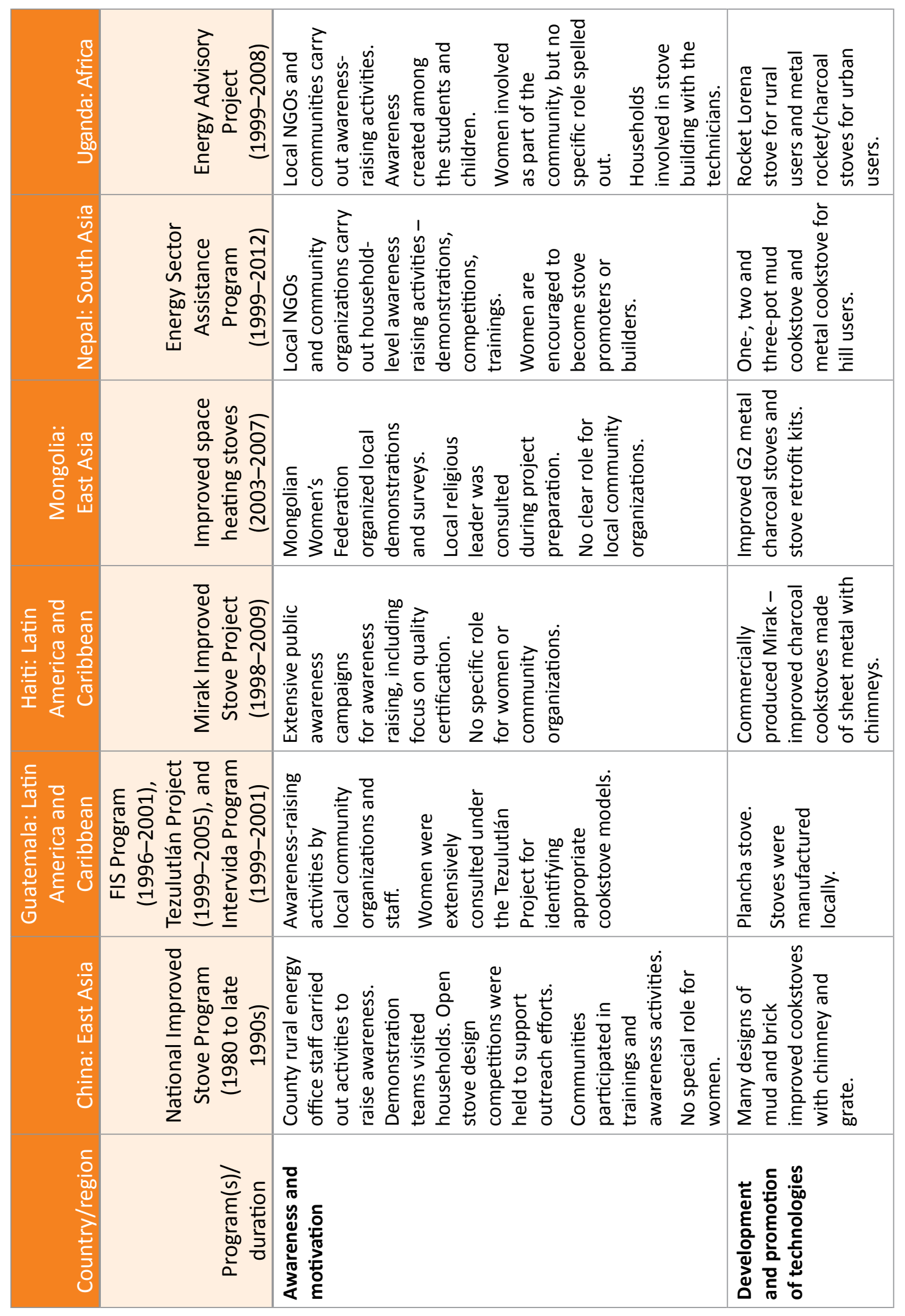




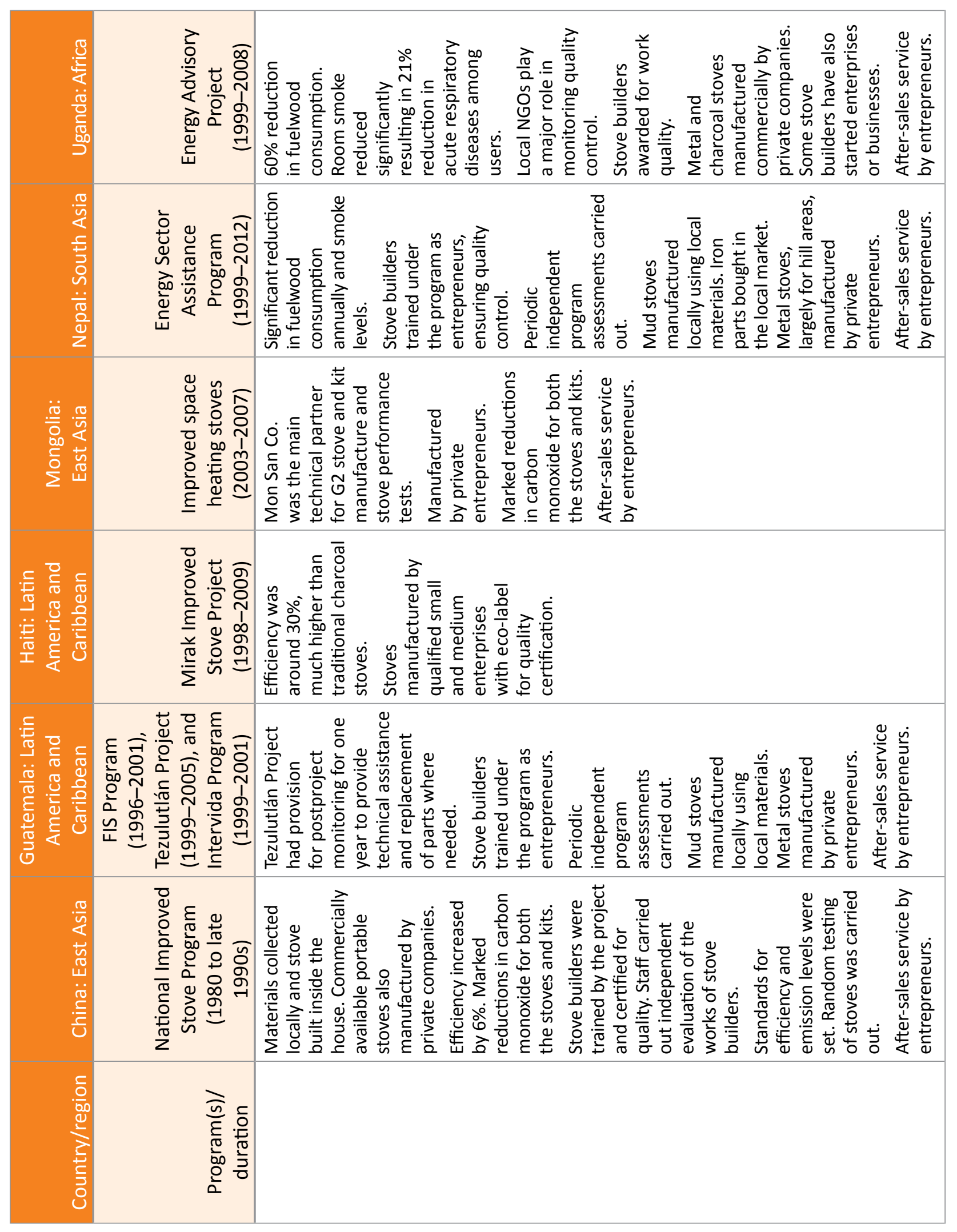




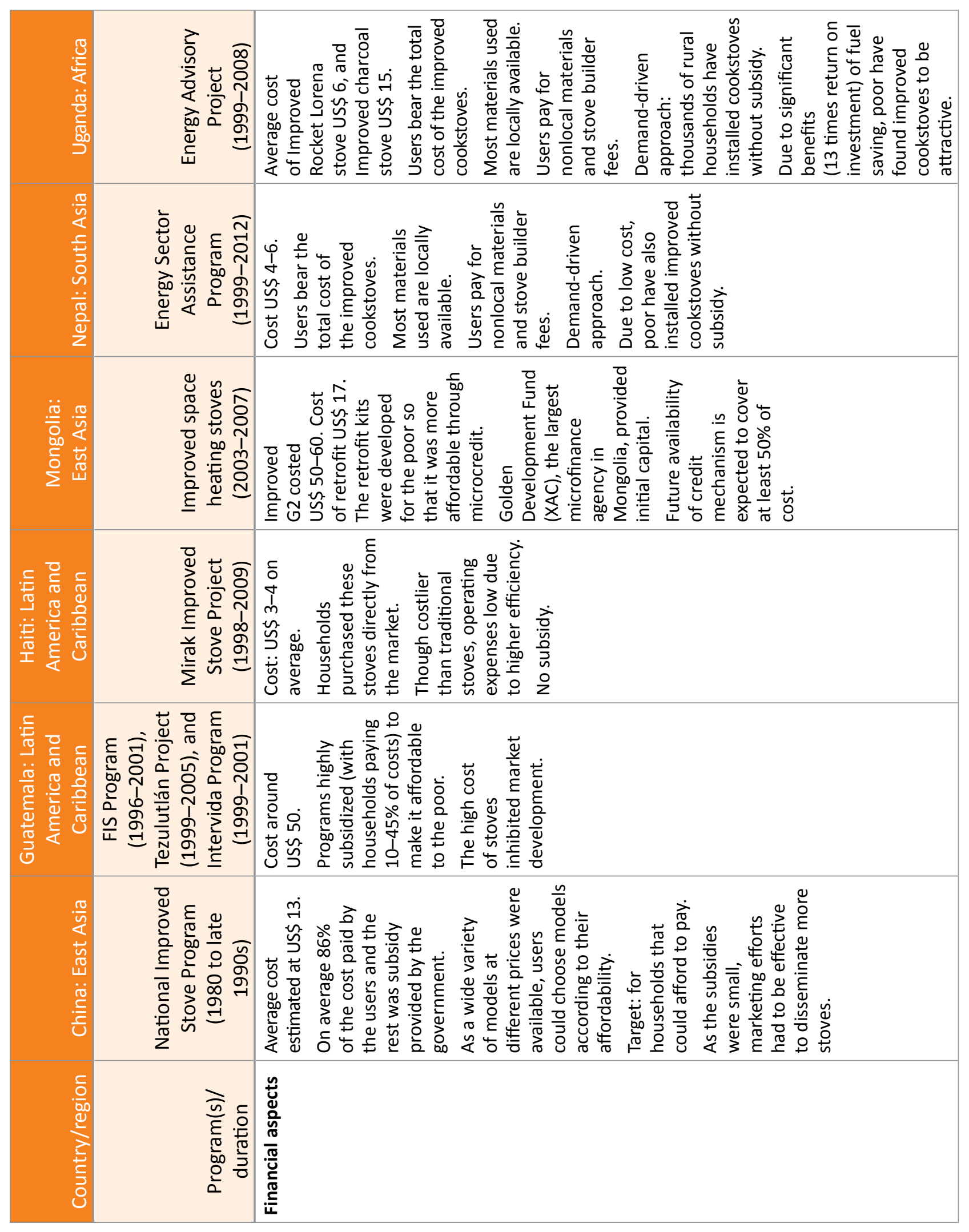


conducting comprehensive surveys of households and stove producers, and testing dissemination strategies, including a program for the private sector and relevant stakeholders to disseminate the retrofit kits.

In Guatemala, the three projects reviewed had a range of objectives, primarily fuelwood saving, reduction of indoor air pollution, promoting health and nutritional status, promoting sustainable livelihoods, and sustainably managing natural resources.

The improved cookstoves component under the Energy Advisory Project in Uganda identified areas with extreme wood scarcity. Rocket Lorena cookstoves, first promoted as a pilot activity, were scaled up later. The second phase of the Energy Advisory Project (2005-2008) aimed to install 300,000 improved cookstoves and in fact successfully installed around 500,000 stoves during this period.

In Nepal, the National Improved Cookstoves Program started in 2000 as an activity of the Alternative Energy Promotion Center and the Energy Sector Assistance Program, supported by the Danish International Development Agency (DANIDA). The program aimed to install 50,000 improved stoves in households in the mid hills as a way to reduce fuelwood consumption. The second phase started in 2007 as a biomass energy component and aimed to install 434,000 improved stoves in the mid hills and Terai, disseminate 10,000 household gasifiers and 1,000 institutional gasifiers, demonstrate 5,000 institutional improved cookstoves, and install 50,000 metal improved cookstoves in the high hills.

In Haiti, the project aimed to assist small and medium enterprises to develop better infrastructure for the production of energy-efficient stoves that reduce the cost of cooking for urban households and improve health conditions. The project goal was to form at least 10 competitive small and medium enterprises that would manufacture and disseminate 50,000 high-quality Mirak stoves over the project period. These small and medium enterprises continued to manufacture and sell more stoves after the end of the project.

\section{Lessons Learnt from International Improved Cookstove Programs}

\section{Institutional arrangements}

All programs reviewed had the respective country government playing a major role, which gave greater credibility to program activities, resulting in higher priority and recognition, thereby supporting efforts to meet the national targets. A strong government backing (as in China and Nepal) and an organizational structure that allows government and program staff to work in a coordinated way (as in Nepal) is essential for success. China practiced one of the most successful approaches, in a program that unfolded over a period of more than 25 years. The program started as a government-led program working directly with the counties (or local governments). Capacity was gradually built and a more commercial approach was taken, which helped rural enterprises take the lead in manufacturing and installation. Cookstoves in China have now evolved into a commercial enterprise across the country, with the government body evolving to the role of quality controller. Lessons from Nepal endorse the value of an integrated institutional management setup wherein the government closely works with key partner NGOs to provide integrative cross-platform energy solutions and services to rural areas, thus allowing the service providers to optimize human resources.

NGOs and the private sector were fundamental to the success of a number of the improved cookstove programs. However, the successful China program and the innovative Haiti program had no significant role for NGOs, while in Guatemala both NGOs and the government were involved in implementing stove programs. Meanwhile, successes in Nepal and 
Uganda were attributable to NGOs as key partners in implementation. While involvement of private sector entities in almost all programs reviewed was as supporting agencies, such as for supplying materials (Nepal and China), as technical partners (Mongolia, Guatemala, and Uganda), as commercial stove manufacturers (Haiti), and as awareness raisers (Mongolia), they would eventually emerge as key stakeholders and as major players for commercialization of cookstoves. The China model shows that private entrepreneurs and businesses can ultimately emerge as the key players, once a program is established, by providing products and service support, and are thus an important component of any cookstove program.

Working with community-based organizations and establishing links between the government and NGOs working on health and hygiene helped in reducing duplication and overlapping of activities. The Guatemalan Tezulutlán Project and Intervida Program were the only ones that did not focus solely on the final product (for example the cookstove), but also paid attention to raising awareness of health benefits and facilitating the community to conduct their own appraisal in order to understand the health issues related to indoor air pollution.

Training and capacity building are essential components of such activities as awareness creation within communities and provision of monitoring services. In China technical training is a major function of the government, while in Uganda and Nepal local NGOs helped with capacity building and maintenance training for beneficiaries. Local communities and community-based organizations have also assisted with stove installation, trained on stove use and maintenance, and been involved in local demonstrations and awareness-raising activities, for example in Nepal, Mongolia, and China. In China and Uganda beneficiaries were involved in the construction of the improved cookstoves in their houses from standardized parts, and also received operation and maintenance trainings.
Almost all programs focused on developing private entrepreneurs, manufacturers, and energy service companies. Under the Energy Advisory Project in Uganda, local persons trained as stove builders became small-scale entrepreneurs by entering the stove business. In Nepal, local women entrepreneurs have been trained as promoters to market and install the stoves. This empowerment has led to motivation among women to better market cookstoves in their communities and has resulted in higher penetration. The program has created a niche market for small local entrepreneurs who are capable of installing low-cost improved cookstoves acceptable to the users.

The only example of poor coordination of programs was in Guatemala, where there was limited interaction between the three stove programs, which resulted in duplication of efforts in stove development and dissemination. Despite this the Social Investment Fund program, with its strong community support, disseminated the majority of the 100,000 plancha stoves in Guatemala in 1996-2002. While the review did not clearly examine the monitoring and evaluation aspects of programs, results showed that China at various times had strong program monitoring through the government, as did Mongolia. Monitoring entities varied from local NGOs in Uganda to local entrepreneurs in Nepal. The Tezulutlán Project in Guatemala offered postproject monitoring for one year to provide technical assistance and replacement of parts as needed. The Haiti project included a provision of supervision.

Lessons learnt: institutional arrangements. From the review of institutional arrangements, the main lessons learnt were as follows:

- An integrated institutional mechanism across energy solutions and intersectoral collaboration for implementation and monitoring are essential, and can allow service providers to optimize resources and help guide policy-level decisions for the programs. 
* Engaging local government has benefits in effective awareness raising, monitoring, increased coordination at the local level, and overall achievement of program objectives.

* The role of entrepreneurs and NGOs can be fundamental to an improved cookstove program as they help in awareness raising, establishing a commercial market, and providing after-sales services, which are key to the success of any program.

\section{Awareness and Motivation}

The building of considerable social capital, for example through awareness raising and community-level organizational structures, was seen in all programs reviewed. Awareness and motivation aspects were handled by different entities in different countries. For the Nepal program, at the user level, local communitybased organizations were used for raising awareness and training activities. This improved program effectiveness because of the rapport such organizations often build with the users. The Uganda program focused on social marketing efforts through extensive community mobilization and raising awareness in households and children through schools. As household awareness of the benefits of the improved cookstoves increased, the program promoted easy and affordable installation of stoves by maximizing use of local materials and training local people as stove builders. This created an environment conducive to wider stove dissemination. Community leaders played crucial roles in awareness raising in Mongolia, where the local religious leader was engaged in program design, an important consideration given the role of fire in Mongolian culture. Other approaches included requiring households to participate in trainings and awareness-raising activities, as in China, or having households assist in stove construction, as in Uganda.

One of the best examples of awareness and motivation is from China, where local government (county rural energy office) staff helped in extensive outreach activities to raise awareness on the benefits of improved stoves. As funds were limited, marketing efforts had to be effective to disseminate more stoves. Demonstration teams visited households and open stove design competitions were held to support the outreach efforts.

Integration of the gender issue in the awareness process was very helpful in Nepal, where women's organizations and women entrepreneurs were involved at the local level, which had a synergistic effect in improved cookstove dissemination. While programs in Nepal have been particularly successful in engaging women as stove promoters and technicians, the role of women did not appear to be explicit for the Chinese, Ugandan, and Mongolian programs.

In most of the successful programs, users were regularly made aware of the quality, benefits, and availability of improved cookstoves as part of the awareness program. Behavioral change ensured real and sustainable improvements through investing in community mobilization instead of hardware, and shifting the focus from cookstove construction for individual households to the creation of wellventilated homes. It should also be kept in mind that awareness and motivation go hand in hand with the marketing of a good stove that has significant advantages over traditional counterparts.

Lessons learnt: awareness and motivation. From the review of awareness and motivation, the main lessons learnt were as follows:

* Community-based and social organizations can play crucial roles in awareness raising and bringing about behavioral change in the use of energy technologies.

* Awareness of health benefits and fuel savings can have a significant impact on creation of demand, leading to sustainability. Awareness-raising activities are successful when heath benefits and gender aspects are integrated. 
* Investing in community mobilization instead of hardware, and shifting the focus from cookstove construction for individual households to the benefits of creation of well-ventilated homes, can be an important factor in motivating people to buy improved stoves.

\section{Development and Promotion of Technologies}

A wide range of improved cookstoves characterize the projects reviewed, from the very simple improved mud stoves in Nepal, to the more sophisticated plancha stove in Guatemala, to the cast-iron G2 stove in Mongolia. The choice of stoves introduced depended on local cooking practices, availability of materials, and user acceptance. A number of stoves added chimneys to reduce indoor air pollution from traditional stoves. This was done in Nepal, Mongolia, China, and Haiti (sheet-metal Mirak stove). In Mongolia, the program developed a stove retrofit kit that could be used to upgrade existing traditional stoves. This was an innovative measure, as many of the households could not afford the improved G2 stoves, which cost around US\$ 50-60 while the kits cost only US\$17. Depending on the type of stove promoted, countries such as Nepal and Uganda use home-constructed stoves with metal parts purchased from local markets. In China, there was greater emphasis on developing rural energy manufacturing enterprises to supply stove parts.

Performance monitoring is an important component of any cookstove program and was dealt with by a variety of agencies using various methods. In Nepal regular monitoring of stove performance was ensured through the establishment of renewable energy test stations, leading to a high level of customer satisfaction. On the other hand, in China the focus was on certifying the stove manufacturers along with random testing of stoves. In Guatemala, the Tezulutlán Project had provision for postproject monitoring for one year to provide technical assistance and replacement of parts where needed. In Uganda, local NGOs played a major role in monitoring of activities for quality control. Monitoring and testing in Mongolia presented particular difficulties due to very limited laboratory and technical capacity. An evaluation highlighted the need for capacity building, and recommended that monitoring and evaluation be outsourced to an organization experienced in monitoring, with a remit to deliver training.

Improved cookstoves showed greater efficiency than traditional stoves in all countries reviewed. Improved cookstoves in Nepal were estimated to reduce fuelwood consumption by $25-40$ percent compared to traditional stoves. In China, according to a 2002 survey, the average efficiency of improved cookstoves was 14 percent compared to 9 percent for traditional stoves. There was a slight reduction in $\mathrm{PM}_{4}{ }^{13}$ and carbon monoxide levels. In Mongolia, five stoves tested showed improved performances, with carbon monoxide emissions reduced by 68 percent. In Uganda the household Rocket stove cut fuel consumption by 60 percent and the institutional stove by 90 percent. Smoke levels in kitchens have been reduced significantly, resulting in a 21 percent reduction in acute respiratory diseases among cookstove users.

As quality assurance needs to be visible to the users, certification of stove quality by a recognized institution plays an important role in convincing consumers to use improved cookstoves. The certification process should be transparent and regular. Eco-labeling of Mirak stoves in Haiti with a quality and energy efficiency label provided consumers with quality assurance. Using public media such as radio, television, and newspapers to regularly remind consumers of the quality labeling can be an effective strategy in scaling up use of commercially produced improved cookstoves. The Nepal program has taken the approach of certifying

\footnotetext{
$13 \mathrm{PM}_{4}=$ particulate matter comprising particles with a diameter of 4 micrometers or less.
} 
promoters rather than stoves. Training is provided to the stove builders to maintain standard efficiency and smoke levels. Quality is maintained through a market mechanism whereby the service provider offers the best service to maintain goodwill and ensure more orders in the future.

The lack of a central improved cookstove certifying agency in Guatemala resulted in duplication of efforts for stove development. Moreover, the programs did not share valuable experiences, which could have made the stove designs more appropriate for the beneficiary households. In all programs, after-sales service was provided by entrepreneurs.

Lessons learnt: development and promotion of technologies. From the review of development and promotion of technologies, the main lessons learnt were as follows:

- Affordable, efficient cookstove designs based on user feedback are essential for program success. Locally made cookstoves are cheaper to build and easier to repair and maintain.

* Performance monitoring for stoves should be an important component of any improved cookstove promotion program, as perception of reduced kitchen smoke has been shown to be a motivating factor in consumer decision making.

* Certification, quality control, and after-sales services are important factors for program success. A transparent, regular certification process for stoves and promoters of stoves can be an important aspect for convincing users and generating demand.

\section{Financial Aspects}

The cost of cookstoves varied in the countries reviewed, with the cheapest in Haiti (US\$3-4) and Nepal (US\$ 4-6) and the costliest in Guatemala (US\$ 75-100) and Mongolia (US\$ 50-60). Improved cookstoves in the price range US\$ 3-6 were affordable to most rural households among all the countries reviewed. Users could afford to pay for the whole cost of the stove in Nepal, Uganda (Rocket Lorena stove at US\$ 6), and Haiti. The Mongolian program developed a stove retrofit kit, which could be used to upgrade existing traditional stoves. This was an innovative measure, as the ger households struggled to afford the improved $\mathrm{G} 2$ stoves, which cost around US\$ 50-60. The kits, on the other hand, cost only US\$ 17 . This may be an option where the stoves, by design, are very expensive.

No financing mechanisms or subsidies are required when cookstoves are affordable even to the poor, as in Nepal and Uganda. This resulted in a commercial approach to improved cookstove dissemination, with users bearing the full cost of the stove. Affordable cookstoves are possible when they are built mostly from locally available materials. China used an interesting approach of initially providing a subsidy, with 86 percent of the stove cost on average being borne by households, and the government, through province, county, township, and village funds, providing the rest. As the program became demand driven, subsidies were eliminated completely from the stove itself and virtually all cookstoves were sold commercially.

The Guatemala Social Investment Fund program was part of a broader government community block grant program in which communities had a choice of using the grants for various development activities, such as schools or road improvement. The communities decided on the use of the block grants based on what was most attractive to them. The expensive Social Investment Fund stove gained popularity and was commonly chosen for the use of these funds. Because the stoves were financed as part of these block grants, in Guatemala the plancha cookstoves were highly subsidized due to the high stove cost (US\$ 75-100). On average, households paid 20 percent of the total cost of the stove over a period of one year. However, Social Investment Fund households paid only about 6 percent of the total cost. 
For poor countries such as Haiti, it was important to bring down the cost of improved cookstoves to an affordable range. In the case of charcoal stoves, this was achieved through mass production, which, encouraged by general consumer acceptance of stoves, allowed small and medium enterprises to operate in a sustainable manner and provide good after-sales services.

In Mongolia, stove manufacturers and rural energy service companies gave customers access to credit through microfinance by liaising them with local microfinance groups, particularly the Golden Development Fund (XAC). This was required because the stoves promoted in Mongolia were for heating mainly with coal and were intended only for poor people in the peri-urban areas of Ulaanbaatar. Under the China National Improved Stove Program, State funds were used for capacity building and motivating users and there were typically no subsidies for the stove itself once the program became fully commercial. This resulted in beneficiaries purchasing improved cookstoves for benefits other than price, creating a sustainable system where all users were willing to pay for the stoves.

Lessons learnt: financial aspects. From the review of financial aspects, the main lessons learnt were as follows:

* Subsidies are not mandatory for a successful cookstove program, if the cookstoves are affordable even to the rural poor. Low-cost stoves can be achieved if they are built mostly from locally available materials.

* A demand-driven program resulting from low-cost stoves, easy availability, a commercialized approach, and consumer perception of benefits can help in the success of a cookstove program.

* Using funds for capacity building and motivation rather than subsidizing stoves or their components would help develop a sustainable system whereby users were willing to pay the full costs and purchase cookstoves for their benefits.

- Credit through microfinance can be used to make expensive stoves affordable to a larger number of households.

\section{Conclusions}

This review of international programs provides some good practices that can support the development of new cookstove initiatives in Bangladesh. While Bangladesh's household energy programs demonstrate some of the best practices internationally, considerable learning still has to take place if Bangladesh is to move ahead to attain its Millennium Development Goals. There are valuable lessons available within the country, such as effective community engagement approaches and workable financial mechanisms, which can be easily duplicated in a new program on improved cookstoves. There are however still important lessons to be learnt in developing a suitable policy agenda that promotes intersectoral collaboration and integrative mechanisms across household energy solutions.

A technically sound cookstove is also essential for program success. Bangladesh needs to integrate and increase its efforts in developing efficient, standardized, and affordable technologies with quality assurance and monitoring mechanisms in place. The approach of targeting households facing fuelwood scarcity, socially marketing the benefits of improved cookstoves to increase their acceptability, making improved cookstoves affordable by using local materials and employing local technicians for construction, and strengthening monitoring are other lessons to take home from the international experiences outlined in this chapter. 


\section{Lessons from Sanitation Initiatives in Bangladesh}

- he Bangladesh Country Environment Analysis states that the health impacts of indoor air pollution could be reduced if people were convinced that the problem was as serious as poor sanitation and bad hygiene practices. The Total Sanitation Campaign is very focused on behavior change, awareness raising, and sensitization, and many of the approaches used could be applied to household energy programs. Both increasing sanitation and reducing indoor air pollution require the adoption of new practices, demand for latrines and cookstoves respectively, a supply chain of entrepreneurs, financing arrangements, and local participation of communities and parishads. Given these synergies, this chapter presents the
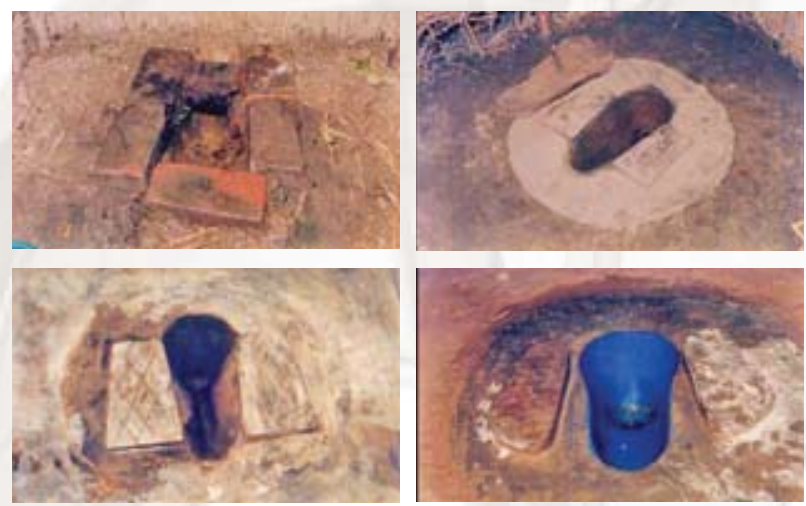

Models of sanitary latrines developed under the Total Sanitation Campaign. experiences of Bangladesh's successful Total Sanitation Campaign to learn lessons for household energy programs.

While there are synergies, it must also be noted that there are differences between these sectors. For example, the communal health impact of open defecation is more pronounced than the impact of smoke in the environment. As communal impacts are at the core of engaging communities, this aspect of the community-led sanitation program possibly may not translate directly to household energy programs. With the above in mind, this chapter provides a brief introduction to Bangladesh's community-led Total Sanitation Campaign and presents lessons from the review of sanitation initiatives for integrating into future improved cookstove programs.

\section{Bangladesh's Total Sanitation Campaign}

With a population of over 150 million, an extremely high population density, and half of its population below the poverty line, Bangladesh was faced with a serious public health challenge in the sanitation sector until a decade ago. The practice of open defecation and the use of unhygienic latrines has been the cause of serious diseases, particularly diarrhea in children below 5 years, productivity loss 
due to sickness, and a decline in the overall quality of life, with the poor being the worst affected. It is estimated that approximately 125,000 children below 5 years die every year (342 children every day) due to lack of proper sanitation facilities in Bangladesh (WaterAid 2003).

Progress in rural sanitation was rather slow during the 1980s and 1990s, with a sanitation coverage growth rate of just 1 percent per annum. Until the end of the 1990s, a number of sanitation initiatives were undertaken by government agencies and NGOs in Bangladesh. However, they were not sustained and could not bring about visible positive results, for a range of reasons. Technology remained the thrust of those initiatives, with people and institutions having little or no access to and control over the process. In addition, the institutions engaged had little contact with the end users (or beneficiaries) and did not consider the needs of those users, which made it impossible for the interventions to make any headway. In 2003 rural sanitation coverage was only 29 percent. If such a trend had continued, it would have taken more than 60 years for the entire country to have safe sanitation facilities (Minnatullah and Ahmed 2003). A nationwide sanitation survey in 2003, published in 2004 (LGD/DPHE/UNICEF 2004), revealed that for the majority of households lack of money was the key reason for not installing a latrine. Figure 6.1 summarizes the various reasons for nonadoption of latrines in Bangladesh.

However, learning from these unsuccessful experiences and inspired by global development efforts (such as the development of the Millennium Development Goals in 2000 and the World Summit on Sustainable Development in 2002), the government of Bangladesh committed itself to achieving the Millennium Development Goal targets through a new national program called the Total Sanitation Campaign, and took a crucial step to eradicate open defecation by 2010 , ahead

Figure 6.1 Reasons for Not Installing a Latrine: Results by Division, Bangladesh

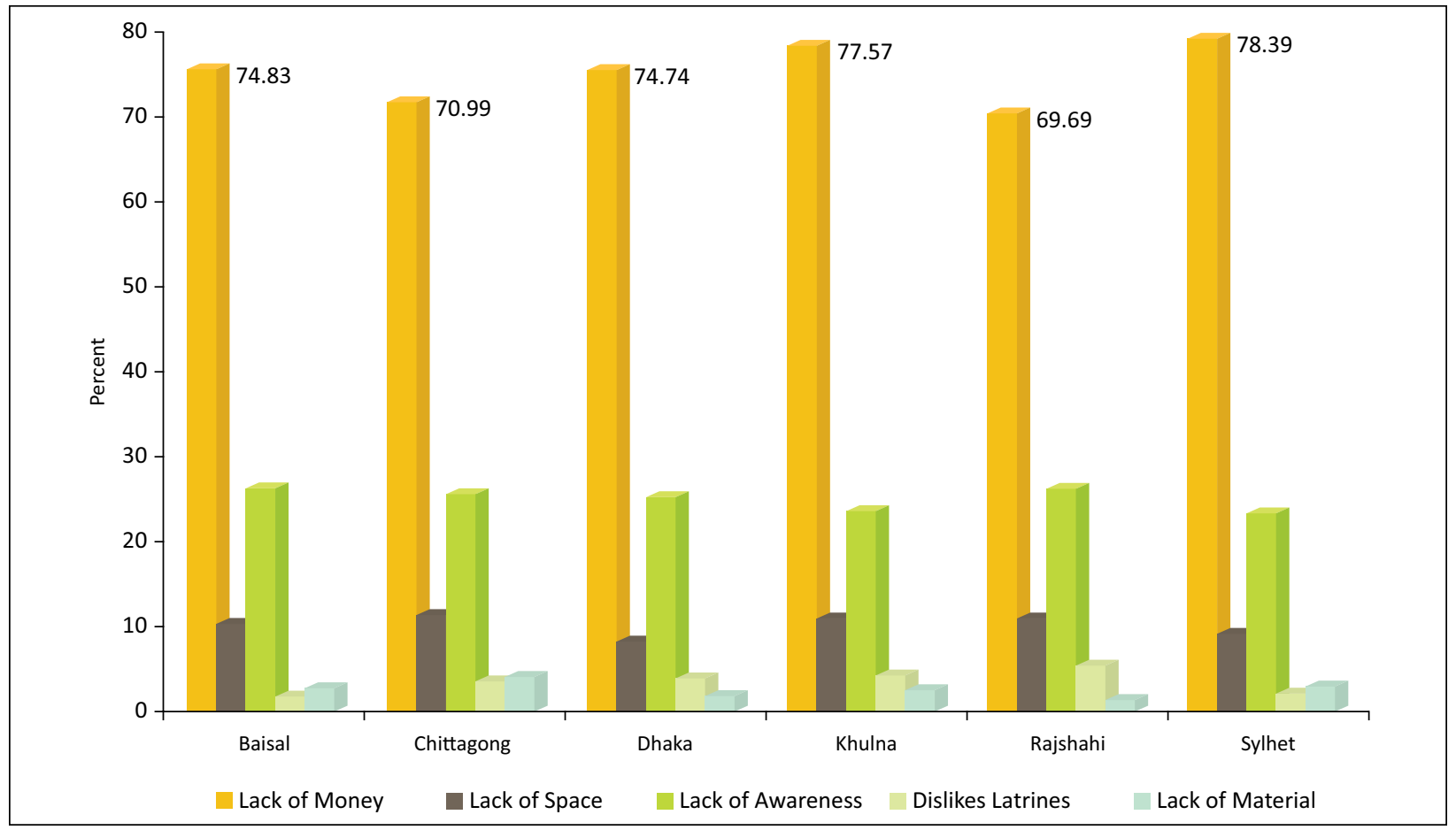

Source: LGD/DPHE/UNICEF 2004. 


\section{Table 6.1 Change in Approach for the Total Sanitation Campaign in Bangladesh}

\begin{tabular}{|l|l|l|}
\multicolumn{2}{c}{ Elements of campaign } & \multicolumn{2}{c}{ Past } & \multicolumn{2}{c|}{ Present/future } \\
\cline { 2 - 3 } Core activity & Constructing latrines & lgniting and facilitating process \\
\hline Latrines designed by & Engineers & Community innovators \\
\hline Number of designs & One or a few & At least 32 so far \\
\hline Materials & Cement, pipes, bricks, etc. & Bamboo, jute bags, plastic, tin, etc. \\
\hline Cost & Higher & Can be under Tk 50 \\
\hline Indicators & Latrines constructed & Open defecation ended \\
\hline Sustainability & Only partial & Complete coverage \\
\hline Motivation & Subsidy & Self-respect \\
\hline Coverage/usage & Partial & Total \\
\hline
\end{tabular}

Source: Kar and Chambers 2004.

of the Millennium Development Goal time frame. The Total Sanitation Campaign received a positive boost at the South Asian Conference on Sanitation (SACOSAN) in 2003, at which a landmark regional policy towards sustainable sanitation - the Dhaka Declaration on Sanitation - was adopted. With this came a commitment to focus on creating demand, sustaining attitudinal and behavioral change, and encouraging wider community participation, thereby moving away from the topdown approaches common to the earlier subsidized sanitation programs. Table 6.1 presents the change in approach of the Total Sanitation Campaign in Bangladesh. This initiative has led to more than 90 million people gaining access to and using latrines in less than five years. ${ }^{14}$

When VERC first piloted a community-led total sanitation approach in a few hamlets with financial and technical support from WaterAid, it was called the " $100 \%$ sanitized village approach". Later Dr. Kamal Kar (the architect of the approach) used the term "community-led total sanitation". This name is

14 The 90 million people in less than five years is an estimate calculated by subtracting the government of Bangladesh 2003 figure of coverage from the 2008 figure, which indicates that 65 percent of the population gained access to latrines in less than five years, and assuming a conservative population estimate of 140 million (as per the 2001 census), i.e. 65/100*140 $=90$ million (very conservatively) in less than five years. now widely used both nationally and internationally. After VERC's pilot study, the community-led total sanitation approach was advocated to the key sector actors and the government of Bangladesh. Though the advocacy work was well planned, it took more than a year to convince the donors, NGOs, and the government. This work paid off, however, as it was the commitment, support, and ownership shown by the government that eventually drove the success of the program. The key difference between the Total Sanitation Campaign and previous sanitation programs was that community-led total sanitation focused on promoting an open defecation-free environment, rather than on provision of latrines. The goal remained to save the estimated 125,000 children under the age of 5 dying each year of water and sanitation-related diseases. Over the years, the government of Bangladesh has laid emphasis on improving the situation through the adoption of a national policy and role creation for the local governments (union parishads) and NGOs for the program.

Considerable progress has been achieved in rural sanitation in Bangladesh through the communityled approach, with the local union parishads and NGOs playing the key role of facilitators. According to the Bangladesh National Sanitation Secretariat the sanitation coverage in June 2008 was around 
Figure 6.2 Progress in Sanitation Coverage (October 2003 to June 2008)

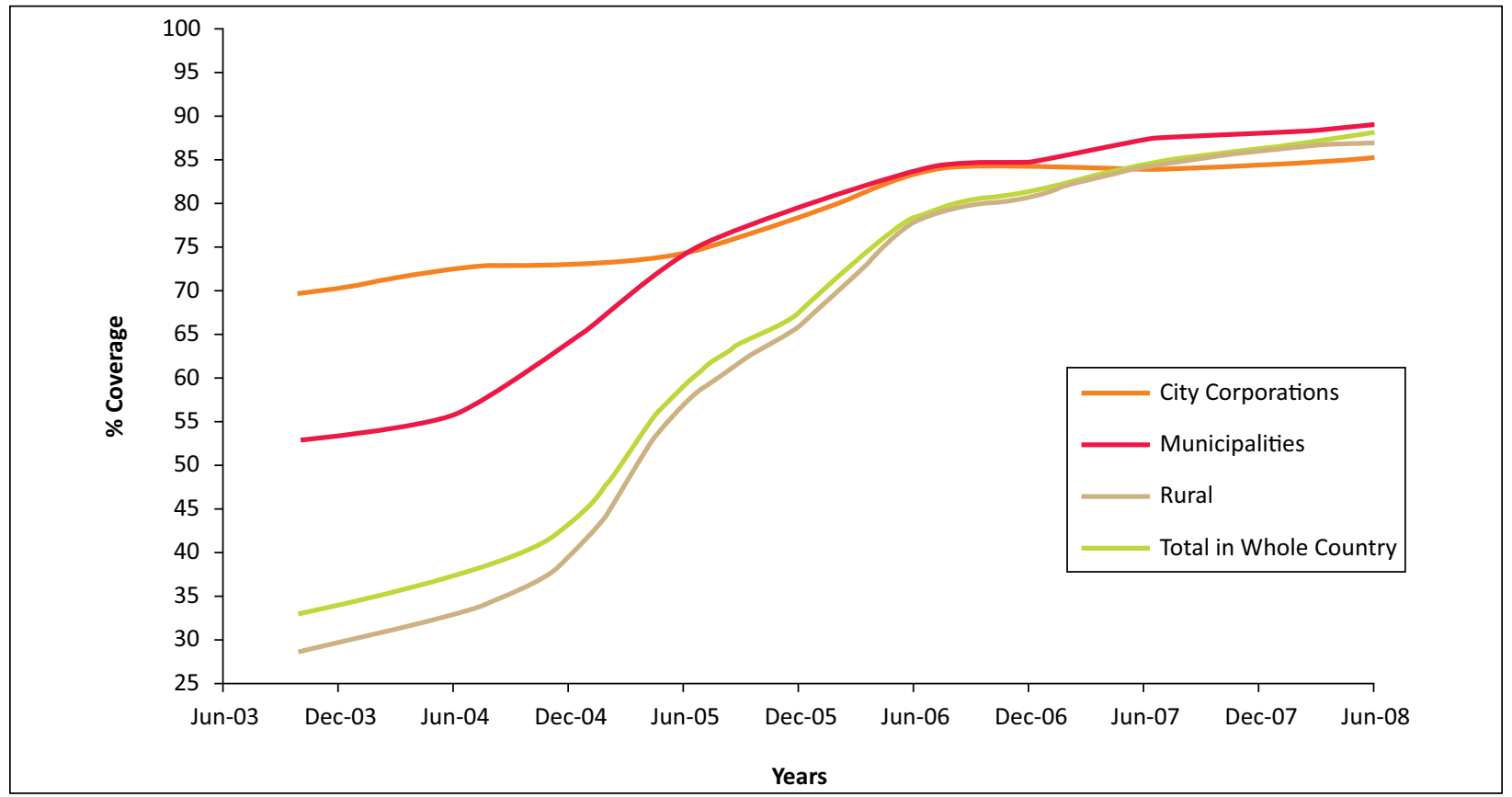

Source: National Sanitation Secretariat, 2008.

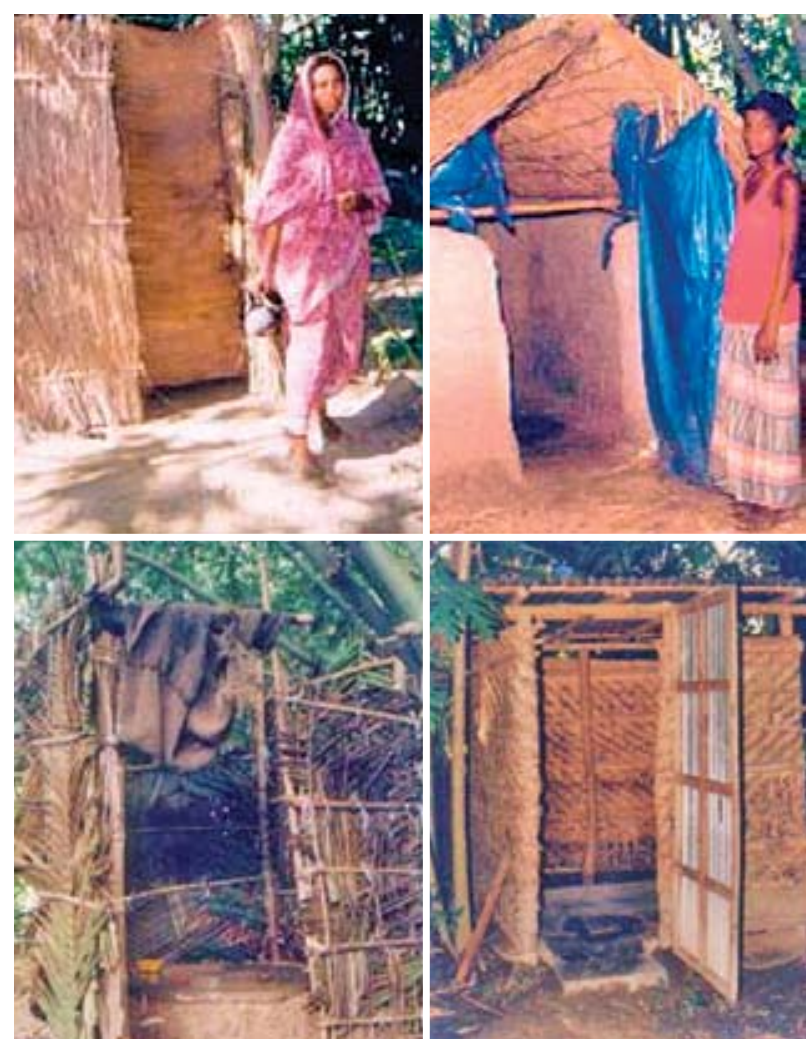

Models of latrines in Total Sanitation Campaign are developed to suit varying economic strata.
88 percent, which is an increase of about 55 percent from the baseline in October 2003. The open defecation rate reduced from 42 percent to less than 10 percent. Figure 6.2 shows the actual progress towards 100 percent sanitation coverage.

A study by VERC found that investment in latrines increased from 5 percent in households of the study sample (424 households) in 2003 to 100 percent in 2006 for the study area. The average family investment for latrines increased from Tk 26.20 in 2003 to Tk 506.80 for better latrine options in 2006.

\section{Comparison of Sanitation Programs in Bangladesh}

Four organizations in Bangladesh, known to have excellent track records in the implementation of the Total Sanitation Campaign, were selected for the detailed review. The selected programs represented a range of approaches, institutional arrangements, and actors, including government institutions, donors, and NGOs. It was difficult to distinguish differences between some aspects of 


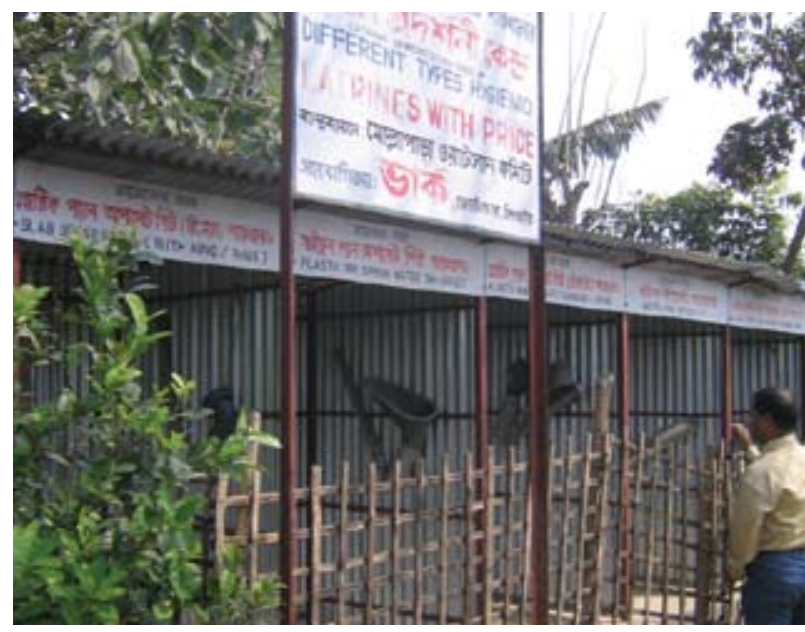

the various programs because of the similarity in the approaches. They all adhered to the principles of community-led total sanitation supported by the government, contributing to the success of the Total Sanitation Campaign. The results of the review are presented under the following themes: institutional arrangements, awareness and motivation, development and promotion of technologies, and financial aspects. Table 6.2 provides a summary and comparison of the findings of sanitation programs in Bangladesh.

\section{Institutional Arrangements}

\section{Summary of Findings}

In the Bangladesh Total Sanitation Campaign, NGOs, local government institutions, and community-based organizations play a critical role in implementing the program. The government's primary role is to utilize its social and legal power (often its offbudget leverage) to mobilize and regulate providers and households to ensure that everyone receives a basic quality of service. A secondary (and separate) role of the government is to provide services to the underserved, where the government is unable to leverage the market or social norms to do so. The NGOs as key players identify partners, extend technical support, and enable the partners to take part in the implementation of the sanitation program. The formal local government institutions involved in the process include the upazila, union, and ward sanitation task forces. The informal institutions are community organizations formed under different programs, such as the community water and sanitation action committee, water point management committee, hygiene education group, children's group, or adolescent girls' groups for reproductive hygiene. These groups function as task forces, and are assigned specific tasks within a range of sanitation and hygiene behavior change promotion activities. They are formed as outcomes of a process involving the facilitating NGO in collaboration with local government institution representatives.

The task forces are mainly required to undertake a needs assessment of actions and resources, prepare a time-bound sanitation plan at the union level, steer the overall process, and report to the immediate senior management task force for coordination and monitoring purposes. Thus the formal and informal institutions are interlinked to each other for planning, implementation, monitoring, and evaluation of sanitation activities in the communities, wards, and unions (Figure 6.3 presents the integrated institutional setup of the sanitation sector in Bangladesh).

The Total Sanitation Campaign is substantially supported by the Bangladesh government alone (BRAC WASH Program), by government and donor jointly (DISHARI), by donor and NGO (SEDA/NGO Forum), or by NGO alone (VERC). BRAC has employed its own bottom-up participation and planning approach through the WASH committees formed at the village level, whose members represent the entire village. The union parishads together with BRAC staff guide the program in setting priorities and mobilizing the village committees. DISHARI involves the existing administrative and local government structures and works by strengthening the institutional capacity of the local government institutions, enabling them to play a steering role. Both VERC and SEDA/NGO Forum use the community as the entry point of their program 


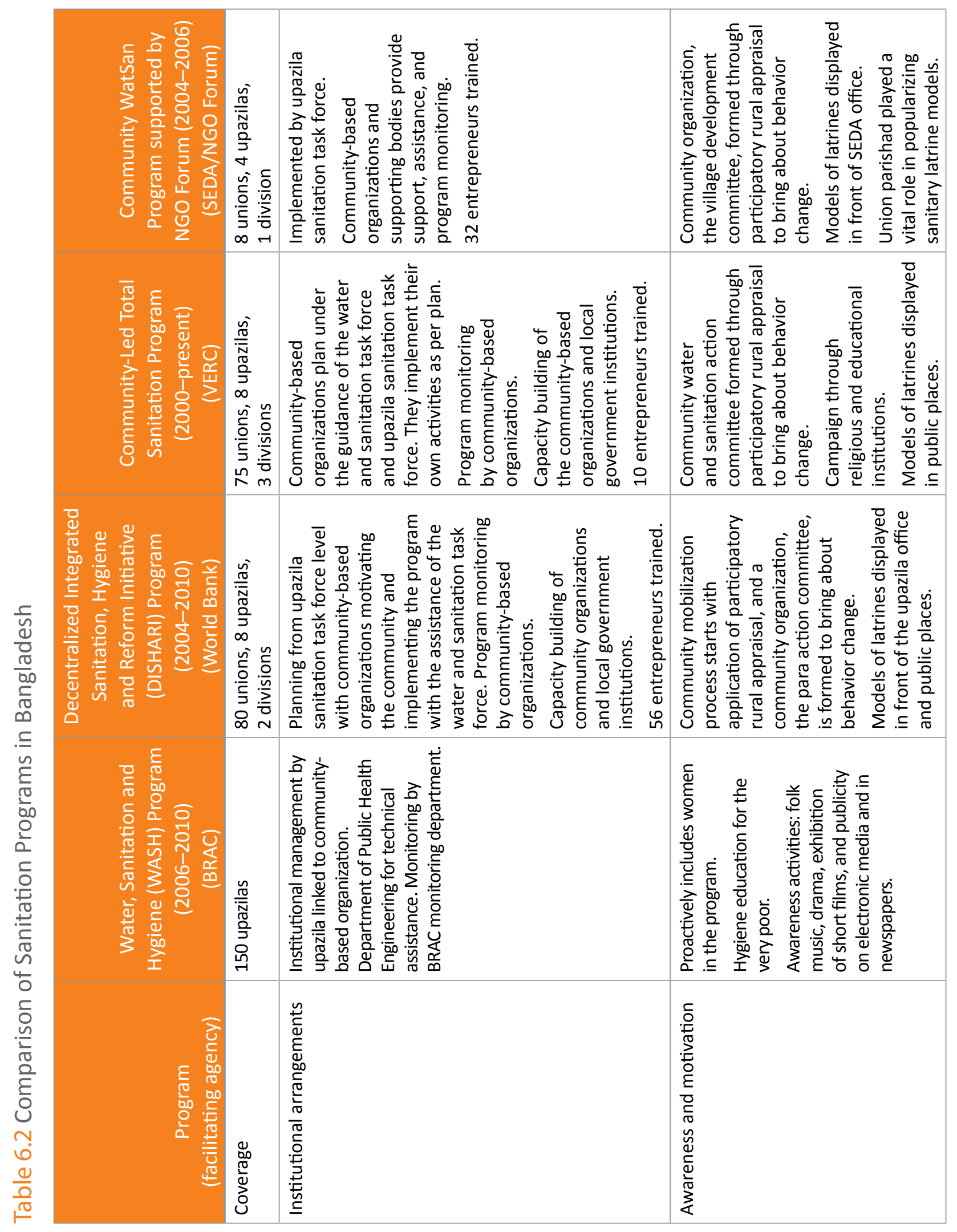




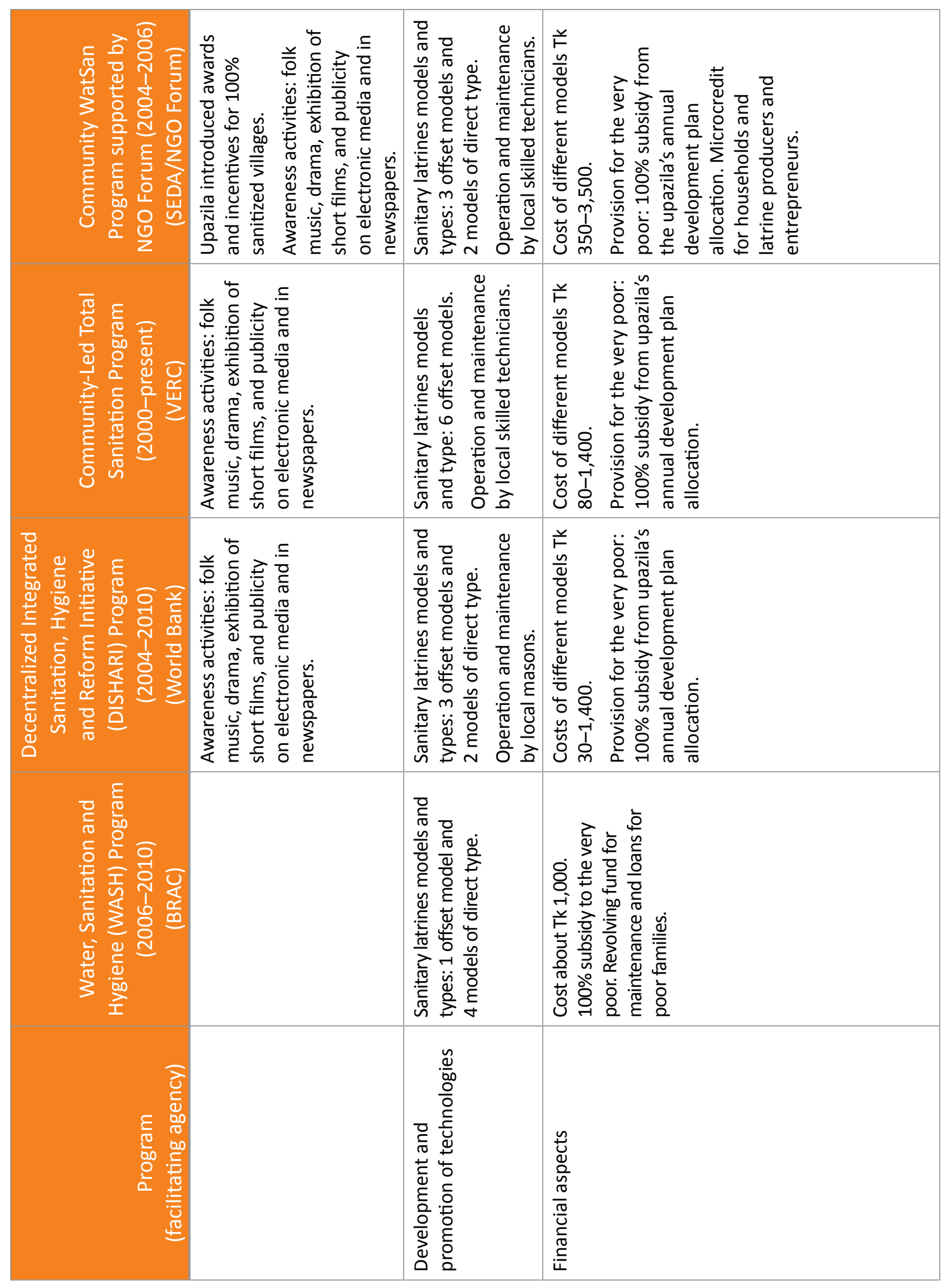


Figure 6.3 Integrated Institutional Setup: Bangladesh Total Sanitation Campaign

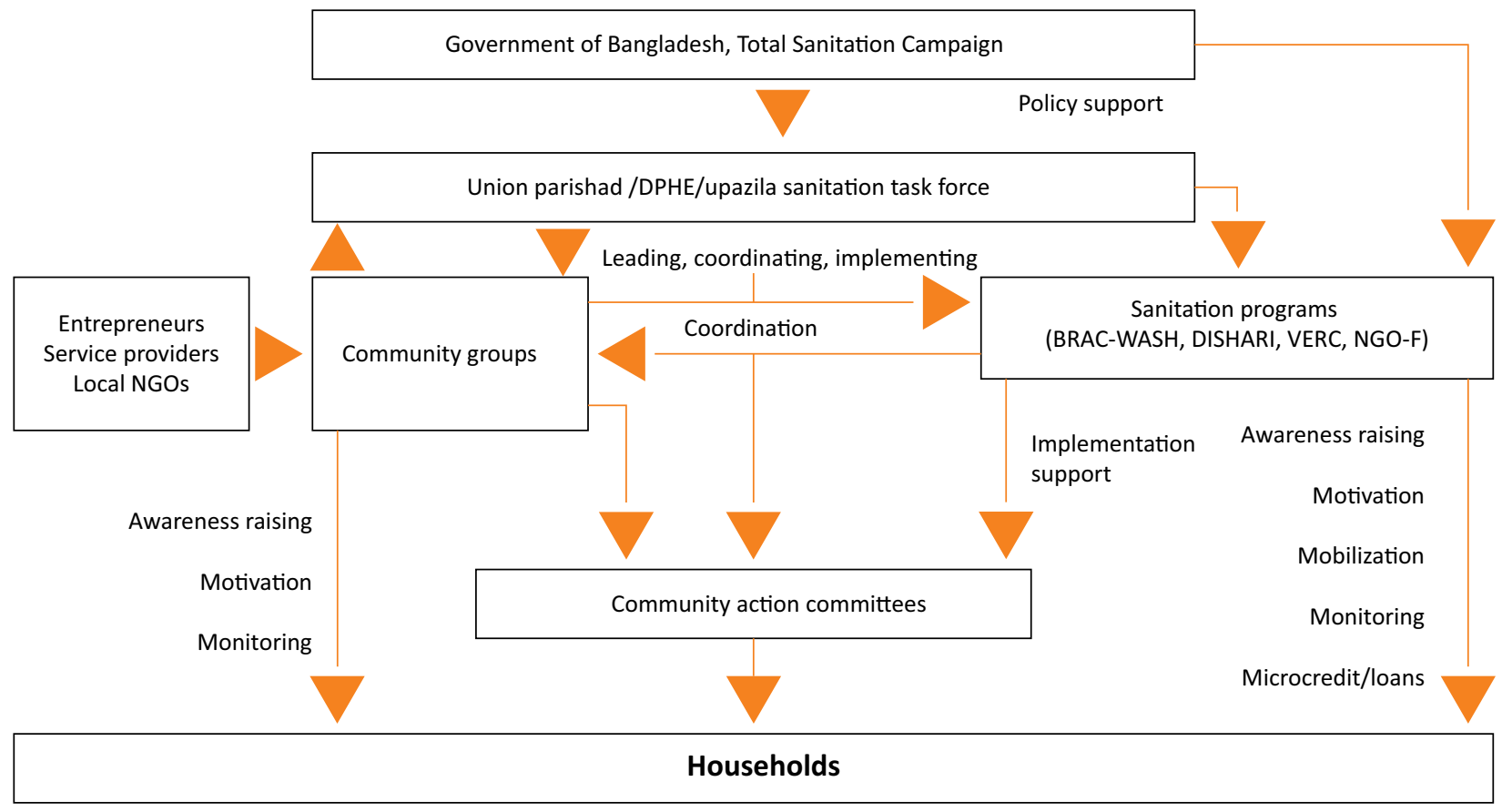

through their community action committees. SEDA/ NGO Forum works with local NGOs, involving village development committees, while VERC's approach focuses on community ignition and participation processes.

Training activities are similar across programs and are principally provided in two broad areas - human skills and technical skills development. Capacity enhancement of facilitating organizations and capacity building of community institutions, stakeholders, and catalysts is provided under the campaign. Capacity-building training on participatory values and facilitation skills is provided for local government staff members. Training and advocacy interventions make stakeholders aware of the issues, resources, and actors; help them explore the potential of building alliances; and clarify their roles and responsibilities. Training is provided to masons on low-cost latrine production to ensure easy access to affordable latrine options.

Participatory monitoring assists proper planning and implementation of activities, and organizational and community monitoring procedures with feedback systems are in place. Monitoring is generally a tri-party arrangement involving the facilitating organizations, local governments, and the community-level committees. The progress of the Total Sanitation Program is monitored from upazila level through the union sanitation task force and ward sanitation task force. The overall national performance and progress across the country are monitored by the National Sanitation Secretariat. The community organizations maintain registers to document the information, decisions, plans, and progress reviews for each activity. The facilitating organization maintains a flow of information up through the hierarchy from community organizations, to ward sanitation task force, to union sanitation task force, to upazila sanitation task force, to district sanitation task force, and finally to the National Sanitation Secretariat.

Strong monitoring teams comprising local community organizations and NGOs regularly monitor the performance of the promoters and adoption trends with regard to sanitary latrine use in program 
areas. Monitoring is done during hygiene education sessions and by the union sanitation task force to ensure quality. The most important feature of the community monitoring system is that the community action committees simultaneously monitor their own progress and impact on health. Local government institution representatives, teachers of educational institutions, members of local clubs, and other locallevel stakeholders are also closely involved in the implementation and monitoring of sanitary latrine use in the communities. The key issues during monitoring are the number of households that installed latrines and whether people are using the installed latrines in a hygienic manner.

\section{Lessons Learnt: Institutional Arrangements}

From the review of institutional arrangements with regard to the Total Sanitation Campaign, the main lessons learnt were as follows:

* Commitment and ownership by the government has been critical for the success of community-led total sanitation. This was achieved by well-planned advocacy work. For instance, awards for unions that had achieved 100 percent sanitation coverage created a strong motivation for local government buy-in.

* Moving from a top-down to an integrated participatory institutional bottom-up approach, where the community plays a key role, is very effective in any largescale development program. Communitybased multilevel participatory monitoring is essential for program success and can become an important tool for motivation.

- Decentralization of administrative roles and actions allows the local government to manage and coordinate financial and administrative tasks effectively, ensuring community-level participation. This means a bigger role for the local government in ensuring (through mobilizing and regulating) that all households under their jurisdiction adopt safe and efficient technologies.

\section{Awareness and Motivation}

\section{Summary of Findings}

Unlike earlier approaches, in the current Total Sanitation Campaign the process of behavior change is initiated without external financial support to households. Behavior change, which has been a key strategic area for sanitation practices, is measured by such indicators as the use of improved sanitation practices, reduced open defecation, safe disposal of child feces, and washing both hands at critical moments.

One of the most noteworthy features of the reviewed programs is the absence of householdlevel subsidy. Community-led total sanitation relies on the participation of every member of the community. The program is based on the precept that communities can arrange cross-subsidies to make sanitation facilities accessible to weaker groups. This is achieved through the formation of self-help groups and linking of funding sources, such as microcredit schemes. However, the approach works only if awareness is created within the communities of the benefits of hygienic practices.

The awareness process consists of ensuring people's participation in all activities, and usually begins by holding an entry participatory rural appraisal session. The union parishad members, as participants of the session, prepare respective ward-level action plans for holding community-level workshops to raise awareness in the community in general and help in the formation of a community water and sanitation committee (Box 6.1).

VERC, SEDA, and DISHARI follow similar strategies for the involvement of village community groups. VERC starts with the community and simultaneously initiates sharing with the upazila 


\section{Box 6.1 Community Engagement Process}

Communities are engaged through a social mapping exercise, developing a map that indicates roads, lanes, crop fields, households, water points, and installed latrines, and the location and hygiene status of institutions (religious and educational). Seasonality trends, incidence of diseases, and availability of water round the year are also determined and assessed through discussions with the community during awareness sessions. Defecation site visits and feces calculations (estimating the huge quantity of human excreta generated at an open defecation site in the community) enable the community to understand their unsanitary living conditions.

A committee is then formed to lead the preparation of detailed plans of action, sharing it with the community for ratification and support, and to endorse the community's direct involvement. Any existing institutions in the community are also brought under the sanitation initiative through discussions with the management committee. Hygiene education is imparted initially by the NGO staff for promotion and monitoring of actions and installations in the community. All its activities are documented for future reference and as a record of progress. Effectively, the community-based organizations are the prime drivers of activities under the Total Sanitation Campaign.

and union sanitation task forces so that any success achieved can be readily shared with upazila and union forums. In the DISHARI program, this initiation process begins by holding workshops with the upazila sanitation task force. SEDA holds orientation sessions making use of the participatory rural appraisal tools. Front-line staff members organize BRAC's sharing sessions.

Ward-level committees conduct awareness-raising activities in the form of folk music, drama, exhibitions of short films, and publicity through electronic media and newspapers, and also organize exposure visits, thematic round table conferences, and workshops. The community mobilization process involves related participatory rural appraisal tools and techniques and includes a transect walk, social mapping, wellbeing ranking, a seasonality trends calendar, an open defecation site visit, feces calculation, flowchart analysis, and drawing up action plans.

To establish gender parity, both men and women are actively involved. The community-based sanitation approach emphasizes active involvement of women in the program process. Women play a pivotal role in the community through the community-based participatory mechanism. They also are involved in the implementation of improvement of behavior practices, cleaning installed latrines, and improving domestic hygiene.

\section{Lessons Learnt: Awareness and Motivation}

From the review of awareness and motivation with regard to the Total Sanitation Campaign, the main lessons learnt were as follows:

- A strong awareness approach that involves active local government-partner linkages with the community as the entry point is very effective in raising awareness.

* The community-led approach empowers and encourages the community to analyze its own environment and sanitary conditions and initiate collective local action to stop open defecation.

* Awareness raising of hygiene practices is at the root of the sanitation program and brings about attitudinal and behavior change, motivating people to adopt latrines.

* The people-centered approach brings credibility to a program and can lead to 100 percent sanitation coverage if it is supported by low-cost technologies.

* Gender parity is an important component of the sanitation program. Giving women active roles provides impetus to the program, as they can effectively impart and activate behavior change and domestic hygiene. 


\section{Development and Promotion of Technologies}

\section{Summary of Findings}

The Total Sanitation Campaign does not advocate a single-model blueprint approach for technology. The traditional approach has been to provide very few technological options, such as the concrete ring slab with water seal. In a move away from this approach whereby a single latrine design is advocated, a wide range of hardware options have been made available and users can choose an appropriate model based on affordability and different socioeconomic and hydrogeological conditions. The VERC program has about 30 options being used by the community. DISHARI is promoting indigenous low-cost options, such as a covered pit latrine and a ventilated offset pit latrine, in order to reach the very poor. The wide range of hardware options include DISHARI's five models of sanitary latrines, VERC's six models, and SEDA/NGO Forum's five models, all of which have been accepted by the community. These sanitary latrines are so designed that all - from the very poor to the rich - can choose in accordance with their economic conditions. Sanitary latrine display centers have been established in program areas to showcase the types and installation costs of each type of latrine. Customers can select and buy sanitary latrines suitable to meet their respective needs from these centers.

Local innovations are actively encouraged to expand the range of options available. Recognizing that the fieldworkers are the front-line staff, the Total Sanitation Campaign helps to form communitybased rural sanitation engineering groups made up of local individuals to develop innovative sanitation technology designs. The campaign facilitates these "engineers" to generate indigenous designs within certain technical parameters. These fieldworkers and village engineers help in the promotion of effective sanitation options by demonstrating models, providing advice, and supporting people during latrine selection and installation. Households hire these engineers for the construction of toilets in their premises. In addition to technological support, the NGOs provide support for setting up village sanitation centers by the local masons, who are trained in good-quality latrine construction.

The services of a number of skilled local technicians and masons, who can make sanitary latrines with locally available raw materials, are available in the program areas. They are skilled enough to build any type of sanitary latrine in the user's premises. The households, in collaboration with the community sanitation committees (which employ cleaners for maintenance), are responsible for operation and maintenance of latrines. The raw materials for making sanitary latrines are indigenous and locally available. Local entrepreneurship has been developed in program areas to produce and sell accessories for sanitary latrines to the communities at reasonable prices.

The field survey showed that householders who initially install lowest-cost latrines typically move

\section{Box 6.2 Moving Up the Sanitation Ladder}

A study by VERC (Saha, Kashem, and Rafi 2006) found that different strata of rural Bangladesh households moved forward on the sanitation ladder from the very low cost sanitation options to the better and more durable options by investing their own resources. A small proportion of the sanitary latrine user households in the study areas - for example around 5-7 percent of families in Manda upazila (VERC) and 10 percent in Sreepur upazila (DISHARI) were found to receive microcredit support for upgrading from different financing organizations (for example BRAC, Grameen Bank, and ASA). The community-led approach and its in-built continuous motivation and mobilization processes motivated people to turn away from open defecation and opt for sanitary latrines to improve their quality of life, adopt better and more sustainable options, and enhance their hygiene behaviors. 


\section{Box 6.3 Financial Mechanism in the National Sanitation Program}

Communities (individual households) invest in hardware installations and their repair and maintenance.

Development partners (such as NGOs) invest in hygiene promotion, mobilization, capacity building, entrepreneurship development, and advocacy.

Government and local government institutions invest in both hardware and hygiene promotion for the very poor as part of their safety net program.

Microcredit facilities are also available for financing the entrepreneurs and for installation of better and more durable sanitation options.

to better and costlier options later (Box 6.2), indicating growing awareness of the benefits of using sanitary latrines. Upgrading in one household often motivates others in the community to follow suit, and has been one of the key reasons behind the success of the sanitary latrine movement in Bangladesh to date.

\section{Lessons Learnt: Development and Promotion of Technologies}

From the review of development and promotion of technologies with regard to the Total Sanitation Campaign, the main lessons learnt were as follows:

* The availability of a wide range of sanitary latrine technologies suited to different socioeconomic and hydrogeological conditions helps reach a greater number of households.

- Promoting indigenous low-cost options, such as covered pit latrine and ventilated offset pit latrine, to reach the very poor plays a major role in achieving better coverage.

* Local innovations in design and the presence of locally available technicians and masons are important factors for acceptance and usage of latrines.

- A strong and effective maintenance approach is essential for continued use of the latrines in a hygienic manner, according to the program.

\section{Financial Aspects}

\section{Summary of Findings}

The government of Bangladesh, particularly at local government level, has a safety net system whereby 20 percent of the annual development plan allocation of the upazila parishads can be used for the very poor, providing them with 100 percent subsidy for sanitary latrines (of the three rings ${ }^{15}$ and one slab type). In addition, the upazilas and unions are awarded a Tk 200,000 block grant for development if they have successfully achieved 100 percent improved sanitation coverage. These awards, presented by the minister in person to local government representatives, have been a major motivational factor for local government, and have inspired unions and upazilas to rapidly scale up and replicate the total sanitation approach. In line with the policies of the government, all reviewed programs allocated financial support to the very poor households to install slab latrines. Box 6.3 lists the financial mechanisms in the Bangladesh sanitation program and Table 6.3 presents the funds available to union parishads for sanitation.

Six types of sanitary latrine models have been developed in the program areas, according to the affordability of the community (Table 6.4). The highest price of the sanitary latrine is Tk 3,500 and the lowest is Tk 30. While SEDA/NGO Forum's

15 A ring is a part of a latrine used to make a tank or protect the pit where the excreta are being deposited. 


\section{Table 6.3 Sources of Funds in Union Parishads for Achieving Total Sanitation}

\begin{tabular}{|c|c|}
\hline Source of fund & Type/amount \\
\hline $\begin{array}{l}\text { Allocation from annual development } \\
\text { plan }\end{array}$ & $\begin{array}{l}20 \% \text { of annual development plan, of which } 75 \% \text { will be used for hardware } \\
\text { and } 25 \% \text { for hygiene promotion. }\end{array}$ \\
\hline Block allocation (lump sum) & $\begin{array}{l}\text { Some union parishads have a special block allocation in their annual } \\
\text { development plan apart from } 20 \% \text { for sanitation coverage. They keep this } \\
\text { block allocation while they formulate the annual development plan. }\end{array}$ \\
\hline Gram sarkar allocation & $\begin{array}{l}\text { After reformation of gram sarkars, the Local Government Division } \\
\text { allocated funds (Tk 5,000) to each gram sarkar for increased sanitation } \\
\text { coverage. The gram sarkar was headed by the union parishad ward } \\
\text { member, who was also head of the ward sanitation task force. }\end{array}$ \\
\hline $\begin{array}{l}\text { Department of Public Health } \\
\text { Engineering }\end{array}$ & $\begin{array}{l}\text { The Department of Public Health Engineering also distributes latrines } \\
\text { through union parishads under the National Sanitation Program. }\end{array}$ \\
\hline Union parishad's own fund & $\begin{array}{l}\text { The union parishads have their own revenue income from different } \\
\text { sources (including taxation). In order to achieve } 100 \% \text { sanitation coverage } \\
\text { by } 2010 \text {, the government of Bangladesh suggested that union parishads } \\
\text { spend } 1 \% \text { of their total income on sanitation. }\end{array}$ \\
\hline $\begin{array}{l}\text { Prize money (block grant from Local } \\
\text { Government Division, Ministry } \\
\text { of Local Government, Rural } \\
\text { Development and Cooperatives) }\end{array}$ & $\begin{array}{l}\text { Prize money is awarded as a block grant from the Ministry to union } \\
\text { parishads who achieve } 100 \% \text { coverage. }\end{array}$ \\
\hline
\end{tabular}

Source: VERC 2007.

\section{Table 6.4 Types of Sanitary Latrines Developed by DISHARI, VERC, SEDA/NGO Forum}

\begin{tabular}{|c|c|c|c|}
\hline \multirow{3}{*}{ Type of sanitary latrine } & \multicolumn{3}{|c|}{ Installation cost (taka) } \\
\hline & & & SEDA/NGO \\
\hline & DISHARI & VERC & Forum \\
\hline Sanitary latrine with 10 rings for soak pit, 1 slab, 1 ring (offset type) & & & 3,500 \\
\hline Sanitary latrine with 5 rings for soak pit, 1 slab, 1 ring (offset type) & & & 1,500 \\
\hline Sanitary latrine with 5 rings for soak pit, 1 slab, 1 ring (offset type) & $1,000-1,400$ & & \\
\hline Sanitary latrine with 5 rings for soak pit, 1 slab, 1 ring (offset type) & & $1,200-1,400$ & \\
\hline Sanitary latrine with 3 rings for soak pit, 1 slab, 1 ring (offset type) & & $700-800$ & \\
\hline Sanitary latrine with 3 rings for soak pit, 1 slab, 1 ring (offset type) & $500-700$ & & \\
\hline Hygienic pit sanitary latrine (direct) & 320 & & $600-800$ \\
\hline Plastic pan latrine with siphon (offset) & & 300 & \\
\hline Plastic vent pipe model with bend pipe, I plastic pan (offset) & & 300 & \\
\hline Plastic pan pit latrine with vent pipe: local materials (offset) & & 140 & \\
\hline Hygienic pit latrine: local materials (direct pit) & 90 & & 350 \\
\hline Motka model pit latrine with vent pipe: local materials (offset) & & 80 & \\
\hline Extreme low-cost hygienic pit latrine: local materials (direct pit) & 30 & & \\
\hline
\end{tabular}


lowest-priced latrine (Tk 350) may be sustainable it is costly for the poor. The lowest-priced DISHARI (Tk 30) and VERC (Tk 80) options are the only latrines affordable to a wider range of households. In the BRAC program, very poor households received Tk 1,000 as subsidy. The remaining sum of approximately Tk 500 was contributed by the households in the form of labor and other related costs. SEDA has also designed two models for richer households - a sanitary latrine with septic tank, and a sanitary latrine (offset) with a soak pit of 10 rings - which cost Tk 40,000 and Tk 3,500, respectively.

A small percentage of the sanitary latrine user households in the study areas were found to have received microcredit support (around 5-7 percent families under the VERC program, 10 percent under DISHARI, and 20 percent under SEDA). BRAC has provided interest-free loans to local entrepreneurs who produced 350,000 slab latrines.

Entrepreneur development is key to the sanitation program and entrepreneurs are considered both as small-scale production units and catalysts that ignite communities to install sanitary latrines. A total of 56 entrepreneurs were trained in Sreepur upazila under DISHARI alone, of which 45 were found to be marketing their products. The remaining 11 were working as masons undertaking installation and repair of sanitary latrines. VERC trained 10 persons as entrepreneurs and all of them are operating their businesses in Manda upazila. Apart from these, 25 private latrine producers who are doing active business in this field see this as an opportunity for a secondary source of income. SEDA trained
32 persons as entrepreneurs in Shibalaya upazila and 24 of them were found to be active in their businesses. The sanitation program promotes private sector involvement in service delivery by providing interest-free loans of Tk 10,000 to local entrepreneurs for manufacturing slabs and rings. Table 6.5 presents the sources of finance available to entrepreneurs. The table shows a high prevalence of self-financed entrepreneurs; the others received financial support from BRAC, Grameen Bank, VERC, SEDA, and other sources, which provided them with seed money, or the initial working capital to establish products and services.

\section{Lessons Learnt: Financial Aspects}

From the review of financial aspects with regard to the Total Sanitation Campaign, the main lessons learnt were as follows:

* A specifically targeted program that captures the needs of the very poor can encourage acceptance of the program, thereby helping attain goals in hygiene practice and sanitation. Government grants and allocations made available for the very poor and as incentives for local government institutions assist in improving outreach and program implementation.

* A wide range of hardware options, suiting both the poorer and richer households, is crucial for achieving 100 percent program coverage.

* A strong entrepreneur development component increases availability of products and services, making it easier for households

\section{Table 6.5 Source of Funds for Entrepreneurs in the Study Area}

\begin{tabular}{|l|r|r|r|}
\multicolumn{1}{c|}{ Source of finance } & Sreepur (\%) & Manda (\%) & Shibalaya (\%) \\
\hline Microfinancing institutions & 15 & 24 & 29 \\
\hline Self-financed & 85 & 76 & 71 \\
\hline Total & $100 \%(45)$ & $100 \%(33)$ & $100 \%(24)$ \\
\hline
\end{tabular}

Note: Figures in parentheses are the total numbers of active entrepreneurs. 
to install latrines, providing impetus to the program. Provision of microcredit support and interest-free loans to local entrepreneurs are important to the sustainability of the program.

\section{Conclusions}

Until the late 1990s sanitation in Bangladesh was poor, with no proper latrines and widespread open defecation. Programs during this period were supply driven and users were not willing to pay for high-cost latrines. Moreover, most of the NGOs implemented small-scale sanitation projects that made little impact. From 2003 onwards, successful advocacy led to government ownership, and the sanitation initiative gained momentum. In the first five years of the Total Sanitation Campaign the uptake of sanitary latrines increased from 20 percent to 80 percent, and now more than 90 million people have access to and use latrines. Presently, although diverse sanitation programs are in place in Bangladesh, they have converged under the Total Sanitation Campaign of the government, which aims to achieve 100 percent sanitation coverage by 2010 . The Total Sanitation Campaign is successful as it inspires communities to undertake sanitation programs using their own initiative and resources for their own good, with support from NGOs and local government institutions.

One of the most important aspects of the sanitation program in Bangladesh is the massive policy thrust it receives from the Bangladesh government. The political commitment was so strong that the Minister and the Secretary of the Local Government Division personally traveled extensively across the country to motivate local government representatives and government officials. This was the key driving force and led to harmonization of activities at various levels, from the national and local government to the community. The greatest success has been bridging of the gap between the policy makers and the households by equally integrating community organizations, NGOs, partners, and local government administration. Decentralization of financial and administrative activities further added to the motivation of unions.

The other main aspect is active community participation, with success achieved through meaningful leadership, coordination, motivation, and mobilization of the community by the community. The onus of the program is on the community, providing it with ownership and therefore motivation. The premise that to achieve the sanitation coverage target communities have to be at the center of planning and implementation of the sanitation programs, as advocated by the National Policy for Safe Water Supply and Sanitation (1998), has been vindicated. Following the policy, the government has put its efforts into institutionalization of community participation through building water and sanitation committees at the ward, union parishad, upazila, and district levels, which has also helped towards ensuring transparency and accountability.

Another major reason for the success of the Total Sanitation Campaign, especially with regard to the access gained by the poor, was the switch in emphasis by the government and NGOs from the promotion of toilets (which are rival and excludable) to the promotion of an open defecation-free environment (which is nonrival and nonexcludable). The sanitation program focuses on poor households and the emphasis is on educating the communities that hygiene practices are a basic need. Increased awareness of the benefits is achieved through a multipronged approach that targets households, teachers, students, and community groups, and reinforces messages through the media.

The sanitation program could not have progressed on community motivation and integrated approaches were it not for the availability of a wide range of low-cost sanitation hardware affordable to the 
very poor. The presence of a strong entrepreneur force furthered the commercialized approach and sanitation products were readily available locally. Providing subsidies to households was not considered as a means for disseminating latrines in the sanitation program. Instead, the program employed the approach of applying community-level peer pressure to encourage sustained motivational change and adoption of hygienic practices.

Thus, the total sanitation program achieved success mainly through transforming government, partner, and community actions into a participatory social movement. The future cookstove program should follow the same path, with the government's role being primarily to ensure that no one is exposed to unsafe (and inefficient) fuel use while cooking, and secondarily to promote, regulate, and license the marketing of fuel-efficient stoves to enable households to choose options that suit their means. The government may also need to target subsidies at carefully identified poor groups, or even provide some stoves free of cost. With the massive policy thrust that it is set to receive from the new Renewable Energy Policy (2009), the future cookstove program can:

- Create an integrated enabling environment for a policy thrust with facilitative roles for the various partners;

- Ensure effective communication for followup, monitoring, and feedback;

* Maximize the use of available resources (natural and human talent, skills, concepts);

* Create market opportunities and business models;

- Develop a wide range of models and finance options affordable even to the very poor;

* Empower people with technical and decisionmaking skills;

- Above all, propel mass mobilization through behavior change. 


\section{Summary and Recommendations}

angladesh is a country with widespread problems involving household biomass energy. Due to the scarcity and high cost of firewood, over one half of its rural population is dependent on leaves, grass, or dung for household cooking (Asaduzzaman, Barnes, and Khandakar 2007). In addition, well over 90 percent of Bangladesh's rural population is involved in some kind of fuel collection, and this is particularly true for women and children. The amount of time spent collecting fuel alone consumes over 150 hours of family labor, which is close to 20 days per year. In addition, the adverse health impacts of consuming biomass fuels in the traditional stoves that are being used in Bangladesh are just beginning to be understood. WHO (2007) estimated that 3 percent of the national burden of disease could be attributed to using solid fuels for cooking, and most of those deaths were caused by respiratory illnesses.

There are several ways to address these household energy problems. One way is to promote the substitution of cleaner fuels, such as kerosene and liquid petroleum gas, for cooking in rural areas. It is highly recommended to make these fuels more available for purchase in rural areas, but they are costly and the development of markets and income to afford them will take a long time. An alternative is to promote the adoption by people dependent on biomass fuels of new types of stoves that are both more efficient and reduce indoor air pollution. There are existing programs in Bangladesh that have been described in this study, but they have generally been on a very small scale and have not always been successful. The existing programs need to be supported, but a way forward is needed that expands their scope to make a real difference to the people depending on biomass for their household energy needs in Bangladesh.

The goal of this study has been to explore options for improving cookstoves in Bangladesh through an evaluation of existing programs, the international experience on improved stoves, and the lessons from successful interventions of the sanitation sector. After all, one of Bangladesh's greatest development successes has been to achieve near total sanitation. The lessons from the Total Sanitation Campaign and other successful improved cookstove approaches employed around the world provide insights for making recommendations for improved stoves in Bangladesh. There are two ways lessons from these programs might be incorporated to improve the promotion of improved stoves in Bangladesh. The first is to examine the characteristics of successful programs as they apply to Bangladesh. The second involves how to move forward in order to achieve the success found in the total sanitation program 
and from other programs around the world. Thus, in the next section, the characteristics that are necessary to have a successful program on improved stoves are examined.

\section{Status of Improved Stoves in Bangladesh}

The improved stove programs in Bangladesh today are small and quite active. There have been many different donors and NGOs involved over the years, and the primary goal, common to many other worldwide programs, has been to reach the poorest households. As a result, the programs have been somewhat trapped in what has been described as the production and sale of low-cost artisan stoves. In addition, the programs are sometimes very output oriented due to the limited amount of financing available and the short time period for implementing them. On the positive side, these stoves at least initially do reduce fuel consumption and thus lead to lower indoor air pollution for families that use them. However, there are also problems with this approach. These stoves need to be replaced or rebuilt almost yearly, and therefore require an extraordinary amount of after-sales support to succeed. This study also has found that consumers are still dissatisfied with the stoves and even modify them to meet their cooking needs. This is not to say that there is no place for a lowcost stove in an overall program, but there needs to be a greater diversity of offerings.

Historically, a wide variety of institutions has been involved in improved stoves in Bangladesh. This is not a problem in itself, but it means that the various aspects of the program can be fragmented. Donors and NGOs have gone in different directions with little learning from mistakes or successful approaches. Some programs stressed the promotion of particular stoves while others concentrated on training or entrepreneur development. There is room for a variety of actors involving improved stoves, but it appears from historical evidence there is a need for greater coordination of efforts if a scaled-up program on improved cookstoves is to be considered. Government agencies are not all equipped to effectively coordinate institutionally complex programs, though the experience of community-led total sanitation illustrates that it is vital to involve them and build their capacity. In addition, the success in sanitation highlights the need for a willingness to learn from other sectors, and to transfer monitoring, financing, licensing, and promotional skills between NGOs and even ministries and departments. Organizations such as IDCOL are well placed to embrace the multisectoral dimensions of improved cookstoves.

Two nonstove programs that have done very well in Bangladesh are the IDCOL household photovoltaic program and the sanitation program. The IDCOL institutional model does not dictate solutions to its working partners, but rather insists on good financing, quality controls, mature technologies, and reliable partners for implementation. In contrast, the sanitation program seems to work well because of the development of a variety of choices for communities, who also have been influential in the implementation of the program.

For issues that are important for stove programs, two matters still seem to be somewhat unresolved. One notable problem in Bangladesh is that there are standards for indoor air pollution or general pollution levels, but there is no institution responsible for testing stoves to determine if they actually perform as claimed by those promoting them. Claims of efficiency, pollution reduction, and durability often are not actually tested by objective, outside groups. In addition, there is no level playing field for subsidies for improved stoves, as the level of subsidy is dependent on the organization promoting the stoves. These problems are not insurmountable, and the next section deals with some of the practices that have contributed to the success of improved stove programs both in Bangladesh and around the world. 


\section{Lessons from Successful Programs}

Key characteristics of successful programs reviewed include strong policy support and participation by a wide group of actors, including community-based organizations, NGOs, private entrepreneurs, local government institutions, and microfinance providers. Trademarks of these programs are that they are not one-dimensional. The programs often touch on such issues as demand generation, entrepreneur development, training, maintenance, and monitoring and evaluation to establish a market-based approach for improved stoves. Generally, programs that pay little attention to developing markets for improved stoves can be successful in the near term, but their long-term impact is constrained. However, it also must be realized that addressing the needs of the poorest households is quite challenging and may require special approaches other than exclusively following a market development approach.

This section details the factors that might be necessary for establishing a cookstove program in Bangladesh. Four areas were considered in examining the successful approaches of other programs:

- Institutional arrangements: having proper institutions to facilitate the program;

- Awareness and motivation: national strategies for developing awareness to problems associated with cooking on traditional stoves;

- Development and promotion of technologies: solving the technological challenges of developing stoves that work well under local conditions;

* Financial aspects: ensuring that the groups promoting interventions are not totally dependent on grant financing and practice financially sound business models.

These lessons are derived from a combination of the programs reviewed in this study and also from a recent study of the difficulties encountered in the improved stove programs in India (Barnes, Kumar, and Openshaw 2009).

\section{Institutional Arrangements}

The programs that have been successful have generally had the support of their governments. For instance, in China the rural energy agency in the Ministry of Agriculture was the champion for the improved stove program. In Guatemala, the program was implemented through a government agency to promote social investments funds. Thus, to facilitate program development and address the weaknesses encountered in existing programs, there needs to be a champion for the improved cookstove program both at national and subnational levels, as was the case for the sanitation program in Bangladesh. An integrated institutional arrangement that features central government, NGOs, community organizations, and the private sector would contribute to the success of a program on improved stoves. It is true that some international agencies or NGOs have programs that have only had marginal support from the government, but those programs are often isolated and dependent on grant funds for continued success.

One possible approach may be to integrate the promotion of improved stoves into the clean households program that has been successfully implemented by the sanitation programs. The reason is that a considerable social and institutional network has been set up to develop sanitation benefit awareness, including sanitation committees and other community organizations. This base may possibly be utilized for improved cookstove programs at only incremental effort by expanding the message of sanitation to comprehensive household health. However, it is sometimes difficult to promote crosssectoral programs through government agencies.

Training and capacity building are essential components of most successful cookstove programs. Training can be provided to entrepreneurs, 
program staff, community-based organizations, and end users (especially women) in technology, design, maintenance, and troubleshooting. In order to increase the dissemination of improved household energy technologies and acceptance by users, programs must develop strategies to provide adequate user training and after-sales service. Such a user-training component should lay particular emphasis on women. However, as indicated by the USAID/Winrock program in which training was a key feature, it is important to have a solid foundation for the training. Many of the other successful program elements need to be in place before training can be effective.

Today any program that uses carbon finance must have well-established monitoring and evaluation procedures because emission reductions must be quantified in a standard manner. Thus, in order to monitor the progress of improved stoves, it would be necessary to develop standards and ways to measure performance and whether stoves meet them. This implies that there would need to be an institution to oversee such standards, quality control, testing, and validation. A monitoring and evaluation program should focus on the effectiveness of the new stoves offered to the public and should evaluate whether or not they adhere to established formal or informal standards. Thus, the quality and durability of improved cookstoves and chimneys need to be evaluated to determine whether stoves actually improve efficiency, reduce emissions, and improve indoor air quality. The cookstoves should be tested both in laboratories and in the field. The former is usually employed early on during product development, while infield investigation is invaluable for understanding the effectiveness of technologies.

\section{Awareness and Motivation}

Discussions with consumers typically indicate that they are not aware of the substantial benefits of improved stoves. They are often familiar with the fact that smoke removal leads to less burning of eyes and cleaner pots, but they rarely associate this with long-term health benefits. Bringing about behavior change by increasing awareness of health issues and the benefits of improved cookstoves could help create a demand approach to improved stoves. Thus, one should not underestimate the importance of raising awareness of long-term benefits, such as better health and avoided death, resulting from reduction in indoor air pollution due to the use of improved cookstoves.

Communities should be made aware of other benefits, such as time savings due to faster cooking, enhancement of soil fertility by returning the crop residues saved to the field, and, as a whole, the development of the rural economy and improvement in the living conditions of communities. If people are aware of all these benefits, the willingness to pay for and the acceptance level of improved cookstoves is likely to improve considerably. As indoor air pollution is an issue that inherently involves women and household-level cooking needs, it is very important to design programs where women have an equal voice as users, technicians, and entrepreneurs. This consideration needs to be included in the program design process and may require getting feedback from potential women beneficiaries. One mechanism by which such awareness raising could be made possible is through existing village-level institutions, such as women's credit groups or water and sanitation committees. This may be particularly beneficial in light of evidence that tackling multiple health and hygiene issues simultaneously can be effective, and that there is a close connection between hygiene practices, such as handwashing, and acute respiratory infection.

The one caveat to raising awareness of the benefits of improved stoves is that the new stoves or products must be effective in removing indoor air pollution and reducing fuel consumption. In this regard, the monitoring of stoves in actual use by households for a significant period of time and having quality products available in the marketplace are essential before embarking on a publicity campaign. 


\section{Development and Promotion of Technologies}

Successful programs should have the right technical design for improved stoves. One lesson from the Bangladesh sanitation program is that it is better to have a variety of designs that are appropriate for different social groups. Although it is important to have inexpensive, locally made stove designs affordable by low-income groups, this is not always the right strategy for everyone. The main advantage of locally made cookstoves is that they are less costly, but as indicated in the GTZ program such stoves need regular maintenance and support, which has not been a strong point in most programs. The supply of grates and chimneys was problematic in many places.

The improved stove programs in Bangladesh have been mainly centered around the artisan stoves due to their low cost, but there are new alternatives that should be considered. There is no reason to abandon efforts to promote affordable stoves, but as indicated in the sanitation program there is also a need for a greater variety of choices. This was also true in China where the program quickly moved from the promotion of artisan stoves to assembly using manufactured parts. Today some stoves are manufactured in small factories. Because they require minimal installation they can be made available through local retail stores. There are other types currently being developed, such as the gasifier stoves, which have higher energy efficiency and are quite clean. Off-the-shelf availability of improved cookstoves would reduce delivery time and maintenance requirements, as such items are sturdier and of higher quality than the artisan stove.

Regardless of the technology of the stove, encouraging community participation in design, implementation, and monitoring of stoves will help increase ownership, ensuring sustainability. Stove designs should be based on cooking needs. In addition to the typical laboratory evaluations of stoves, it is important to include householdlevel research to assist with designs of improved stoves, making them more user friendly. Many insights, such as the development of stoves that can accommodate different-sized pots and maintain efficiency over a number of years without too much care and maintenance, can be gained by consulting with women, who use stoves every day.

The proper use and maintenance of stoves is important to maintaining the efficiency of the stoves. The surveys indicate that changing the dimensions of improved stoves is quite common, and this is likely to lead to reductions in efficiency. Improved cookstove users should be discouraged from changing dimensions and designs on their own. Awareness programs are necessary to highlight the negative impacts such changes have on the efficiency and indoor air pollution reduction of the stoves and the life of the components. User training may also make the improved cookstoves partially, if not fully, self-sufficient in respect of maintenance. Maintenance at a reasonable cost is crucial for sustainable use of improved cookstoves. In fact, a good user manual combined with a durable stove may be an effective way to ensure that stoves are maintained at a high level of performance.

Carbon-financed stove programs differ from many others in that there is implicitly a stronger focus on sustainability, because the award of credits depends on sustained use of the stove over many years. Therefore, in addition to rigorous frequent monitoring requirements, most projects need to make explicit provision for regular examination and maintenance of stoves. This helps to ensure that stoves continue to perform well in terms of fuel savings and emission reductions, and satisfy user needs. Some carbon-financed stove projects are considering making a provision to fund annual maintenance of stoves, mindful of the fact that performance can change over time without, for example, ensuring that grates remain in place and chimneys remain clear. Although it can be difficult and costly to incorporate such rigorous monitoring 
requirements into donor-funded programs, this level of follow-up is often required, and its absence is responsible for the failure of many government and NGO interventions. This degree of monitoring and technical assistance requires a specific budget line, a skilled team, and careful organization.

\section{Financial Aspects}

The type of subsidies and means of financing improved cookstove, renewable energy, or sanitation programs is covered in detail in this report. However, the issue of subsidy justification is generally not addressed in most reviewed studies. Subsidy justification is important because in this program review, subsidies have both encouraged success and sometimes led to failure of some programs. In fact, one shortcoming of many improved cookstove programs worldwide is that the organizations promoting the stoves often implement them based on some form of subsidy or grant given by an international donor or government organization. Therefore, the stoves are available mainly through specialized programs and are not available in the market. This in turn limits the expansion of the program and has often resulted in the promotion of a single stove deemed appropriate by the financing organization as opposed to that demanded by the public for whom the programs are intended. Thus, the level and type of subsidy for improved cookstove programs can have a significant impact on the success of the program, and therefore this issue warrants further elaboration.

Some programs have experienced problems because of an overreliance on subsidies. Despite laudable program objectives, subsidies have often failed to meet their stated goal of making services more affordable to the poorest families or households. It is no coincidence that in developing countries the populations with access to high-quality energy services are the middle- and upper-income households. Even well-intended infrastructure subsidy programs can have problems (Barnes and Halpern 2000). Subsidies have often been implicit, such as default or nonpayment of loans. They have also been poorly targeted, such as the kerosene subsidies in Indonesia some years ago. In Indonesia kerosene prices were kept well below the international price because the country was rich in petroleum resources. However, this meant that higher-income households who could readily afford to pay for the fuel benefited more from the subsidy than lower-income households who often still cooked with biomass energy. Another characteristic of subsidies is that they have been indiscriminate, such as a subsidy for a quantity that is well above that needed by the poor or rural populations. Finally, many subsidies become complex or difficult to administer to targeted groups, and overly restrictive with respect to end use or technology, depriving users of choices.

The effective programs in this study can generally be considered as being based on good subsidy policies. Of course, some countries have performed better than others, but generally all have achieved some success in relation to subsidy policies. It is difficult to evaluate good versus poor subsidy policies as it is not a one-dimensional issue. According to most subsidy theories, several criteria need to be reviewed to evaluate whether a subsidy is justified or not, including program efficiency, equity, and effectiveness (World Bank 2002), and these are applied below to promoting improved cookstoves in Bangladesh.

Program efficiency. Efficiency refers to maximizing the social or economic benefits under the assumption that even the best energy projects have an opportunity cost, raising the question: Is it an efficient investment for society? For this, the economic rate of return needs to be calculated. For most improved cookstove projects, the economic rate of return is positive and can be quite high. A recent study of the global benefits of improving cooking practices in developing countries indicates that the benefits include health improvement, time savings, and environmental benefits, such as avoided deforestation and carbon emissions. 
The costs involve both the retail cost of improved cookstoves and the various aspects necessary to promote them if not done by a single company. For improved cookstoves WHO (2006) found the benefit-cost ratio, including all economic benefits, to be about 50; so it is a highly desirable program. Even if some of the benefits of such programs were overestimated, the programs could have significant economic benefits for countries such as Bangladesh (Box 7.1).

Because improved cookstoves require less fuel, this reduces the time spent in collecting biomass fuels or the money spent on purchasing them. An improved cookstove saves about 25 percent of fuel and collection time, representing significant annual savings. It is important to remember that the payoff period for improved cookstoves is fairly short, and thus good stoves should be attractive for purchase without a subsidy. However, the research, promotion, and development costs of stoves may be prohibitive for many entrepreneurs or microfinance organizations. In addition, the very poor may find it difficult to pay for an improved cookstove. Consequently, innovative approaches that will enhance markets are required to make stoves affordable to the very poor. Finally, the development of a variety of improved cookstoves

\section{Box 7.1 Conclusions of the WHO Cost-Benefit Evaluation for Household Energy and Health Interventions}

Investments in household energy and health interventions are potentially cost-beneficial and in some cases cost saving from both an economic and financial point of view. A recent WHO study evaluated both the costs and benefits of household energy programs, including improved stoves and fuel substitution. The benefits for stoves and the use of cleaner fuels were quantified by examining reduced health costs for reduction of disease, workdays saved through not contracting illnesses, reduction of costs in purchased fuel, avoided fuel collection costs due to greater efficiency of stoves, and the value of reduced fuel collection pressure on the environment.

The study concluded that improved cookstoves led to the greatest overall benefit to society. This holds true particularly in urban settings where the majority of the population already pays for fuel. From an economic standpoint, making improved cookstoves available by 2015 to half of those still burning biomass fuels in traditional stoves in 2005 would result in a cost of US\$ 34 billion per year, and generate an economic return of US\$ 105 billion per year.

The majority of costs accounted for related to fuels and stove purchase, and to a lesser extent program costs traditionally paid for by governments and donors. The economic benefits for improved cookstoves are dominated by time savings resulting from reduced fuel collection and cooking time, in excess of 70 percent for each WHO region. In some regions, avoided illness was also significant, as a local and global environmental benefit. Savings in health care were quite small and accounted for just 0.1 percent of the total economic benefits. This is because despite the significant impact of indoor air pollution on human illness among children and older adults, the illness rates are low in the main population.

Thus, for a household the main benefits perceived include any cost savings for purchased fuels and avoided labor costs for collecting biomass energy. Without significant publicity of such issues, the relationship between indoor air pollution and the long-term health costs, along with the illnesses among children, is invisible to the general public. People are aware of burning of the eyes and an uncomfortable feeling when breathing smoke from fires in households, but they are not cognizant of the long-term impact that smoke has for them and their families. In addition, they probably undervalue the avoided labor costs of fuel collection, which often comprises small amounts of time spread over a week. These are issues that should be dealt with through consumer education on the benefits of improved biomass stoves or promotion of modern cooking fuels such as liquid petroleum gas.

Source: WHO 2006. 
at different price levels, as was done for latrines in the sanitation program, may also be effective in promoting marketability.

A complicating factor is that except for households that purchase fuels for cooking, the benefits of improved cookstoves are often not in immediate cash benefits, which can distort the incentives for purchasing them. The saved labor is reflected as the opportunity cost of time valued at local agricultural wage rates. The health costs are often avoided only years in the future. The advantages of avoiding deforestation only indirectly benefits local people and are more of a national or regional gain. Thus, except for households that purchase biomass fuels, many of the economic benefits are distant from everyday life, even though they are important.

Equity. In addition to evaluating economic returns, the equity of programs is also a consideration for choosing programs that may qualify for subsidies. Equity refers to the efficacy of the subsidy. In other words, do the subsidies actually reach poor people who are reliant on biofuels for their everyday cooking and do they have an impact on improving welfare? This brings up the issue of affordability and program design.

Many improved cookstove programs have been so concerned with equity issues that they have actually caused problems in program effectiveness, as in Bangladesh. To make improved cookstoves more accessible and acceptable to the poor many projects have subsidized all phases of stove development and dissemination. This has proved problematic for sustainability and therefore affected the overall impact of the programs. The idea was to develop stoves for the poorest of the poor, so that programs were well targeted, but unfortunately this meant the development of very cheap stoves that break down frequently and often do not perform as advertised. While these small interventions based on grant financing have had some success, they did not result in wide-scale adoption of improved cookstoves. The lesson is that sometimes an overconcern for equity leads to ineffective programs.

Before turning to program effectiveness, two different approaches to subsidies, which are identified in the best-practice work on adoption of improved cookstoves, will be reviewed. One approach is to promote the development of marketing for a wide variety of stoves and provide modest subsidies to make the stoves more affordable. Poor people do have money and are willing to pay for quality stoves. This is similar to the situation with photovoltaic lighting systems in which subsidies of 20 percent, along with affordable credit, are given to households for purchasing systems that cost U\$ 200 (Tk 13,700) or more. High-quality improved cookstoves are likely to cost US\$30-50, and thus in the initial stage of market development there could be modest subsidies that actually encourage the development and marketing of new varieties of stoves.

Another approach to address the equity issue, which can complement the modest product subsidy and market support approach, is to make high-quality improved cookstoves an option for community development programs. Programs such as the one that was successful in Guatemala offered fairly expensive improved biomass stoves as one option among many different development alternatives that included improving roads, schools, or other infrastructure. These stoves are very durable, last many years, and are raised off the ground to make them more convenient to use. Because the program was not directed at the poorest of the poor, the stove option was very attractive to those communities. In such a situation, the community has a choice of programs, so the stove alternative has to be a desirable option or product. This means that the stove developers would have to produce a product that meets the needs of people cooking with all forms of biomass energy. This type of program is extremely equitable, because generally everyone in the community would receive the stove. Although some people in the community could afford to pay for the stove, which means that some of the 
targeting of the program is inefficient, it is actually those influential in the village that make decisions on the selection of various development options. The stove is disseminated to all in the community, so in a sense there is a cross-subsidy between the more influential households and the poor because of the requirement that the community grants be equally applied to all in the community.

Properly targeted subsidies are fundamental to the sustainability of cookstove programs. Subsidies often create a mindset of subsidy dependence among households. Cash income obviously is scarce among households using biomass fuels, and they are often willing to wait for subsidized stoves despite the benefits to families. As subsidized commodities are generally limited in quantity, the spread of technology becomes self-limiting. In such a situation, subsidized supply of improved cookstoves results in a low market demand and could actually stifle entrepreneurship in the development of new markets. However, some types of subsidies could help promote market development while taking into consideration the needs of various income groups. In Bangladesh, it is possible to promote improved cookstoves that combine market development with specific types of subsidies that would promote equity.

Effectiveness. As indicated earlier, one of the main concerns around the world is that many improved cookstove programs have not been very effective, for a variety of reasons. The main emphasis of this study is on identifying the characteristics of effective energy programs so that insights can be gained from the types of subsidies used in such programs. The case studies were selected based on their overall accomplishments. The rationale for examining these best practices is that the problem programs often receive much attention, and the best programs often gain little consideration. Nothing could be worse than pouring subsidies into a program that does not work properly even if it is directed at the poor. Ineffective programs end up not benefiting anyone. This has been the problem with many of the improved cookstove programs around the world that are based on extensive donor financing. It is not that the stoves are not disseminated, but that the product is poorly constructed and does not last, or does not meet user requirements. Consumers do not repurchase the stoves and thus there is very little program impact over the long term.

To be effective, the use of subsidy incentives to promote stove adoption has to be done in a way such that the program is sustainable over the long term. This means that after an initial phase of project development, there is a significant chance that the program will continue with modest, or even without, direct product subsidies. Thus, the main approach is to provide support for institutions necessary to promote the development of safe, efficient and pollution-reducing stoves, with an emphasis on the initial financing of marketing, technical development of stoves, development of standards, and other aspects of the program. This will entail developing and promoting stoves for a range of households, from the very poor to the more wealthy.

The successful international practices for improved cookstoves and the Bangladesh experience with sanitation services provide some interesting alternatives to the high direct product subsidies that have been so ineffective. In China, the approach of a program that eventually resulted in over 100 million stoves being sold through the market and energy agencies was to provide subsidies for the research, development, and promotion of improved cookstoves while leaving the sale of the stoves to entrepreneurs and retailers. Loans could still be provided through microcredit organizations for the purchase of approved improved cookstoves. In the case of China, the subsidies are used for market development and there are no subsidies for the stoves. The consequence is that stove retailers and entrepreneurs get assistance for market development but their success is dependent on consumers purchasing their products. 
Another approach, reviewed above, is that established in Guatemala, which is somewhat similar to the Bangladesh sanitation program. As indicated, it involves the purchase of approved improved cookstoves through some type of community development fund. The community purchases the approved stoves from retailers. They are then distributed to most or all in the community at markeddown prices. In this manner market development is not compromised, because entrepreneurs actually sell the stoves to the community.

To summarize, these subsidy approaches go hand in hand with both market development and support for entrepreneurs. A key component of acceptability is user satisfaction with the technology and aftersales service, due to which they are more willing to make the required payments. Loan financing for the technologies will be more effective only if there are a number of options to suit different clientele. People will only repay the financing for such stoves if they are very satisfied with the technology and after-sales service. Entrepreneurship development can help address both the supply-side issues and sustainability through a commercial approach.

\section{Way Forward}

The review of the status of improved stove programs in Bangladesh along with the best practices from around the world leads to several recommendations for consideration by the government of Bangladesh. The overall goal is to have a more unified program without diminishing the creativity of the various groups advocating improved stoves in Bangladesh. In fact, the recommendations ideally should lead to greater creativity and a variety of approaches. In this sense, the government's role is not to be the main actor, but rather to facilitate a process that would promote greater variety, improved durability, better safety, and greater efficiency of improved stoves. The ultimate goal is eventually to have a variety of improved stoves for sale in retail markets all over Bangladesh.
An obvious role for the government to play is in the establishment of an executing agency to support various aspects of improved cookstove promotion throughout the country. This would include wellstructured loans and subsidies for qualified projects, testing and certification of stoves, monitoring and evaluation to determine the effectiveness of projects financed, and publicity campaigns on the health impacts of indoor air pollution and benefits of new cookstoves. The executing agency would have welldefined and important activities. For example, in the case of testing and certification, the executing agency would need to give the responsibility for testing stoves both in the laboratory and in the field to a technical group. The international literature on improved stoves mostly agrees that laboratory tests are a good start to assess whether stoves meet certain standards, but the real test is in conducting evaluations in the field. There are now techniques available to do this, but it is not an easy process and protocols would have to be developed that are fair to those interested in promoting stoves. The role of this technical group would be to certify that a stove being promoted in the marketplace actually meets certain standards in terms of efficiency, pollution, durability, and safety.

This should be done in a way that would not stifle creativity, but ensures that the public receives a product that performs according to the specifications of the manufacturer or retailer. Once certified, the stove could possibly qualify for government assistance in terms of loans, marketing, and dissemination, or even some form of modest subsidy. Consumers purchasing efficient air conditioners in developed countries often receive rebates, which is a modest subsidy to lower the capital cost of efficient equipment. In a similar vein, for more expensive stoves, this approach could be easily justified by the health and environmental benefits to encourage people with modest incomes to adopt improved stoves.

To administer the program an institution with an efficient commercial approach and good field-level 
experience in quality-assured technology promotion and dissemination may be well suited to perform some important functions in promoting improved stoves. One model that might be applicable to promotion of improved stoves is IDCOL's program for household photovoltaic systems. Under this system an organization would provide loans and partial grants to NGOs, private companies, or microfinance organizations to promote stoves. This is not a simple process, as it involves several different types of activities.

Certifying or qualifying stoves for program. One problem with older improved stove programs around the world and even some today is that there was no independent system to verify their performance. For example, a new stove that is custom installed in a home may work quite well for a few months, but as cracks develop in a stove and the dimensions of the interior changes, the efficiency or combustion qualities of the stove may deteriorate. Thus, it would be beneficial to have an independent agency or an arm of the agency implementing the stove program certify that the stoves are of high quality and will deliver promised performance under actual conditions of use. The performance criteria would be both energy efficiency and smoke reduction, along with ease of use by consumers. This could be done by financing a technical agency to test and certify products that would be sold under the program. This is important because consumers should be able to purchase stoves that either have guarantees similar to the photovoltaic programs in Bangladesh or at least be assured that they will perform as promised. It is also vital to be sure that stoves are safe and will not actually increase indoor air pollution.

Qualification of firms or NGOs. Just as consumers should have confidence in the performance of the products that they buy, they also should trust the organizations that are selling or providing financing for the cost of stoves. Thus, firms that participate in the program should have a track record of providing high-quality service to consumers or consumer groups. The factors that might be considered are the length of time the firm has been operating, the transparency of their accounting system, the experience with similar programs, the ability to deliver on promised goals, staff that are qualified, and a legal and accounting system that would permit agreements with lending or grant-giving institutions. The firm should be able to implement a program for improved stoves that protects consumers and the promoting agency from undelivered promises.

Proposal evaluation: technical feasibility and financial viability. One of the roles of the agency that promotes improved stoves will be evaluation of proposals to ensure that they are technically feasible, financially sound, and economically justifiable. Poor technical stove designs and excessive subsidies have been a problem for many improved stove programs around the world. To avoid this the design of the stove program should not only encourage innovative product development, but also financial and economic viability. This does not mean that there should be no subsidies, but rather that they should be structured in ways to promote the financial viability of the program. The programs should be able to continue even if subsidies are withdrawn. This might mean charging higher prices or finding alternative financing, but it is important that stove programs do not disappear if there is a withdrawal of subsidy support for the stove itself.

Development of diversity of products. Internationally stoves designs for poor and middleclass households have flourished. Firms such as Environfit, Siemens, and others are developing improved wood stoves, alcohol fuel stoves, and many other designs. There are also some recent more traditional stove designs available in Bangladesh. At the beginning of most successful programs there will be a diversity of products that will compete for customers, and customers will chose between them based on their utility. It is therefore important at least in the initial stages of any program to test a diversity of stoves that address the various needs 
of different types of consumers. These can include both affordable and more expensive stoves.

One way to develop a diversity of improved stoves might be to have an improved stove grant competition. This competition would award financing to innovative proposals to design different types of improved stoves. The grants could be not only for technical design of stoves, but also for innovative ways to sell and market existing stoves. At present virtually 100 percent of rural households in Bangladesh use biomass energy, burning a wide variety of fuels, including leaves and grass, dung, and wood. It will be challenging to design stoves to burn efficiently for all these different types of fuels and there may not be any one solution. Perhaps there could be a series of competitions that address different aspects of stove design, marketing, and sales during the initial phase of the program.

In this move towards diversity, it would be important not to reinvent what has already been done in other countries. As indicated, there is a wide variety of international approaches to stove development and grants might be appropriate for local firms or NGOs to develop a cooperation plan to disseminate or adapt to local conditions many models that are now available worldwide. Typically, this might involve a period of consumer testing and redesign that could be covered under a product or business development grant. One lesson from international programs is that there has been much duplication of effort because of poor communication between those involved with improved stoves, and perhaps a workshop on local and international experience at the beginning of the program would be warranted.

Monitoring of stoves in the field. In the past monitoring of stove performance involved specialists going out to the field, looking at whatever stoves were available, and conducting informal interviews with those adopting stoves. The result was perhaps somewhat informative, but the process was rather rudimentary in comparison to the sophisticated consumer product development and marketing studies currently available. Recently many of the international companies involved in promoting improved stoves have begun to take more seriously the monitoring and evaluation of the stoves operating under actual conditions. There is now more inexpensive equipment to monitor energy efficiency and indoor air pollution in people's homes. These technical measures can be complemented by periodic consumer interviews, and in this way products can be refined and perfected for consumers. Most private companies and NGOs have very little financial ability to do this kind of intensive research. Thus it would be a good idea for either the firm that is involved in stove certification or another local firm to carry out such work. It would be necessary at least in the initial stages to use grant funds to complete this essential work.

Proper balance between loans and grants. Many programs around the world have experienced difficulties due to a lack of proper balance between product pricing, subsidies, and loans. The key is that consumers must be willing to pay for the service that is provided by the stove. Many of the best international programs subsidize support for stove programs through, for example, technical studies, marketing, and monitoring. However, they often do not provide subsidies for the stove itself, as in China. In other countries with successful programs, there have been modest subsidies of 10 percent to 20 percent provided for the stoves. The hope is that once the initial program succeeds, then the subsidy can be removed and the stove can be a commercial product. One problem with extensive subsidies is that no market development takes place for the selling of stoves, with the result that most stoves are sold through the program and not through retail outlets. These programs often have no lasting impact, because if the stoves break down after the program is completed, there are no repair facilities or availability of stoves in the marketplace for repurchase. 
Possibility of community-based grants. In addition to the loan and grant approach, once a variety of effective stoves are developed and in the marketplace, consideration might be given to the use of community-based funds for providing improved stoves to whole communities, as is the case with the sanitation program. Such stoves would of course be purchased in the market and therefore would encourage market competition and the overall development of commercial approaches to improved stoves. This type of program should be equitable as most community grants involve projects that benefit everyone in the communities. This is the type of program that was implemented in Guatemala, and the improved stoves option was popular for the use of community development funds. The stoves under that program were relatively expensive, so the community grants were essential.

Publicity campaign on indoor air pollution and health. Once a wider variety of quality stoves are in the marketplace, a national publicity campaign to publicize the health implications of indoor air pollution could be implemented through a chosen agency. This should not be done before stoves that are in the marketplace are tested and certified because it would not be good to publicize health issues before proper solutions are available to consumers. The campaign would provide information on health problems and the possible ways to alleviate them. The ways to reduce indoor air pollution would be through interfuel substitution, proper kitchen and house ventilation, adjustment of cooking techniques, and improved cookstoves.

The possible program described above should not involve any type of prohibition on the private sector or NGOs developing their own programs with their own financing. In fact, the grants and loans should be available to all that qualify, and the technical agency could verify the effectiveness of the stoves of any agency on an as-needed basis. Such groups would certainly have their own technical staff to qualify their own products. The idea is to develop a level playing field for those involved in the promotion of improved stoves in Bangladesh and to create a conducive atmosphere that encourages different organizations to development and retail a wider range of improved stoves in the country. Thus, the overall goal of government activities should be to promote the development of improved stoves in Bangladesh to alleviate the problems caused by both indoor air pollution and shortage of biomass fuels.

\section{Conclusions}

Bangladesh's new Renewable Energy Policy endorses creating a better environment for renewable energy technologies and promoting market development for improved cookstoves (Government of Bangladesh 2009). This study supports this policy direction through examining possible strategies to move forward the development of markets for improved stoves in Bangladesh. This is not an easy task as it involves many different types of forces that need to work toward achieving better success with improved stoves. On the supply side, the improved stoves available in the market today are low cost, but have suffered from durability problems and low adoption rates. On the demand side, consumers still do not appreciate the long-term benefits of improved stoves and even those adopting improved stoves alter them in ways that make them less efficient. No doubt there needs to be a wider variety of better stoves in the marketplace.

In conclusions, the future of an indoor air pollution reduction program for mitigating the ill-effects of biomass burning requires the dedication of government institutions, civil society, and the private sector. The requirements would be to pique the interest of entrepreneurs in developing better stoves, to establish a subsidy or loan program that does not destroy market incentives for stove promotion, and to develop standards or an aftersales service program to make sure that consumers are being sold products that are both reliable and 
effective. Although this will not be easy, the benefits of improved stoves would be high for the poorest populations in Bangladesh, including the reduction in the labor required to collect fuelwood for daily cooking tasks and the improved health resulting from cleaner indoor environments. In developed countries, a government certification process for wood heating stoves has improved efficiency levels from 50 percent to over 80 percent and reduced emissions to very low levels. There is no reason that developing countries, including Bangladesh, should have populations dependent on stoves that have had the same efficiencies and pollution levels for hundreds of years. 


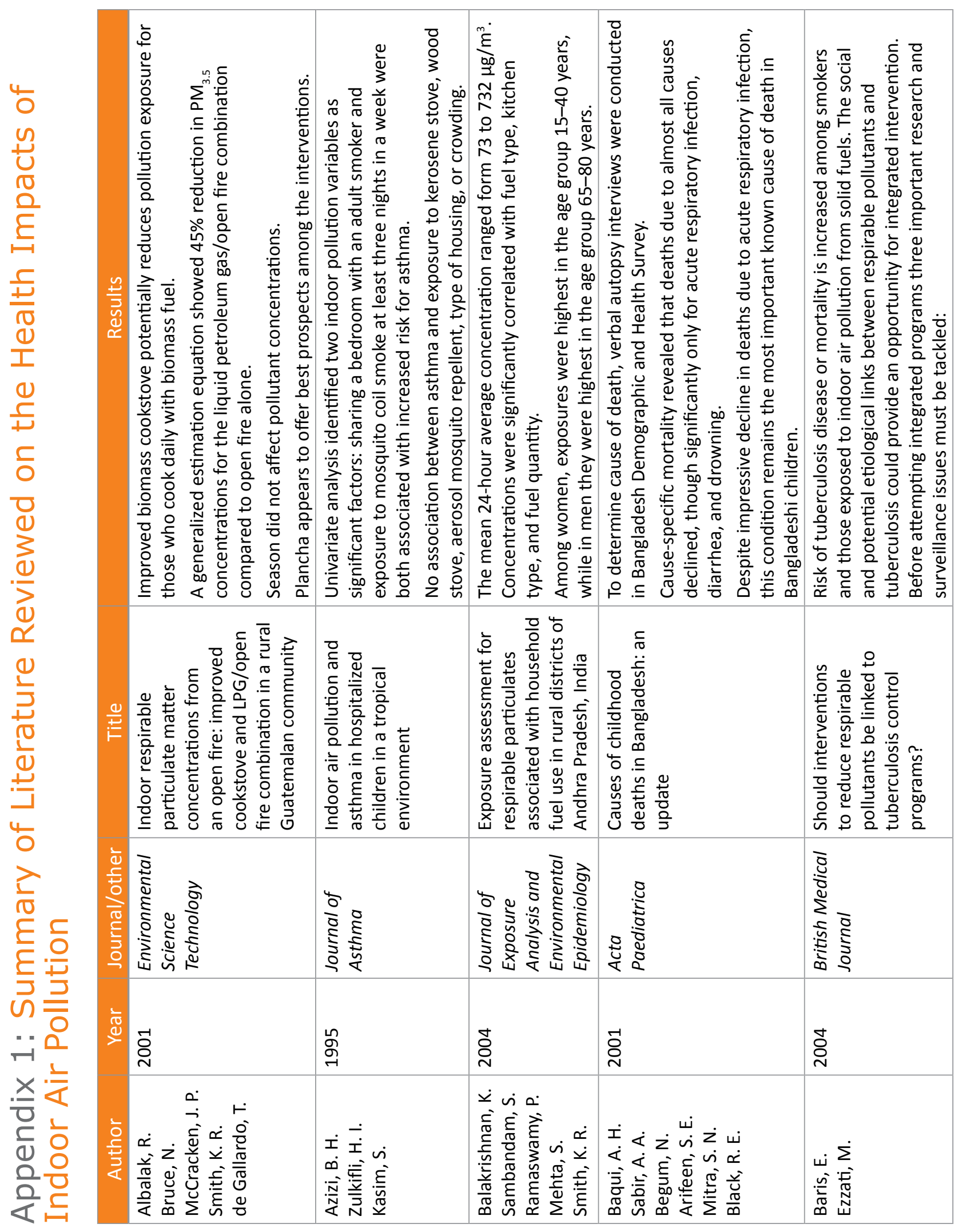




\begin{tabular}{|c|c|c|c|}
\hline 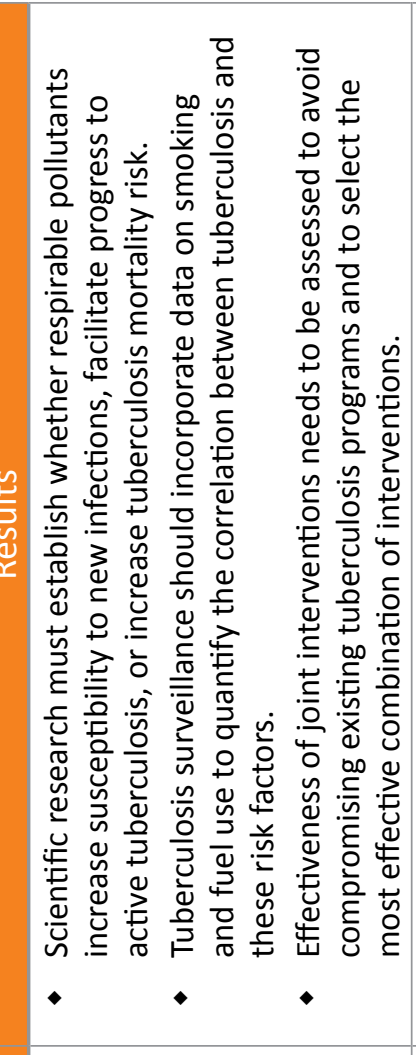 & 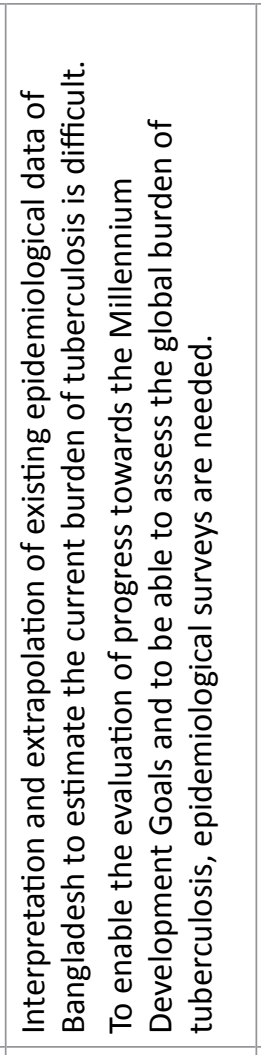 & 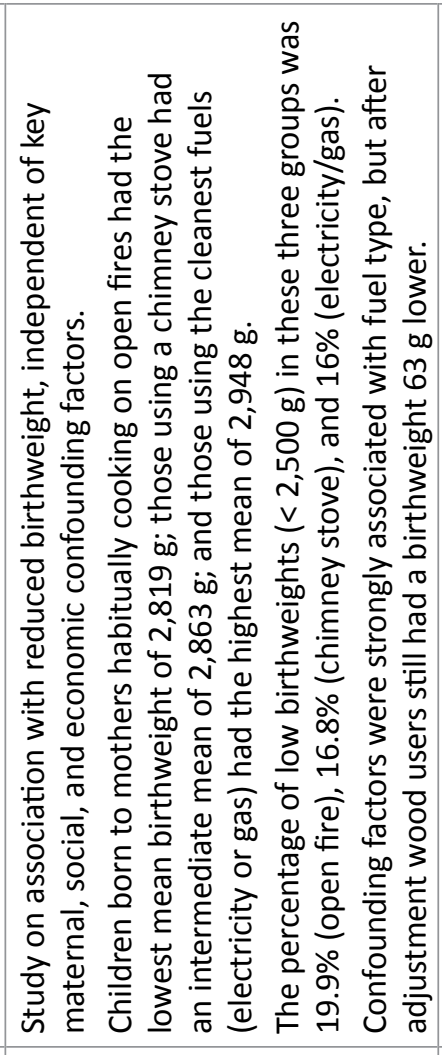 & 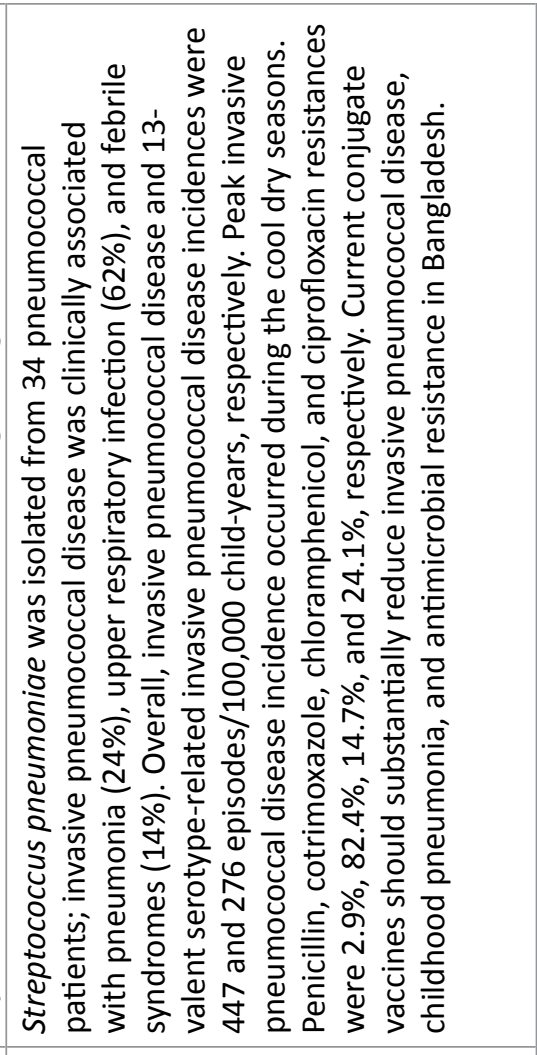 \\
\hline & 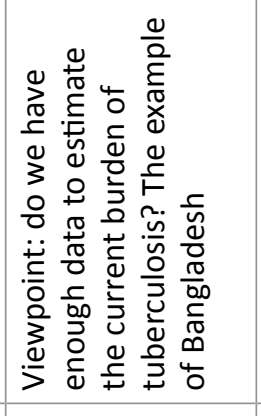 & 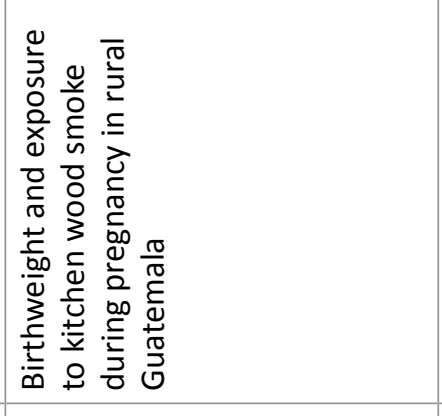 & 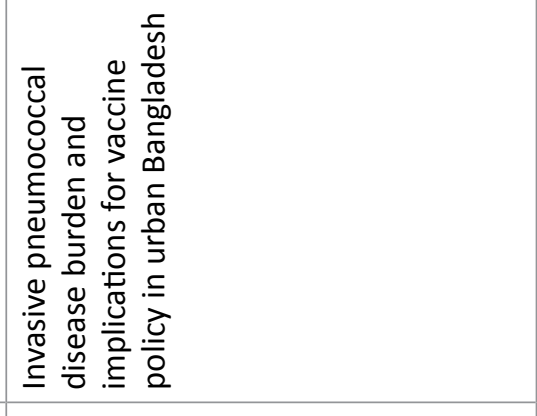 \\
\hline & 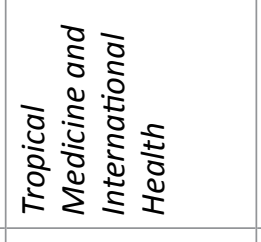 & 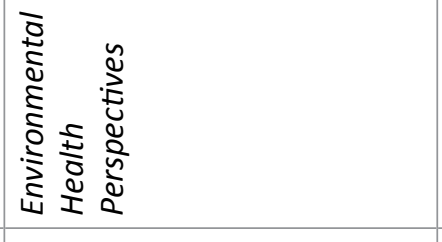 & 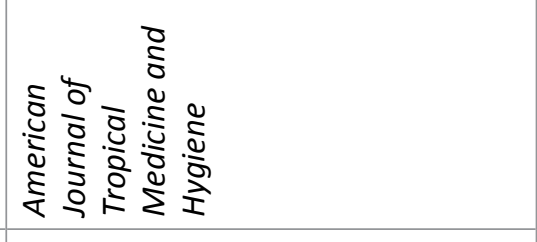 \\
\hline & ఫ্ & ర్ & 离 \\
\hline & 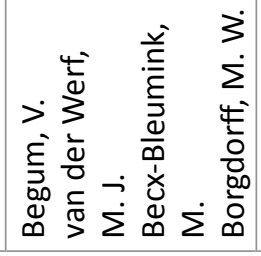 & 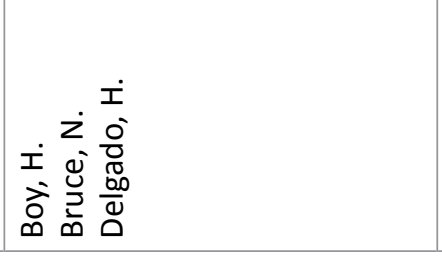 & 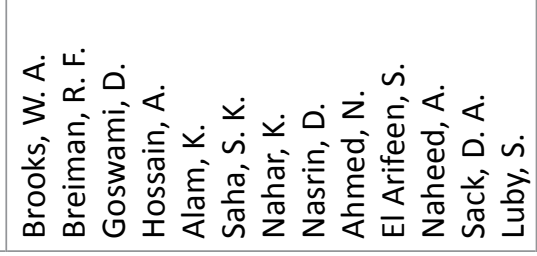 \\
\hline
\end{tabular}




\begin{tabular}{|c|c|c|c|}
\hline 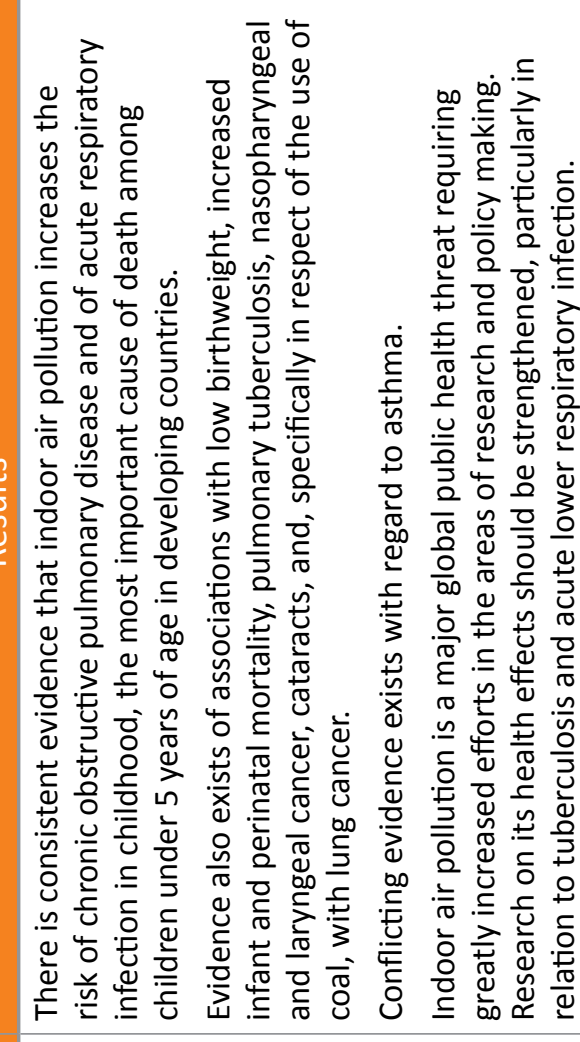 & 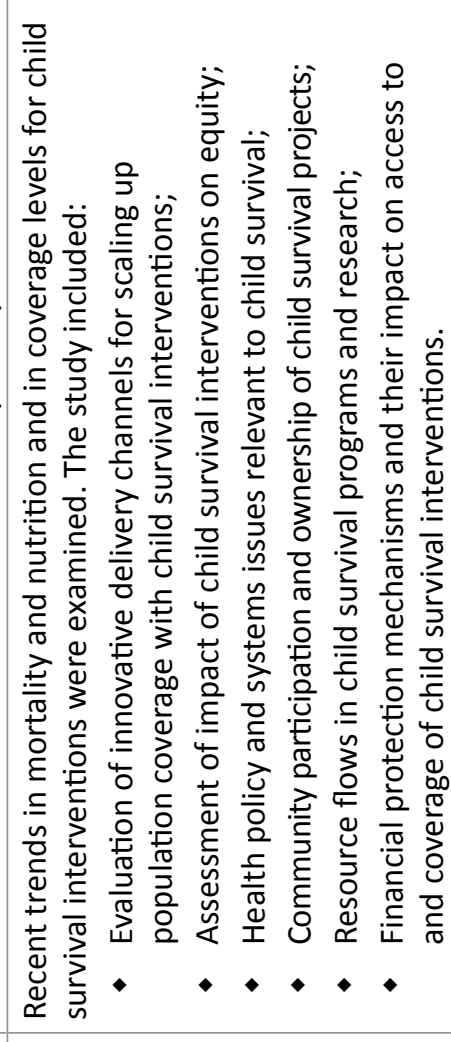 & 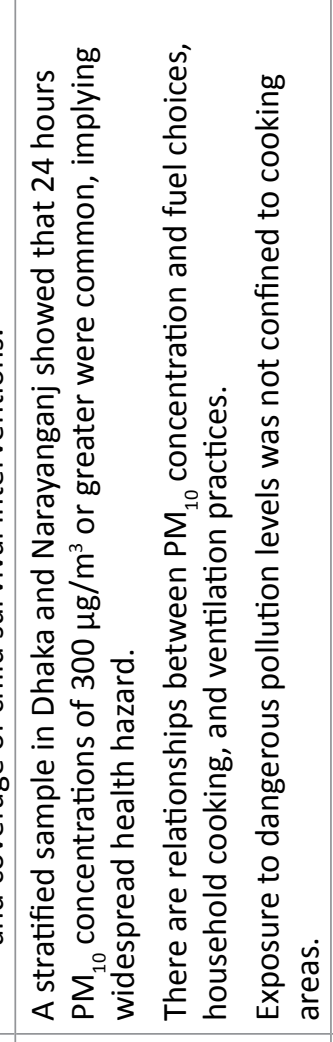 & 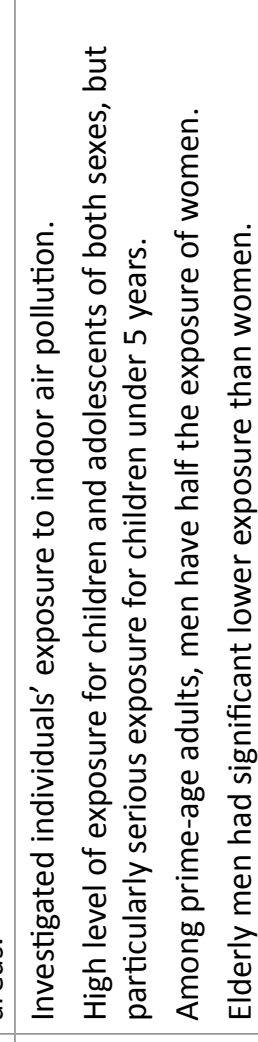 \\
\hline 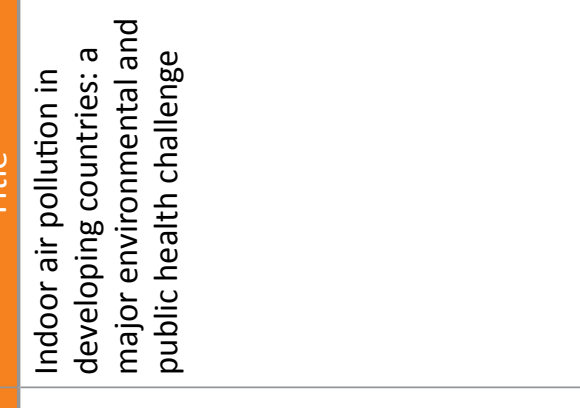 & 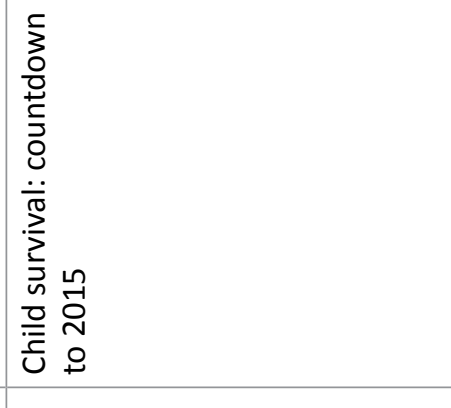 & 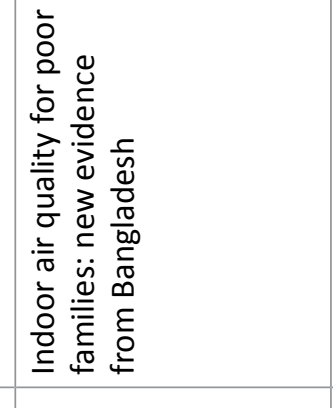 & 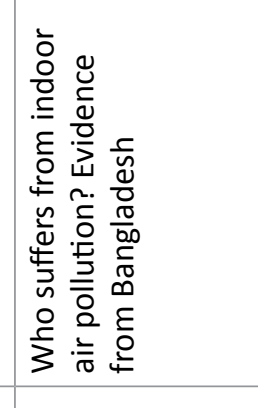 \\
\hline 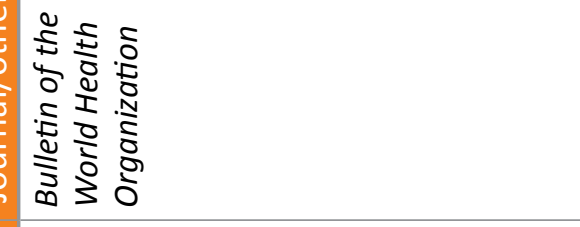 & 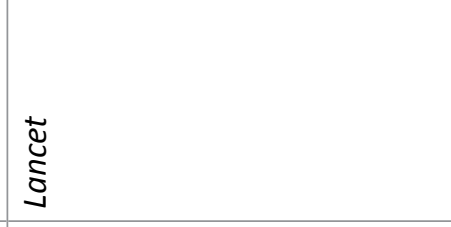 & 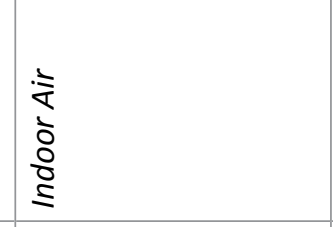 & 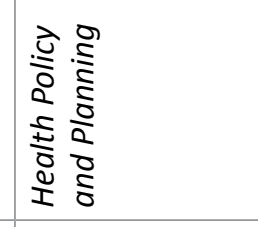 \\
\hline : & ठ্ণ & 总 & 总 \\
\hline 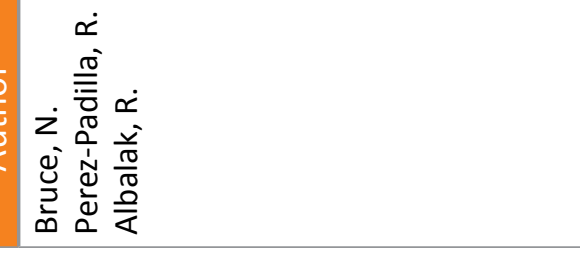 & 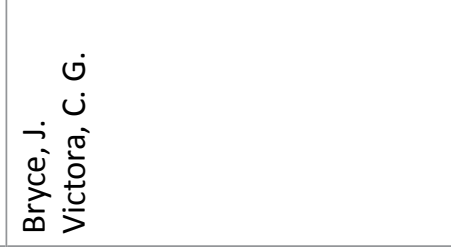 & 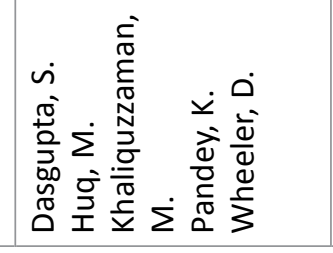 & 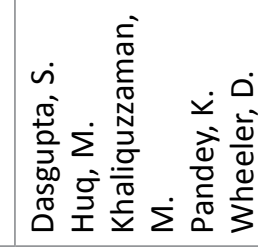 \\
\hline
\end{tabular}




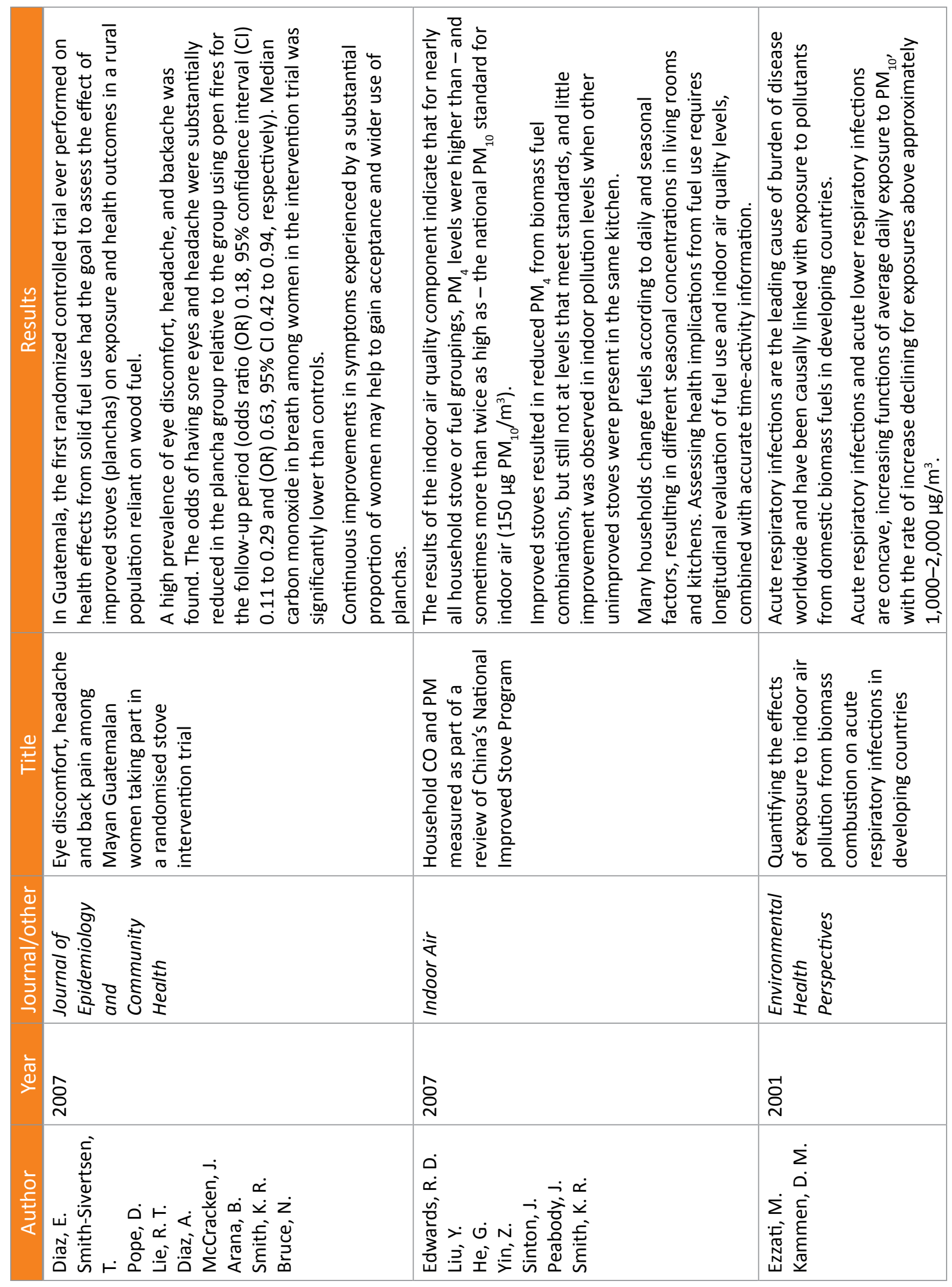




\begin{tabular}{|c|c|c|}
\hline 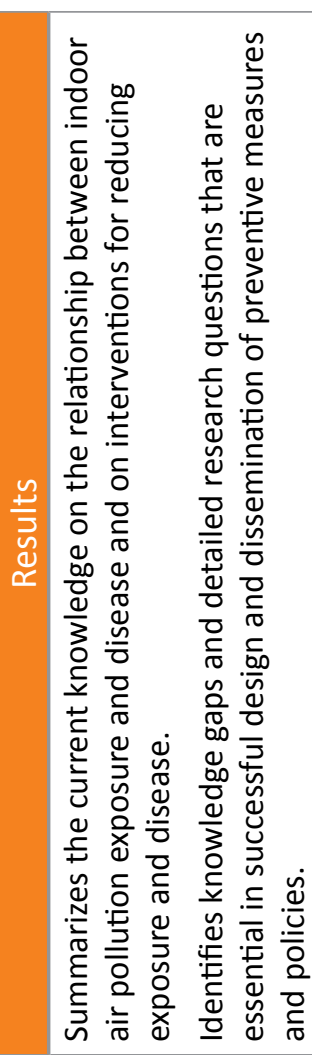 & 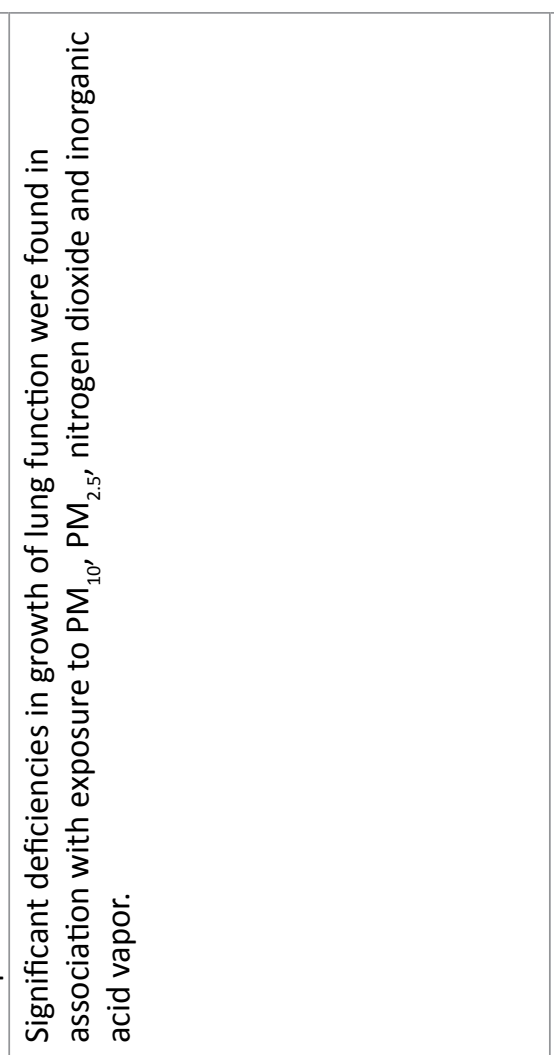 & 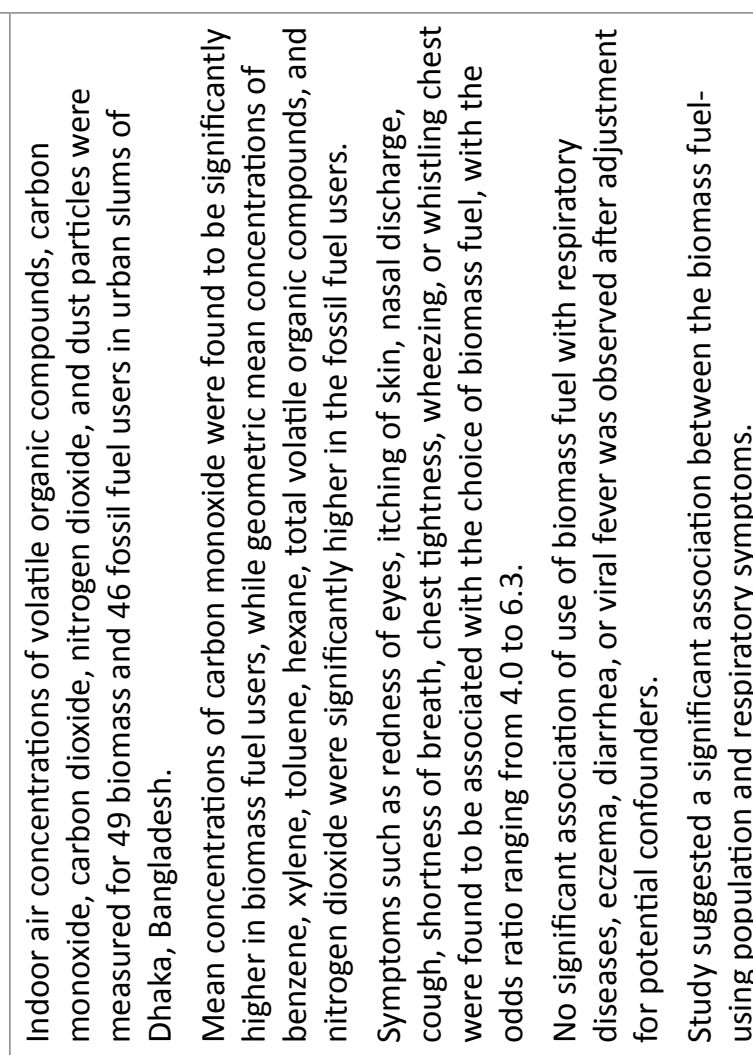 \\
\hline 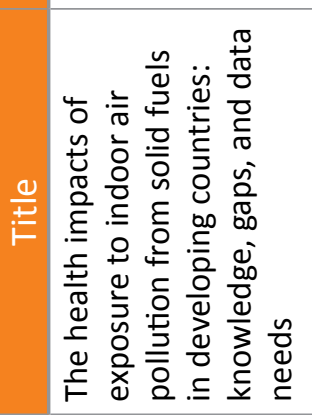 & 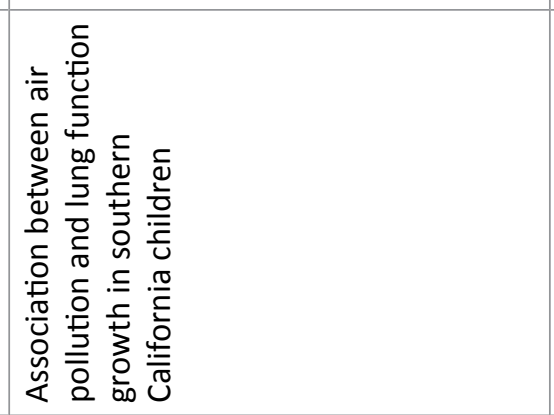 & 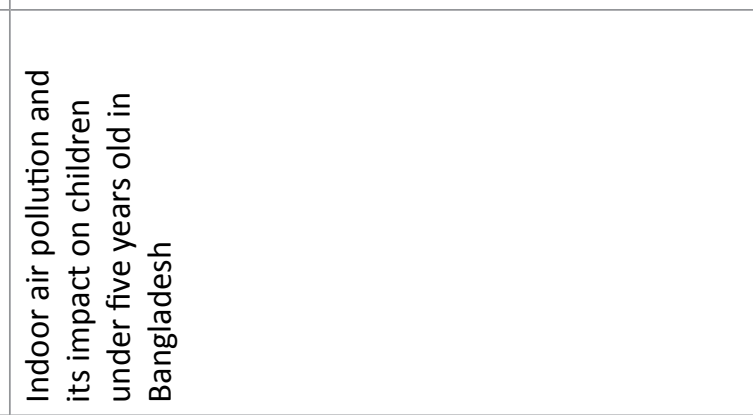 \\
\hline 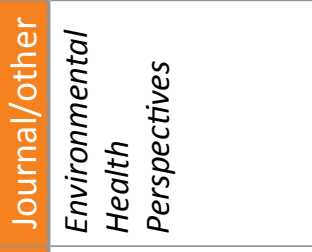 & 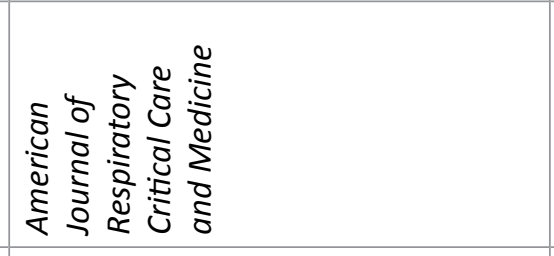 & 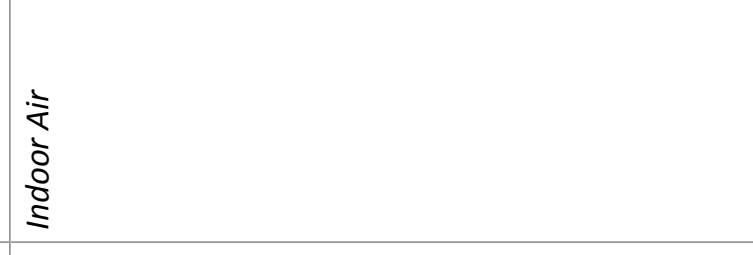 \\
\hline$\stackrel{\overbrace{}}{\circ}$ & ర్ల & ¿े \\
\hline 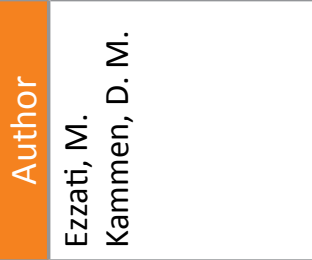 & 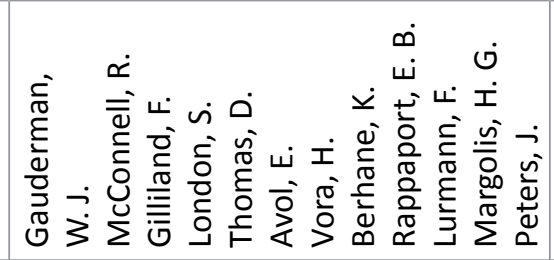 & 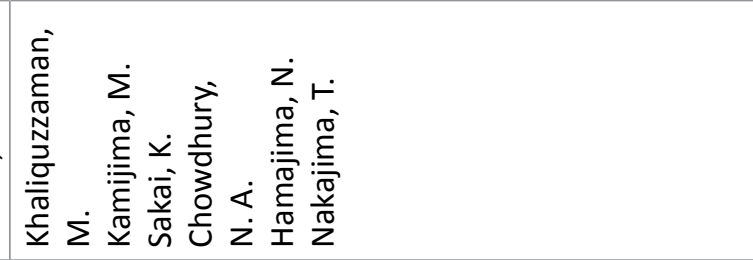 \\
\hline
\end{tabular}




\begin{tabular}{|c|c|c|}
\hline 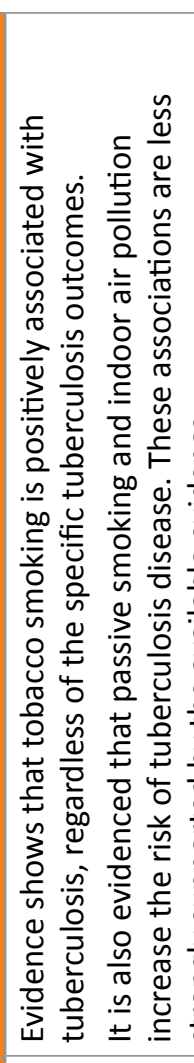 & 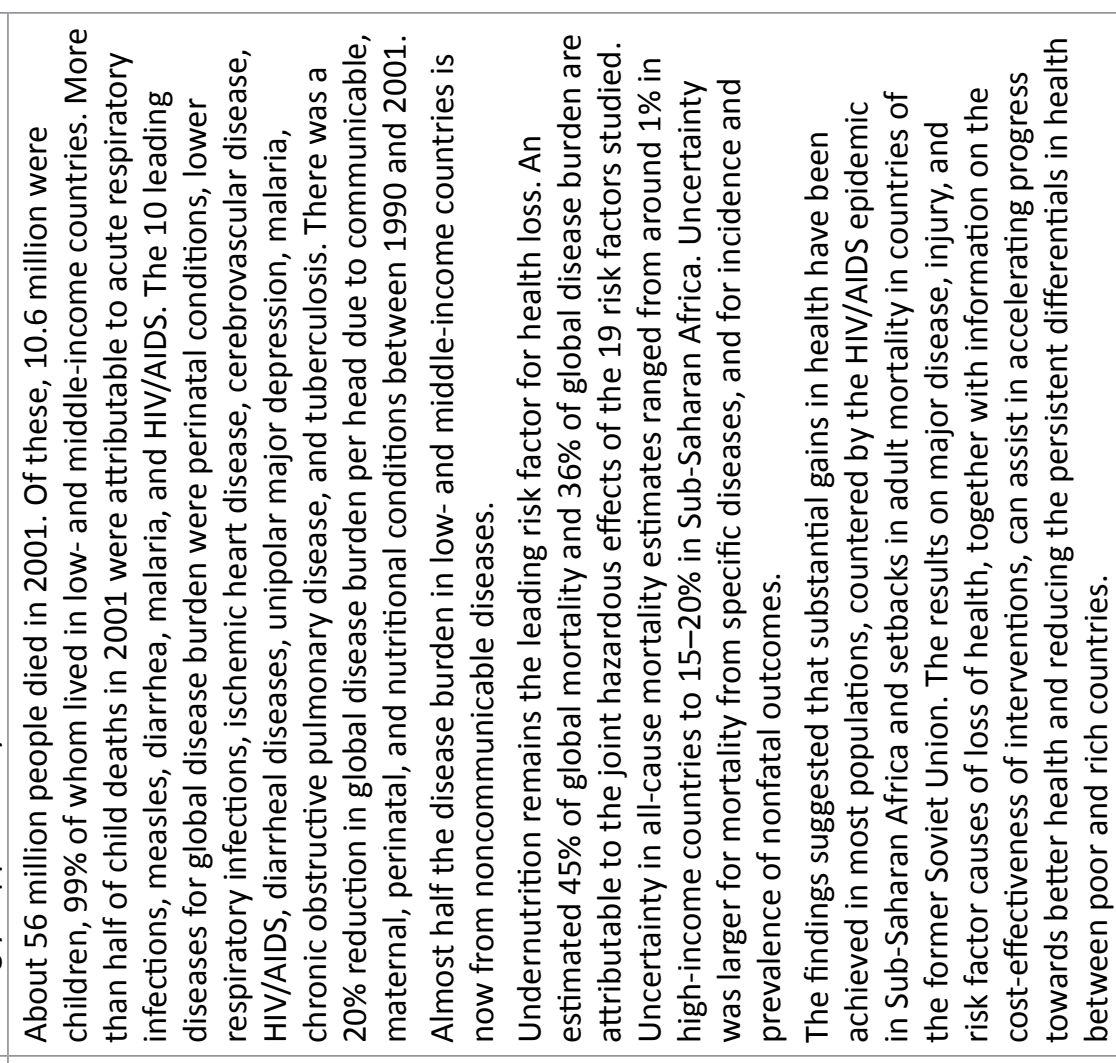 & 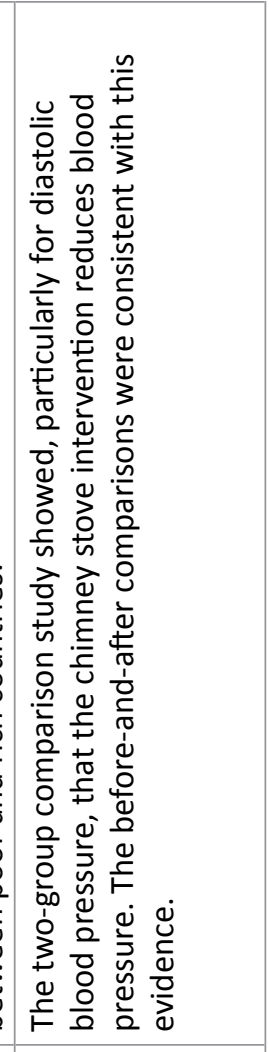 \\
\hline 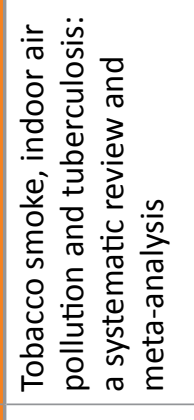 & 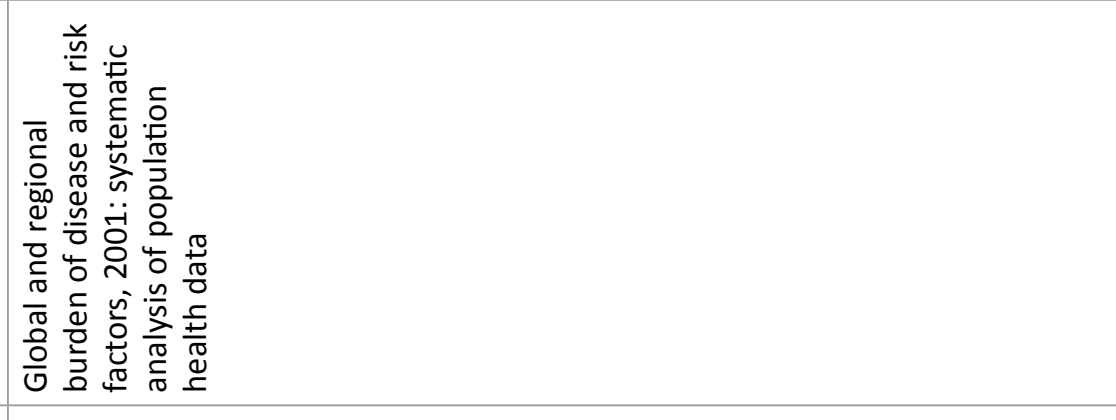 & 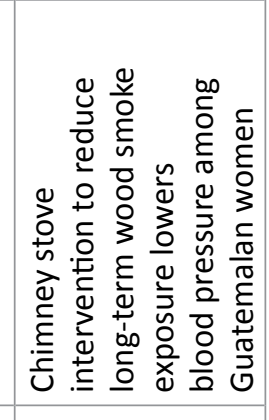 \\
\hline 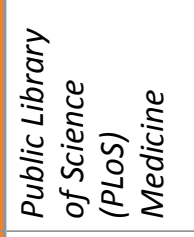 & 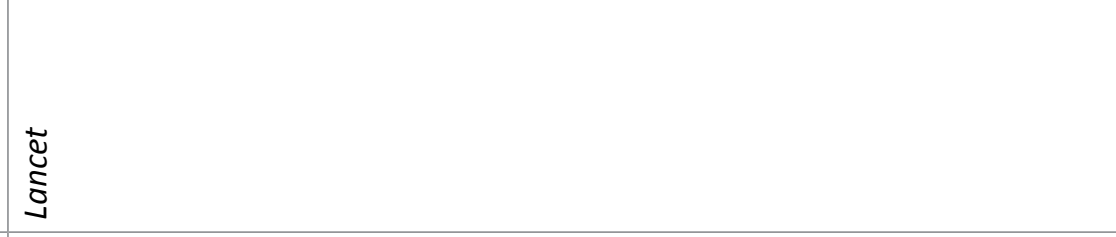 & 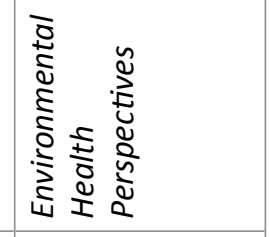 \\
\hline ì & : & ఫ্ণ \\
\hline 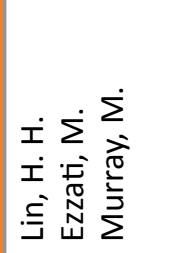 & 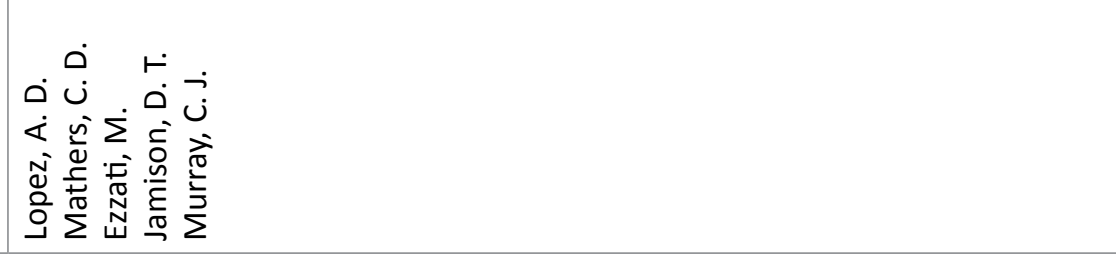 & 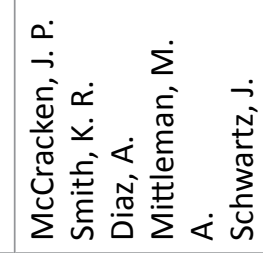 \\
\hline
\end{tabular}




\begin{tabular}{|c|c|c|}
\hline & 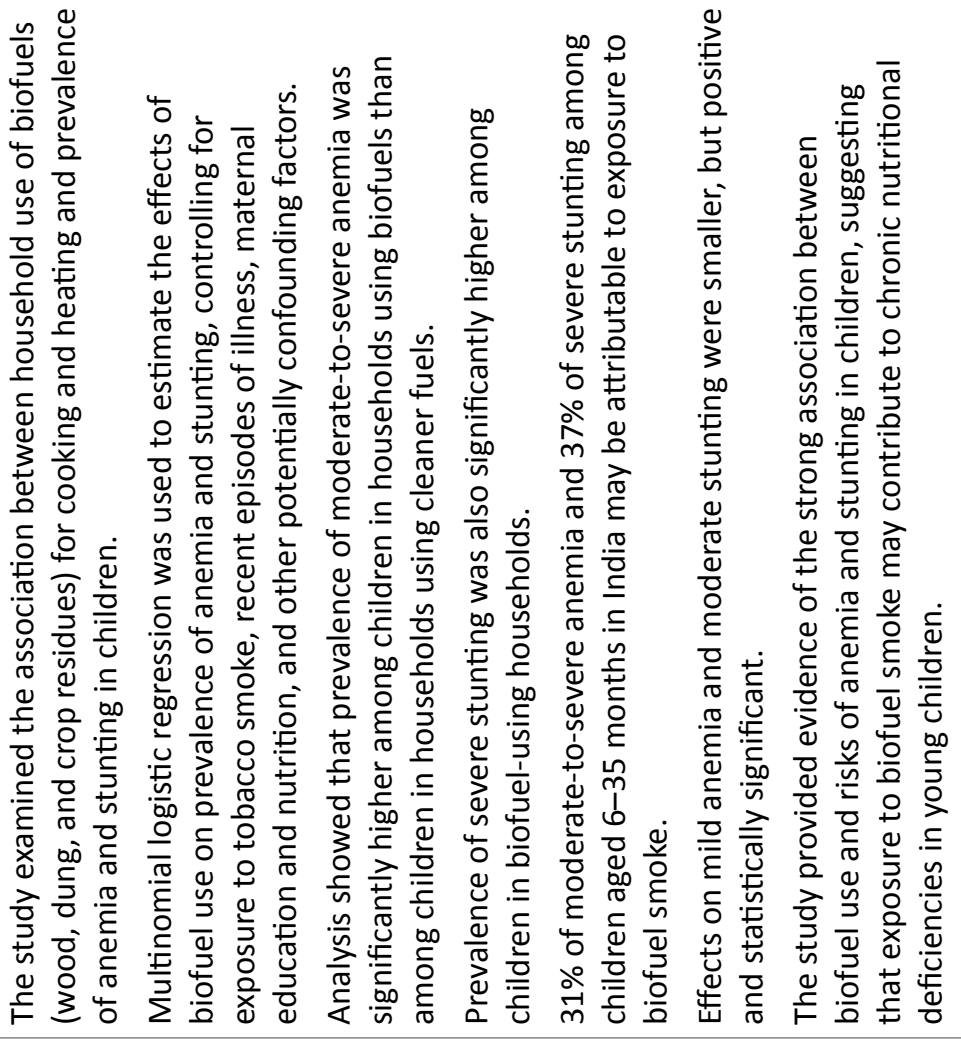 & 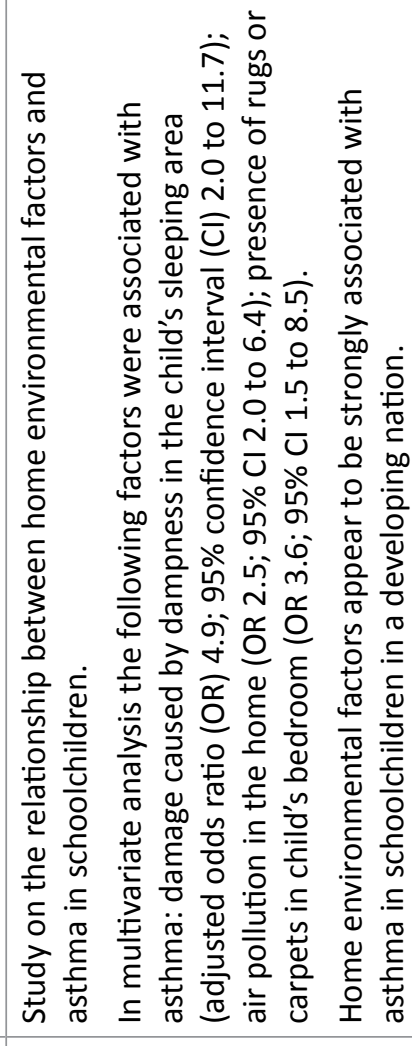 \\
\hline & 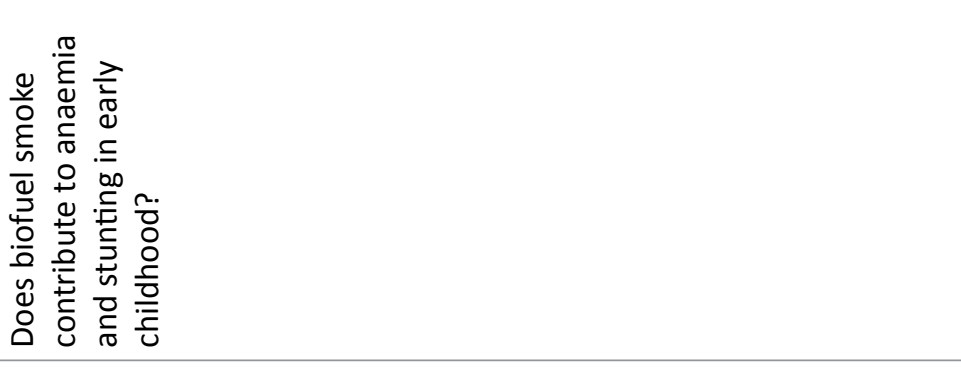 & 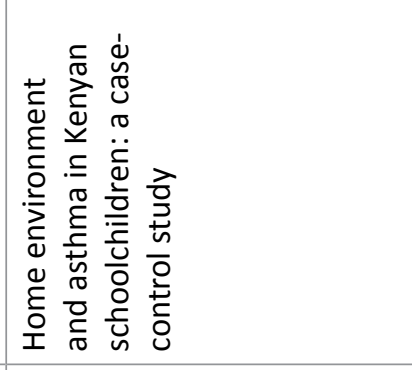 \\
\hline & 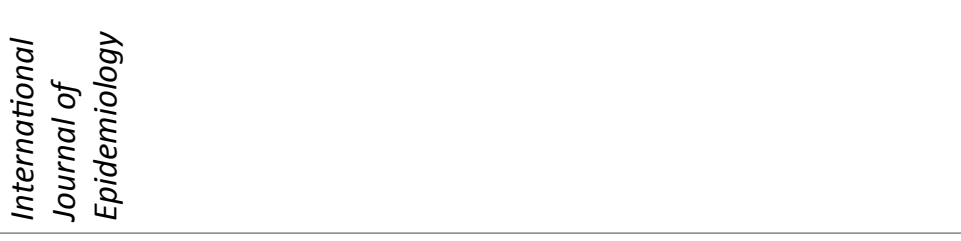 & $\begin{array}{l}\text { x } \\
\text { o } \\
\stackrel{5}{f}\end{array}$ \\
\hline$>$ & 유 & $\begin{array}{l}\text { Цू } \\
\text { જ }\end{array}$ \\
\hline & 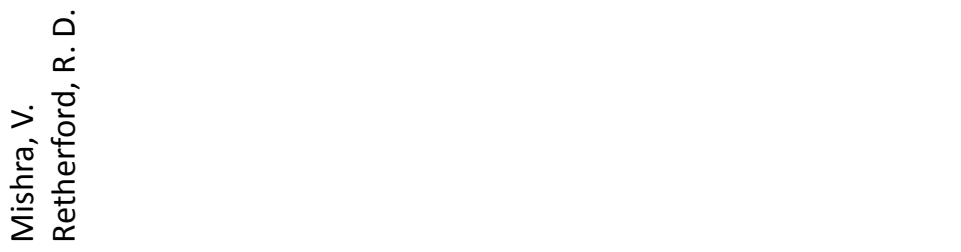 & 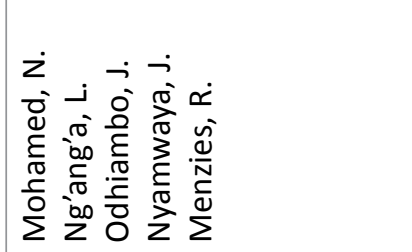 \\
\hline
\end{tabular}




\begin{tabular}{|c|c|c|c|}
\hline & 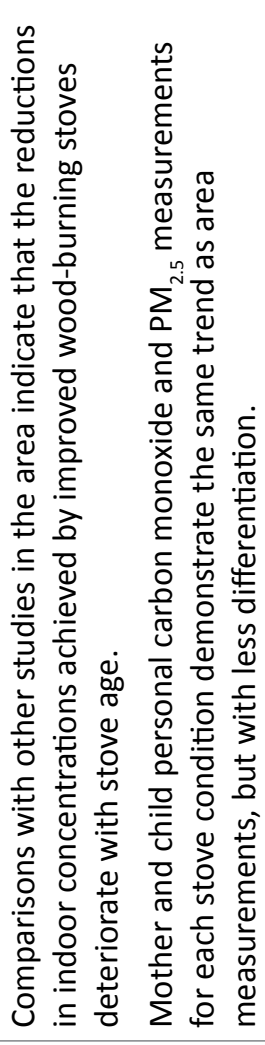 & 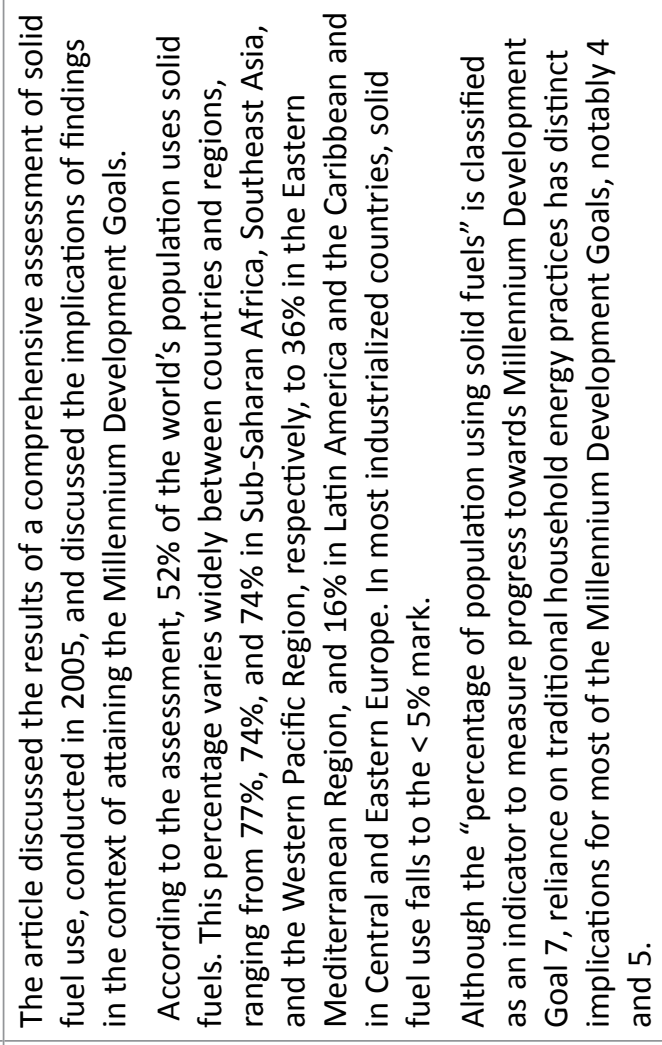 & 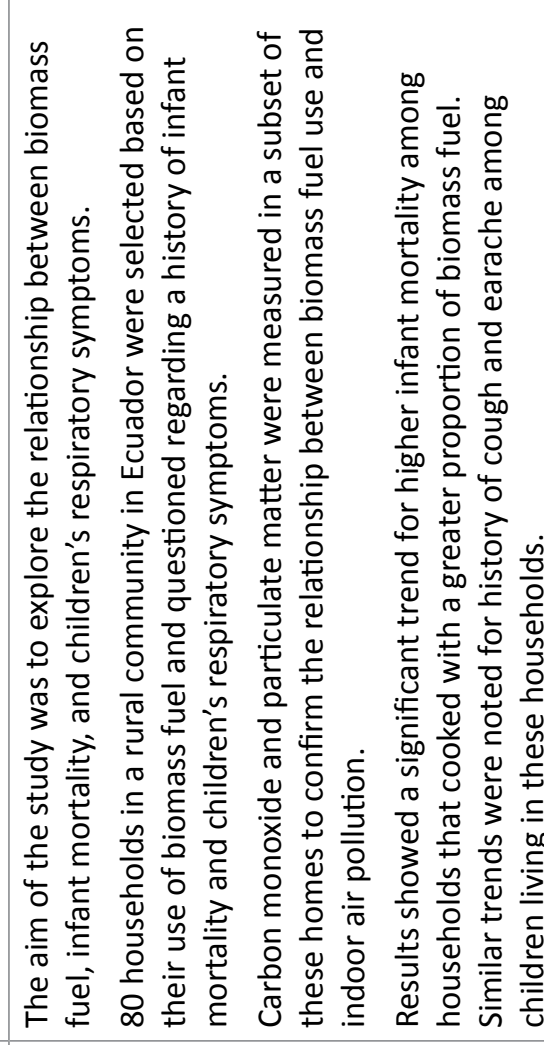 \\
\hline & 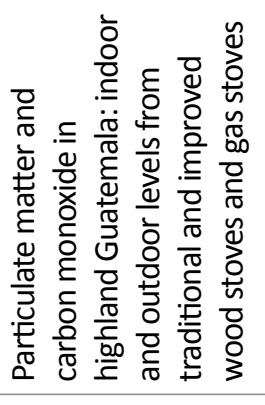 & 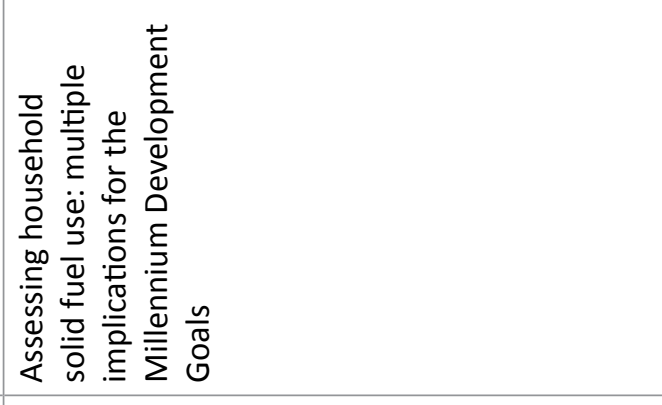 & 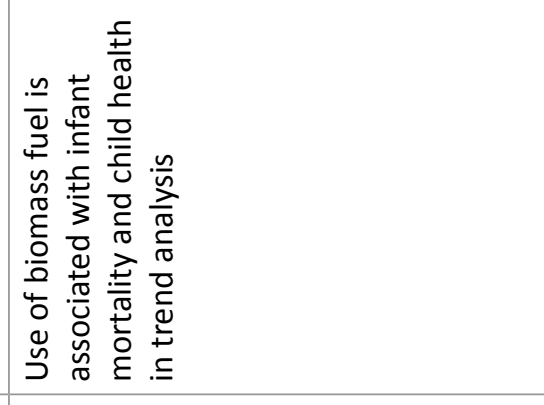 \\
\hline & $\begin{array}{l}\vdots \\
\vdots \\
\vdots \\
\vdots \\
\vdots \\
\vdots \\
\vdots\end{array}$ & 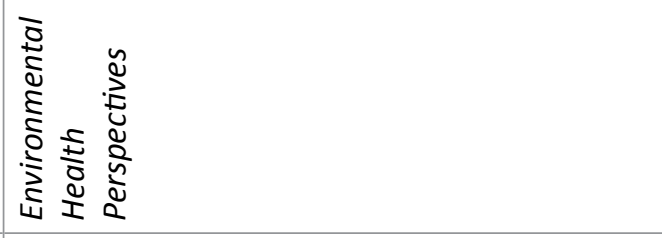 & 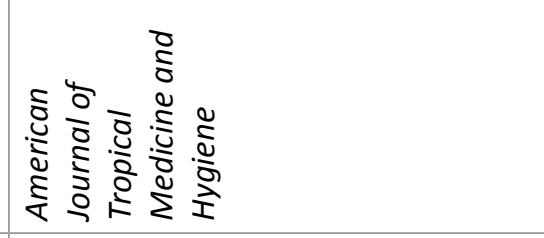 \\
\hline & ষ্ণ & ঠั & D \\
\hline & 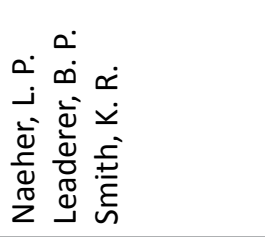 & 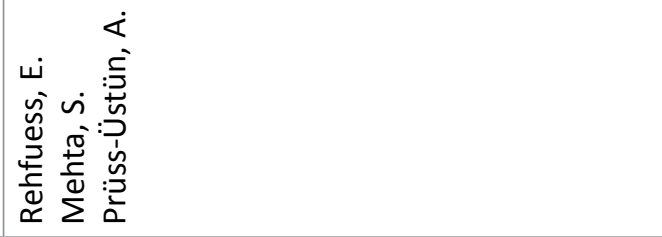 & 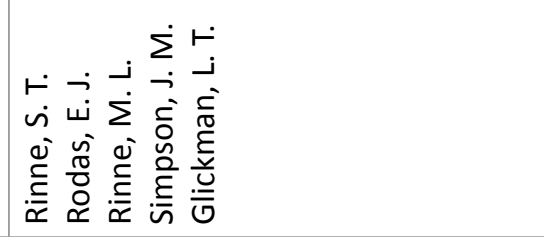 \\
\hline
\end{tabular}




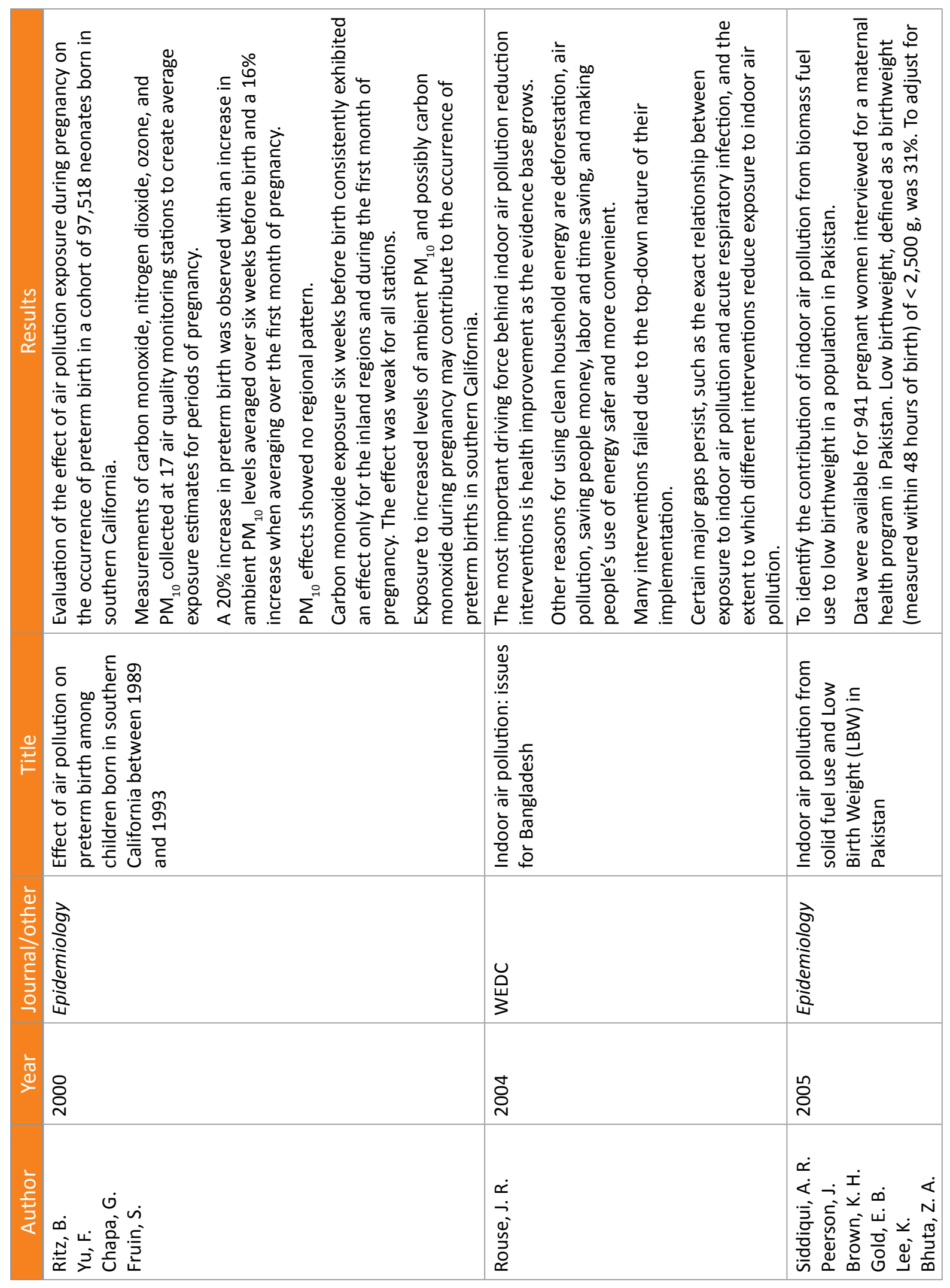




\begin{tabular}{|c|c|c|c|}
\hline & 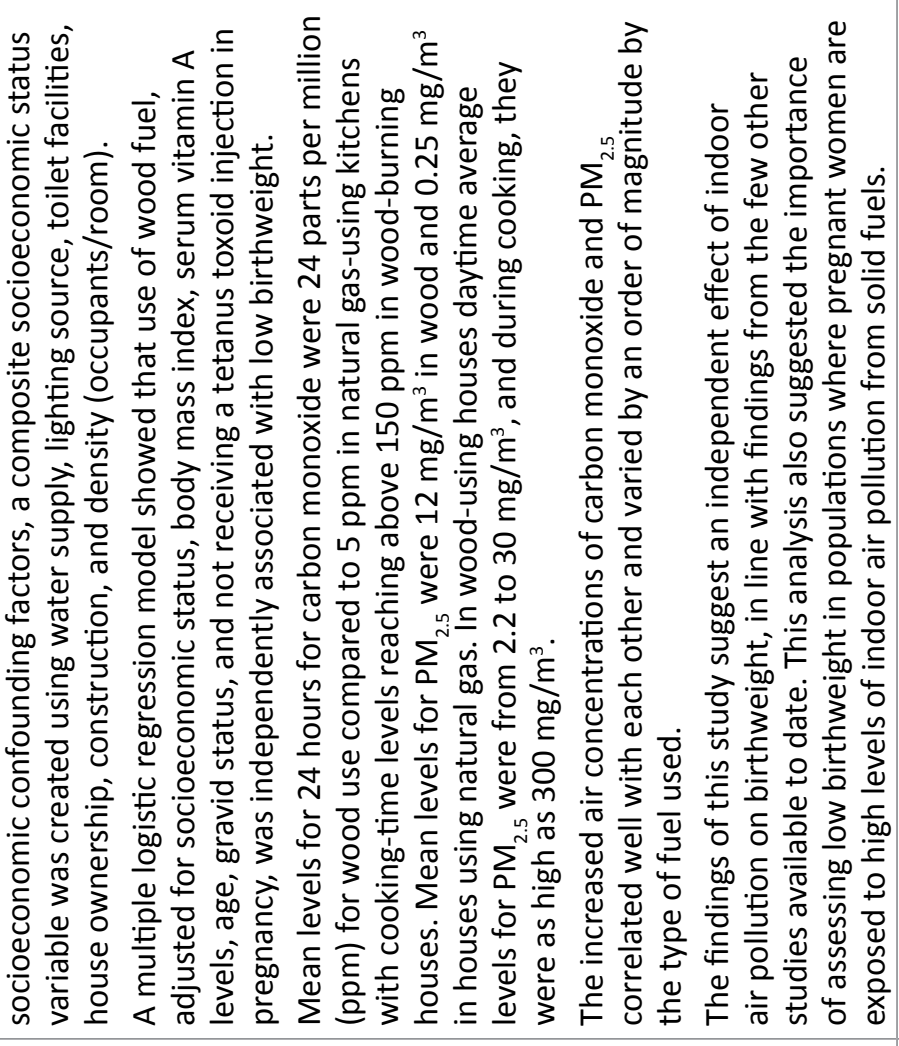 & 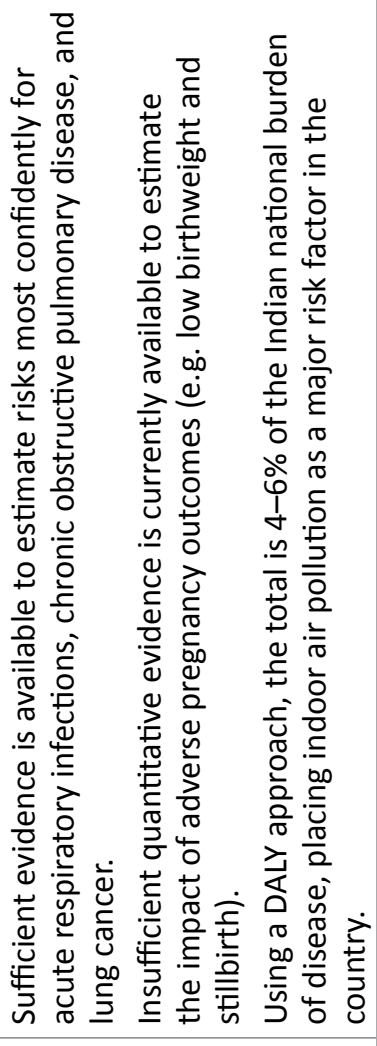 & 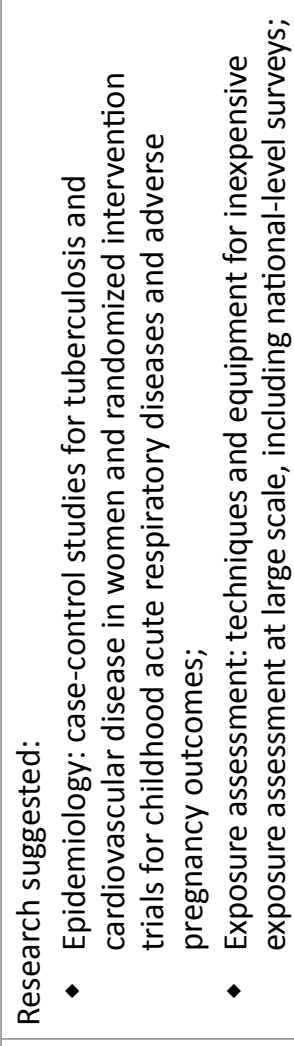 \\
\hline & & 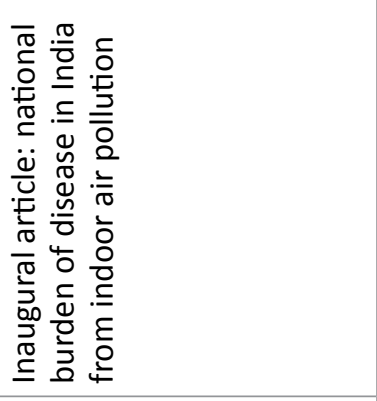 & 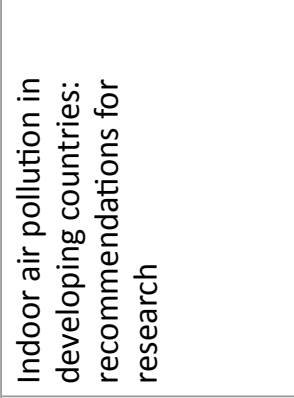 \\
\hline & & 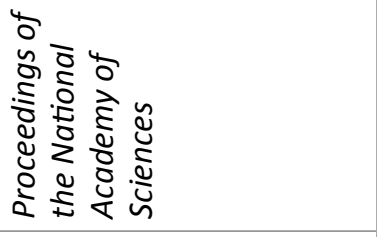 & 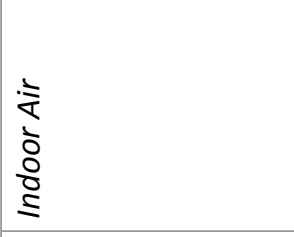 \\
\hline & & ঠ & ర్ \\
\hline & & 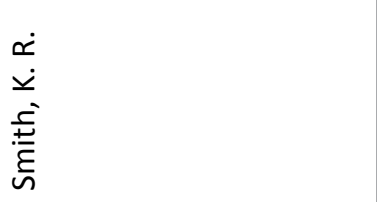 & 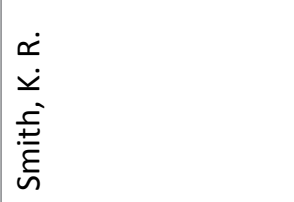 \\
\hline
\end{tabular}




\begin{tabular}{|c|c|c|c|c|}
\hline 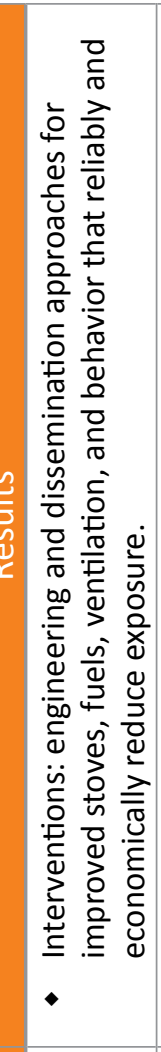 & 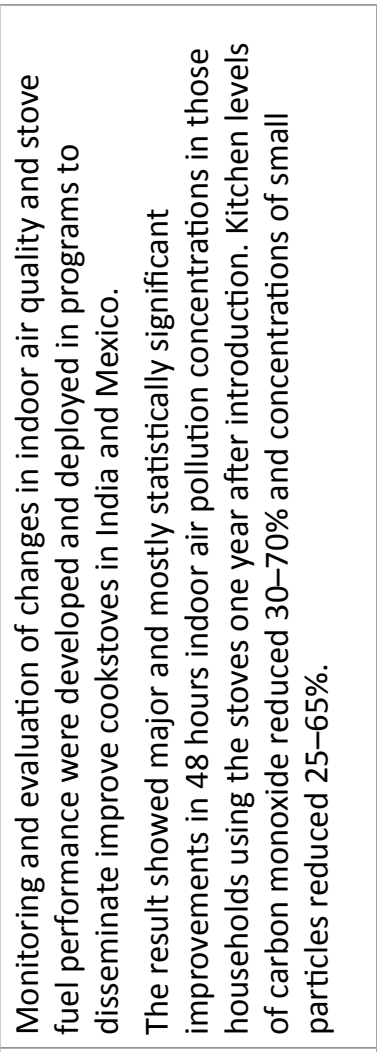 & 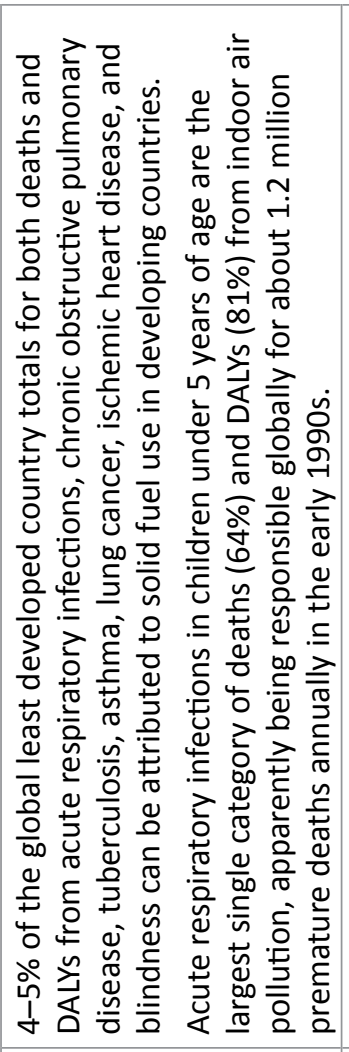 & 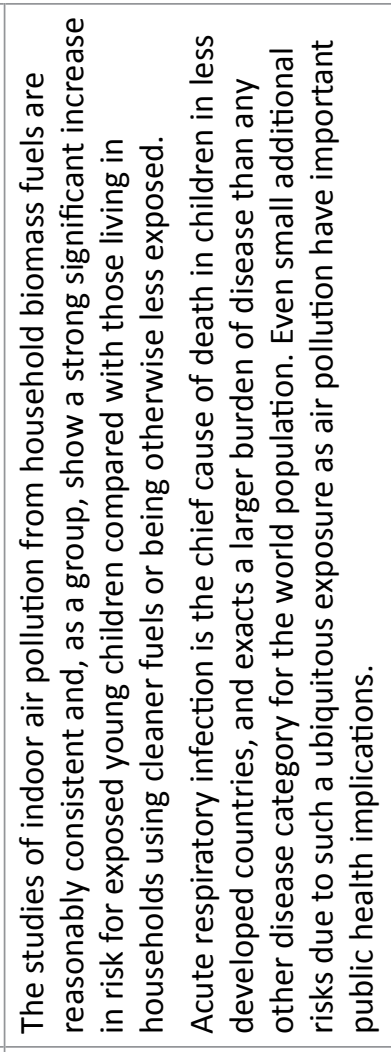 & 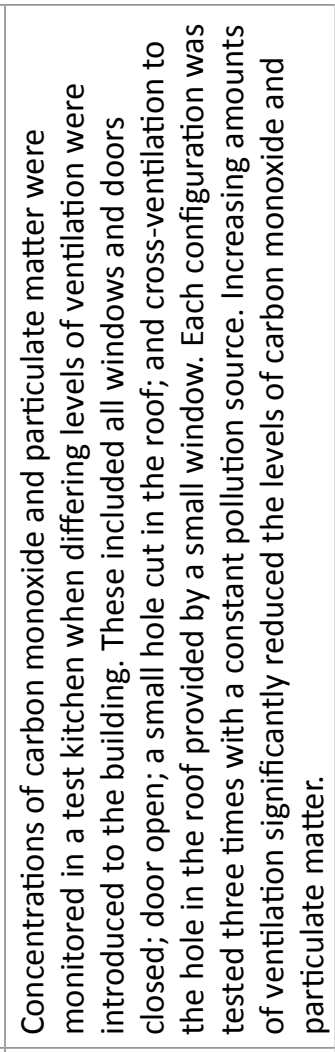 \\
\hline & 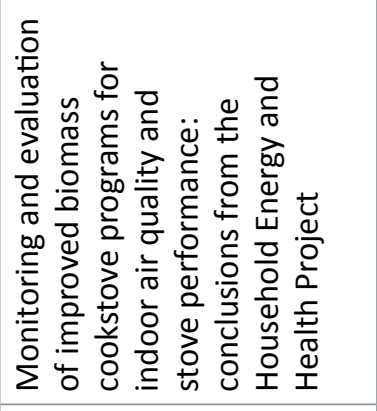 & 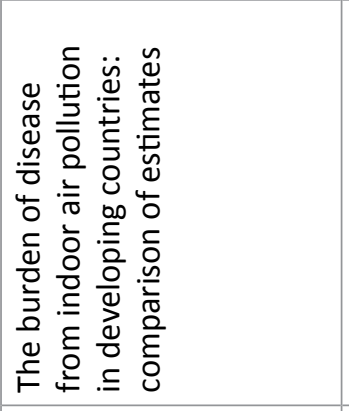 & 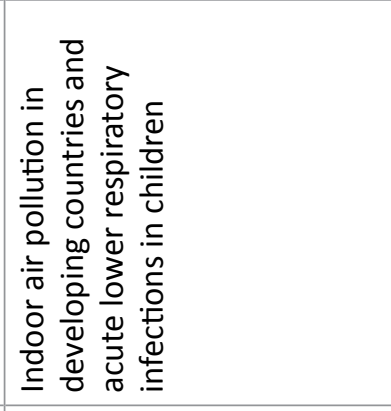 & 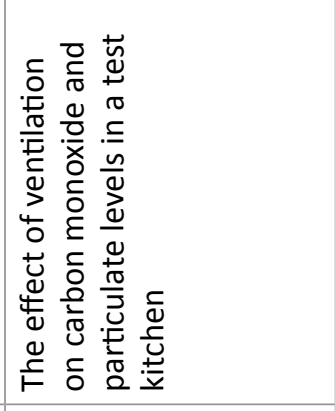 \\
\hline & 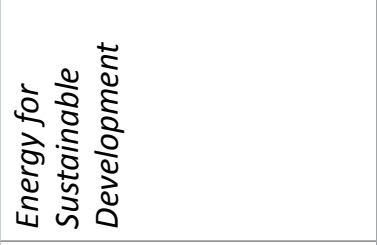 & 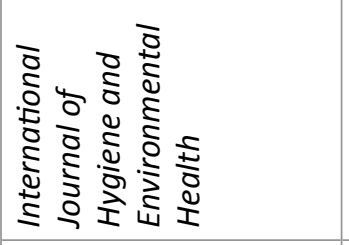 & $\begin{array}{l}\text { ๖. } \\
\text { d } \\
\stackrel{1}{1}\end{array}$ & 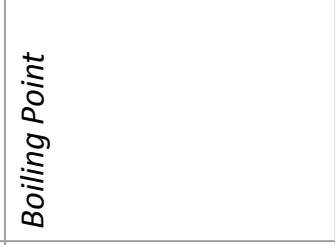 \\
\hline & ᄋి & ஜి & ষ্ণ & ஓి \\
\hline & 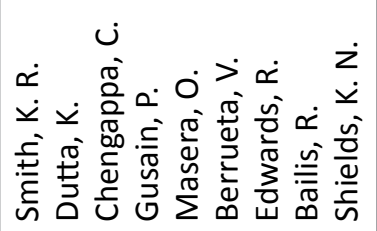 & 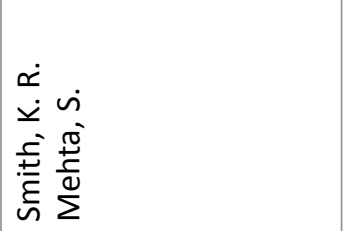 & 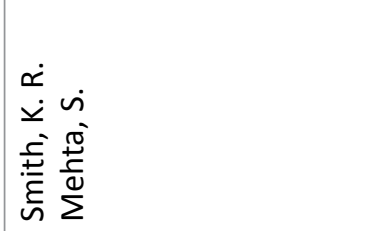 & 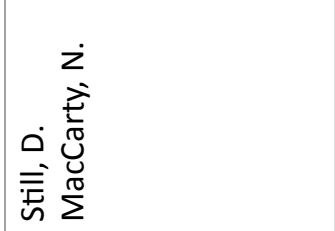 \\
\hline
\end{tabular}




\begin{tabular}{|c|c|c|c|c|}
\hline & 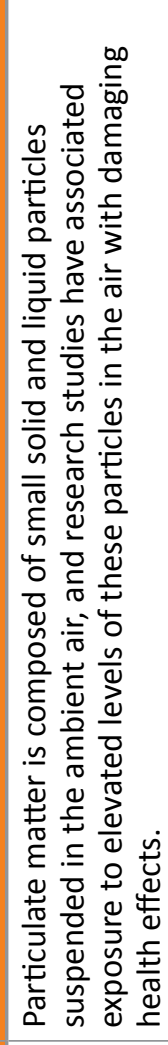 & 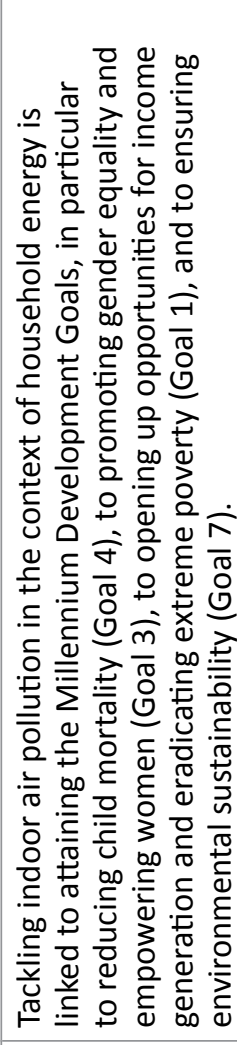 & 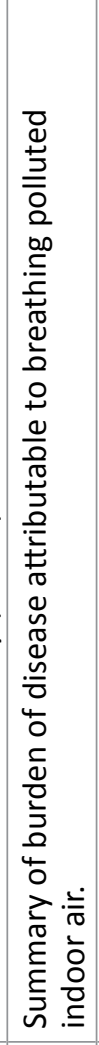 & 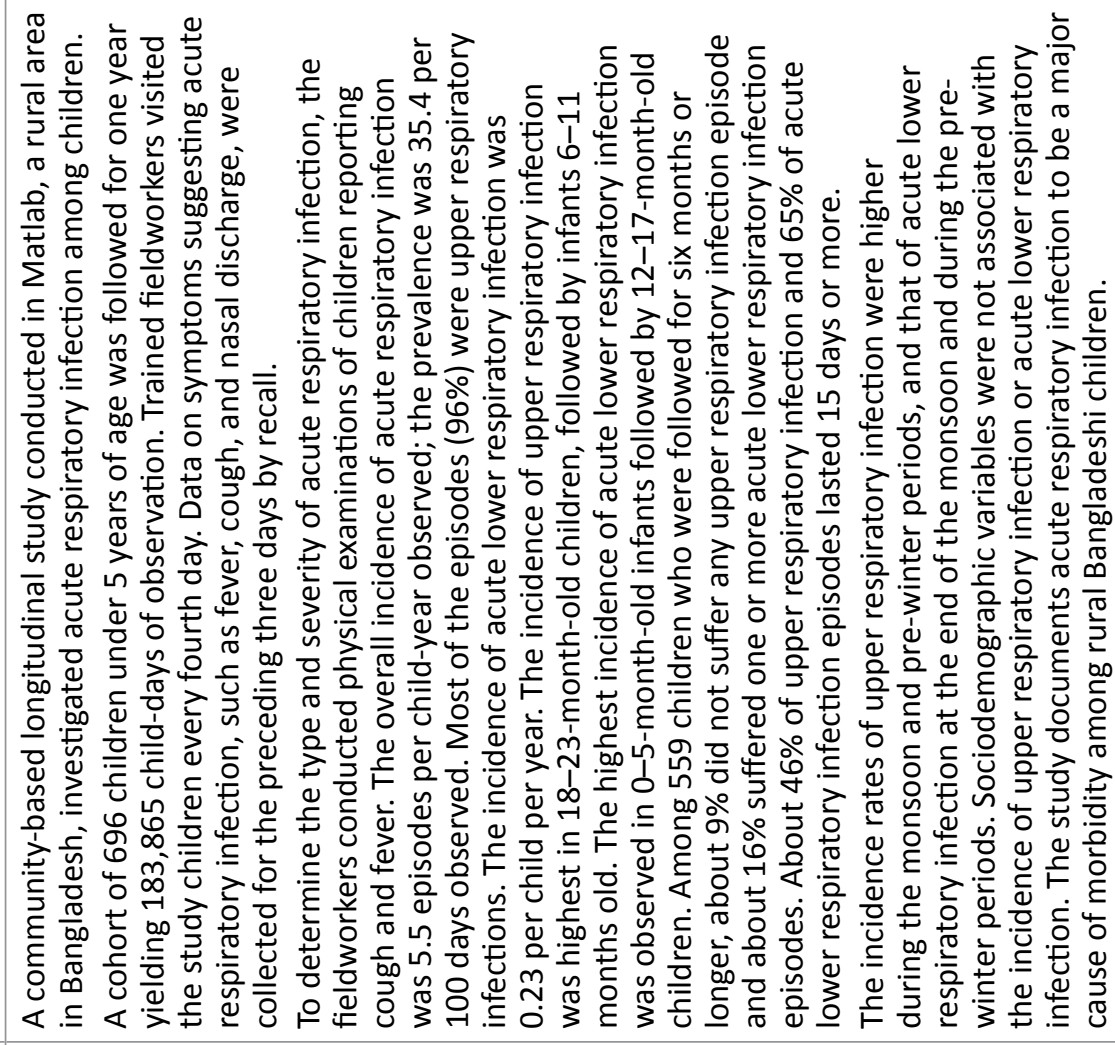 \\
\hline & 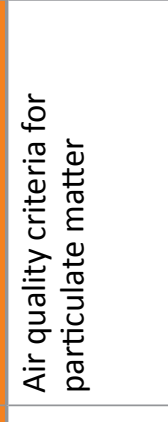 & 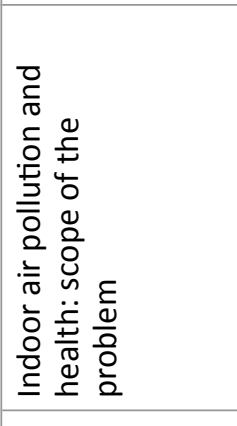 & 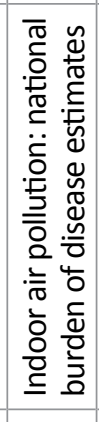 & 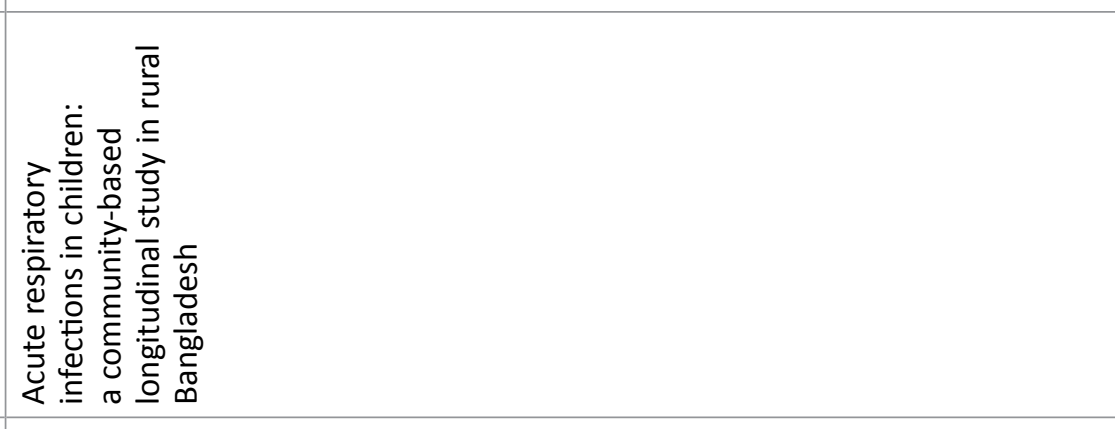 \\
\hline & 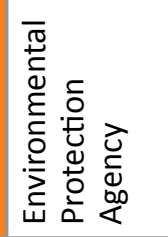 & 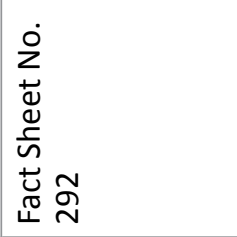 & 욱 & 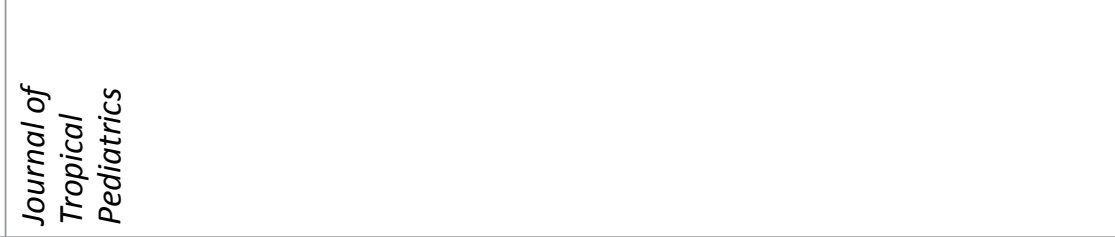 \\
\hline 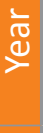 & ర্ৰ & 足 & i্ & ન્ \\
\hline & 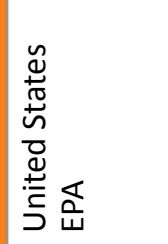 & 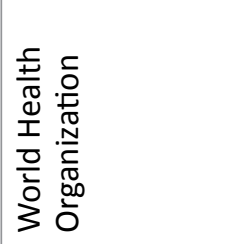 & 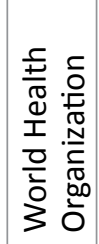 & 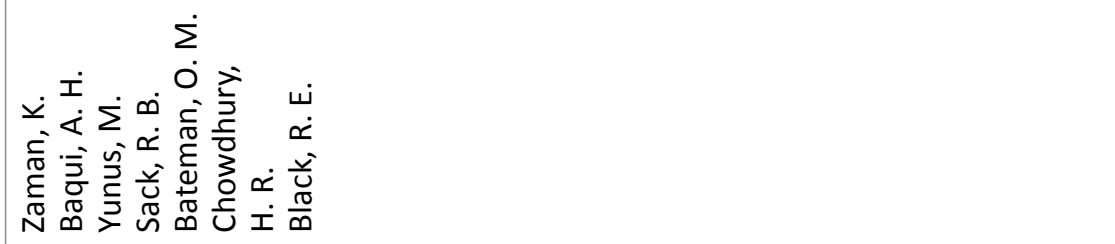 \\
\hline
\end{tabular}




\begin{tabular}{|c|c|}
\hline 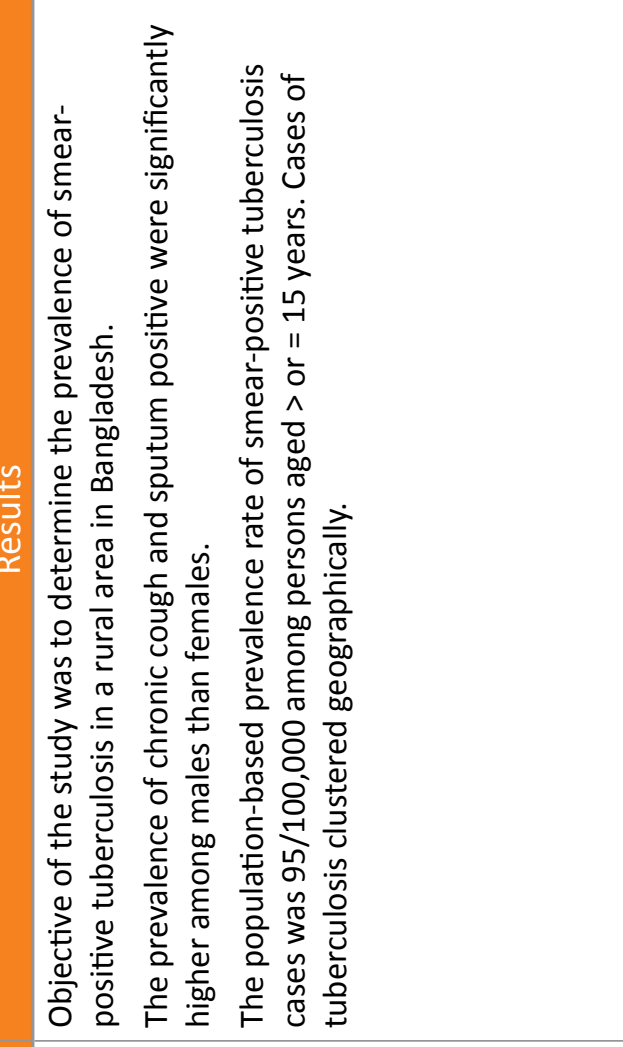 & 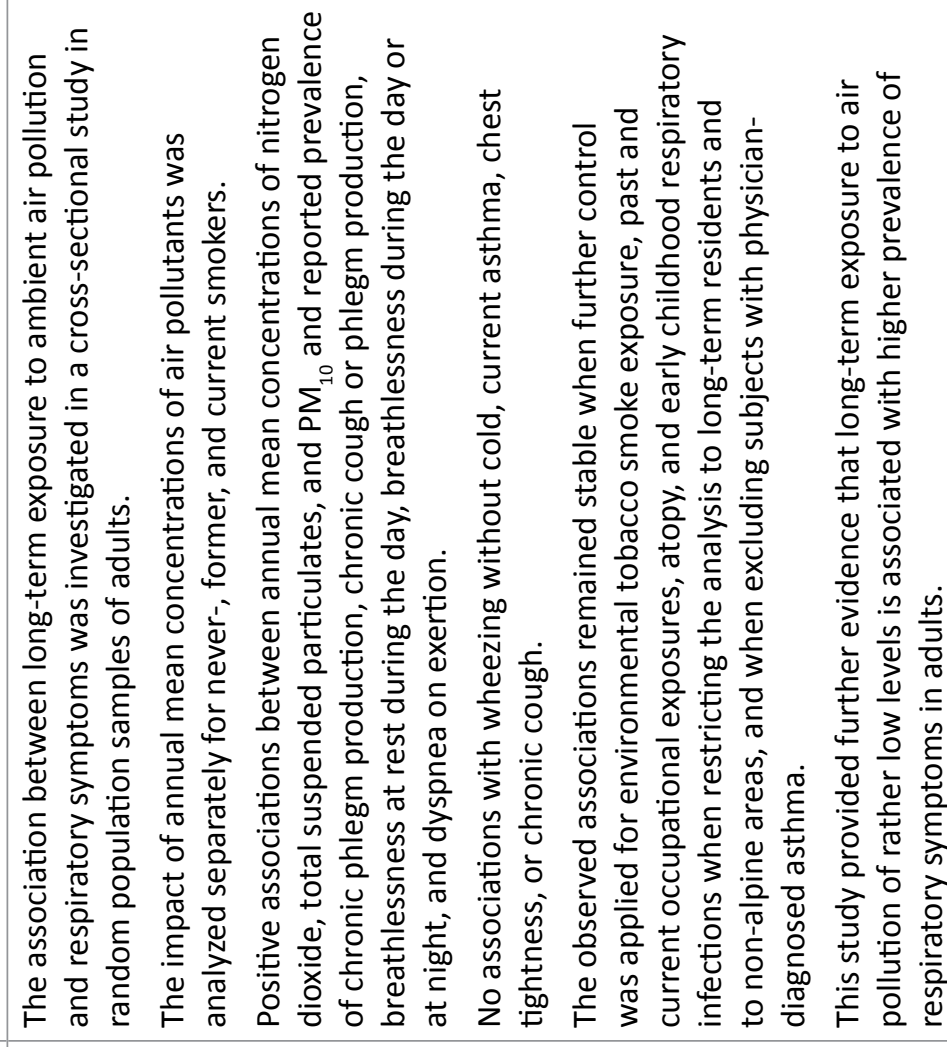 \\
\hline 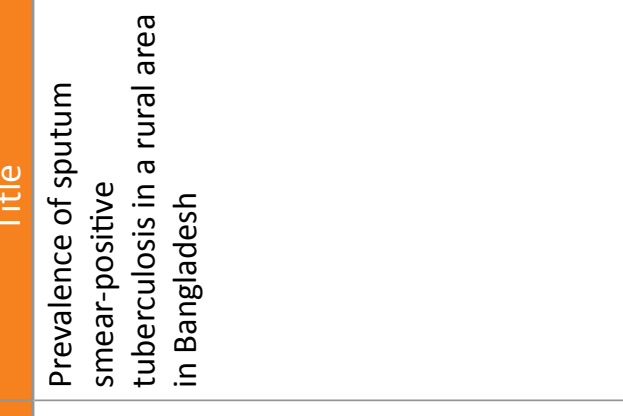 & 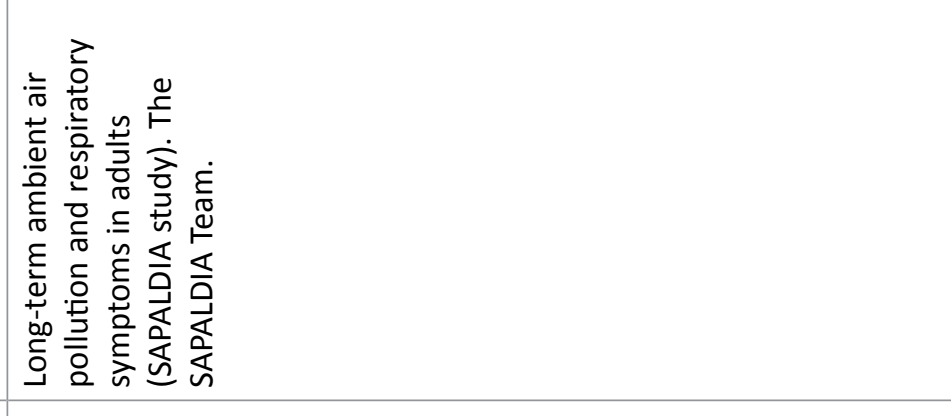 \\
\hline 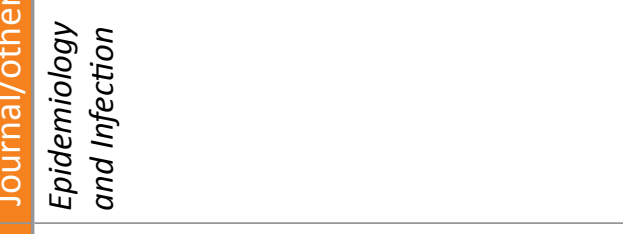 & 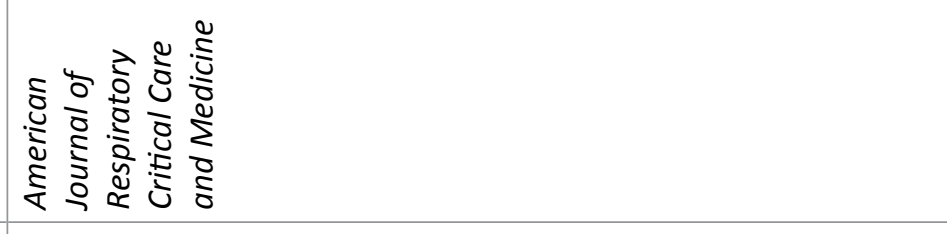 \\
\hline$\stackrel{\varpi}{~}$ & 令 \\
\hline 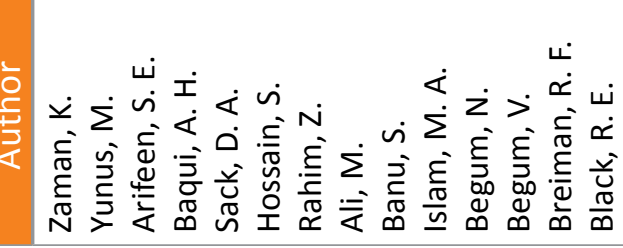 & 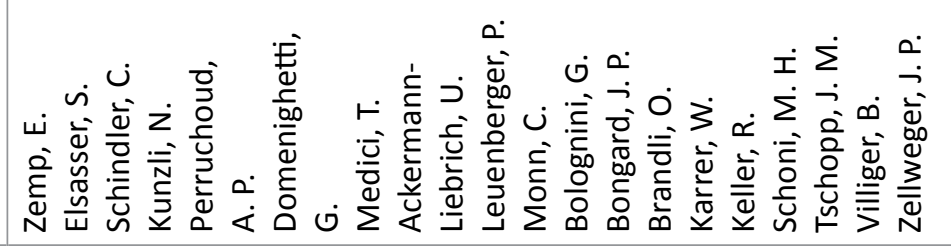 \\
\hline
\end{tabular}




\section{Appendix 2: Rapid Review Programs}

\begin{tabular}{|c|c|c|}
\hline $\begin{array}{l}\text { Name of institution/ } \\
\text { organization }\end{array}$ & Key approach & Key features \\
\hline $\begin{array}{l}\text { World Bank-WSP, DISHARI } \\
\text { Program }\end{array}$ & $\begin{array}{l}\text { Total sanitation through } \\
\text { upazila parishad }\end{array}$ & $\begin{array}{l}\text { Capacity building of local government institution for } \\
\text { sanitation in collaboration with national-level NGO. } \\
\text { Safe water, environmental health and hygiene } \\
\text { practice components being addressed in a } \\
\text { comprehensive manner. }\end{array}$ \\
\hline NGO Forum & $\begin{array}{l}\text { Addressing safe water } \\
\text { supply, sanitation, and } \\
\text { hygiene issues }\end{array}$ & $\begin{array}{l}\text { Implementation through partnership with local } \\
\text { NGOs. } \\
\text { Model village development for demonstration and } \\
\text { scaling up of the learning of water and sanitation } \\
\text { interventions. }\end{array}$ \\
\hline $\begin{array}{l}\text { Department of Public Health } \\
\text { Engineering, UNICEF }\end{array}$ & $\begin{array}{l}\text { Total sanitation coverage in } \\
\text { upazila }\end{array}$ & $\begin{array}{l}\text { Implementation through alliance with local NGOs - } \\
\text { government sanitation committees in coordination } \\
\text { role. } \\
\text { Community participation in water technology } \\
\text { installation. } \\
\text { Local entrepreneurship development. } \\
\text { Women and children are in key role. }\end{array}$ \\
\hline BRAC, WASH & $\begin{array}{l}\text { Water, Sanitation and } \\
\text { Hygiene Program }\end{array}$ & $\begin{array}{l}\text { Water supply and community management. } \\
\text { School sanitation and hygiene education. } \\
\text { Sanitation and hygiene. } \\
\text { Community management water supply and } \\
\text { technologies. }\end{array}$ \\
\hline $\begin{array}{l}\text { Dhaka Ahsania Mission, } \\
\text { DANIDA }\end{array}$ & $\begin{array}{l}\text { Decentralized total } \\
\text { sanitation }\end{array}$ & $\begin{array}{l}\text { Local NGO collaboration for implementation - water } \\
\text { point-centered community-based organizations } \\
\text { in key role with support from local government } \\
\text { institutions. } \\
\text { Water, sanitation, and hygiene behavior promotion } \\
\text { in combined manner. }\end{array}$ \\
\hline CARE WatSan Program & $\begin{array}{l}\text { Addressing livelihood } \\
\text { situation towards poverty } \\
\text { reduction }\end{array}$ & $\begin{array}{l}\text { Addressing water and sanitation needs of the poor } \\
\text { and poorest in selected areas. } \\
\text { Subsidy provision for hardware supply. } \\
\text { Hygiene education is inclusive of sanitation program. }\end{array}$ \\
\hline VERC & $\begin{array}{l}\text { People-initiated } 100 \% \\
\text { sanitation }\end{array}$ & $\begin{array}{l}\text { As outcome of community-level entry participatory } \\
\text { rural assessment session and initiation of } \\
\text { mobilization - community-based organizations in } \\
\text { lead role. } \\
\text { Addressing poverty reduction concern through } \\
\text { water and sanitation. } \\
\text { Range of technology options. }\end{array}$ \\
\hline
\end{tabular}




\begin{tabular}{|c|c|c|}
\hline $\begin{array}{l}\text { Name of institution/ } \\
\text { organization }\end{array}$ & Key approach & Key features \\
\hline & & $\begin{array}{l}\text { No subsidy on environmental hygiene but limited } \\
\text { subsidy on water (in view of ability to pay analysis). } \\
\text { Utilization of local skills and materials. } \\
\text { Involvement of local government institutions. } \\
\text { Women and children's issues given special attention. } \\
\text { Hygiene behavior change monitoring by community. } \\
\text { Basics of sanitation technology enhanced through } \\
\text { orientation for sustainability. }\end{array}$ \\
\hline $\begin{array}{l}\text { Department of Public Health } \\
\text { Engineering, DANIDA }\end{array}$ & $\begin{array}{l}\text { HYSAWA } \\
\text { Coastal area water and } \\
\text { sanitation }\end{array}$ & $\begin{array}{l}\text { Working through the involvement of local } \\
\text { government institutions. } \\
\text { Formation of community-based organizations } \\
\text { centering round water points. } \\
\text { No subsidy on environmental hygiene but limited } \\
\text { subsidy on water. } \\
\text { Implementing NGO works under supervision of local } \\
\text { government institution. } \\
\text { Public place sanitation is addressed. } \\
\text { Same as above. }\end{array}$ \\
\hline $\begin{array}{l}\text { Department of Public Health } \\
\text { Engineering }\end{array}$ & $\begin{array}{l}\text { Rural piped water supply } \\
\text { project }\end{array}$ & $\begin{array}{l}\text { Safe water supply through pipeline in rural } \\
\text { communities. } \\
20 \% \text { recovery of installation cost. } \\
\text { Payment of tariff for supply of water on monthly } \\
\text { basis. }\end{array}$ \\
\hline
\end{tabular}





\section{Bibliography}

\section{References}

Albalak, R., N. Bruce, J. P. McCracken, K. R. Smith, and T. de Gallardo. 2001. "Indoor Respirable Particulate Matter Concentrations from an Open Fire: Improved Cookstove and LPG/Open Fire Combination in a Rural Guatemalan Community." Environmental Science and Technology 35 (13): 2650-5.

Asaduzzaman, M., D. F. Barnes, and S. R. Khandakar. 2007. Restoring Balance: Bangladesh's Rural Energy Realities. Energy Sector Management Assistance Program, Development Economics Research Group, World Bank.

Azizi, B. H., H. I. Zulkifli, and S. Kasim. 1995. "Indoor Air Pollution and Asthma in Hospitalized Children in a Tropical Environment." Journal of Asthma 32 (6): 413-8.

Balakrishnan, K., S. Sambandam, P. Ramaswamy, S. Mehta, and K. R. Smith. 2004. "Exposure Assessment for Respirable Particulates Associated with Household Fuel Use in Rural Districts of Andhra Pradesh, India." Journal of Exposure Analysis and Environmental Epidemiology 14 (Suppl. 1): S14-25.

Baqui, A. H., A. A. Sabir, N. Begum, S. E. Arifeen, S. N. Mitra, and R. E. Black. 2001. "Causes of Childhood Deaths in Bangladesh: An Update." Acta Paediatrica 90 (6): 682-90.
Baris, E., and M. Ezzati. 2004. "Should Interventions to Reduce Respirable Pollutants Be Linked to Tuberculosis Control Programmes?" British Medical Journal 329 (7474): 1090-3.

Barnes, D., and J. Halpern. 2000. "The Role of Energy Subsidies." In: Energy Services for the World's Poor. World Bank Energy and Development Report. Washington, DC: World Bank.

Barnes, D., P. Kumar, and K. Openshaw. 2009. Cleaner Hearths, Better Homes: Improved Stoves for India and the Developing World. Oxford: Oxford University Press.

Begum, V., M. J. van der Werf, M. Becx-Bleumink, and M. W. Borgdorff. 2007. "Viewpoint: Do We Have Enough Data to Estimate the Current Burden of Tuberculosis? The Example of Bangladesh." Tropical Medicine and International Health 12 (3): 317-22.

Boy, E., N. Bruce, and H. Delgado. 2002. "Birthweight and Exposure to Kitchen Wood Smoke During Pregnancy in Rural Guatemala." Environmental Health Perspectives 110 (1): 109-14.

Brooks, W. A., R. F. Breiman, D. Goswami, A. Hossain, K. Alam, S. K. Saha, K. Nahar, D. Nasrin, N. Ahmed, S. El Arifeen, A. Naheed, D. A. Sack, and S. Luby. 2007. "Invasive Pneumococcal Disease Burden and Implications for Vaccine Policy in Urban 
Bangladesh." American Journal of Tropical Medicine and Hygiene 77 (5): 795-80.

Bruce, N., R. Perez-Padilla, and R. Albalak. 2000. "Indoor Air Pollution in Developing Countries: A Major Environmental and Public Health Challenge." Bulletin of the World Health Organization 78 (9): 1078-92.

Bryce, J., and C. G. Victora. 2005. "Child Survival: Countdown to 2015." Lancet 365 (9478): 2153-4.

Dasgupta, S., M. Huq, M. Khaliquzzaman, K. Pandey, and D. Wheeler. 2006a. "Indoor Air Quality for Poor Families: New Evidence from Bangladesh." Indoor Air 16 (6): 426-44.

Dasgupta, S., M. Huq, M. Khaliquzzaman, K. Pandey, and D. Wheeler. 2006b. "Who Suffers from Indoor Air Pollution? Evidence from Bangladesh." Health Policy and Planning 21: 444-58.

Diaz, E., T. Smith-Sivertsen, D. Pope, R. T. Lie, A. Diaz, J. McCracken, B. Arana, K. R. Smith, and N. Bruce. 2007. "Eye Discomfort, Headache and Back Pain among Mayan Guatemalan Women Taking Part in a Randomised Stove Intervention Trial." Journal of Epidemiology and Community Health 61 (1): 74-9.

Edwards, R. D., Y. Liu, G. He, Z. Yin, J. Sinton, J. Peabody, and K. R. Smith. 2007. "Household CO and PM Measured as Part of a Review of China's National Improved Stove Program." Indoor Air 17 (3): 189-203.

Ezzati, M., and D. M. Kammen. 2001. "Quantifying the Effects of Exposure to Indoor Air Pollution from Biomass Combustion on Acute Respiratory Infections in Developing Countries." Environmental Health Perspectives 109 (5): 481-8.

Ezzati, M., and D. M. Kammen. 2002. "The Health Impacts of Exposure to Indoor Air Pollution from Solid Fuels in Developing Countries: Knowledge, Gaps, and Data Needs." Environmental Health Perspectives 110 (11): 1057-68.

Gauderman, W. J., R. McConnell, F. Gilliland, S. London, D. Thomas, E. Avol, H. Vora, K. Berhane,
E. B. Rappaport, F. Lurmann, H. G. Margolis, and J. Peters. 2000. "Association between Air Pollution and Lung Function Growth in Southern California Children." American Journal of Respiratory Critical Care and Medicine 162 (4 Pt 1): 1383-90.

Ghimire, P. C. 2005. Final Report on Technical Study of Biogas Plants Installed in Bangladesh. National Program on Domestic Biogas in Bangladesh, a partnership program of Netherlands Development Organization (SNV) and Infrastructure Development Company Ltd. (IDCOL).

Government of Bangladesh. 2009. Renewable Energy Policy of Bangladesh. Prime Minister's Office, Bangladesh.

GTZ (German Technical Cooperation). n.d. Killer in the Kitchen. Sustainable Energy for Development Program. Bangladesh: GTZ.

Gurley, E., Md. S. Shomik, A. Brooks, and S. Luby. 2008. Measuring the Health Effects of a Pilot Indoor Air Pollution Intervention in Bangladesh. Draft protocol. International Centre for Diarrhoeal Disease Research, Bangladesh.

Johnson, N. G., and M. Bryden. 2006. "Direct Contact Hazards of Cookstoves: Burns, Cuts, and Scalds." German Technical Cooperation (GTZ). Boiling Point No. 52.

Kar, K., and R. Chambers. "Keynote Speeches." 2004. In: M. F. Ahmed, A. J. Shamsuddin, et al., eds. Proceedings of South Asian Conference on Sanitation (SACOSAN), Dhaka, Bangladesh, 21-23 October 2003. Dhaka: Local Government Division.

Khaliquzzaman, M., M. Kamijima, K. Sakai, N. A. Chowdhury, N. Hamajima, and T. Nakajima. 2007. "Indoor Air Pollution and Its Impact on Children under Five Years Old in Bangladesh." Indoor Air 17 (4): 297-304.

Khan, A. M. H. R. 2000. "Development of Downdraft Wood Burning Stove in Bangladesh." In: Energex 2000: Proceedings of the 8th International Energy Forum, Las Vegas, July 23-28, 2000. 
LGD/DPHE/UNICEF (Local Government Division, Department of Public Health Engineering, and United Nations Children's Fund). 2004. Nationwide Sanitation Survey.

Lin, H. H., M. Ezzati, and M. Murray. 2007. "Tobacco Smoke, Indoor Air Pollution and Tuberculosis: A Systematic Review and Meta-Analysis." PLoS Medicine 4 (1): e20.

Lopez, A. D., C. D. Mathers, M. Ezzati, D. T. Jamison, and C. J. Murray. 2006. "Global and Regional Burden of Disease and Risk Factors, 2001: Systematic Analysis of Population Health Data." Lancet 367 (9524): 1747-57.

McCracken, J. P., K. R. Smith, A. Diaz, M. A. Mittleman, and J. Schwartz. 2007. "Chimney Stove Intervention to Reduce Long-Term Wood Smoke Exposure Lowers Blood Pressure among Guatemalan Women." Environmental Health Perspectives 115 (7): 996-1001.

Minnatullah, K. M., and S. A. Ahmed. 2003. Total Sanitation: A Prerequisite for the Sustenance of Freshwater Resources in Bangladesh.

Mishra, V., and R. D. Retherford. 2007. "Does Biofuel Smoke Contribute to Anaemia and Stunting in Early Childhood?" International Journal of Epidemiology 36 (1): 117-29.

Mohamed, N., L. Ng'ang'a, J. Odhiambo, J. Nyamwaya, and R. Menzies. 1995. "Home Environment and Asthma in Kenyan Schoolchildren: A Case-Control Study." Thorax 50 (1): 74-8.

Naeher, L. P., B. P. Leaderer, and K. R. Smith. 2000. "Particulate Matter and Carbon Monoxide in Highland Guatemala: Indoor and Outdoor Levels from Traditional and Improved Wood Stoves and Gas Stoves." Indoor Air 10 (3): 200-5.

Rehfuess, E., S. Mehta, and A. Prüss-Üstün. 2006. "Assessing Household Solid Fuel Use: Multiple Implications for the Millennium Development Goals." Environmental Health Perspectives 114: 373-8.
Rinne, S. T., E. J. Rodas, M. L. Rinne, J. M. Simpson, and L. T. Glickman. 2007. "Use of Biomass Fuel Is Associated with Infant Mortality and Child Health in Trend Analysis." American Journal of Tropical Medicine and Hygiene 76: 585-91.

Ritz, B., F. Yu, G. Chapa, and S. Fruin. 2000. "Effect of Air Pollution on Preterm Birth Among Children Born in Southern California Between 1989 and 1993." Epidemiology 11: 5.

Rouse, J. R. 2004. Indoor Air Pollution: Issues for Bangladesh. Water, Engineering and Development Centre (WEDC), Loughborough University.

Saha, S. K., M. A. Kashem, and S. M. Rafi. 2006. Walking Through Sanitation Ladder: A Participatory Study on the Trends and the Drivers of Community Movement in VERC-WAB's People Initiated 100\% Sanitation Approach.

Siddiqui, A. R., J. Peerson, K. H. Brown, E. B. Gold, K. Lee, and Z. A. Bhuta. 2005. "Indoor Air Pollution From Solid Fuel Use and Low Birth Weight (LBW) in Pakistan." Epidemiology 16 (5): S86.

Smith, K. R. 2000. "Inaugural Article: National Burden of Disease in India from Indoor Air Pollution." Proceedings of the National Academy of Sciences of the United States of America 97 (24): 13286-93.

Smith, K. R. 2002. "Indoor Air Pollution in Developing Countries: Recommendations for Research." Indoor Air 12 (3): 198-207.

Smith, K. R., K. Dutta, C. Chengappa, P. P. S. Gusain, O. Masera, V. Berrueta, R. Edwards, R. Bailis, and K. Naumoff Shields. 2007. "Monitoring and Evaluation of Improved Biomass Cookstove Programs for Indoor Air Quality and Stove Performance: Conclusions from the Household Energy and Health Project." Energy for Sustainable Development 11 (2): 5-17.

Smith, K. R., and S. Mehta. 2003. "The Burden of Disease from Indoor Air Pollution in Developing Countries: Comparison of Estimates." International Journal of Hygiene and Environmental Health 206 (4-5): 279-89. 
Smith, K. R., J. M. Samet, I. Romieu, and N. Bruce. 2000. "Indoor Air Pollution in Developing Countries and Acute Lower Respiratory Infections in Children." Thorax 55 (6): 518-32.

Still, D., and N. MacCarty. 2006. "The Effect of Ventilation on Carbon Monoxide and Particulate Levels in a Test Kitchen." Boiling Point 52: 24-6.

United States EPA (Environmental Protection Agency). 2004. Air Quality Criteria for Particulate Matter. Final Report (http://cfpub.epa.gov/ncea/ $\mathrm{cfm} /$ recordisplay. $\mathrm{cfm}$ ?deid=87903).

United States EPA (Environmental Protection Agency). 2006. PM Standards (http://www.epa. gov/oar/particlepollution/standards.html).

VERC (Village Education Resource Center). 2007. Annual Report 2007. Savar: VERC.

WaterAid. 2003. Water, Sanitation and Hygiene Promotion: A National Strategy for Economic Growth, Poverty Reduction and Social Development. Poverty Reduction Strategy Paper.

WHO (World Health Organization). 2005. Indoor Air Pollution and Health: Scope of the Problem. WHO Fact Sheet No. 292. Geneva: WHO.

WHO (World Health Organization). 2006. Evaluation of the Costs and Benefits of Household Energy and Health Interventions at Global and Regional Levels. Geneva: WHO.

WHO (World Health Organization). 2007. Indoor Air Pollution: National Burden of Disease Estimates. Geneva: WHO.

WHO (World Health Organization). 2008. Evaluating Household Energy and Health Interventions: A Catalogue of Methods. Geneva: WHO (http://www. who.int/indoorair/publications/methods).

World Bank. 2002. Rural Electrification and Development in the Philippines: Measuring the Social and Economic Benefits. Energy Sector Management Assistance Programme (ESMAP) Report No. 255/02. Washington, DC: World Bank.
World Bank. 2006. Bangladesh Country Environmental Analysis, Volume I: Main Report. Social Development Unit, South Asia Region, World Bank.

World Bank. 2008. Poverty Assessment of Bangladesh: Creating Opportunities and Bridging the East-West Divide. Report No. 44321-BD. Poverty Reduction, Economic Management, Finance and Private Sector Development Unit, South Asia Region, World Bank.

Zaman, K., A. H. Baqui, M. Yunus, R. B. Sack, O. M. Bateman, H. R. Chowdhury, and R. E. Black. 1997. "Acute Respiratory Infections in Children: A Community-Based Longitudinal Study in Rural Bangladesh." Journal of Tropical Pediatrics 43 (3): 133-7.

Zaman, K., M. Yunus, S. E. Arifeen, A. H. Baqui, D. A. Sack, S. Hossain, Z. Rahim, M. Ali, S. Banu, M. A. Islam, N. Begum, V. Begum, R. F. Breiman, and R. E. Black. 2006. "Prevalence of Sputum Smear-Positive Tuberculosis in a Rural Area in Bangladesh." Epidemiology and Infection 134 (5): 1052-9.

Zemp, E., S. Elsasser, C. Schindler, N. Kunzli, A. P. Perruchoud, G. Domenighetti, T. Medici, U. Ackermann-Liebrich, P. Leuenberger, C. Monn, G. Bolognini, J. P. Bongard, O. Brandli, W. Karrer, R. Keller, M. H. Schoni, J. M. Tschopp, B. Villiger, and J. P. Zellweger. 1999. "Long-Term Ambient Air Pollution and Respiratory Symptoms in Adults (SAPALDIA Study). The SAPALDIA Team." American Journal of Respiratory Critical Care and Medicine 159 (4 Pt 1): 1257-66.

\section{Other Relevant Source Items}

Ahmed, A. 2003. Experience on Sanitation in Bangladesh: The Challenge Ahead. UNICEF.

Ahmed, A. 2007. Shifting Outlook: Policy Advocacy on Sanitation. WaterAid, Bangladesh. 
Ahmed, F., and M. Rahaman. 2000. Grameen Bank Provided USD 30 million to Install Latrines in Borrower's Homes. ITN-Bangladesh.

Ali, M. R. 2005. "Participation and Sharing: Private Development Organization." In: National Sanitation for All by 2010 (in Bengali). Dhaka: Local Government Division.

Appropriate Rural Technology Institute. 2007. Stove Monitoring Report: Reduction of Exposure to Indoor Air Pollution through Household Energy and Behavioral Improvements Project. Pune, India: Appropriate Rural Technology Institute.

Bangladesh Council of Scientific and Industrial Research. n.d. Improved Cookstove Dissemination (Phase II) Project. Dhaka: Institute of Fuel Research and Development, Bangladesh Council of Scientific and Industrial Research.

Cowlin, S., R. Kaufmann, R. Edwards, and K. Smith. 2005. Impact of Improved Stoves on Indoor Air Quality in Ulaanbaatar, Mongolia (http://www.esmap.org/ filez/pubs/31305MongolialAP090905forWeb.pdf).

Dasgupta, S., M. Huq, M. Khaliquzzaman, and D. Wheeler. 2007. Improving Indoor Air Quality for Poor Families: A Controlled Experiment in Bangladesh. Washington, DC: World Bank.

DFID/WEDC (UK Department for International Development and Water, Engineering and Development Centre). 1998. Guidance Manual on WSS Programmes.

Dhaka Ahsania Mission. 2005. Sanitation for All by 2010: Strategy Options. Discussion Paper for Round Table in CIRDAP, July 31, 2005. Dhaka: Dhaka Ahsania Mission.

Ellery, M. 2008. An Inclusive Approach to Safeguarding the Basic Needs of the Poor. Typescript. Water and Sanitation Program, Pakistan.

ESMAP (Energy Sector Management Assistance Program). 2006. Project Concept Paper for Dissemination of Improved Stoves in Haiti.
ESMAP (Energy Sector Management Assistance Program). 2007. Haiti: Building a Sustainable Market for Improved Stoves. Factsheet.

ESMAP (Energy Sector Management Assistance Program). 2007. Haiti: Strategy to Alleviate the Pressure of Fuel Demand on National Woodfuel Resources. ESMAP Technical Paper 112/07.

ESMAP (Energy Sector Management Assistance Program). 2009. Improved Stoves for India and the Developing World. Washington, DC: World Bank.

Government of Bangladesh. 1998. Fifth Five-Year Plan (1997-2002).

Government of Bangladesh. 2005. Bangladesh: Unlocking the Potential. National Strategy for Accelerated Poverty Reduction. General Economics Division, Planning Commission, Government of Bangladesh.

Government of Bangladesh. 2005. National Sanitation Strategy.

Government of Bangladesh. 2008. Sanitation in Bangladesh. Bangladesh Country Paper, SACOSAN-III.

Government of Bangladesh. Rural Development and Cooperative Division (http://www.rdcd.gov.bd/).

GTZ (German Technical Cooperation). ICS Training Manual.

Helal, M., and A. Ayub. 2005. Total Sanitation: A Community Stake. Dhaka: NGO Forum for Drinking Water Supply and Sanitation.

Hurvey, P., S. Baghri, and B. Reed. 2002. Emergency Sanitation. WEDC, Loughborough University, United Kingdom.

IDCOL (Infrastructure Development Company Limited). 2006. Annual Report 2005-2006.

IDCOL (Infrastructure Development Company Limited). n.d. IDCOL's Rural Electrification and Renewable Energy Development Program (REREDP). Dhaka: IDCOL. 
IDCOL/SNV (Infrastructure Development Company Limited and Netherlands Development Organization). 2006. Implementation Plan: National Domestic Biogas and Manure Program in Bangladesh.

IDCOL/SNV (Infrastructure Development Company Limited and Netherlands Development Organization). 2007. IDCOL Model Biogas Plant Construction Manual. National Domestic Biogas and Manure Program.

Islam, S. R. 2005. "Problems of Rural Sanitation in Bangladesh." In: Sanitation for All by 2010 (in Bengali). Dhaka: Local Government Division.

ITN (International Training Network)-Bangladesh. 2003. Sanitation Analysis: Water Supply and Sanitation Research in Bangladesh. Dhaka: Bangladesh University of Engineering and Technology.

Kar, K. 2003. Subsidy or Self-Respect? Participatory Total Sanitation in Bangladesh. Institute of Development Studies Working Paper 184.

Kristin, K., Q. Wodon, V. Foster, and J. Halpern. 2005. Water, Electricity, and the Poor: Who Benefits from Utility Subsidies? Directions in Development. Washington, DC: World Bank.

LGED (Local Government Engineering Department). n.d. Electricity Generation from Poultry Waste: Muslim Mission, Faridpur. Sustainable Rural Energy (Comp 2.6).

Ministry of Power, Energy and Mineral Resources. n.d. Status of Renewable Energy in Bangladesh. Country Report.

REEIN (Renewable Energy and Environmental Information Network). n.d. Involvement of LGED in Biogas Technology in Bangladesh (http://www. reein.org/biomass/lged/lged.htm).

Renewable Energy Information Network. RET Projects in Brief (http://www.lged-rein.org/ database.php?pageid=21).
Saurav, K. S., R. Thapa, and K. Bajracharya. n.d. National Improved Cook Stove Dissemination in the Mid-Hills of Nepal: Experiences, Opportunities and Lessons Learnt. Asia Regional Cookstoves Program (http://www.arecop.org/zip/ICS_midhill.pdf).

Shamsuddin, A. J. 2006. Reaching 100\% Sanitation Coverage in Bangladesh by 2010: Key Issues (http://www.buet.ac.bd/itn/cwp/documents/ kickoffmetnepal/AjsSanPresenNepal.pdf).

Sinton, J. E., K. R. Smith, J. W. Peabody, L. Yaping, Z. Xiliang, R. Edwards, and G. Quan. 2004. "An Assessment of Programs to Promote Improved Household Stoves in China." In: K. R. Smith, et al., eds. Energy for Sustainable Development Volume 8 No. 3.

Social Development Foundation. 2005. Private Financing of Public, Private and People's Participation. Rural Piped Water Pilot of Social Investment Program. Dhaka: Social Development Foundation.

TRUST. 2004. Final Report on Impact Study on Improved Cooking Stoves (ICS) Program Effectiveness.

UNICEF (United Nations Children's Fund). Bangladesh Statistics (http://www.unicef.org/infobycountry/ bangladesh_bangladesh_statistics.html).

United Nations. We Can End Poverty: 2015 Millennium Development Goals (http://www. un.org/millenniumgoals/).

United States EPA (Environmental Protection Agency). 2006. Air Quality Criteria for Ozone and Related Photochemical Oxidants. EPA/600/R05/004aF-cF. Washington, DC: EPA (http://cfpub. epa.gov/ncea/cfm/recordisplay.cfm?deid=149923).

USAID (United States Agency for International Development). 2007. Environmental Vulnerability in Haiti: Findings and Recommendations. USAIDHaiti (http://www.wilsoncenter.org/events/docs/ Haiti_Final.pdf). 
WHO (World Health Organization). 2004. Global and Regional Burden of Disease. Geneva: WHO.

Winrock International and USAID. 2005. Management of Aquatic Ecosystems through Community Husbandry (MACH): Annual Report, November 2004-October 2005.

World Bank. 2005. Scaling Up Rural Sanitation in South Asia: Lessons Learned from Bangladesh, India and Pakistan. Water and Sanitation ProgramSouth Asia.

World Bank. n.d. Mongolia: Heating in Poor, Peri-urban Ger Areas of Ulaanbaatar. Final Draft. Asia Sustainable and Alternative Energy Program, Sustainable Development Department, World Bank.

\section{Personal Communications}

Aktaruzzaman, Kazi. Director, Bangladesh Council of Scientific and Industrial Research Laboratories. Personal interview, Dhaka, January 2008.

Bajgain, Sundar. Technical Adviser to NDBMP, Netherlands Development Organization (SNV).
Personal interviews, Dhaka, September 2006 and January 2008.

Islam, Formanul. Director (Legal), Infrastructure Development Company Limited (IDCOL), Dhaka. Personal interview, January 2008.

Islam, M. Additional Chief Engineer (Planning), Local Government Engineering Department, Dhaka. Personal interview, January 2008.

Khaliquzzaman, Md., and Otto Gomm. German Technical Cooperation (GTZ), Dhaka. Personal interviews, September 2007 and January 2008.

Khan, Hasan Rashid. Former Project Director, Institute for Fuel Research and Development, Bangladesh Council of Scientific and Industrial Research. Personal interview, January 2008.

Nuruzzaman, A. K. M. Manager Operations, Palli Karma Shahayak Foundation (PKSF), Dhaka. Personal interview, January 2008.

Rahman, Mahbubur. Grameen Shakti, Dhaka. Personal interviews, September 2007 and January 2008. 




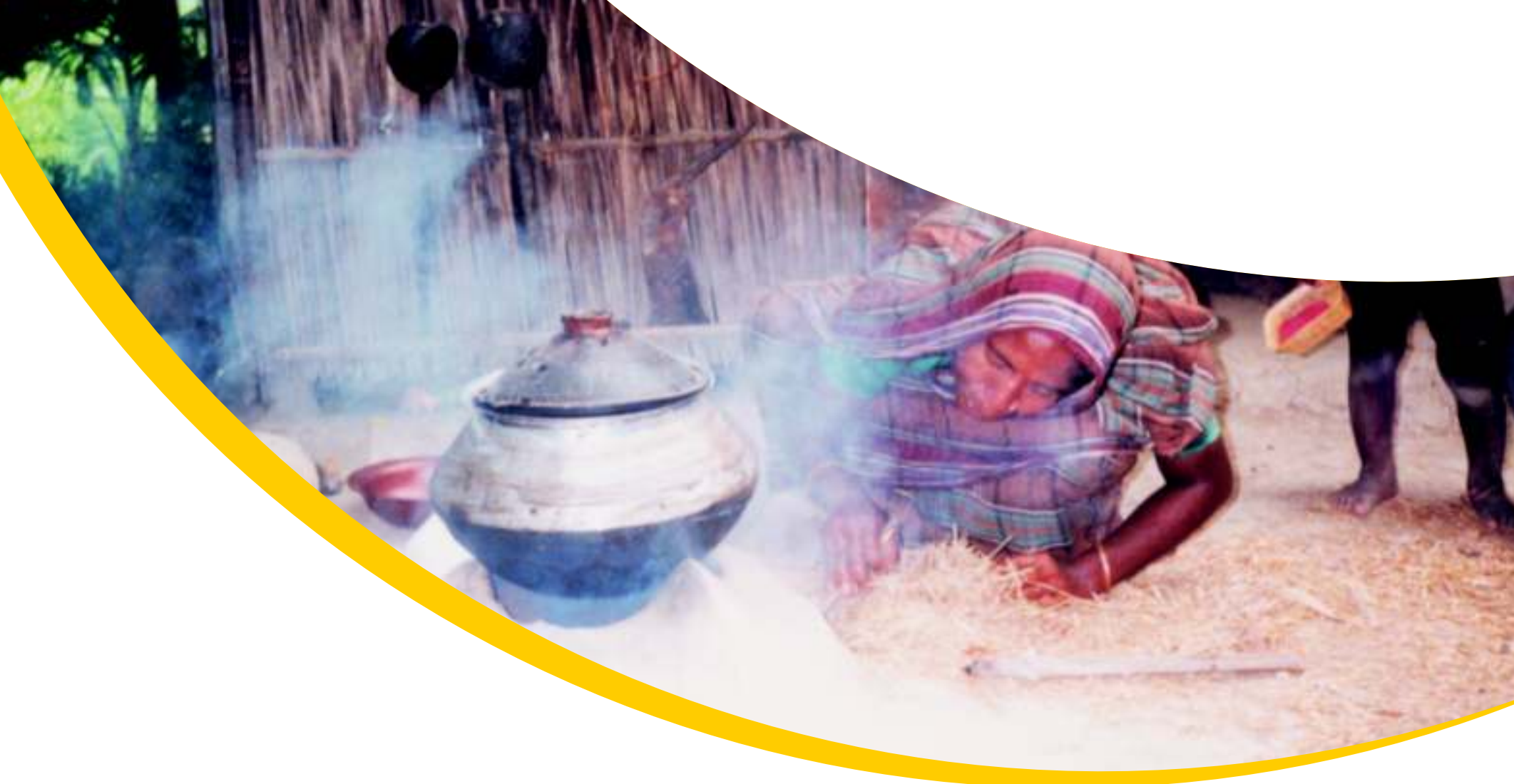

